Universidad de Lima

Escuela de Posgrado

Maestría en Administración y Dirección de Negocios

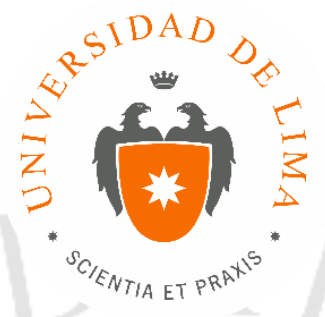

\title{
PLAN DE NEGOCIO PARA LA IMPLEMENTACIÓN DEL TALLER AUTOMOTRIZ TIKI CARS
}

Trabajo de investigación para optar el Grado Académico de Maestro en Administración y Dirección de Negocios

Virma Suares Avilez

Código 19880698

María Liliana Valle Vera

Código 20030853

$$
\text { Lima - Perú }
$$

07 de diciembre de 2016 


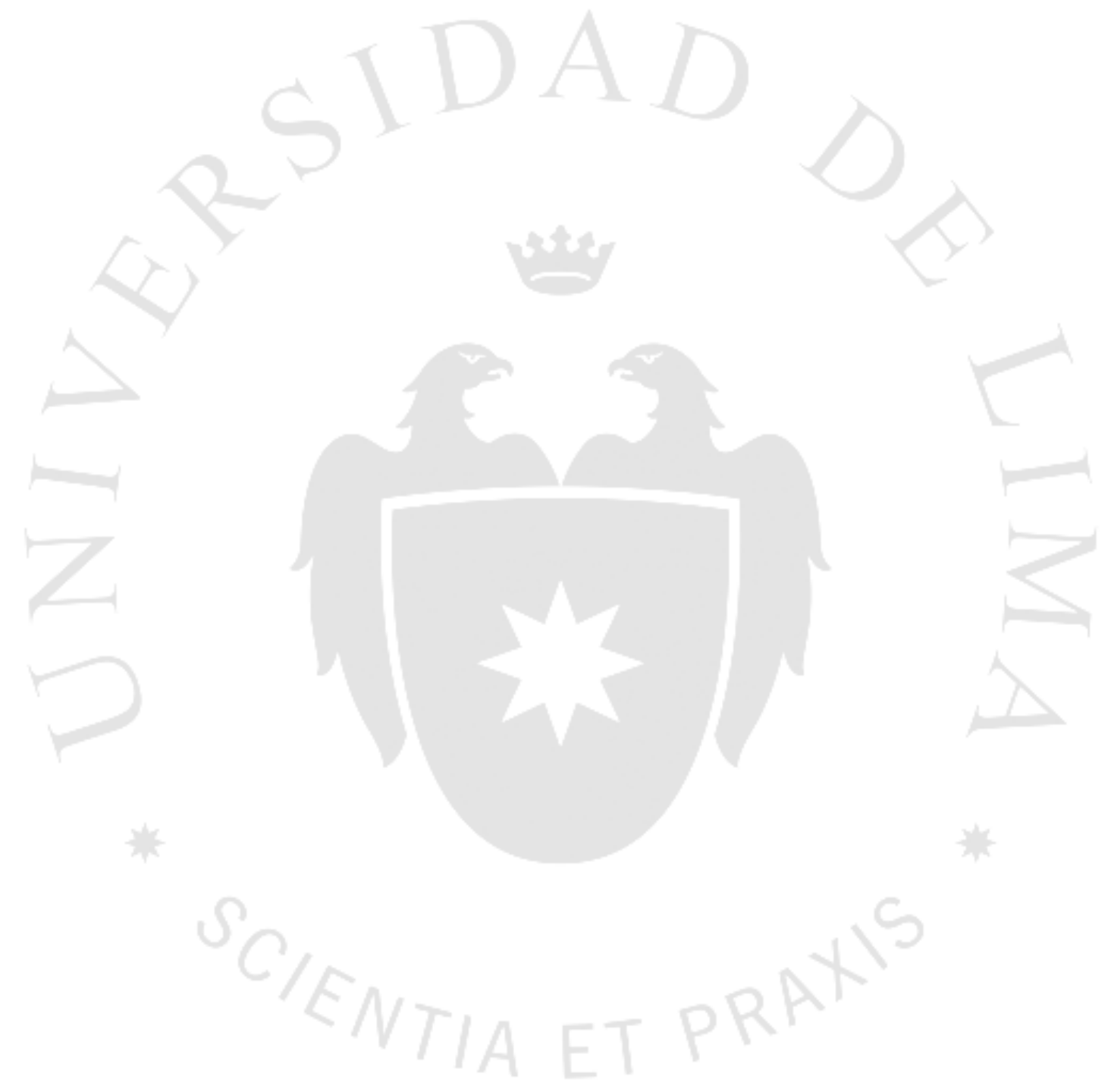




\section{PLAN DE NEGOCIO PARA LA IMPLEMENTACIÓN DEL TALLER AUTOMOTRIZ TIKI CARS}




\section{TABLA DE CONTENIDO}

\section{INTRODUCCIÓN}

RESUMEN EJECUTIVO. 1

CAPITULO I: ASPECTOS GENERALES DEL NEGOCIO.......................2

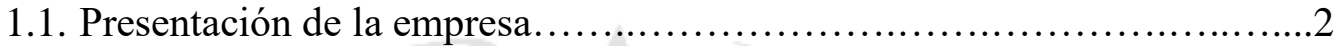

1.2. Marco teórico y Mercado.................................................2

1.3. Motivación del proyecto.........................................4

1.4. Percepción de la necesidad: análisis problema-solución...................5

1.5. Descripción de la idea y la oportunidad..............................6

1.6. Justificación del atractivo de la propuesta..............................8

1.7. Estrategia inicial y Objetivos de alcance................................9

1.8. Impacto comercial y responsabilidad social........................... 10

\section{CAPITULO II: IDEA, INVESTIGACIÓN Y VALIDACIÓN DE SOLUCIÓN... 12}

2.1 Diseño y metodología de la investigación............................12

2.2 Validación de hipótesis............................................12

2.3 Validación de la solución..............................................13

2.4 Muestreo poblacional...............................................13

2.5 Análisis de tendencias y patrones..................................... 14

2.6 CANVAS del modelo de negocio..................................16

CAPÍTULO III: PLANEAMIENTO ESTRATÉGICO..............................17

3.1. Visión............................................................. 17

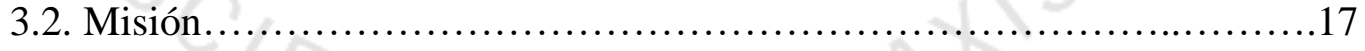

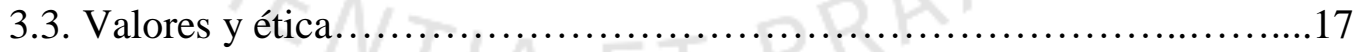

3.4. Cultura organizacional.......................................... 18

3.5. Objetivos Estratégicos............................................ 19

3.6. Análisis externo: Político, legal, circunstancial, económico, geográfico, social, demográfico, cultural, tecnológico, ambiental (PESTEL)..........21

3.7. Análisis interno: Competidores potenciales, clientes, proveedores, productos sustitutos, barreras de entrada (PORTER). 
3.8. Análisis sectorial e Identificación de riesgos y amenazas. Análisis

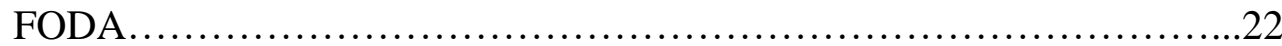

CAPÍTULO IV: PLAN DE MARKETING...................................23

4.1. Planteamiento de objetivos generales de marketing..................23

4.2. Estrategias de marketing ...........................................23

4.2.1. Segmentación y Perfil del cliente...................................23

4.2.2. Posicionamiento y ventaja competitiva............................24

4.3. Mercado objetivo.................................................24

4.3.1. Tendencia de mercado.........................................24

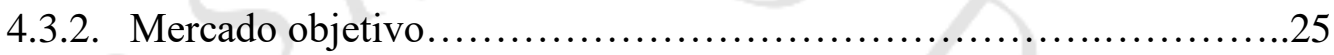

4.3.3. Identificación de agentes (clientes, usuarios, compradores, intermediarios, mayoristas, minoristas, comisionistas) $\ldots \ldots \ldots \ldots \ldots \ldots . \ldots . \ldots . \ldots$

4.3.4. Potencial crecimiento del mercado...............................28

4.4. Desarrollo y estrategia del marketing mix.............................29

4.4.1. Política de gestión del cliente........................................29

4.4.2. Estrategia de producto: especificaciones, calidad, variabilidad y

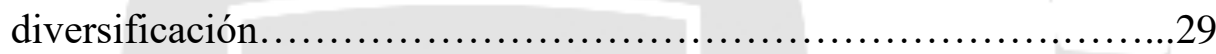

4.4.3. Estrategia de precios: análisis de costos y precios...................30

4.4.4. Política comercial..................................................32

4.4.5. Estrategia comunicacional y canal..............................32

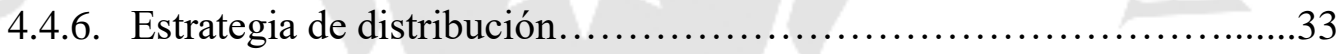

4.5. Plan de Ventas (objetivos anuales, alcance de la oferta) y Proyección de la Demanda (crecimiento y desarrollo)................................33

CAPÍTULO V: PLAN DE OPERACIONES.....................................34

5.1 Políticas Operacionales.........................................34

5.2 Equipos, actividades y procesos.................................... 34

5.2.1. Diseño y capacidad de Instalaciones.................................34

5.2.2. Equipos de trabajo y apoyos................................... 35

5.2.3. Gestión de proveedores, compras y stock..............................36

5.2.4. Tercerización o integración de procesos...........................36

5.2.5. Implementación de las actividades por fases. Cadena de valor..........36

5.2.6. Proceso de elaboración de bienes y/o prestación de servicio............37

5.2.7. Flujograma de la actividad. Diagrama de Grantt......................37

5.2.8. Balance Scorecard: control de gestión por indicadores.................38 


\section{CAPÍTULO VI: ESTRUCTURA ORGANIZACIONAL Y RECURSOS}

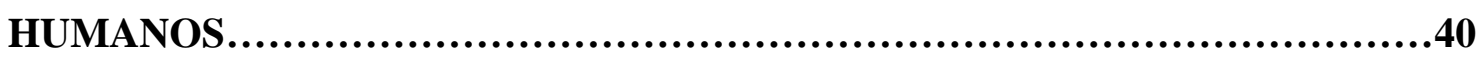

6.1. Objetivos Organizacionales..........................................40

6.1.1. Naturaleza de la Organización..........................................40

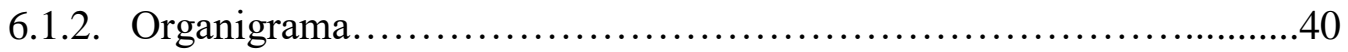

6.2. Diseño de Puestos y Responsabilidades....................................40

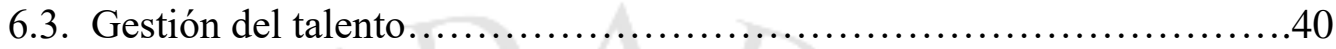

6.3.1. Selección y contratación..............................................40

6.3.2. Remuneración y desempeño............................................ 41

6.3.3. Empowerment y reconocimiento.........................................41

6.3.4. Capacitación, motivación y desarrollo..................................... 41

6.4. Estructura de gastos de RRHH............................................

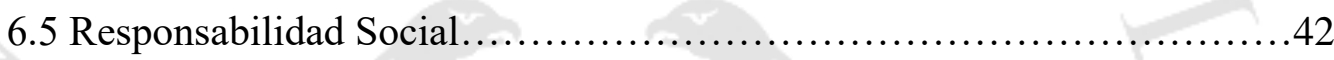

CAPÍTULO VII: PLAN ECONÓMICO-FINANCIERO_............................45

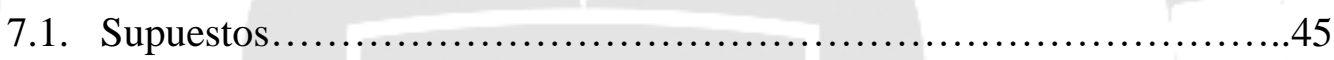

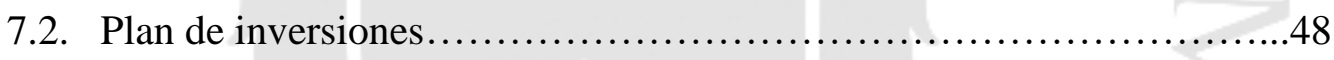

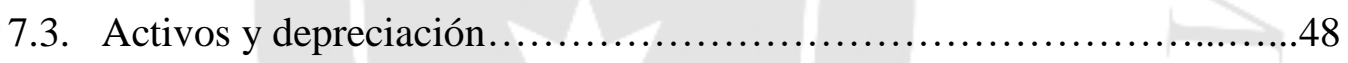

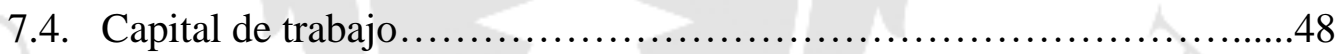

7.5. Balances previsionales (Balance general) ..............................49

7.6. Cuentas de Explotación previsionales (GGPP) ...........................50

7.7. Proyección de ventas y Flujo de Tesorería (Cash flow)....................50

7.8. Análisis de viabilidad y rentabilidad financiera. TIR VAN...............51

7.9. Políticas de aplicación de resultados....................................52

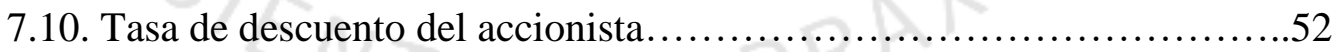

7.11. Indicadores de rentabilidad representativos (WACC, TIR, VAN, ROI, Pay

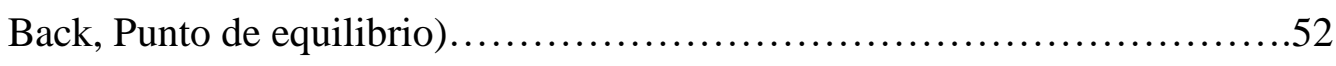

7.12. Análisis de riesgo y costo de oportunidad...............................53

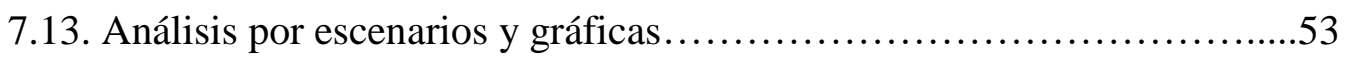

7.14. Principales riesgos del proyecto (cualitativos)...........................54 


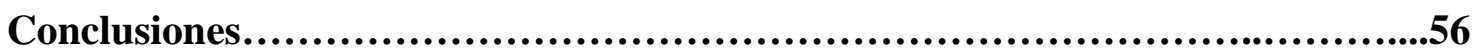

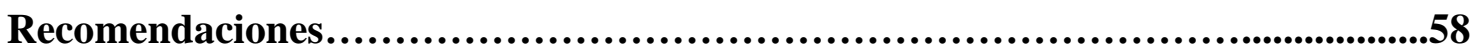

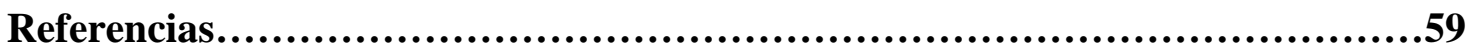

Bibliografía.........................................................................61

Anexos..................................................................63 


\section{ÍNDICE DE FIGURAS}

Figura 1. 1 Ventajas competitivas.......................................... 108

Figura 2. 1 Distribución de zonas APEIM por niveles............................108

Figura 2. 2 Distribución de hogares según nivel socioeconómico...................109

Figura 2. 3 Población para determinar la muestra a encuestar........................110

Figura 3.1 Valores y ética................................................110

Figura 3. 2 Cultura Organizacional............................................. 112

Figura 3.3 Objetivos estratégicos...................................... 112

Figura 3. 4 Problemática.................................................113

Figura 3. 5 Estrategia frente a problemática..................................113

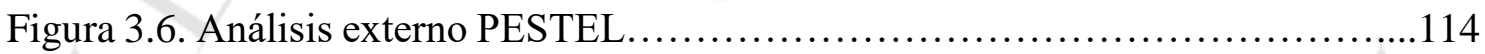

Figura 3. 7 Análisis interno PORTER.......................................... 115

Figura 4. 1 Objetivos generales de marketing................................ 115

Figura 4. 2 Participación porcentual de las empresas aseguradoras...................116

Figura 4. 3 Venta anual de autos nuevos....................................... 116

Figura 4. 4 Evolución de ventas de autos nuevos 2015 - 2016 .....................117

Figura 4. 5 Marketing mix............................................. 118

Figura 5. 1 Diseño y capacidad de instalaciones.............................. 119

Figura 5. 1 Diseño y capacidad de instalaciones............................... 120

Figura 5. 2 Equipos y trabajos de apoyo.................................... 120

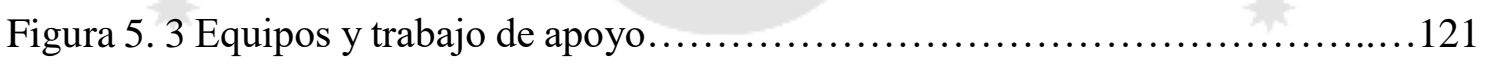

Figura 5.4. Just in time................................................ 121

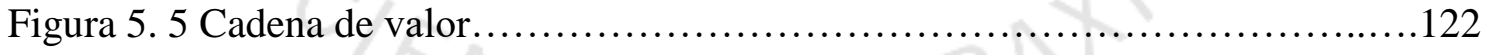

Figura 5. 6 Actividades por fases citas........................................ 123

Figura 5. 7 Actividades por fases recepción del vehículo..........................124

Figura 5. 8 Actividades por fases: Servicios y procesos de entrega.................126

Figura 5. 9 Actividades por fases: proceso post - servicio......................127

Figura 5.10 Actividades por fases: recordatorio de llamadas.......................128

Figura 5. 11 Diagrama de Grant.......................................... 129

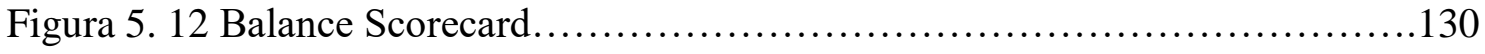

Figura 6. 1 Manual de funciones: Administrador................................131 
Figura 6. 2 Manual de Funciones y Servicios Jefe de Taller......................... 132

Figura 6.3 Asesor de servicios.............................................. 133

Figura 6.4. Capacitaciones............................................. 134

Figura 6. 5 Responsabilidad Socia..................................... 134

Figura 6. 6 Implementación de LED y paneles solares............................ 135 


\section{ÍNDICE DE TABLAS}

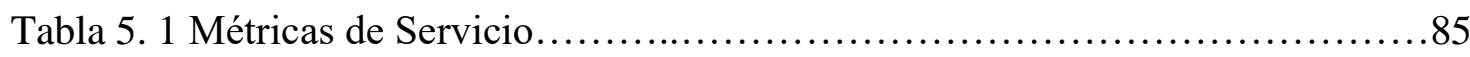

Tabla 6. 1 Gasto Personal administrativo....................................... 86

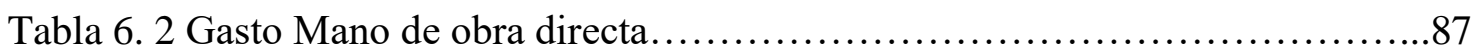

Tabla 7. 1 Venta y Proyección de ventas....................................... 88

Tabla 7. 2 Margen mantinimiento Tiki menor autos............................. 89

Tabla 7. 3 Mantenimiento Tiki menor camionetas.............................. 90

Tabla 7.4. Mantenimiento Tiki Mayor autos.................................... 91

Tabla 7.5 Mantenimiento Tiki Mayor camionetas..............................92

Tabla 7. 6 Margen contratistas lavado.......................................... 93

Tabla 7. 7 Margen servicio plachado......................................... 94

Tabla 7. 8 Crecimiento porecentual de márgenes................................95

Tabla 7. 9 Depreciación activos fijos...................................96

Tabla 7. 10 Amortización intangibles.........................................97

Tabla 7. 11 Capital de trabajo................................................ 98

Tabla 7. 12 Balance General al 30 setiembre 2016................................99

Tabla 7. 13 Estados de resultados...............................................100

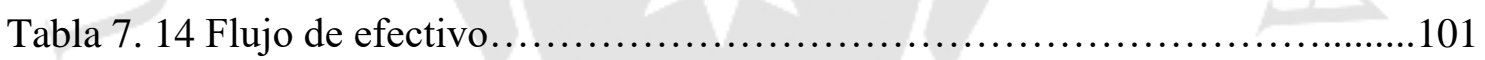

Tabla 7. 15 Indicadores de viabilidad financiera.................................102

Tabla 7. 16 Tasa de descuento del accionista.................................... 103

Tabla 7. 17 Indicadores de rentabilidad representativos............................104

Tabla 7. 18 Indicadores de rentabilidad escenario optimista........................105

Tabla 7. 19 Indicadores de rentabilidad escenario pesimista........................106

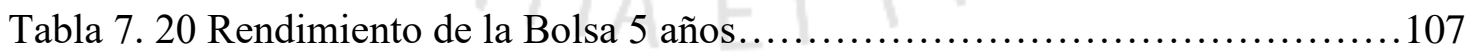




\section{INTRODUCCIÓN}

La presente tesis es fruto del trabajo realizado a lo largo del MBA de la Universidad de Lima y el Tecnológico de Monterrey. Consiste en el desarrollo de la idea de negocio de un taller de mecánica innovador, centrado en la atención al cliente, calidad en el servicio, confianza, seguridad por los trabajos realizados y ahorro del tiempo al ofrecer servicios de recojo y entrega del vehículo en el lugar indicado por el cliente.

En este proyecto se ha buscado recoger todos los temas aprendidos a lo largo del MBA, lo cual le ha permitido al proyecto crecer con el inicio de cada nuevo curso. El Taller Tiki Cars ha iniciado sus operaciones a fines de abril del 2016 cuando abre sus puertas al público en La Molina. A la fecha de la presente entrega, el taller crece a tasas promedio de $14 \%$ mensual, con clientes satisfechos y se encuentra trabajando actualmente con las compañías de Seguro La Positiva y Mapfre. 


\section{RESUMEN EJECUTIVO}

El presente trabajo presenta el diseño, elaboración y creación de una idea de negocio de taller de mecánica automotriz denominado Tiki Cars.

En el primer capítulo, que engloba los aspectos generales del negocio, se desarrolla el marco teórico, problemática del sector automotriz, las necesidades, se presenta la idea, la oportunidad y justificación de la propuesta.

En el capítulo 2 se perfila la idea de negocio, se presentan las hipótesis, el diseño de la muestra, las encuestas y el Canvas del modelo de negocio.

En el capítulo 3 como parte del planeamiento estratégico se presenta la misión, visión y valores de la empresa, análisis interno y externo y análisis FODA.

En el capítulo 4 se desarrollan el plan de marketing describiendo el mercado objetivo, desarrollo de la estrategia marketing mix, plan de ventas y proyección de la demanda.

En el capítulo 5 se presenta el plan de operaciones en donde se destacan las principales políticas operacionales, actividades y procesos del negocio. En el capítulo 6 se explica toda la estructura de recursos humanos, así como los objetivos organizacionales y gestión del talento. Por último, en el capítulo 7 se despliega todo el plan económico financiero del negocio demostrando los resultados de los principales indicadores de rentabilidad: valor actual neto (VAN), tasa interna de retorno (TIR) e índice de rentabilidad (IR); los cuales son también incorporados en el análisis de escenarios.

Finalmente, en las conclusiones se validan las hipótesis con los resultados de las encuestas realizadas y se analiza la viabilidad financiera del proyecto. 


\section{CAPÍTULO I: ASPECTOS GENERALES DEL NEGOCIO}

\subsection{Presentación de la empresa}

Tiki Cars es un taller automotriz que se dedica al mantenimiento, reparación, planchado, pintura y lavado de vehículos ubicado en el distrito de La Molina.

\subsection{Marco teórico y mercado (benchmark y mejores prácticas empresariales)}

En un artículo publicado en el diario Gestión (2016) el Banco Central de Reserva del Perú, espera un crecimiento en la economía del país del 3.8\% para el año 2016 y $4 \%$ para el 2017, lo que aseguraría un aumento en la capacidad adquisitiva de la población que trae consigo mayor demanda por productos y servicios (BCR, 2016 citado en Diario Gestión, 2016)

En base a otro artículo publicado en el Diario Gestión (2015) se considera que los vehículos son bienes de alto costo y que su demanda está relacionada con la situación económica y política de un país. En el caso de Perú, la recuperación económica y el proceso de pacificación en la década de 1990 causaron que la venta de autos se incremente. Entre 1998 y 1999, la crisis económica mundial tuvo un efecto en las ventas y en año 2000 se colocaron sólo 10,000 autos nuevos. En el año 2005 se registra una curva ascendente hasta que en los años 2008 y 2009 la crisis externa vuelve a afectar el mercado automotriz peruano. Después de ello, las ventas se recuperan y en el 2015 se observa una caída del 5\% frente al 2014 y actualmente después de los resultados de las elecciones presidenciales se espera que vuelva a repuntar (Ver figura 4.3). 
Figura 4.3

Venta anual de vehículos nuevos

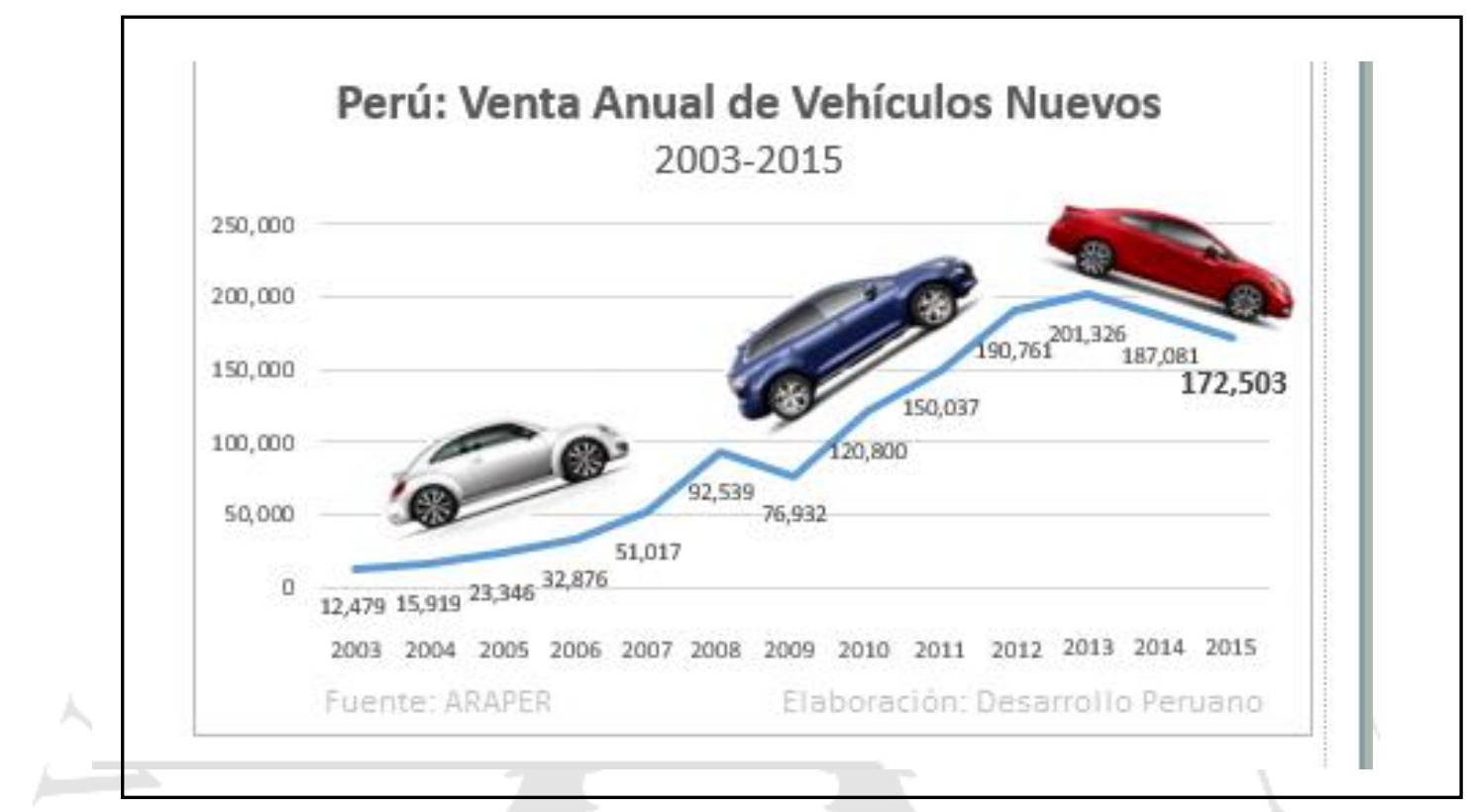

Fuente: ARAPER (2015)

De acuerdo a Kasriel- Alexander (2016), las mega tendencias para el 2016 son las siguientes: Compradores agnósticos, Comprando tiempo, Retando la edad, Hacedores del cambio, Desdibuja miento de género, Comida verde, Bienestar mental, Consumidores sobre conectados, Comprar para controlar y Gastos de solteros.

Tiki Cars se diferencia por la experiencia que se brinda al cliente, la cual se basa en: el ahorro de tiempo en traer y llevar el carro a donde el cliente indique, ahorro de tiempo por los servicios de planchado y pintura in situ, servicio de calidad, confiabilidad, uso de aceites sintéticos, precios competitivos, página web con recomendaciones para usuarios linkeadas a Facebook, horario de atención hasta las 23.00 horas, cámaras de video colocadas en los vehículos que le permitirán al cliente, a través de su celular o PC, hacer seguimiento del servicio solicitado y también por la responsabilidad social. Por ello, es que las megatendencias que se aplicarían serían: Comprando tiempo, Bienestar mental y Hacedores del cambio.

Kasriel-Alexander (2016) explica que el ahorrar tiempo está muy vinculado a nuevos intentos de comprar tiempo, más allá de la conveniencia. Muchos perciben el 
tiempo como algo lujoso. Se busca que los clientes ahorren tiempo al ofrecerles la posibilidad de recoger y entregar el vehículo del lugar que nos indiquen (distritos de La Molina, Surco, Miraflores, San Isidro, San Borja), se les está ahorrando tiempo de traslado. Por otra parte, el ofrecer el servicio de planchado en el mismo taller, hace posible que el tiempo de entrega el vehículo se reduzca, esto permite la diferenciación de otros talleres de mecánica que tercerizan este servicio teniendo que devolver el auto en $10 \mathrm{o}$ hasta en 15 días.

Por otro lado, según el artículo de Kasriel-Alexander (2016), otra megatendencia para el 2016 es el Bienestar Mental; la fascinación con promover el bienestar interno demuestra que los consumidores están buscando algo más allá de la salud física. Este interés en esforzarse por el bienestar mental es también una respuesta a la presión misma de la vida.

En el caso de taller de mecánica, otro punto diferenciador es la responsabilidad social, expresada a través del servicio psicológico al personal de trabajadores. Estos últimos, contarán con servicios de orientación psicológica y capacitación. Esto garantizará el bienestar mental de los trabajadores, beneficiando así la calidad del servicio prestado al cliente. La responsabilidad social expresada en considerar a los trabajadores del taller en el Régimen General en vez del Régimen de Microempresa, se verá reflejada en la productividad de los trabajos realizados. En el caso de los clientes la responsabilidad es relevante porque hay una megatendencia que defiende el cuidado del medio ambiente. De acuerdo a las Megatendencias para el 2015 (Un planeta con recursos), hay una creciente preocupación mundial por el deterioro ambiental y el aseguramiento de recursos estratégicos (Ernst \& Young Global, 2015).

La competencia del taller son todos los talleres multimarca ubicados en la Avenida Javier Prado en La Molina, que cuentan con la fidelización de los clientes y el monopolio cautivo de hacer los mantenimientos con el concesionario hasta los 5 años, porque si no lo hacen con ellos los autos pierden la garantía.

\subsection{Motivación del proyecto}

La motivación del presente proyecto es brindar una experiencia al cliente, que se basa en: el ahorro de tiempo en traer y llevar el carro a donde el cliente indique, ahorro de tiempo por los servicios de planchado y pintura in situ, servicio de calidad, confiabilidad, uso 
de aceites sintéticos, precios competitivos, página web con recomendaciones para usuarios linkeadas a Facebook, horario de atención hasta las 23.00 horas, cámaras de video colocadas en los vehículos que le permitirán al cliente, a través de su celular o PC, hacer seguimiento del servicio solicitado y también por la responsabilidad social.

Además, como estrategia a largo plazo, se busca crecer horizontalmente ofreciendo productos con nuevas tecnologías, lo cual está relacionado al sueño del hijo del dueño de producir carros modernos, eficientes y cuidadosos del medio ambiente. La licencia actual de funcionamiento permite también la venta de automóviles en el local lo cual permitiría su comercialización en el futuro.

\subsection{Percepción de la necesidad: análisis problema-solución}

Los problemas encontrados en el rubro de taller de servicio son los siguientes:

\section{- Tiempo}

Actualmente los talleres de mecánica en la zona de los distritos de La Molina, Miraflores, Surco no cuentan con cabinas de planchado y zona de pintura en el mismo local, pues las Municipalidades no lo permiten en sus parámetros de licencia de funcionamiento. El taller de Servicio Tiki Cars tiene la ventaja competitiva que cuenta con cámaras de planchado y pintura dentro del mismo taller lo que le permite hacer un servicio de planchado y pintura en máximo 5 días mientras que los otros talleres se demoran como mínimo dos semanas dependiendo de la magnitud.

El tráfico en Lima es un problema, en un artículo publicado por el diario El Comercio, se menciona que la aplicación Waze publicó una encuesta sobre el índice global de satisfacción de los conductores, en la que se halló que Lima entre todas las capitales de Sudamérica es considerada como la peor capital para conducir debido al desorden, congestión vehicular, entre otros (Waze, 2016 citado en El Comercio, 2016). Generalmente tener que ir al taller a realizar los servicios de mantenimiento o lavado demanda a las personas dejar el valioso recurso del tiempo para tener que hacer el servicio. Los clientes van a estar dispuestos a pagar con tal de ahorrar tiempo. 


\section{- Tráfico en Lima}

Los talleres automotrices de Lima utilizan en su mayoría aceites minerales y se afilian a una única marca. Los aceites sintéticos tienen la ventaja que duran más tiempo que los aceites minerales y están preparados para las pistas con mucho tráfico protegiendo y alargando la vida de las piezas del automóvil (Mobil, 2016).

\section{- Pocos talleres multimarca en el distrito de La Molina}

En el distrito de La Molina solamente existen concesionarios de autos (talleres de una sola marca de vehículos que tienen costos bien elevados de mantenimiento)

\section{- Excesivos precios por los mantenimientos preventivos y correctivos en los} talleres que representan marcas de carros (concesionarios)

Los costos de los concesionarios son muy elevados debido a que tienen el monopolio del servicio al supeditar la garantía del auto siempre y cuando hagan el servicio de mantenimiento en su taller. Si los autos presentan fallas, generalmente esa falla va a aparecer dentro de los primeros $1,000 \mathrm{~km}$, después la probabilidad de que aparezca es mínima.

\section{- Confianza por servicios de calidad}

A veces de los talleres no dan garantía por los servicios ofrecidos.

\subsection{Descripción de la idea y la oportunidad}

La idea y oportunidad defendidas en Tiki Cars y que lo hacen ser un taller mecánico que se diferencia están vinculadas a los siguientes puntos:

\section{- Tiempo}

Con el recojo, entrega a domicilio y programación de citas, todos los servicios que brinda el taller, permitirán ahorro de tiempo a los clientes.

Para los servicios de mantenimiento Tiki Menor, si se saca cita (se programa con anticipación) el servicio estará listo en dos horas y el servicio de mantenimiento Tiki Mayor se realizará dentro del mismo día. 
Para los servicios de lavado de salón, se cuenta con una máquina marca Karsher, ahorradora de agua que permite el secado en menos tiempo, entregándose el trabajo también el mismo día de ingreso.

Los servicios de planchado menores se harán como máximo en una semana para que los clientes sientan la rapidez además de la calidad del servicio. Esto se logrará gracias a contar con el espacio e infraestructura para el planchado y las cámaras de pintura en el mismo taller. Se harán los servicios de planchado y pintura en máximo 7 días a diferencia del resto de talleres concesionarios que se demoran en promedio 15 días. Si bien muchos talleres cuentan actualmente con sistemas de citas para los servicios de mantenimiento, ninguno ofrece atención de 07.00 a 23.00 horas. La Municipalidad de La Molina ha autorizado a Tiki Cars a operar de 07.00 a 23.00 horas y se diferencia por los siguientes puntos:

- Se hará una página web donde el cliente pueda sacar una cita para hacer sus servicios y se emitirán quincenalmente consejos para el cuidado del vehículo y seguridad.

- $\quad$ Si el cliente desea se puede recoger el auto de su domicilio o del lugar indicado. De regreso, se le puede entregar el carro en el lugar que indique o recogerlo del taller.

- Si el cliente desea que recojan el auto de su domicilio o trabajo, el inventario del vehículo se hará ahí y se emitirá la orden de trabajo a través del sistema mediante el uso de tabletas.

- Aceites sintéticos como medida para el efecto negativo del tráfico en los vehículos

Se ha realizado el análisis de costos y traer a través de dealers aceites sintéticos importados de Miami es más económico que comprar los aceites minerales en Lima. Tiki Cars se diferencia en que los clientes van a poder escoger entre diversas marcas de lubricantes y van a ser sintéticos en vez de minerales, ya que los primeros son de mejor calidad y dan mayor protección a los vehículos. 


\section{- Pocos talleres multimarca en el distrito de La Molina}

En el distrito de La Molina existen, en su mayoría, concesionarios de autos (talleres de una sola marca de vehículos).

La legislación municipal actual, prohíbe la construcción de talleres de mecánica en el distrito, solamente las permite en la avenida Javier Prado pero prohíben la construcción para el servicio de planchado y pintura.

- Excesivos precios por los mantenimientos preventivos y correctivos en los talleres que representan marcas de carros (concesionarios)

Si bien los precios ofrecidos no serán demasiado baratos, Tiki Cars tiene un precio competitivo respecto a los talleres concesionarios (Ver Anexos 1 y 2).

\section{- Confianza por los servicios}

Se cuenta con mecánicos certificados con experiencia egresados de SENATI. Se brinda garantías por los servicios.

\section{- Aviso a nuestros clientes de su próximo servicio}

Los servicios de mantenimiento duran aproximadamente entre 4 a 6 meses. Una secretaria se encargará, mediante la utilización del sistema, de avisar a los clientes del próximo servicio programado. La diferenciación respecto a los otros talleres multimarca que ofrecen el mismo servicio será en que si vienen por el aviso del próximo servicio, se harán acreedores de un $5 \%$ de descuento.

\subsection{Justificación del atractivo de la propuesta}

Además de la experiencia diferenciadora y el desarrollo personal de los trabajadores, el valor de Tiki Cars engloba los siguientes puntos:

- Ubicación en La Molina porque actualmente hay pocos talleres multimarca en esa zona. 
- Se cuenta con licencia para hacer planchado y pintura en el mismo local del taller (in situ).

- $\quad$ Se ofrece aceites sintéticos de diversas marcas para el mantenimiento de los vehículos a precios de mantenimiento con aceites minerales por tener la capacidad de hacer importaciones directas con dealers de Estados Unidos.

- $\quad$ Se cuenta con una moderna sala de espera donde se ofrecen bocaditos, bebidas calientes, frías, periódico de día, wifi, cable, zona con juegos para niños.

- $\quad$ Se ofrecen obsequios por los servicios.

- $\quad$ Se da garantía por los servicios prestados.

(Ver Figura 1.1)

Figura 1.1

Ventajas competitivas

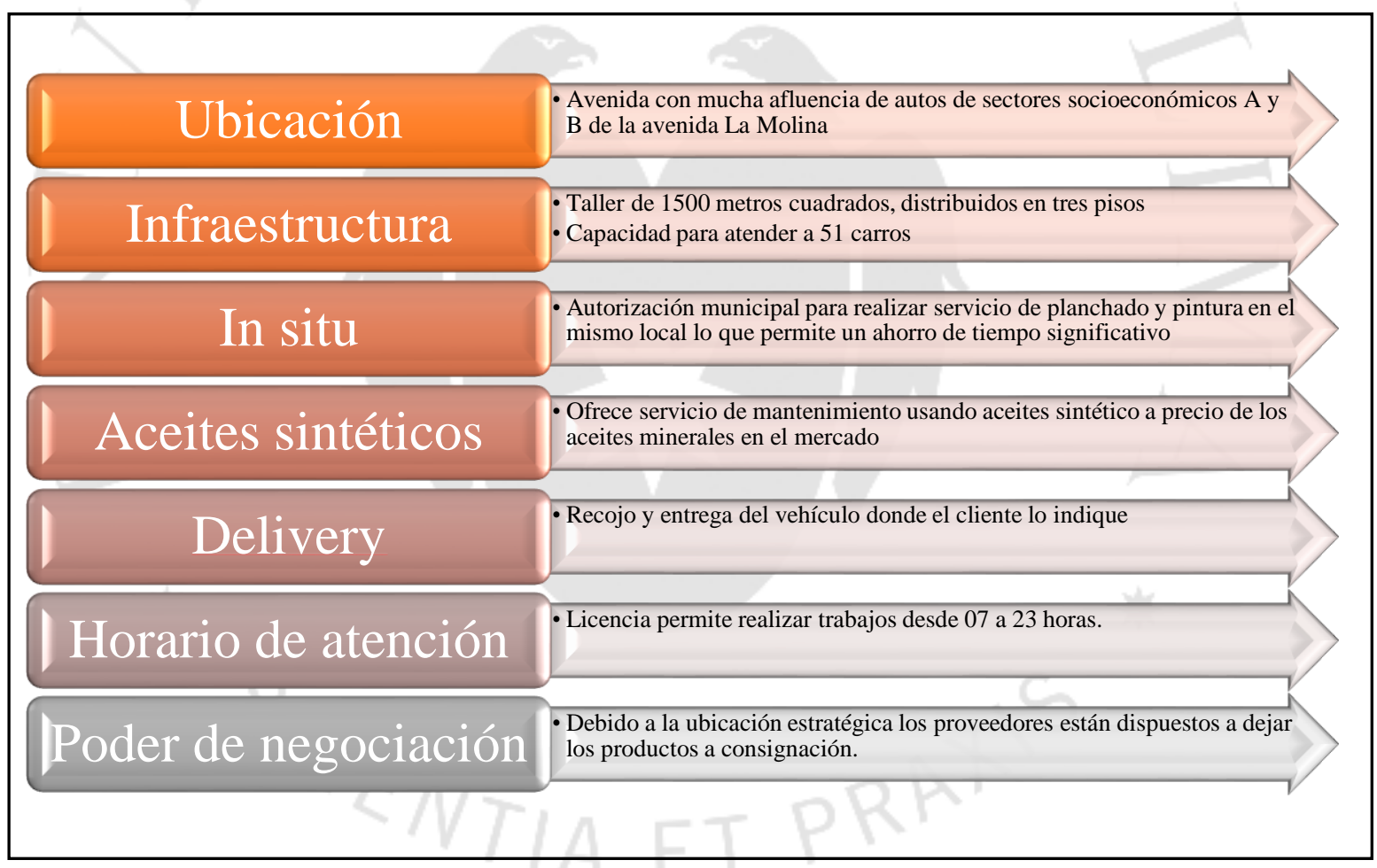

Fuente: Realización propia

\subsection{Estrategia inicial y Objetivos de alcance}

La estrategia inicial se caracteriza por ofrecer una experiencia diferenciadora a los clientes desde que este separa una cita, durante su estancia en el taller, al momento de recoger y dejar su vehículo. La idea es impactar desde el principio aplicando los principios de la atención centrada en el cliente. 
Como parte de los objetivos de alcance se puede destacar ser el taller de mecánica líder de La Molina que brinde servicios de calidad con una atención personalizada y diferenciadora. El objetivo de Tiki Cars es que cada cliente se sienta importante y reconocido y que todo el personal (desde la recepcionista hasta el mecánico) se esfuerce para que la experiencia de todos y cada uno de los clientes sea especial desde el momento que llama por teléfono hasta que recibe su carro al finalizar el servicio.

Así mismo, se busca colaborar con la comunidad al formar al personal de Tiki Cars con capacitaciones que los hagan crecer como profesionales y su gratificación con el trabajo se vea reflejada en el trato con el público.

\subsection{Impacto comercial y responsabilidad social}

La propuesta de valor de Tiki Cars es brindar una experiencia por un servicio de calidad que ahorre tiempo.

\section{- Experiencia}

La experiencia se inicia desde la contestación de la llamada telefónica si los clientes desean programar una cita para su servicio. Al llegar al taller, el asesor se acercará al cliente con mucha amabilidad y atenderá sus necesidades y le hará su presupuesto con las recomendaciones respectivas. Si es un servicio que dura poco tiempo, el cliente puede esperar en la salita de espera donde encontrará sabrosas meriendas, bebidas frías y calientes, el periódico del día y un servicio gratuito de wifi.

Si el cliente desea dejar el carro, se le ofrecerá llevarlo al destino que necesite.

Al culminar el servicio, se le preguntará al cliente si desea recoger el carro del taller o si desea que se lo lleven a su domicilio para lo cual se llevará el POS inalámbrico o podrá hacer depósito en la cuenta del taller. Al terminar el servicio siempre el cliente recibirá un obsequio como gratitud por su servicio.

\section{- Responsabilidad social}

Tiki Cars se caracteriza no sólo por brindar una experiencia diferente a los clientes del rubro de taller de servicio, sino que se preocupa por formar y asistir a sus trabajadores. De esta manera no sólo se asegura de brindar un buen servicio al cliente sino que también vela por la calidad de vida de su capital humano. 
Por ello se proponen talleres de capacitación a los trabajadores en temas como:

- $\quad$ Empatía y buen trato

- $\quad$ Comunicación efectiva y asertividad

- $\quad$ Manejo de conflictos

- Además de los temas de capacitación propuestos, los trabajadores contarán con espacios dedicados a su cuidado personal como por ejemplo:

- Sesiones de relajación durante el trabajo (estiramientos y respiraciones)

- $\quad$ Orientación psicológica para trabajadores que lo requieran

- $\quad$ Orientación vocacional para hijos de los trabajadores.

Por otro lado, Tiki Cars busca proteger el medio ambiente y a la comunidad por lo cual busca generar impactos positivos a nivel económico, social y ambiental, teniendo en consideración las expectativas de sus principales grupos de interés (Ver punto 6.5). 


\section{CAPÍTULO II: IDEA, INVESTIGACIÓN Y VALIDACIÓN DE SOLUCIÓN}

\subsection{Diseño y metodología de la investigación}

La presente investigación es de tipo descriptiva, se busca diseñar y elaborar una idea de negocio para un taller de mecánica automotriz analizando las necesidades de los clientes en este sector para desarrollar soluciones que proporcionen ventajas competitivas a la empresa en el mercado peruano.

Se utilizan las redes sociales y las encuestas como mecanismo de recolección de información para conocer al mercado objetivo y poder crear estrategias diferenciadoras e innovadoras (Ver Anexo 9).

Como indican Hernández, Fernández-Collado y Baptista (2014) se está trabajando bajo el método cuantitativo puesto que se recolecta información acerca de las necesidades y realidades del mercado en cuanto a los servicios de mecánica, planchado, pintura y lavado, la cual es medida y analizada de forma precisa. De esta manera se explicarían ciertas pautas de comportamiento en el cliente y se comprobarían las hipótesis planteadas en el proyecto.

Siguiendo a Hernández Fernández-Collado y Baptista (2014) de acuerdo a la naturaleza de los datos, se empleará también una metodología cualitativa, ya que es una investigación que se basa en el análisis subjetivo e individual, esto la hace una investigación interpretativa, referida a lo particular.

La presente investigación busca solucionar los problemas que se presenten en el sector de Talleres automotrices en el sector 7 de Lima Metropolitana (Surco, Miraflores, San Isidro, San Borja, La Molina).

\subsection{Validación de hipótesis}

Hipótesis principal

Los clientes están interesados en recibir una experiencia por servicio de mecánica, planchado y pintura, que les permita ahorrar tiempo y a la vez obtener un servicio de calidad con un trato centrado en la persona que los haga sentir cómodos y con deseos de retornar. 


\section{Hipótesis secundaria 1}

El tráfico de Lima hace necesaria la utilización de aceites sintéticos. Un taller que ofrezca servicio de mantenimiento con la utilización de aceites sintéticos a precios de aceites minerales será preferido frente a los demás talleres multimarca. Para esto se explicará mediante el uso de las redes sociales, página web y explicación a cada uno de los clientes en persona, cuando visitan el taller, las ventajas del empleo de los aceites sintéticos

\section{Hipótesis secundaria 2}

El recojo y entrega del auto a domicilio representa una ventaja competitiva frente a los demás talleres de mecánica para los servicios de lavado de salón, mantenimiento y planchado y pintura.

\section{Hipótesis secundaria 3}

La formación del personal en un taller de mecánica con capacitaciones que los hagan crecer como profesionales y en su vida personal, logrará gratificación con su trabajo y se verá reflejada en el trato con el público.

\subsection{Validación de la solución}

La solución se validará a través del uso de encuestas en la web, estudio de las tendencias mundiales para el 2016, entrevistas con compañías de seguros y clientes, promociones en Facebook, retroalimentación de los clientes atendidos (Ver Anexo 9).

\subsection{Muestreo poblacional}

Según la Asociación Peruana de Empresas de Investigación de Mercados (Apeim, 2016), al 2015 en Lima Metropolitana hay 2, 686,690 hogares. Para el modelo de negocio de Tiki Cars, el nicho central lo conforman las personas de los distritos de La Molina, Surco, Miraflores, San Borja y San Isidro que pertenecen al sector 7. De este sector la propuesta de Tiki Cars estará dirigida a los niveles socioeconómicos A y B (Ver Figuras 2.1, 2.2).

En base a la información de Apeim (2016), la cantidad de personas que viven en los distritos de La Molina, Surco, San Borja y Miraflores de los sectores A y B son 215, 926 hogares. Este número va a ser un insumo necesario para determinar la cantidad de personas a encuestar. Se le conoce como N o población total. 
Figura 2.3

Población para determinación de la muestra a encuestar

\begin{tabular}{|c|c|c|c|}
\hline \multicolumn{4}{|c|}{ Tamaño de la Población de la Muestra y demanda potencial } \\
\hline Hogares & $2,686,690.00$ & & \\
\hline & NSEA & NSEB & \\
\hline & $5.20 \%$ & $22.30 \%$ & \\
\hline Población & $139,707.88$ & $599,131.87$ & \\
\hline Zona 7 & $57 \%$ & $17.30 \%$ & \\
\hline Población & $79,633.49$ & $103,649.81$ & $183,283.31$ \\
\hline Población con auto & $87 \%$ & $39 \%$ & \\
\hline Demanda Potencial & $69,281.14$ & $40,423.43$ & $109,704.56$ \\
\hline
\end{tabular}

Para obtener el número de personas a encuestar, se utilizó la siguiente fórmula:

$$
\mathrm{n}=\frac{\mathrm{Z}^{2} * \mathrm{p} *(1-\mathrm{p}) * \mathrm{~N}}{\mathrm{e}^{2} *(\mathrm{~N}-1)+\mathrm{Z}^{2} * \mathrm{p} *(1-\mathrm{p})}
$$

Donde:

Z: es la distribución normal 1.96

$\mathrm{N}$ : Población total

P: Probabilidad de éxito 50\%

E: Margen de error: 5\%

Se obtiene un tamaño de muestra a encuestar de 384. A la fecha de entrega del presente trabajo se han realizado 273 encuestas.

En base a la fórmula y a la información de Apeim (2016) la demanda potencial podría ser el porcentaje que tienen carros del sector socioeconómico A, B que equivale a 109, 704.56 hogares.

\subsection{Análisis de tendencias y patrones}

\section{Megatendencias: Ahorro de tiempo y Bienestar Mental}

Según Kasriel-Alexander (2016) cada vez hay más consciencia del valor del tiempo, muchas personas compran en tiendas de proximidad o recurren al comercio electrónico. 
Además, los compradores requieren un servicio al cliente con horarios más amplios y algunas compañías usan las redes sociales como herramienta para resolver problemas con el consumidor.

Respecto a esta tendencia, el taller Tiki Cars, confeccionará una página web para que los clientes puedan sacar su cita para una fecha y hora determinada y en caso lo desee tendrá la posibilidad que el carro se recoja y lleve a su domicilio.

Como parte del servicio, los clientes podrán visualizar el estado de su carro a través de una aplicación móvil conectada a una cámara en su automóvil. Asimismo, se le envían mensajes a su celular y a su correo electrónico sobre avance del estado de su servicio en tiempo real.

El propósito de Tiki Cars es que las personas valoren la experiencia del servicio, la confianza en la detección de fallas y la garantía por los servicios prestados. Con ello, el taller será recomendado y se ganarán clientes adicionales.

Con respecto al bienestar mental, Kasriel-Alexander (2016), sugiere que los consumidores actualmente están buscando servicios que promuevan el bienestar mental más que el físico. Por lo tanto, Tiki Cars busca capacitar a sus trabajadores para que ofrezcan un buen trato a los clientes. Si los trabajadores son capacitados y además se les ofrece espacios de orientación, su bienestar se verá reflejado en el trato al otro; ese clima de cordialidad y respeto es uno de los objetivos de Tiki Cars. El enfocarse y cuidarse uno mismo (propio bienestar mental y físico), de acuerdo a Kasriel-Alexander (2016), incrementaría el darse cuenta de los otros, llevando así a desarrollar la empatía, la cual es un constructo fundamental en el trato con los clientes. 


\subsection{CANVAS del modelo de negocio}

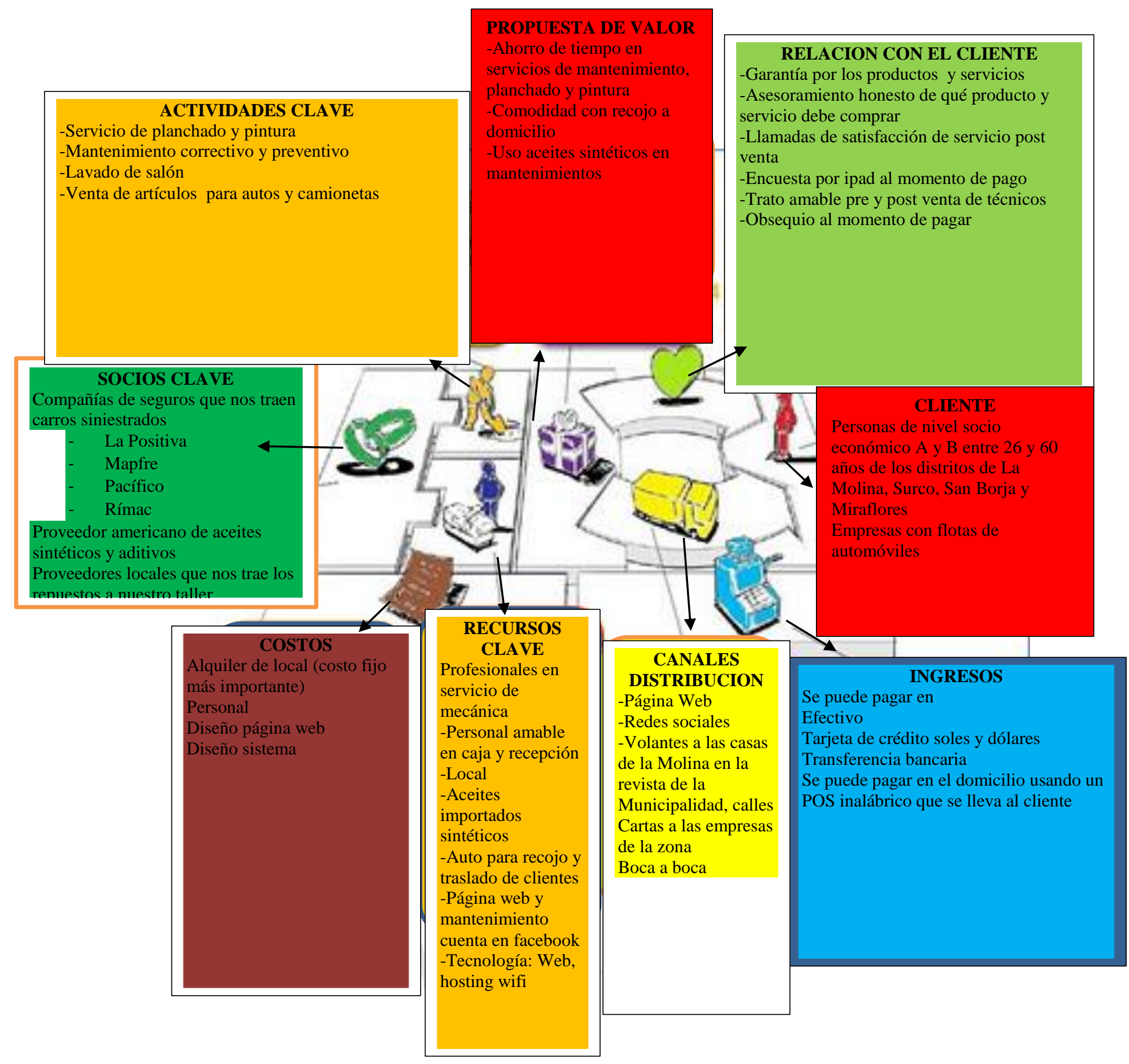

Fuente: Realización propia 


\section{CAPÍTULO III: PLANEAMineto ESTRATÉGICO}

\subsection{Visión}

La visión de Tiki Cars es:

Ser la marca de talleres de mecánica líder y de mayor confianza y prestigio en Lima, con presencia en diversas ubicaciones estratégicas de la capital, sobre la base de un comportamiento ético, impecable con nuestros clientes, colaboradores y la sociedad.

\subsection{Misión}

La misión de Tiki Cars es:

Generar plena satisfacción en nuestros clientes brindándoles servicios y productos de alta calidad, oportunamente, de acuerdo a sus necesidades, a precios competitivos y con calidez, cordialidad y respeto; y ser una organización modelo en el cumplimiento de nuestras obligaciones con nuestros colaboradores y la sociedad. Así mismo buscamos colaborar con la comunidad al formar a nuestro personal con capacitaciones que los hagan crecer como profesionales y su gratificación con el trabajo se vea reflejada en el trato con el público.

\subsection{Valores y ética}

Tiki Cars se caracteriza, en primer lugar, por defender la honestidad, desde la identificación de las fallas de los vehículos hasta entrega de los mismos con todos sus componentes intactos. En segundo lugar, se encuentra el compromiso de nuestros trabajadores que se expresa desde el trato al cliente en la separación de la cita hasta la entrega del vehículo en el lugar, tiempo, y condiciones acordados. En tercer lugar, se destaca el respeto en el trato hacia cliente y entre los mismos trabajadores. Finalmente, se resalta la puntualidad que forma parte de nuestra propuesta diferenciadora que consiste en el ahorro de tiempo del cliente (Ver Figura 3.1). 
Figura 3.1

Valores y ética

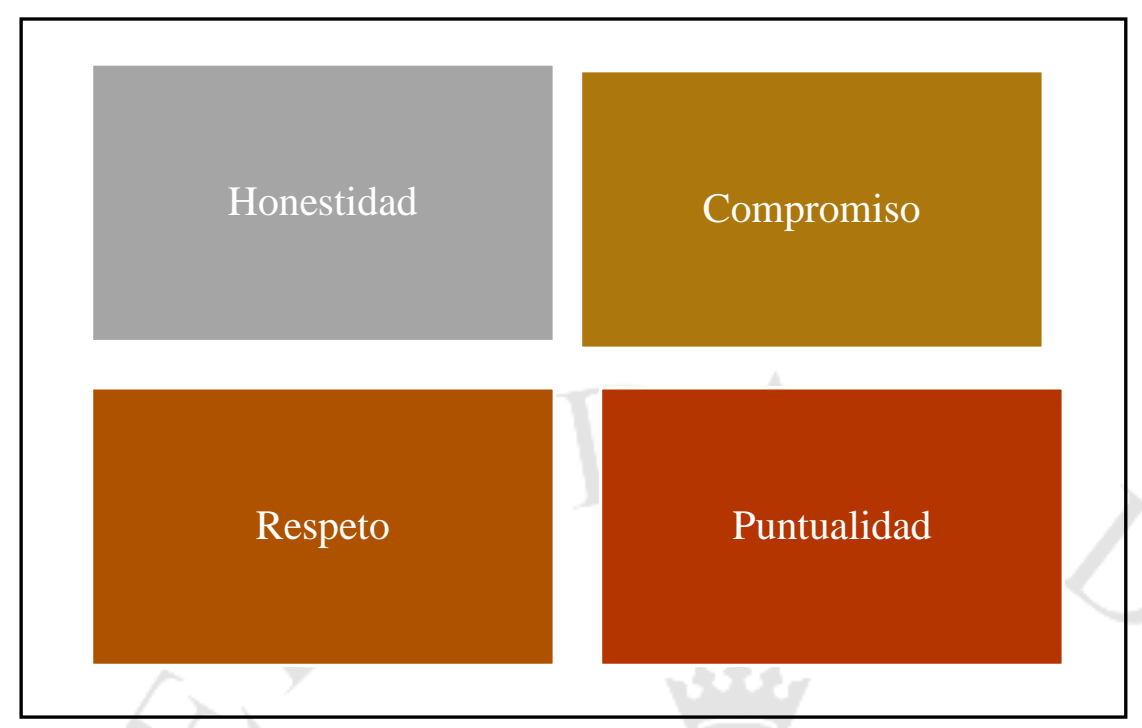

Fuente: Realización propia

\subsection{Cultura organizacional}

La cultura organizacional de la empresa consiste en un servicio centrado en el cliente (como parte de nuestra estrategia diferenciadora se destaca el ahorro de tiempo, que es un factor que da facilidades al cliente desde que se separa la cita hasta que se entrega el vehículo). En segundo lugar, se destaca la garantía en los diversos servicios, esto hace referencia no sólo a los servicios de mecánica automotriz sino también a los servicios complementarios que hacen que la experiencia del cliente en Tiki Cars sea diferenciadora, como, por ejemplo: la sala de espera equipada (wifi incluido), bocaditos, café e infusiones para el cliente, llamada de recordatorio de próximo servicio entre otros. Por último, en tercer lugar, todos los trabajadores se caracterizan por priorizar el trabajo, la dedicación al mismo es un elemento común en todos y cada uno de los trabajadores de Tiki Cars (Ver Figura 3.2) 
Figura 3.2

Cultura organizacional

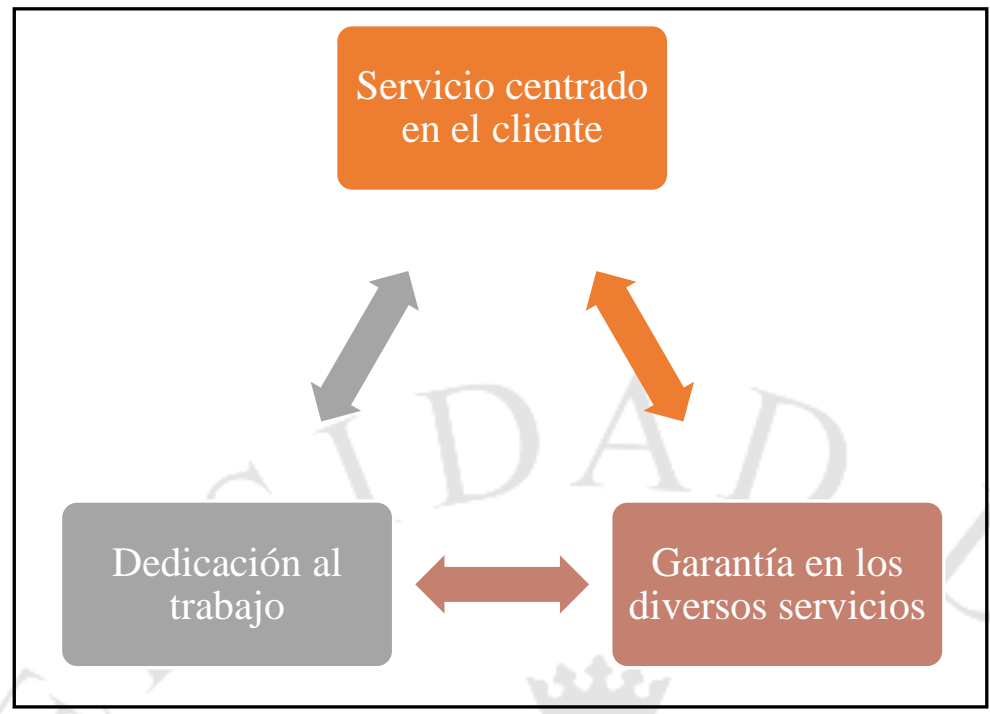

Fuente: Realización propia

\subsection{Objetivos Estratégicos}

En la figuras 3.3 se indican las estrategias a seguir de acuerdo a la misión, visión y valores de la empresa, 3.4 se especifica la problemática principal y en la figuara 3.5 se detallan las estrategias a seguir para resolver dicha problemática.

\section{Figura 3.3}

Objetivos estratégicos

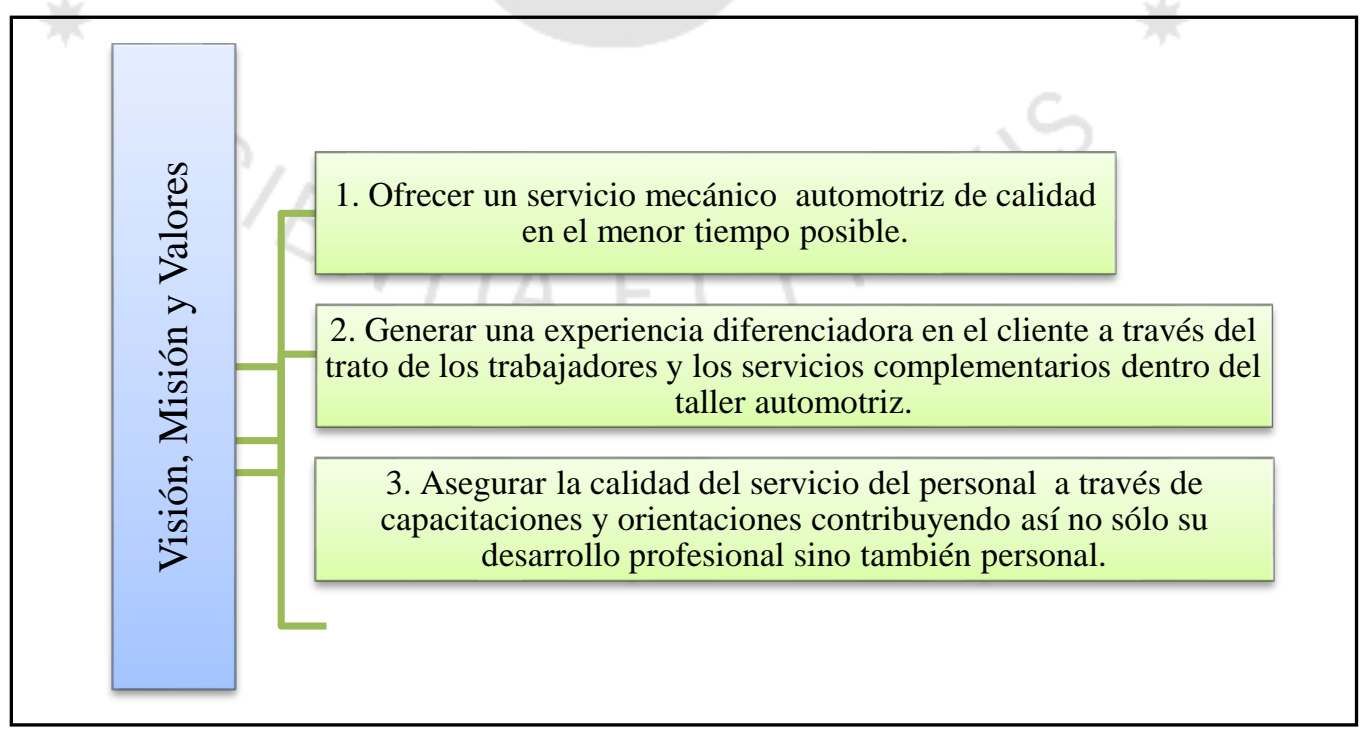

Fuente: Realización propia 
Figura 3.4

Problemática

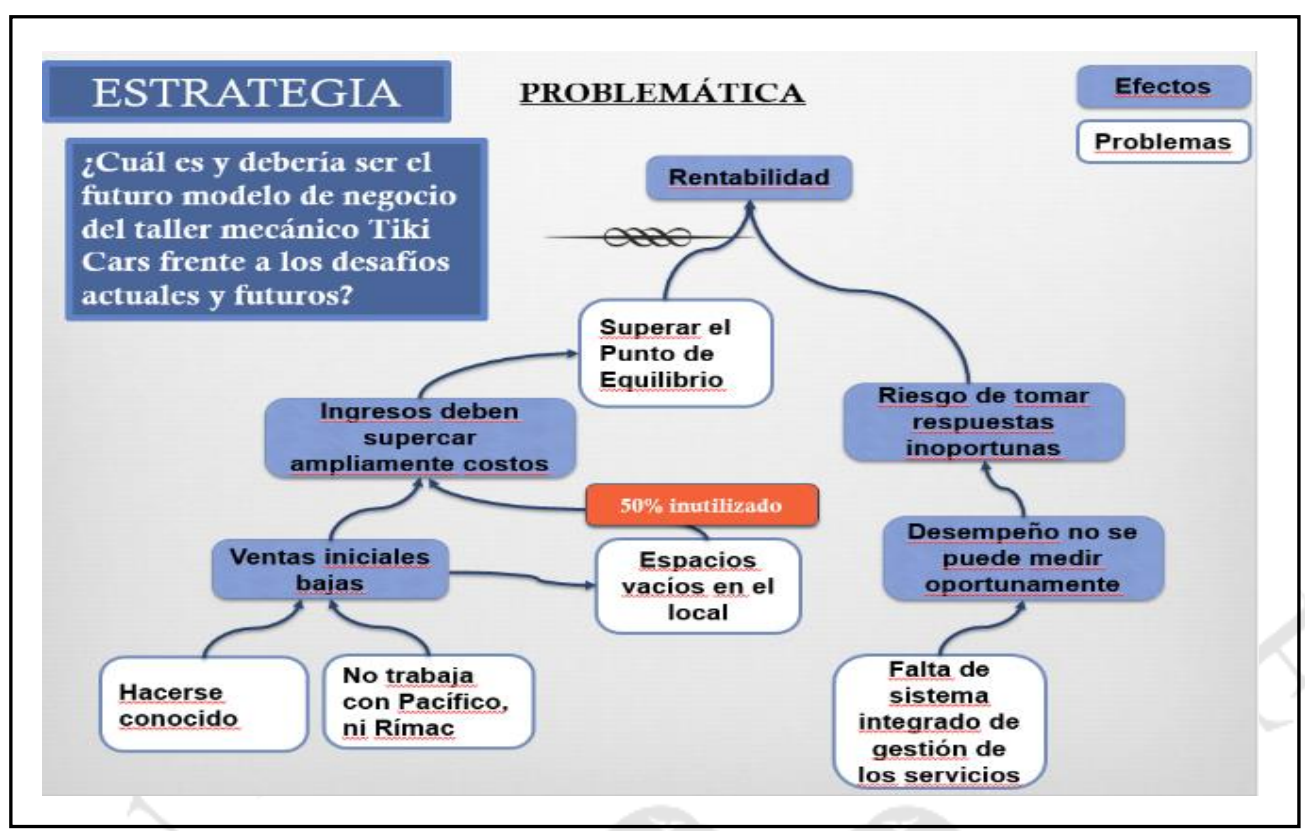

Fuente: Realización propia

Figura 3.5

Estrategia frente a problemática

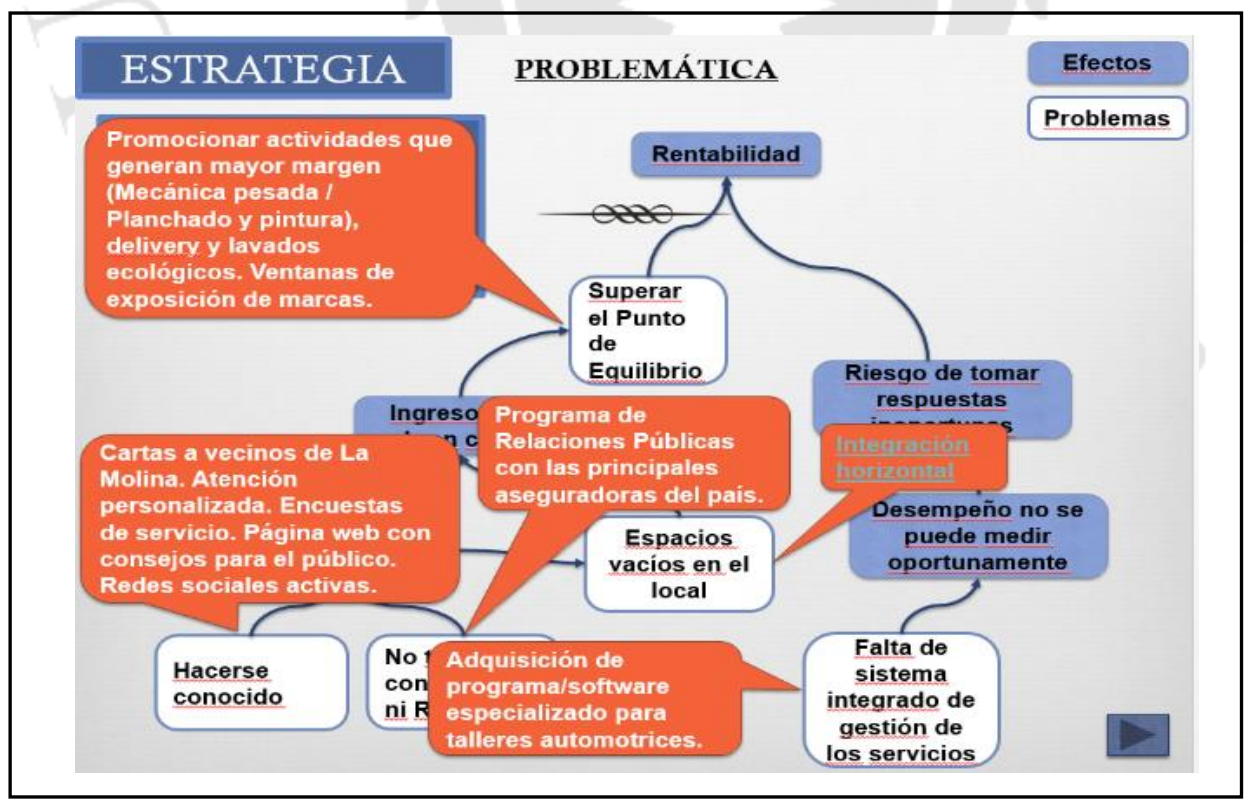

Fuente: Realización propia 


\subsection{Análisis externo: Político, legal, circunstancial, económico, geográfico, social, demográfico, cultural, tecnológico, ambiental (PESTEL)}

En la Figura 3.6 se puede observar que existen diversas variables externas que tienen influencia en el desarrollo del servicio mecánico automotriz. En el plano político, se espera un aumento en el ingreso disponible de los consumidores dado que el gobierno anunció disminuir los impuestos. En el plano legal, Tiki Cars, estará al día en relación a las regulaciones acerca del empleo, salud y seguridad laboral. En cuanto al plano económico se observa que el PBI (Producto Bruto Interno) crecerá en 4.2\% aumentando de esta forma la capacidad adquisitiva de las personas (Ver Figura 3.6).

En el plano socio cultural, las personas prefieren productos ecológicos, en Tiki Cars los servicios y productos ofrecidos buscan proteger y garantizar la seguridad y mantenimiento del medio ambiente. En cuanto al plano tecnológico, Tiki Cars estará atento al desarrollo de las nuevas tecnologías del sector automotriz, para así poderlas integrar a su servicio. Por último, en el plano ecológico, Tiki Cars incorporará las regulaciones medio ambientales del sector automotriz. Dada la preocupación por el calentamiento global, Tiki Cars cuenta con maquinaria y equipo que promueven el cuidado del medio ambiente. Asimismo, se generarán campañas de reciclaje y desecho de residuos, contribuyendo así con la responsabilidad social.

\subsection{Análisis interno: Competidores potenciales, clientes, proveedores, productos sustitutos, barreras de entrada (PORTER)}

Con respecto a la influencia de variables internas, se observa que los competidores potenciales son talleres automotrices con monopolio de servicios de mantenimiento que aseguran la garantía, sobre todo por ser de la marca del vehículo. En relación a los clientes, estos son personas entre 26 y 60 años de edad (adultos jóvenes y adultos intermedios) que pertenecen a los distritos de La Molina, Miraflores, San Isidro, Surco y San Borja, de los sectores socioeconómicos A y B. Asimismo, la carta de clientes está compuesta por empresas aseguradoras y flotas de las compañías. Los proveedores de Tiki Cars son: el dealer de lubricantes y aditivos en USA, Ekonollantas y Volticentro. Los productos sustitutos de Tiki Cars serían las motos, bicicletas y transporte público. Finalmente, como barreras de entrada estarían los permisos municipales y la fuerte inversión que se debe hacer en infraestructura y tecnología dado el tipo de servicio que ofrecemos (Ver Figura 3.7). 
3.8 Análisis sectorial e Identificación de riesgos y amenazas. Análisis FODA y Estrategia de éxito (FODA cruzado)

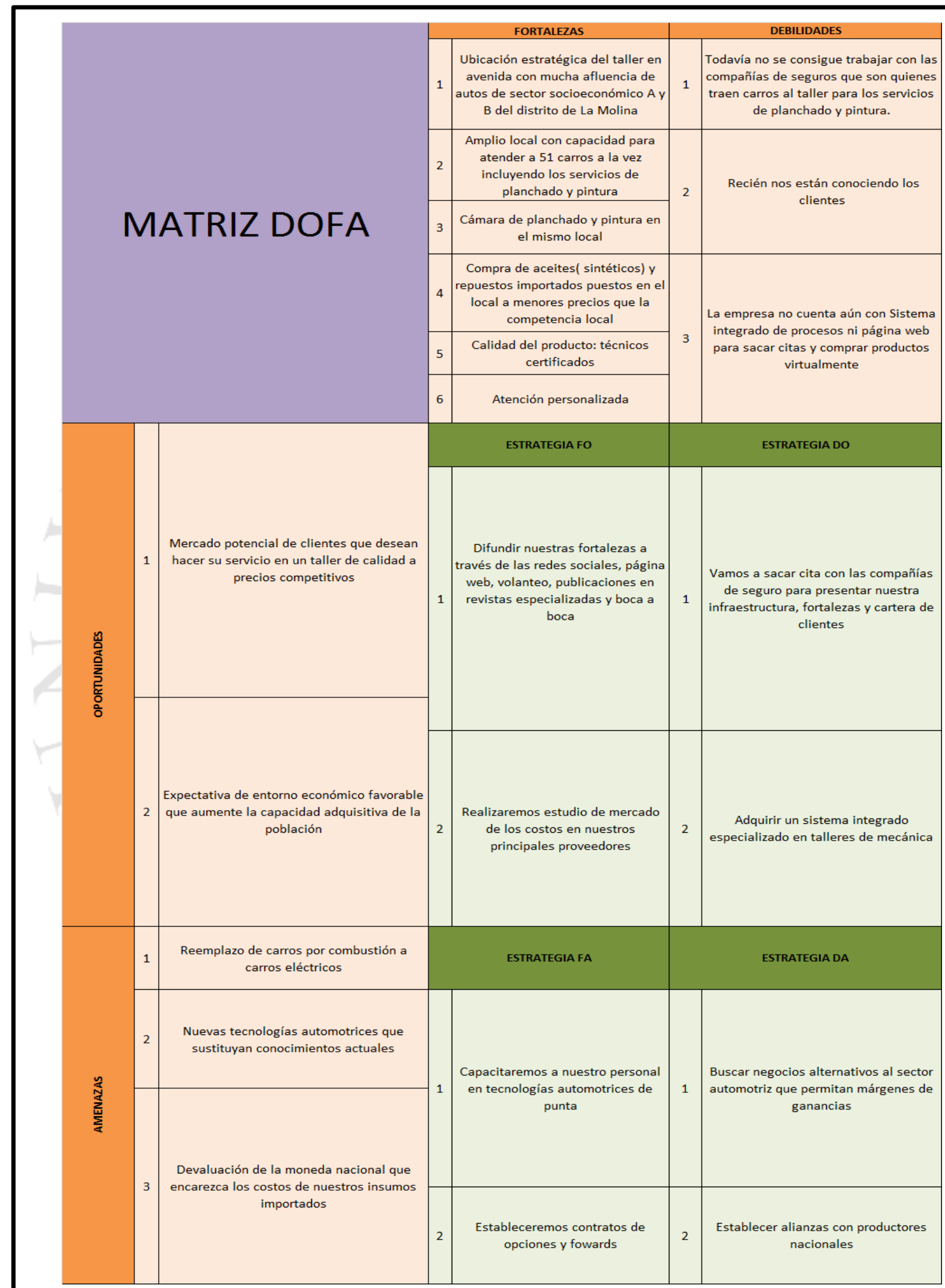

Fuente: Realización propia 


\section{CAPÍTULO IV: PLAN DE MARKETING}

\subsection{Planteamiento de objetivos generales de marketing}

En correspondencia la Visión, Misión, Valores y Objetivos Estratégicos, se han elaborado los objetivos generales de marketing de Tiki Cars (Ver Figura 4.1).

Figura 4.1

Objetivos generales de marketing

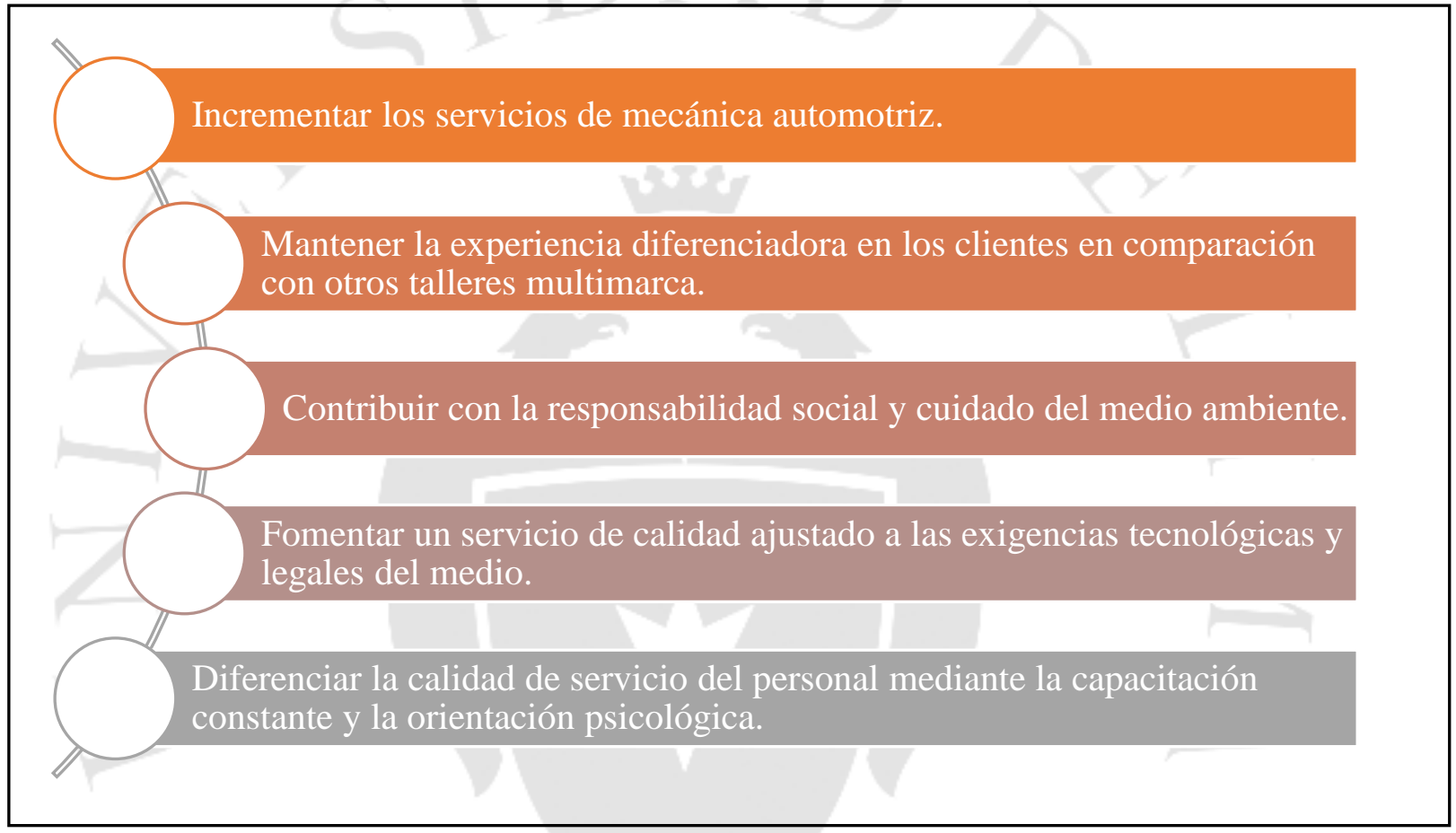

Fuente: Realización propia

\subsection{Estrategias de marketing}

\subsubsection{Segmentación y Perfil del cliente.}

- Geográfico: Lima Metropolitana

- Demográfico y socioeconómico: Personas de nivel socioeconómico A y B que necesitan ahorrar tiempo, del Sector 7 de Lima Metropolitana (La Molina, San Borja, Surco y Miraflores) que desean un servicio de calidad. Las edades fluctúan entre 26 y 60 años.

- $\quad$ Psicográfico: Personas que manejen autos. 
- Empresas aseguradoras: en el Perú es un Oligopolio (pocas empresas concentran el mayor porcentaje de participación del mercado) (Ver Figura 4.2) que necesitan un taller que realice planchado y pintura en el distrito de La Molina de manera rápida (menos de 10 días).

- Flotas de autos: empresas con flotas de autos que necesiten un taller de mecánica multimarca en La Molina con capacidad de darles crédito, con espacio suficiente para recibir sus unidades, que le brinde un servicio de calidad.

\subsubsection{Posicionamiento y ventaja competitiva.}

- Ubicación en La Molina porque actualmente no hay talleres multimarca con cabina de planchado y pintura en el mismo local.

- Contar con licencia para hacer planchado y pintura en el mismo local del taller (in situ).

- Ofrecer aceites sintéticos de diversas marcas para el mantenimiento de los vehículos a precios de mantenimiento con aceites minerales por tener la capacidad de hacer importaciones directas con dealers de Estados Unidos (Anexo 8).

- Horario de atención de 08.00 a 23.00 horas.

- $\quad$ Servicios de recojo y entrega a donde el cliente indique.

\subsection{Mercado objetivo}

\subsubsection{Tendencia y tamaño de mercado}

La tendencia del mercado automotor peruano es creciente desde hace varios años y aunque desacelerado, el tamaño de mercado continúa con una tendencia alcista

Según Diego Sánchez, gerente general The Warranty Group Perú el mercado automotor peruano creció 5\% en el 2015, lo que representa cerca de 172,000 autos nuevos (Saucedo, 2015). Para el 2016, año que ha sido marcado por gran incertidumbre por el periodo electoral, el mercado automotor peruano alcanzará la cifra de 2.6 millones de vehículos y entrará 100,000 nuevas unidades al mercado (Gestión, 2016). Después de los 
resultados de las elecciones presidenciales, se espera una rápida recuperación económica que conducirá al crecimiento de la tendencia del parque automotor que se traducirá en un incremento del mercado de vehículos que necesiten realizar sus servicios de mantenimiento, planchado y pintura.

\subsubsection{Mercado objetivo.}

El mercado objetivo de Tiki Cars son las personas entre 26 y 60 años los segmentos socioeconómicos A y B del Sector 7 que según APEIM (2016) son los distritos de La Molina, Miraflores, Santiago de Surco, San Borja que tengan automóvil. Según la información estadística publicada por APEIM, nuestro público objetivo representa una demanda potencial de 215, 926 hogares, en las que el $87 \%$ del nivel socioeconómico A tienen auto y gastan en promedio S/ 447.00 en transporte (Ver Figuras 2.1, 2.2 y 2.3).

Figura 2.1

Distribución de zonas APEIM por niveles

\section{Apeim}

(\%) VERTICALES

DISTRIBUCIÓN DE ZONAS APEIM POR NIVELES 2016 - LIMA METROPOLITANA

\begin{tabular}{|c|c|c|c|c|c|c|c|}
\hline \multirow{2}{*}{ Zona } & \multicolumn{5}{|c|}{ Niveles Socioeconómicos } & \multirow{2}{*}{ Muestra } & \multirow{2}{*}{ Error $(\%)^{*}$} \\
\hline & NSE A & NSE B & NSE C & NSE D & NSE E & & \\
\hline Total & 100 & 100 & 100 & 100 & 100 & 4,964 & 1.6 \\
\hline Zona 1 (Puente Piedra, Comas, Carabayllo) & 2.1 & 5.1 & 11.7 & 13.8 & 17.3 & 289 & 5.5 \\
\hline Zona 2 (Independencia, Los Olivos, San Martin de Porras) & 5.0 & 14.6 & 17.9 & 12.1 & 4.5 & 324 & 5.3 \\
\hline Zona 3 (San Juan de Lurigancho) & 0.0 & 9.1 & 11.2 & 12.4 & 16.4 & 283 & 6.1 \\
\hline Zona 4 (Cercado, Rimac, Breña, La Victoria) & 6.9 & 11.3 & 10.5 & 7.7 & 5.7 & 498 & 4.4 \\
\hline $\begin{array}{l}\text { Zona 5 (Ate, Chaclacayo, Lurigancho, Santa Anita, San } \\
\text { Luis, El Agustino) }\end{array}$ & 4.2 & 5.9 & 10.9 & 16.2 & 12.6 & 347 & 5.2 \\
\hline $\begin{array}{l}\text { Zona } 6 \text { (Jesús Maria, Lince, Pueblo Libre, Magdalena, San } \\
\text { Miguel) }\end{array}$ & 15.8 & 15.6 & 3.3 & 1.3 & 0.5 & 286 & 5.7 \\
\hline $\begin{array}{l}\text { Zona } 7 \text { (Miraflores, San Isidro, San Borja, Surco, La } \\
\text { Molina) }\end{array}$ & 57.0 & 17.3 & 3.0 & 1.8 & 1.4 & 321 & 5.6 \\
\hline $\begin{array}{l}\text { Zona 8(Surquillo, Barranco, Chorrillos, San Juan de } \\
\text { Miraflores) }\end{array}$ & 6.2 & 9.5 & 8.1 & 6.3 & 4.5 & 284 & 5.9 \\
\hline $\begin{array}{l}\text { Zona 9(Villa El Salvador, Villa Maria del Triunfo, Lurín, } \\
\text { Pachacamác) }\end{array}$ & 0.0 & 3.1 & 11.8 & 17.9 & 18.3 & 279 & 5.6 \\
\hline $\begin{array}{l}\text { Zona } 10 \text { (Callao, Bellavista, La Perla, La Punta, Carmen } \\
\text { de la Legua, Ventanilla) }\end{array}$ & 2.7 & 8.4 & 11.0 & 9.9 & 16.6 & 1,004 & 3.1 \\
\hline Otros & 0.0 & 0.2 & 0.7 & 0.7 & 2.2 & 49 & 14.3 \\
\hline
\end{tabular}

Fuente: Apeim (2016) 
Figura 2.2

Distribución de hogares según nivel socioeconómico, perfil de hogares y gastos por Nivel Socio Económico

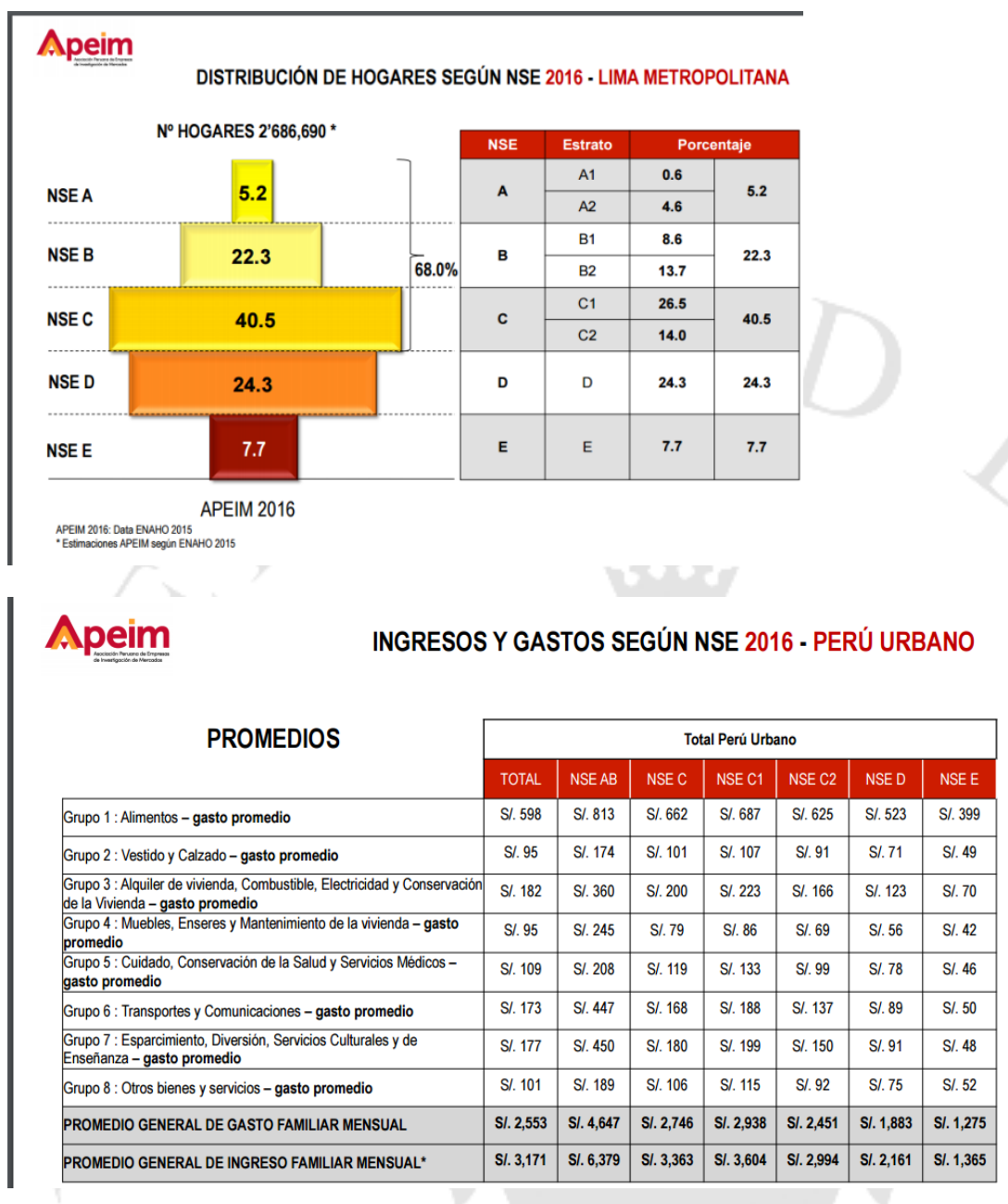

\section{Apeim}

PERFIL DE HOGARES SEGÚN NSE 2016 - LIMA METROPOLITANA

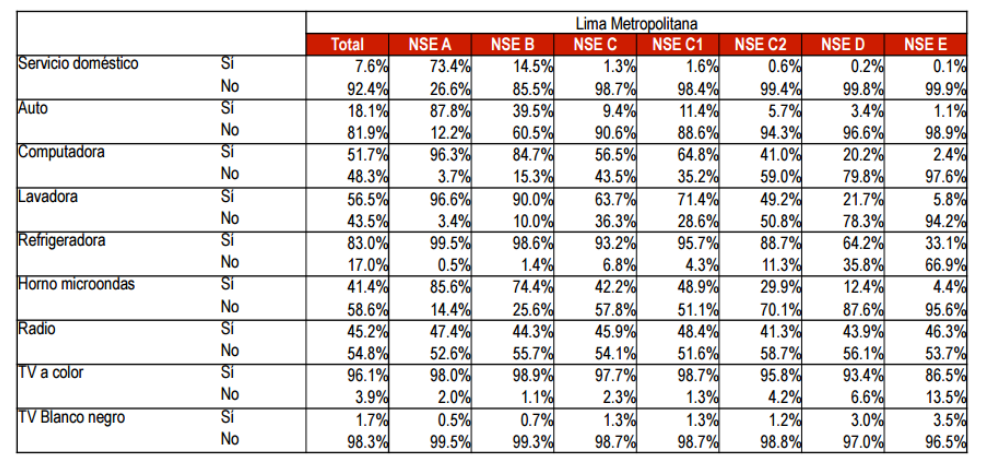

Fuente: Apeim (2016) 
Figura 2.3

Población para determinación de la muestra a encuestar

Tamaño de la Población de la Muestra y demanda potencial

\begin{tabular}{lrrr} 
Hogares & \multicolumn{2}{c}{$2,686,690.00$} & \\
& NSEA & NSEB & \\
& $5.20 \%$ & $22.30 \%$ & \\
Población & $139,707.88$ & $599,131.87$ & \\
& & & \\
& & & \\
Zona 7 & $57 \%$ & $17.30 \%$ & \\
Población & $79,633.49$ & $103,649.81$ & $183,283.31$ \\
& & & \\
Población con auto & $87 \%$ & $39 \%$ & \\
& & & \\
Demanda Potencial & $69,281.14$ & $40,423.43$ & $109,704.56$ \\
\hline
\end{tabular}

4.3.3 Identificación de agentes (clientes, usuarios, compradores, prescriptores, intermediarios, mayoristas, minoristas, comisionistas).

Habiendo identificado a los clientes en el punto anterior, a continuación, se señalará a los agentes más importantes con los que se trabajará:

- Mayoristas

Llantas: Ekono llantas. Perú

Baterías: Volticentro. Perú

Lubricantes y Aditivos: Magwholesale. USA

- Comisionistas

El servicio de lavado y planchado y pintura se trabaja a través de contrato de locación de servicio con dos empresas que brindan los servicios de planchado, pintura y servicio de lavado. Ellos ganan entre el 30\% y 35\% del valor de venta facturado y traen sus propios materiales y equipos. 


\subsubsection{Potencial de crecimiento del mercado.}

Si bien las ventas de autos nuevos ha tenido una tendencia decreciente en Perú en el año 2016 (Ver Figura 4.4), el potencial de crecimiento de mercado es alto debido al cambio del ciclo económico de la economía que se espera que con el nuevo gobierno se inicie un periodo de fuertes inversiones con crecimiento de la economía y por consiguiente de la demanda. El objetivo es posicionar los productos y servicios de la empresa de una forma diferenciada y adaptada a las nuevas exigencias de los clientes.

Según la Asociación Automotriz del Perú (AAP), a setiembre de 2016 se han vendido 100,540 autos nuevos. Con esto se corrobora la tendencia decreciente en el sector automotriz que se inició en el año 2014.

\section{Figura 4.4}

Evolución de ventas de autos nuevos 2015 - 2016

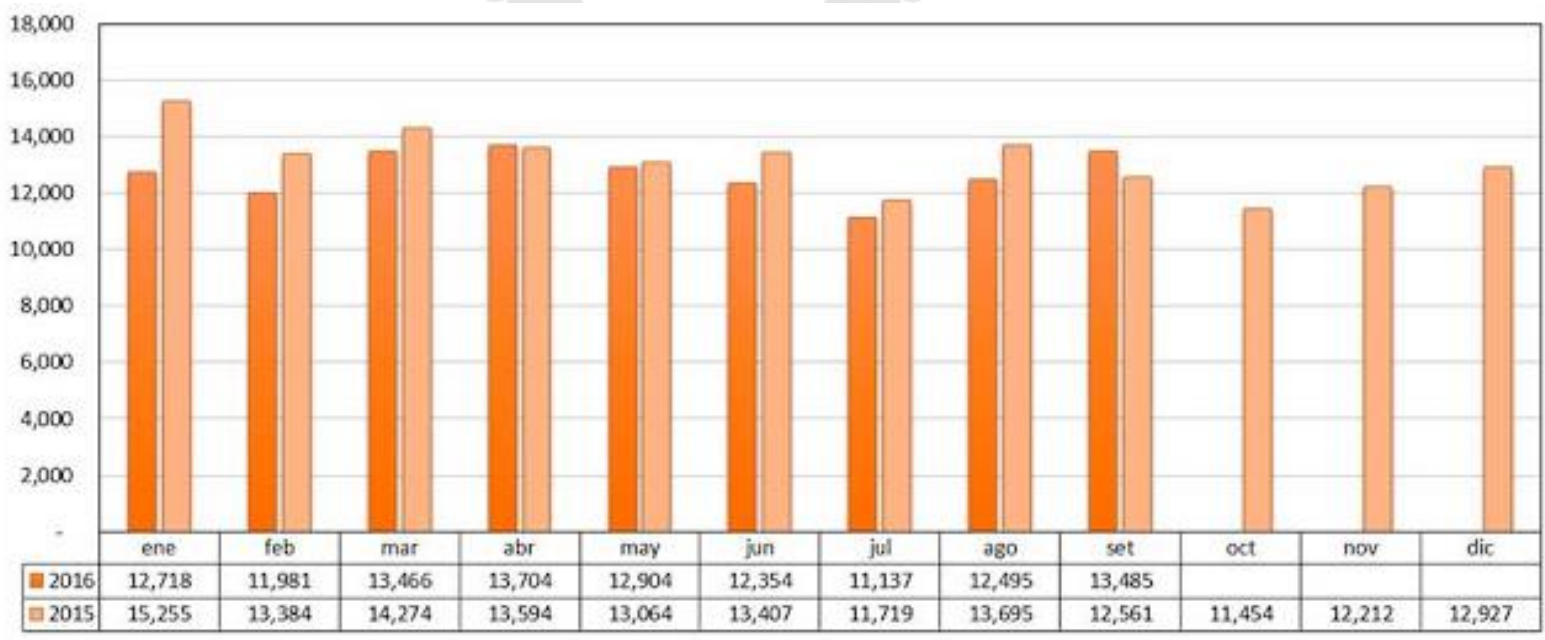

ESTADISTICA DE INMATRICULACIÓN DE VEHICULOS LIVIANOS. En el gráfico se muestra el comportamiento mensual de la inmatriculación de vehiculos livianos a setiembre 2016

Fuente: SUNARP - AAP

V. Menores: motocicietas $y$ trimotos

V. Livianos: automónies, camionotas, pick up, furgonetas, station uagan, SUVs, fodotermenos

V. Pesados: camicnes, tractocamiones, minibús, ómibus

La rivalidad competidora en el sector 7 del mercado limeño está representada por:

- Empresas concesionarias que tienen de alguna manera "el monopolio" de los servicios de mantenimiento de los autos nuevos hasta que se les acabe la garantía (por lo menos 3 años). 
- Talleres multimarca: Germania Automotriz y Gallo autos.

\subsection{Desarrollo y estrategia del marketing mix.}

El desarrollo y la estrategia del Marketing Mix se explican en la Figura 4.5.

\subsubsection{Política de gestión del cliente.}

Para Tiki Cars lo más importante es el cliente por eso el objetivo es que el cliente se vaya satisfecho después de haber realizado su servicio. Uno de los principales objetivos de Tiki Cars es conseguir que su fuente principal de entrada de clientes provenga de recomendaciones de otros clientes. La satisfacción y fidelización del cliente es la única opción viable en un mercado como el peruano. Tiki Cars fideliza a sus clientes a través de la experiencia por el servicio prestado:

- Explicación de los servicios al cliente: se debe definir detalladamente los servicios que se le van a realizar al vehículo del cliente por el servicio presupuestado. Se ha definido un modelo de Orden de trabajo y hoja de inventario para que se le explique al cliente en qué consiste el trabajo que se va a realizar, el precio (Ver Anexos 3 y 4).

- Ejecución del servicio: se planifica el trabajo a realizar de forma detallada y se mantiene al cliente informado con cada avance del servicio a su carro (teléfono, whats app, correo).

- Servicio post venta: A través de llamadas telefónicas para verificar que el servicio fue de su agrado (Ver Anexo 5).

\subsubsection{Estrategia de producto: especificaciones, calidad, variabilidad $y$ diversificación.}

- Calidad: los técnicos que trabajan en Tiki Cars, son profesionales certificados con estudios técnicos y en un caso con capacitación en Japón. Probablemente la competencia tercerice el servicio de contratación personal a un Consultora de Recursos Humanos. En el caso de Tiki Cars, al hacerse la selección en la 
propia empresa, se asegura que el personal seleccionado cumpla con el perfil requerido para el puesto.

- Garantía: los servicios que se prestan en Tiki Cars cuentan con garantía. Todo servicio asegura al cliente de cualquier falla que pudiera provenir del servicio prestado hasta el próximo servicio. Para evitar los errores, se realiza un doble checklist por el mecánico y Jefe de Taller antes que salga el auto del taller (Ver Anexo 6). No todos los talleres multimarca aseguran la garantía por los servicios prestados. Si bien se supone que los concesionarios deben asegurar la garantía por los mantenimientos no se ha logrado visualizar el ofrecimiento en sus páginas web.

\subsubsection{Estrategia de precios: análisis de costos y precios.}

Para determinar el precio se ha tenido en cuenta el análisis de la competencia según anexos 1 y 2 y estructura de costos que se detalla en el plan económico financiero.

Los servicios de planchado y pintura tienen un margen de ganancia de $65 \%$. Los servicios de mecánica, tienen un margen de $90 \%$, los servicios de lavado un margen de $65 \%$.

Tabla 7.3

Margen Mantenimiento Tiki Menor Camionetas

\begin{tabular}{|c|c|c|c|c|c|c|c|c|c|c|c|}
\hline \multirow[t]{2}{*}{ MARGEN } & \multicolumn{11}{|c|}{ MANTENIMIENTO TIKI MENOR DOLARES CAMIONETA } \\
\hline & & AÑO & & & & & & & & & \\
\hline \multicolumn{12}{|c|}{ Repuestos } \\
\hline Código & Descripcion & Cantidad & Costo & COSTO TOT & V.V & V.V.T & MARGEN & MARGEN TOT & $\%$ & Descuento & P.V.P \\
\hline 00129 & EMPAQUE TAPON DE CARTER & 1 & 0.29 & 0.29 & 0.55 & 0.55 & 0.27 & 0.27 & $94 \%$ & $0 \%$ & 0.65 \\
\hline 00126 & ACEITE 10 W30 SINTETICO SHELL & 6 & 5.24 & 31.45 & 10.19 & 61.12 & 4.95 & 29.67 & $94 \%$ & $0 \%$ & 72.12 \\
\hline 00079 & FILTRO DE ACEITE & 1 & 9.97 & 9.97 & 19.38 & 19.38 & 9.41 & 9.41 & $94 \%$ & $0 \%$ & 22.87 \\
\hline 00133 & LIMPIA PARABRISAS PRESTONE GL & 1 & 1.07 & 1.07 & 2.09 & 2.09 & 1.01 & 1.01 & $94 \%$ & $0 \%$ & 2.46 \\
\hline & Mano de Obra & & 16.57 & 42.78 & 32.20 & 83.14 & 15.63 & 40.36 & $94 \%$ & & 98.10 \\
\hline Código & Descripcion & Cantidad & Costo & COSTO TOT & V.V & V.V.T & MARGEN & MARGEN TOT & $\%$ & Descuento & P.V.P \\
\hline 10100 & MATERIALES (GRASA,WAYPE,DISOLVENTES & 1 & 1.99 & 1.99 & 3.86 & 3.86 & 1.88 & 1.88 & $94 \%$ & $0 \%$ & 4.56 \\
\hline 10101 & MANTENIMIENTO PREVENTIVO TIKI & 1 & 14.36 & 14.36 & 27.90 & 27.90 & 13.54 & 13.54 & $94 \%$ & $0 \%$ & 32.92 \\
\hline 10245 & LIMPIEZA, CHEQUEO Y REGULACION DE FF & 1 & 9.57 & 9.57 & 18.60 & 18.60 & 9.03 & 9.03 & $94 \%$ & $0 \%$ & 21.95 \\
\hline 10345 & LAVADO SIMPLE (CORTESIA) & 1 & 5.74 & 5.74 & 11.16 & 11.16 & 5.42 & 5.42 & $94 \%$ & $0 \%$ & 13.17 \\
\hline \multirow[t]{4}{*}{ TOTAL } & & & 31.66 & 31.66 & 61.52 & 61.52 & 29.87 & 29.87 & $94 \%$ & & 72.60 \\
\hline & & & 48.23 & 74.43 & 93.73 & 144.66 & 45.50 & 70.23 & $94 \%$ & & 170.70 \\
\hline & & & & $\mathbf{7 4 . 4 3}$ & & 139.75 & & 65.31 & $88 \%$ & & 164.90 \\
\hline & & & & $\mathbf{7 4 . 4 3}$ & & 135.51 & & 61.08 & $82 \%$ & & 159.90 \\
\hline
\end{tabular}


Tabla 7.4

Mantenimiento Tiki Mayor autos

\begin{tabular}{|c|c|c|c|c|c|c|c|c|c|c|c|}
\hline \multirow[t]{3}{*}{ MARGEN } & \multicolumn{2}{|l|}{ MANTENIMIENTO TIKI MAYOR DOLARES AUTO } & \multirow[t]{2}{*}{ TC } & \multicolumn{2}{|l|}{3.4} & & & \multirow[b]{4}{*}{ MARGEN TOT } & & \multirow[b]{4}{*}{ Descuento } & \multirow[b]{4}{*}{ P.V.P } \\
\hline & \multirow{2}{*}{\multicolumn{2}{|c|}{ Repuestos }} & & \multirow[b]{3}{*}{ COSTO TOT } & \multirow[b]{3}{*}{$\mathbf{V . V}$} & \multirow[b]{3}{*}{ V.V.T } & \multirow[b]{3}{*}{ MARGEN } & & \multirow[b]{3}{*}{$\%$} & & \\
\hline & & & \multirow[b]{2}{*}{ Costo } & & & & & & & & \\
\hline Código & Descripcion & Cantidad & & & & & & & & & \\
\hline 00129 & EMPAQUE TAPON DE CARTER & 1 & 0.29 & 0.29 & 0.55 & 0.55 & 0.27 & 0.27 & $94 \%$ & $0 \%$ & 0.65 \\
\hline 00126 & ACEITE 10W30 SINTETICO SHELL & 4 & 5.24 & 20.96 & 10.19 & 40.74 & 4.95 & 19.78 & $94 \%$ & $0 \%$ & 48.08 \\
\hline 00079 & FILTRO DE ACEITE & 1 & 4.99 & 4.99 & 9.69 & 9.69 & 4.70 & 4.70 & $94 \%$ & $0 \%$ & 11.43 \\
\hline 00078 & BUJIAS & 4 & 1.84 & 7.35 & 3.57 & 14.29 & 1.73 & 6.94 & $94 \%$ & $0 \%$ & 16.86 \\
\hline 00077 & FILTRO DE AIRE & 1 & 7.47 & 7.47 & 14.52 & 14.52 & 7.05 & 7.05 & $94 \%$ & $0 \%$ & 17.13 \\
\hline \multirow[t]{2}{*}{00133} & LIMPIA PARABRISAS PRESTONE GL & 1 & 1.07 & 1.07 & 2.09 & 2.09 & 1.01 & 1.01 & $94 \%$ & $0 \%$ & 2.46 \\
\hline & Mano de Obra & & 20.89 & 42.13 & 40.61 & 81.88 & 19.71 & 39.75 & $94 \%$ & & 96.62 \\
\hline Código & Descripcion & Cantidad & Costo & COSTO TOT & V.V. & V.V.T & MARGEN & MARGEN TOT & $\%$ & Descuento & P.V.P \\
\hline 10100 & MATERIALES (GRASA,WAYPE,DISOLVENTES & 1 & 1.99 & 1.99 & 3.86 & 3.86 & 1.88 & 1.88 & $94 \%$ & $0 \%$ & 4.56 \\
\hline 10101 & MANTENIMIENTO PREVENTIVO TIKI & 1 & 11.04 & 11.04 & 21.46 & 21.46 & 10.42 & 10.42 & $94 \%$ & $0 \%$ & 25.33 \\
\hline 10102 & BALANCEO Y ROTACION DE RUEDAS & 4 & 3.52 & 14.08 & 5.86 & 23.44 & 2.34 & 9.36 & $66 \%$ & $0 \%$ & 27.66 \\
\hline 10245 & LIMPIEZA, CHEQUEO Y REGULACION DE FF & 1 & 7.36 & 7.36 & 14.31 & 14.31 & 6.95 & 6.95 & $94 \%$ & $0 \%$ & 16.88 \\
\hline 10345 & LAVADO SIMPLE (CORTESIA) & 1 & 4.42 & 4.42 & 8.59 & 8.59 & 4.17 & 4.17 & $94 \%$ & $0 \%$ & 10.13 \\
\hline \multirow[t]{2}{*}{ TOTAL } & & & 28.33 & 38.89 & 54.08 & 71.66 & 25.75 & 32.77 & $84 \%$ & & 84.56 \\
\hline & & & 49.23 & 81.02 & 94.69 & 146.61 & 45.46 & 72.52 & $90 \%$ & & 173.00 \\
\hline
\end{tabular}

Tabla 7.5

Mantenimiento Tiki Mayor camionetas

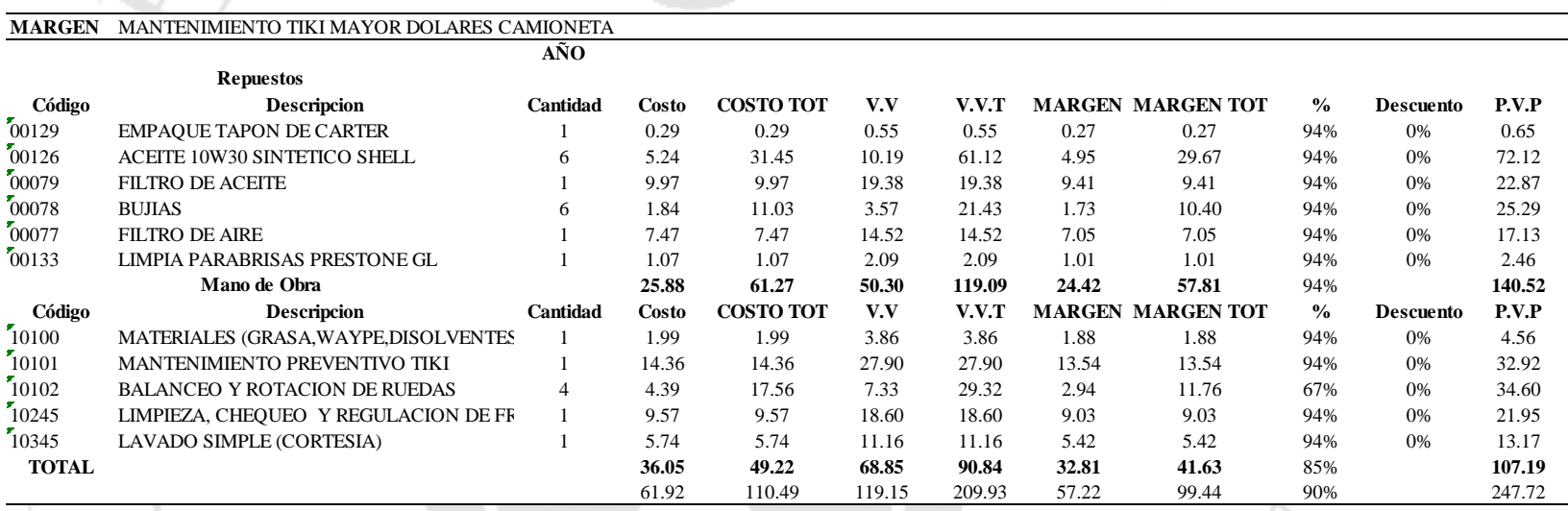

Tabla 7.6

Margen contratistas Lavado

\begin{tabular}{|c|c|c|c|c|c|c|c|c|c|c|c|c|}
\hline \multirow{3}{*}{$\begin{array}{l}\text { MARGEN CONTRATISTAS (LAVADO) } \\
\text { LAVADOR (01) JORGE CONDORI } \\
\text { AYUDANTE LAVADO (02) }\end{array}$} & \multicolumn{12}{|c|}{$\mathbf{3 1 \%}$} \\
\hline & \multicolumn{6}{|c|}{ COSTO AUTO } & \multicolumn{6}{|c|}{ COSTO CAMIONETA } \\
\hline & AUTO & INSUMO & OSSUB TOT & V.V & MARGEN & $\%$ & :AMIONE & TINSUMC & OSSUB TOT & V.V & MARGEN & $\%$ \\
\hline LAVADO,ASPIRADO Y PULVERIZADO DE MOTOR. & 6.52 & 4.28 & 10.80 & 25.44 & 14.63 & $58 \%$ & 6.52 & 5.42 & 11.94 & 33.07 & 21.12 & $64 \%$ \\
\hline LAVADO,ASPIRADO,PULVERIZADO DE MOTOR Y E & 16.43 & 4.81 & 21.24 & 52.99 & 31.75 & $60 \%$ & 21.36 & 5.70 & 27.06 & 68.89 & 41.83 & $61 \%$ \\
\hline LAVADO SALON & 65.71 & 14.48 & 80.18 & 211.96 & 131.78 & $62 \%$ & 85.42 & 20.89 & 106.31 & 275.55 & 169.24 & $61 \%$ \\
\hline TRATAMIENTO DE PINTURA & 65.71 & 8.11 & 73.82 & 211.96 & 138.14 & $65 \%$ & 85.42 & 10.50 & 95.92 & 275.55 & 179.63 & $65 \%$ \\
\hline LAVADO PREMIUN & 98.56 & 22.59 & 121.15 & 317.95 & 196.80 & $62 \%$ & 128.13 & 31.39 & 159.52 & 413.33 & 253.80 & $61 \%$ \\
\hline UNDERCOATING & 131.42 & 15.78 & 147.20 & 423.93 & 276.73 & $65 \%$ & 170.84 & 25.98 & 196.83 & 551.11 & 354.28 & $64 \%$ \\
\hline PRECIOS NO INCLUYEN IGV & & & & & & & & & & & & \\
\hline
\end{tabular}


Tabla 7.7

Margen servicio planchado

\begin{tabular}{|c|c|c|c|c|c|c|c|c|c|c|c|c|}
\hline \multicolumn{13}{|l|}{ MARGEN CONTRATISTAS (PLANCHADO) } \\
\hline PLANCHADOR (01) ABRAHAM & \multicolumn{6}{|c|}{ COSTO AUTO } & \multicolumn{6}{|c|}{ COSTO CAMIONETA } \\
\hline AYUDANTE PLANCHADO (01) & AUTO & INSUM & SUB TOT & V.V & MARGEI & $\%$ & 'AMIONE & TINSUM & OSSUB TOT & V.V & MARGEN & N $\%$ \\
\hline PLANCHADO H/H PARTICULAR SOLES & 12.69 & 0.75 & 13.44 & 42.29 & 28.85 & $68 \%$ & 12.69 & 0.75 & 13.44 & 42.29 & 28.85 & $68 \%$ \\
\hline PLANCHADO H/H MAPFRE DOLARES & 3.60 & 1.75 & 5.35 & 12.00 & 6.65 & $55 \%$ & 3.60 & 1.75 & 5.35 & 12.00 & 6.65 & $55 \%$ \\
\hline PLANCHADO H/H POSITIVA DOLARES & 4.17 & 2.75 & 6.92 & 13.90 & 6.98 & $50 \%$ & 4.17 & 2.75 & 6.92 & 13.90 & 6.98 & $50 \%$ \\
\hline
\end{tabular}

\subsubsection{Política comercial.}

- Objetivos de venta: para los primeros meses, se busca cubrir los costos fijos y variables, luego un crecimiento de $15 \%$ y para los siguientes años se busca un crecimiento de $6 \%$.

- Condiciones de venta: al contado para el público en general; con tarjeta de crédito el abono se realiza a las 48 horas. A las flotas de empresas y compañías de seguros se les da crédito de 30 días útiles.

- Organización de la fuerza de venta: en Tiki Cars se cuenta con 2 Asesores de Servicio y un Jefe de Taller.

- Política de remuneración: todo el personal se encuentra en Planilla, se les paga sueldos superiores al mercado. A partir del segundo año se realizarán políticas de comisiones e incentivos para el personal, desde la recepcionista hasta el señor encargado de la limpieza.

- Canales de venta: los medios que usará Tiki Cars para llegar al cliente son avisos en redes sociales, en su página web, volantes y promociones a los vecinos de La Molina, avisos en una revista especializada en autos 2 veces al año (Ver Anexo 10).

- Sistemas de control: para controlar la actividad comercial se debe generar reportes de control, esto se encuentra en proceso de ejecución.

\subsubsection{Estrategia comunicacional y canal.}

- Promoción de venta: exhibidores en Tiki Cars y banners con descuentos.

- Publicidad: En revistas de autos y Google

- Utilización de las redes sociales y desarrollo de página web 


\subsubsection{Estrategia de distribución.}

No hay distribución para nuestros servicios de planchado, pintura, mantenimiento y lavado. Lo que si se ofrece es servicio de delivery a domicilio en el recojo y entrega.

\subsection{Plan de Ventas (objetivos anuales, alcance de la oferta) y Proyección de la Demanda (crecimiento y desarrollo).}

Tiki cars tiene capacidad para atender a 50 carros al día, por 24 días al mes es una atención de 1200 carros al mes y 14,400 carros al año.

Al sexto mes de operaciones se tienen 8 carros en promedio al día. Se espera para los próximos 6 meses llegar a tener 15 carros al día y para el primer año tener 20 carros al día con un ticket promedio de S/.450.00 nuevos soles.

El servicio que deja más margen en Tiki Cars, son los servicios mecánica y luego los de planchado y pintura. Las estrategias de ventas deben dirigirse hacia ese objetivo. El diferenciador tangible del servicio de mecánica será la visualización del estado del avance del mantenimiento del auto a través de la cámara y el acceso online desde un dispositivo móvil o PC del cliente; además de los avisos al correo y mensajes de texto al celular del avance del servicio.

Los servicios de planchado y pintura son proporcionados en su mayoría por las compañías de seguros. Actualmente se trabaja con la Positiva y con Mapfre Compañía de Seguros. Se debe trabajar intensamente para conseguir ser taller autorizado de Rímac y Pacífico que son las compañías de seguro con mayor participación de mercado. 


\section{CAPÍTULO V: PLAN DE OPERACIONES}

\subsection{Políticas Operacionales.}

Con el fin de optimizar los procesos operativos, cada mes se revisará la página web, se buscará mejorar el sistema de acuerdo a los requerimientos del mercado, se hará seguimiento y control a los procesos, se revisarán los precios de acuerdo a la información de los proveedores y la competencia. Permanentemente se hará una búsqueda continua de nuevas tecnologías.

\subsection{Equipos, actividades y procesos.}

\subsubsection{Diseño y capacidad de Instalaciones.}

El taller ubicado en el distrito de La Molina cuenta con $1539 \mathrm{~m}^{2}$ distribuidos en tres pisos. En el primer piso, se encuentra la zona de recepción, cafetín, oficinas administrativas, zona de diagnóstico, mecánica ligera, lavado y almacén de carros en tránsito, cuartos de máquinas, baños y cambiadores. En el segundo piso, se encuentra la zona para mecánica pesada, comedores y almacenes. Por último, en el tercer piso se encuentra la zona de planchado y pintura (Ver figura 5.1) Diseño y Capacidad de Instalaciones). Tiki Cars tiene capacidad para atender a 52 vehículos en total.

\section{Figura 5.1}

Diseño y capacidad de Instalaciones

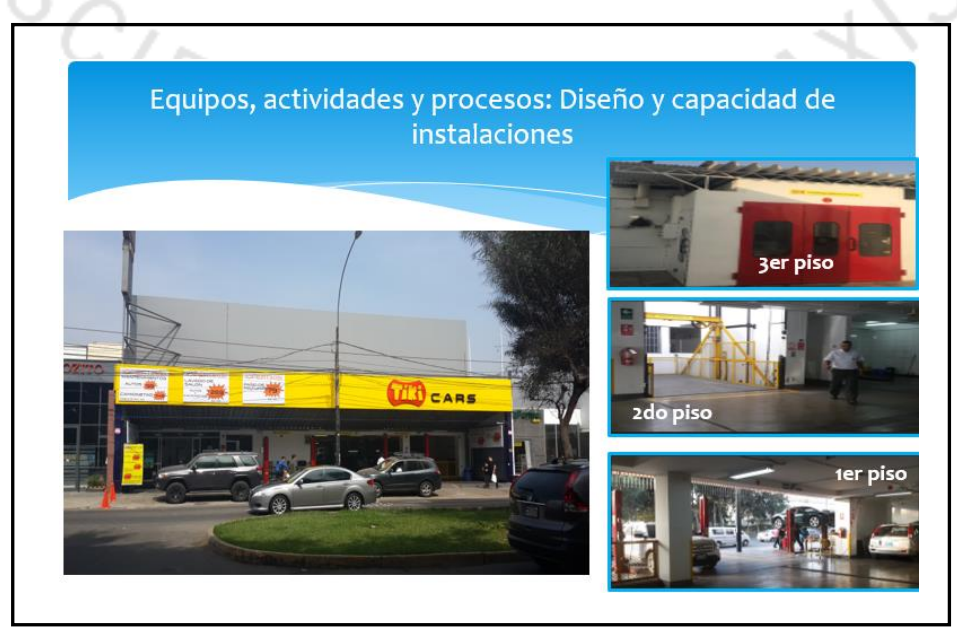

Fuente: Realización propia 


\subsubsection{Equipos de trabajo $\mathrm{y}$ apoyos.}

Para poder realizar todos los servicios ofrecidos Tiki Cars cuenta con todos los equipos e infraestructura de punta para ofrecer servicios de calidad. Para los servicios de mecánica cuenta con tres elevadores de poste, cinco elevadores neumáticos y escáner de última generación. Para el servicio de lavado cuenta con un elevador de pistón, máquinas de lavado karcher ahorradoras de agua. Para los servicios de planchado y pintura cuenta con un horno de pintura, máquina de traccionamiento, soldadura mig, entre otros (Ver Figura 5.2 Equipos de trabajo y apoyo).

Figura 5.2

Equipos de trabajo y apoyos

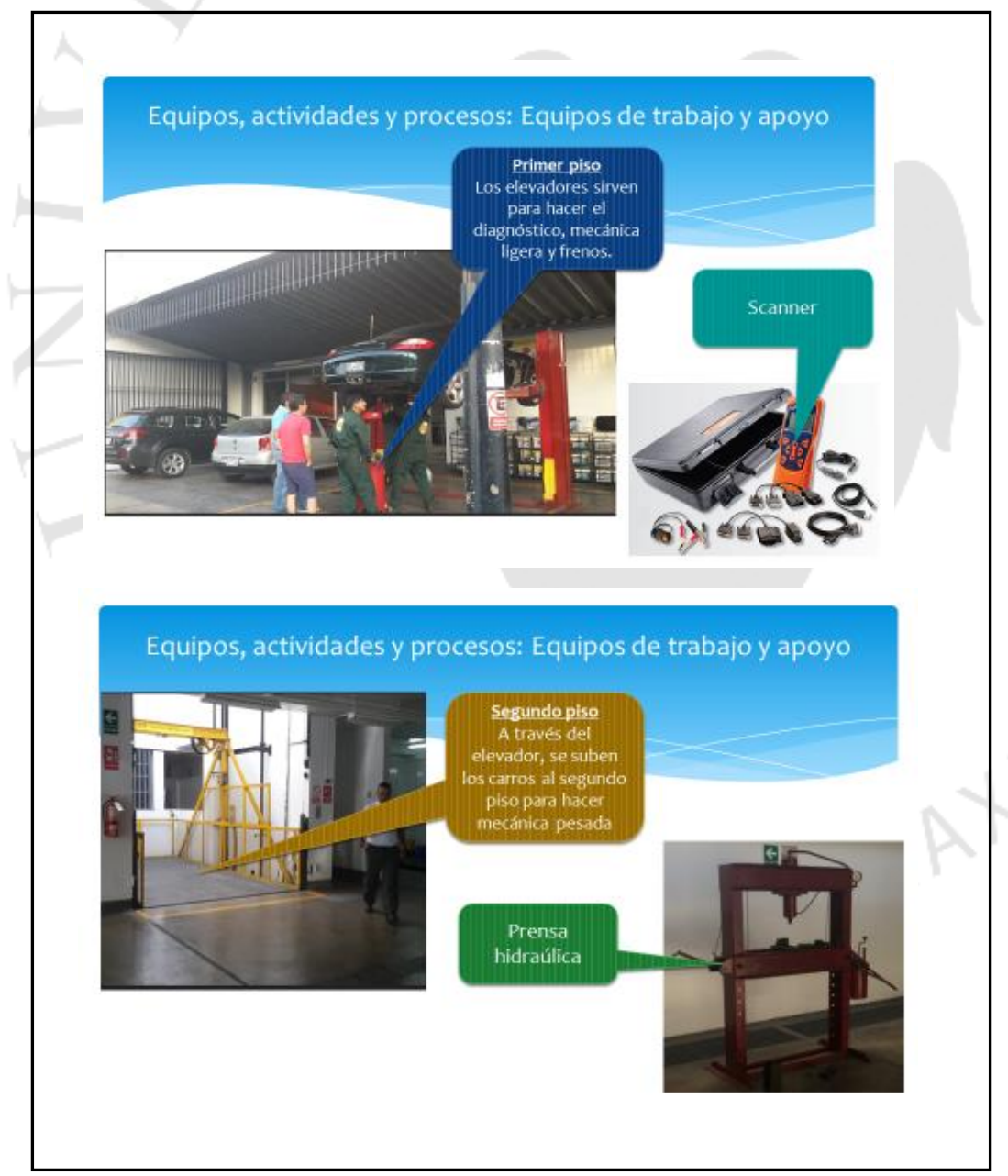

Fuente: Realización propia 


\subsubsection{Gestión de proveedores, compras y stock.}

Tiki Cars ha logrado gestionar con sus principales proveedores ventas a consignación. Tanto las llantas, baterías como accesorios de autos son dejados en exhibición en el taller y son facturados una vez vendidos. Solamente se compran los aceites sintéticos mediante una importación anual para asegurar el stock. Debido a que el taller es multimarca, la compra de los filtros y repuestos se realiza un día antes si el servicio es con cita o el mismo día una vez que se recibe la unidad ("Just in time") (Ver Figura 5.4 Just in time). Los mismos proveedores traen al taller los repuestos la mayoría de las veces.

Figura 5.4

Just in time

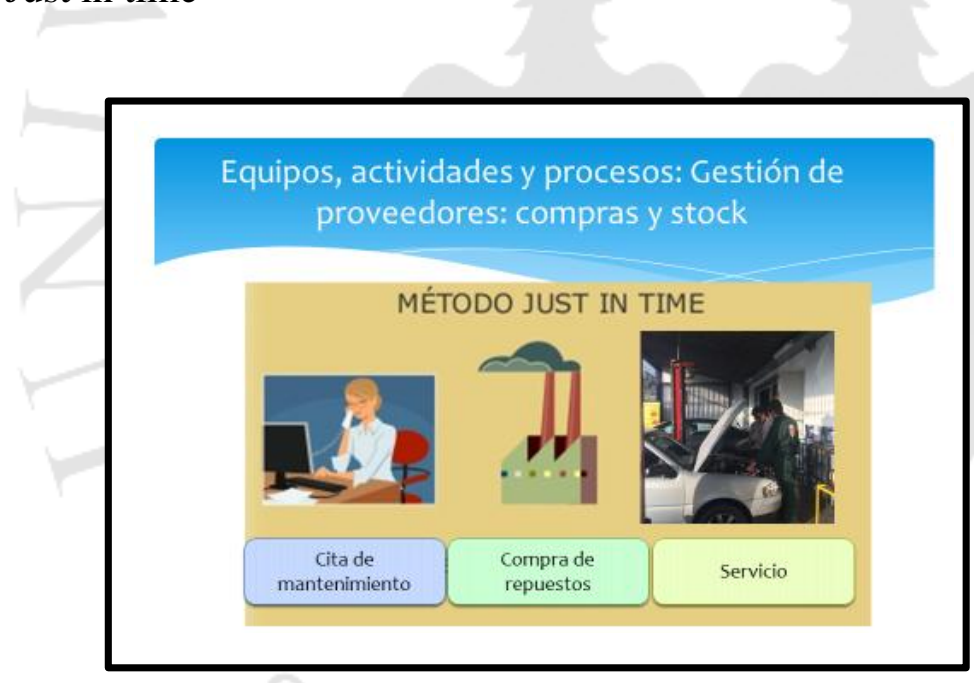

Fuente: Realización propia

\subsubsection{Tercerización o integración de procesos.}

Todo el personal de Tiki Cars se encuentra en planilla, sólo se terceriza el servicio de lavado, planchado, pintura y actualmente enllante y balanceo.

\subsubsection{Implementación de las actividades por fases. Cadena de valor.}

Las fases son las siguientes: citas, recepción del vehículo, asignación de los servicios a realizar, ejecución de los servicios, proceso de inspección, 
proceso de entrega y proceso de seguimiento post-servicio (Ver Figura 5.5 Cadena de valor).

Figura 5.5

Cadena de valor

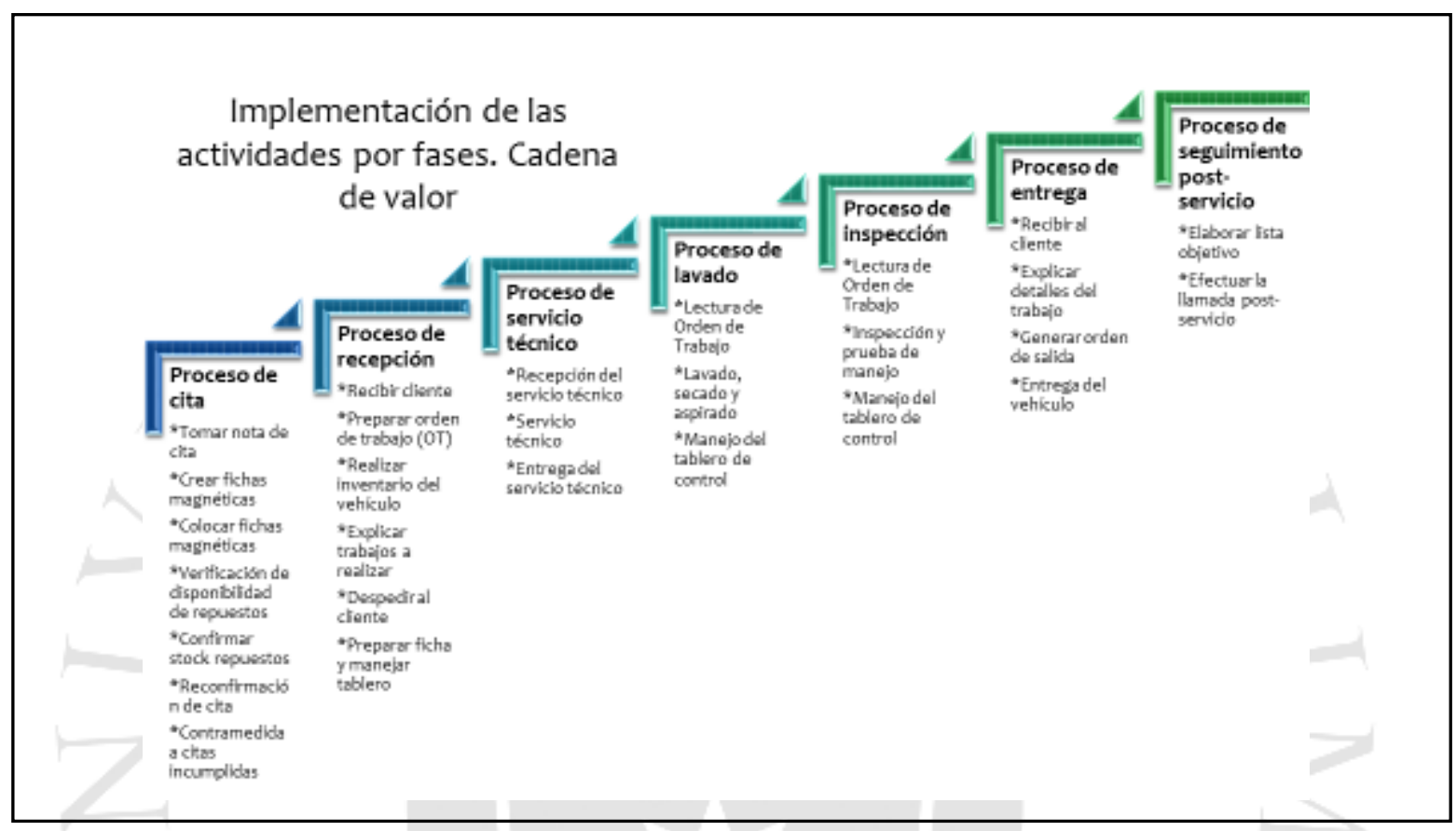

\subsubsection{Proceso de elaboración de bienes y/o prestación de servicio.}

Los principales servicios que se realizan en el taller son: mecánica ligera, mecánica pesada, servicio de lavado, undercounting, ozonización, planchado, pintura, alineamiento, enllante, balanceo, dirección, frenos, entre otros.

\subsubsection{Flujograma de la actividad. Diagrama de Grantt.}

Se han diseñado los flujogramas para el proceso de las citas, recepción de vehículos, servicio, entrega y post-servicio, en los cuales se detalla paso a paso cada uno de los procesos y todo el personal involucrado (Ver Figuras 5.6, 5.7, 5.8 5.9, 5.10 Actividades por fases).

En el corto plazo se busca diseñar una página web para ofrecer nuestros servicios, publicar recomendaciones y saca citas. También se 
busca desarrollar un sistema integrado que permita tomar decisiones financieras y estratégicas de manera oportuna. En largo plazo, se busca crecer horizontalmente a través de la venta de motos eléctricas y paneles solares. Toda esta planificación se detalla en el Diagrama de Grantt (Ver Figura 5.11 Diagrama de Grantt).

\subsubsection{Balance Scorecard: control de gestión por indicadores.}

Como objetivos estratégicos, se busca aumentar el servicio de planchado y pintura, satisfacer al cliente y aumentar el ticket promedio. En base a esto se ha diseñado el Balance Scorecard que permite enlazar estrategias y objetivos clave con el desempeño y resultados (Ver Figura 5.12 Balance Scorecard).

Figura 5.12

Balance Scorcard

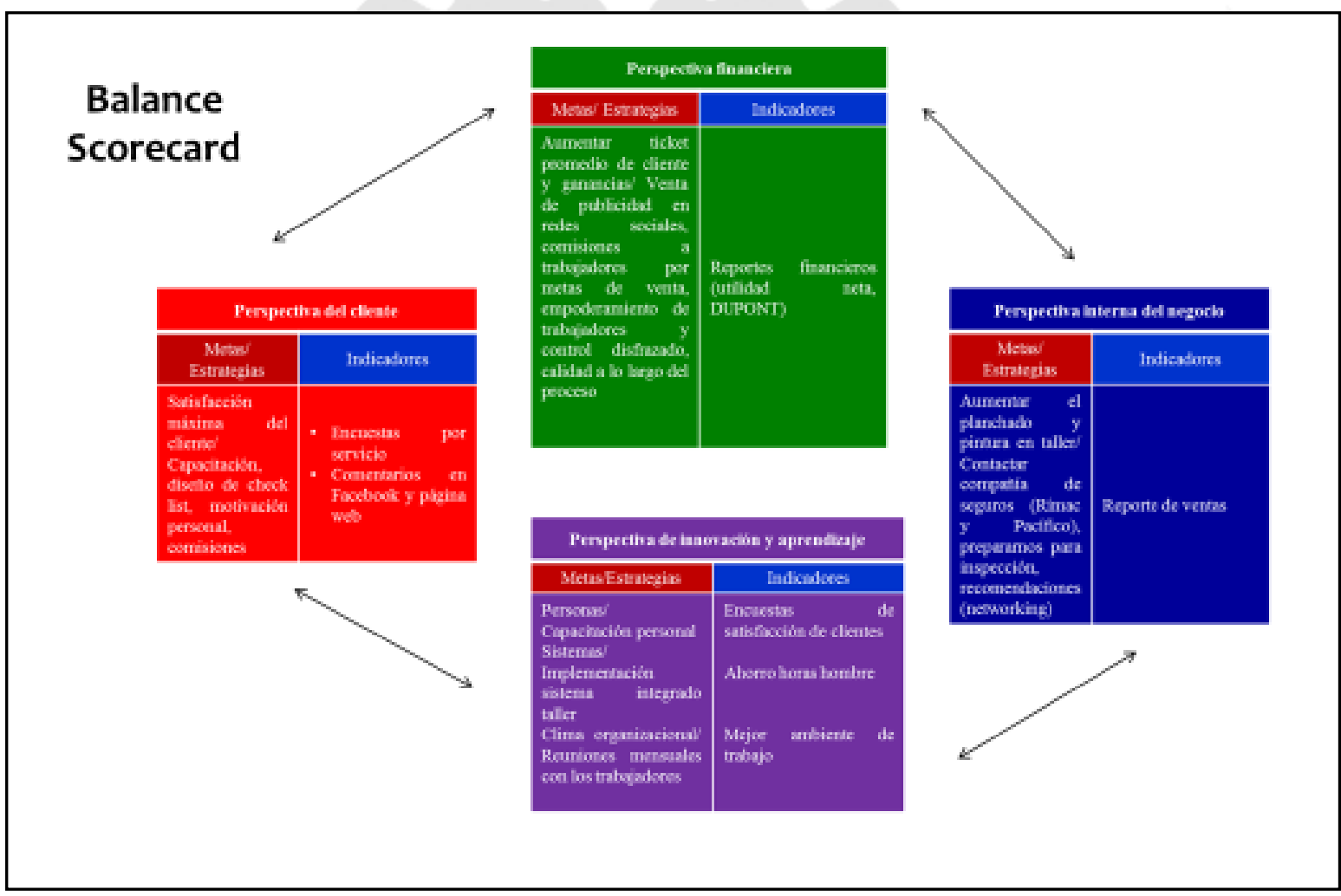

Fuente: Realización propia 
Tabla 7.1

Ventas y proyección de ventas

\begin{tabular}{|c|c|c|c|c|c|c|c|c|}
\hline \multirow{2}{*}{ VENTAS REALES } & \multirow{2}{*}{ DIAS LABORADOS } & \multirow{2}{*}{ CANT. CLENTES } & \multirow{2}{*}{$\%$ SERVICIOS \pm} & \multicolumn{3}{|c|}{ ROM DE CLIENTES DIARA } & \multicolumn{2}{|c|}{ TOTAL DE VENTAS DEL MES } \\
\hline & & & & LUN - VIER & SABADO & & SOLES & \% VENTAS \pm \\
\hline ABRIL & 6 & 7 & & 1 & 1 & S/. & $2,371.53$ & \\
\hline MAYO & 25 & 113 & & 5 & 6 & S/. & $50,128.70$ & \\
\hline JUNIO & 25 & 152 & $35 \%$ & 6 & 8 & S/. & $56,492.73$ & $13 \%$ \\
\hline JULIO & 24 & 161 & $6 \%$ & 7 & 8 & S/. & $64,684.76$ & $15 \%$ \\
\hline AGOSTO & 26 & 190 & $18 \%$ & 7 & 9 & S/. & $89,191.31$ & $38 \%$ \\
\hline SEPTIEMBRE & 26 & 173 & $-9 \%$ & 6 & 9 & S/. & $84,048.94$ & $-6 \%$ \\
\hline OCTUBRE & 25 & 199 & $15 \%$ & 8 & 8 & S/. & $93,462.09$ & $11 \%$ \\
\hline PROMEDIO VENTAS 3 MESES & & & & & & S/. & $88,900.78$ & $14 \%$ \\
\hline PROYECCION VENTAS 2017 & & & & & & S/. & $1,226,830.72$ & \\
\hline PROYECCION VENTAS 2016 & & & & & & S/. & $643,073.82$ & \\
\hline
\end{tabular}

\begin{tabular}{ccc}
\hline \multirow{2}{*}{ VENTAS REALES } & \multicolumn{2}{c}{ PROM DE VENTAS DIARAS } \\
& LUN - VIER SOLES & SABADO SOLES \\
\hline ABRIL & 550 & 50 \\
MAYO & 2373 & 1738 \\
JUNIO & 2588 & 3078 \\
JULIO & 2954 & 4314 \\
AGOSTO & 3927 & 4712 \\
SEPTIEMBRE & 3906 & 3341 \\
OCTUBRE & 4276 & 5122
\end{tabular}

Tabla 5.1

Métricas de Servicio

METRICAS SERVICIOS TALLER TIKI CARS

$\begin{array}{rrrrr}\text { JULIO } & \text { AGOSTO } & \text { SETIEMBRE } & \text { OCTUBRE } & \text { NOVIEMBRE } \\ 29 & 31 & 34 & 43 & 29 \\ 7 & 6 & 10 & 4 & 13 \\ & 2 & & 3 & 1 \\ 12 & 14 & 20 & 23 & 12 \\ 37 & 21 & 19 & 25 & 36 \\ 30 & 30 & 27 & 37 & 27 \\ 39 & 45 & 32 & 43 & 33 \\ 15 & 11 & 14 & 8 & 18 \\ & 4 & 4 & 12 & \end{array}$




\section{CAPÍTULO VI: ESTRUCTURA ORGANIZACIONAL Y RECURSOS HUMANOS}

\subsection{Objetivos Organizacionales.}

\subsubsection{Naturaleza de la Organización.}

Tiki Cars es un taller de mecánica automotriz que brinda los servicios de planchado, pintura, mecánica ligera y pesada, lavado, enllante, ozonización, balanceo, dirección, venta de autopartes, entre otros.

\subsubsection{Organigrama.}

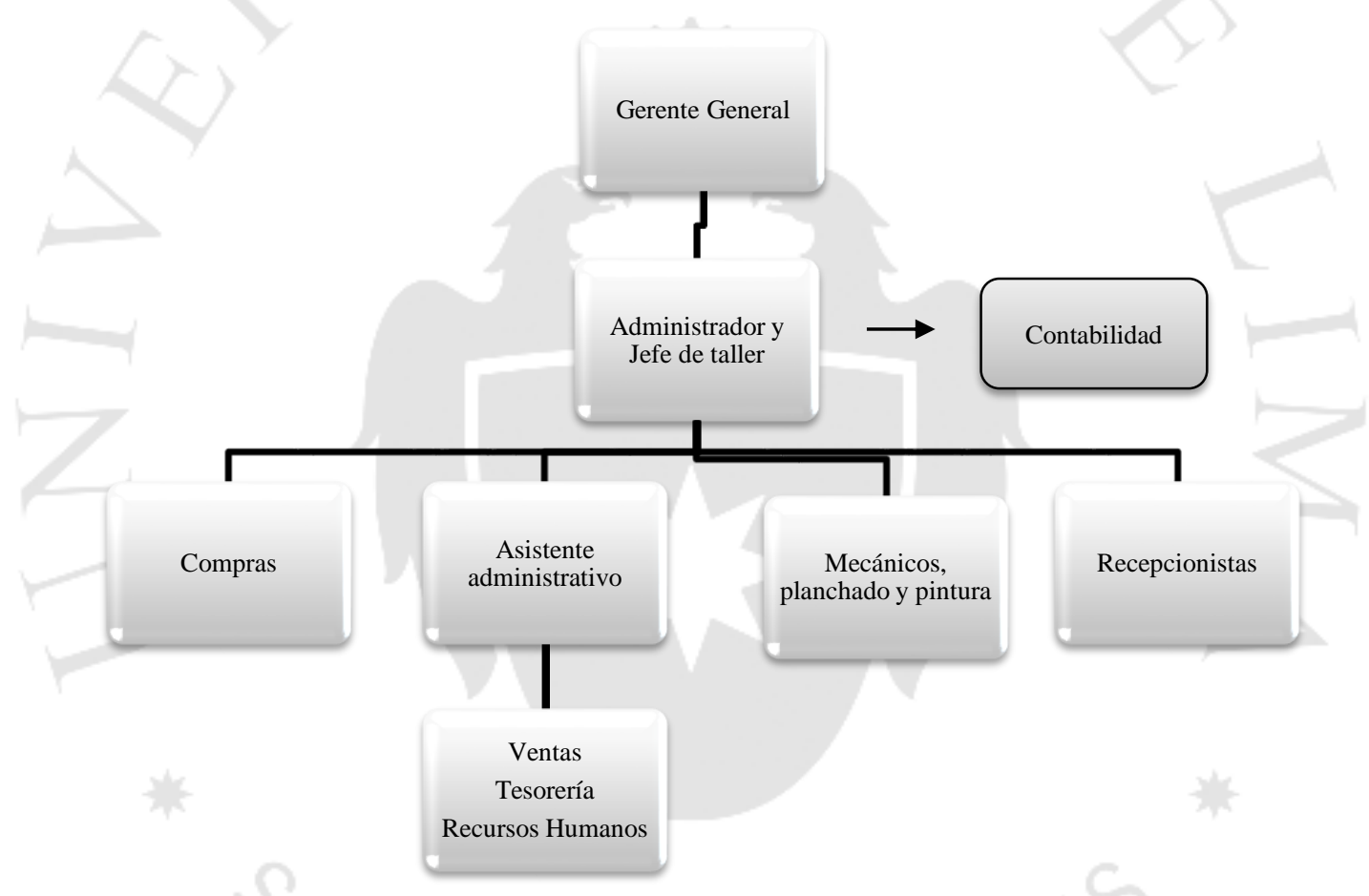

\subsection{Diseño de Puestos y Responsabilidades.}

El diseño de los puestos: descripción del puesto de trabajo, misión, funciones, responsabilidades, perfil requerido, aptitud para el cargo e ideas claves están detallados en las Figuras 6.1, 6.2, 6.3 manual de funciones y servicios.

\subsection{Gestión del talento.}

\subsubsection{Selección y contratación.}

Los mecánicos son contratados del SENATI así como los practicantes. El personal administrativo son personas con experiencia en el sector automotriz, amables y 
proactivos. Es importante agregar que se ha contratado personal de confianza que trabajaba en la estación de servicio que se encuentra actualmente alquilada a Repsol.

Se selecciona personal nuevo a través de una solicitud a SENATI, por recomendación de personal de confianza de otros talleres, poniendo avisos en el periódico y a través de bolsas de trabajo virtuales.

\subsubsection{Remuneración y desempeño.}

La remuneración del personal es de acuerdo al mercado. A los trabajadores se les paga de acuerdo al Régimen General a pesar de ser una microempresa (Ver Tabla 6.1 y 6.2).

\subsubsection{Empowerment y reconocimiento.}

Se delega autoridad a los empleados subordinados ya que Tiki Cars confía en su capacidad, pero son evaluados mediante las encuestas. Ellos no tienen que consultar para tomar una decisión, pero deben aceptar la responsabilidad por las consecuencias de cada decisión. No obstante, siempre que tengan dudas pueden acercarse a su superior para consultar con la mayor confianza.

\subsubsection{Capacitación, motivación y desarrollo.}

Dos veces al año se realizan simulacros de incendio y terremotos, uso de extintores. Mensualmente se realizan capacitaciones sobre seguridad en el trabajo y atención al cliente. Se coordinan con los proveedores capacitaciones respecto a productos, servicios y nuevas tecnologías (Ver Figura 6.4 Figuras Capacitaciones).

\subsection{Estructura de gastos de RRHH.}

La estructura se explica en las Tablas Gastos personal administrativo y Gastos en mano de obra directa. 


\subsection{Responsabilidad social.}

De acuerdo a la Norma ISO (Organización Internacional de Normalización) 26000 una organización debe ser responsable de los impactos que sus decisiones $\mathrm{y}$ actividades ocasionan en la sociedad $\mathrm{y}$ medio ambiente mediante un comportamiento ético y transparente. Este comportamiento debería en primer lugar, contribuir al desarrollo sostenible incluyendo la salud y el bienestar de la sociedad; en segundo lugar, considerar las expectativas de los grupos de interés; en tercer lugar, cumplir con la legislación aplicable y ser coherente con la normativa internacional de comportamiento; y en cuarto lugar integrar todo lo mencionado en la organización y llevarlo a la práctica en sus relaciones (Comisión de Normalización y de Fiscalización de Barreras Comerciales No Arancelarias, 2010).

Cabe destacar que los grupos de interés de Tiki Cars son, en primer lugar, los clientes corporativos y clientes en general, tienen como expectativas la calidad del servicio, los procesos menores por economías de escala, la rapidez en el servicio, la garantía y respuestas rápidas, en segundo lugar, las aseguradoras cuyas expectativas giran en torno a la calidad en el servicio, el buen precio (oligopolio). En tercer lugar, se encuentra el Estado cuyas expectativas implican la recaudación de impuestos, el cumplimiento de las normas tributarias, laborales y de salud. En cuarto lugar, otro grupo de interés es la Municipalidad, cuya expectativa gira en torno al cumplimiento de las Normas Municipales y Defensa Civil. En cuarto lugar. Por último, la Comunidad como grupo de interés reúne a los vecinos que permitirán generar más clientes en el futuro.

Cuando las empresas aplican la responsabilidad social, expresada en objetivos, generan impactos en el entorno. Estos impactos son de tres tipos: económico, social y ambiental. A continuación, se describirá algunos de los objetivos de corto y mediano plazos de la empresa vinculados a la responsabilidad social y sus impactos económicos, sociales y ambientales. 
Tiki Cars tiene como objetivo, en primer lugar, convertirse en taller autorizado de las compañías de seguros Rímac o Pacífico. El impacto económico positivo de ello sería la generación de mayor ingreso para la empresa, en cambio, el impacto económico negativo sería el mayor requerimiento de inversión en capital de trabajo. Dentro del impacto social, este objetivo daría mayor empleo y mejores ingresos a los trabajadores; pero también se observaría que los trabajadores podrían no utilizar los instrumentos o vestimenta adecuada para protegerse durante el trabajo (como por ejemplo, el no uso de las máscaras de pintura). El impacto ambiental que tendría este objetivo sería el uso intenso de energía ya que el horno tendría que estar encendido durante mucho tiempo; además, se tendría que usar más agua.

En segundo lugar, otro objetivo de Tiki Cars, es mediante la integración horizontal, es vender motos eléctricas a mediano plazo. Ello tendría como impacto económico mayor ingresos a la empresa por diversificación de servicios; sin embargo, esto a su vez podría quitar espacio en el local. Como impacto social, con este objetivo, Tiki Cars contribuiría a disminuir el tráfico en Lima, tomando conciencia del cuidado del medio ambiente. No obstante, se debe considerar que podrían darse accidentes ya que la población no respeta a las motos por falta de educación vial. En cuanto al impacto ambiental, con el uso de las motos, se contribuiría a disminuir las emisiones de gases de efecto invernadero que son producidos en su mayoría por automóviles.

Por último, en tercer lugar, otro objetivo de Tiki Cars es ser el proveedor número 1 en el Perú de carga eléctrica. Como impacto económico, este objetivo generará mayores ingresos y un mejor posicionamiento; no obstante, esto haría que la recuperación de la inversión sea lenta y afectaría la industria del petróleo a largo plazo. En cuanto al impacto social, con este objetivo se contribuye al desarrollo de la conciencia ambiental y al ahorro de las familias peruanas. Finalmente, como impacto ambiental, el cumplimiento de este objetivo contribuiría al cuidado del medio ambiente.

En Tiki Cars se promueve la responsabilidad social con los trabajadores dándoles los beneficios de una empresa de régimen general cuando deberían 
recibir los beneficios de una microempresa. Asimismo, se brinda orientación psicológica al colaborador y se está planificando una obra social por Navidad.

Por otro lado, Tiki Cars cumple con el manejo de residuos sólidos (ver Figura 6.5). Además, se está tratando de implementar el lavado ecológico una vez que se incremente el número de clientes. Respecto al medio ambiente, el objetivo de Tiki Cars es ir migrando progresivamente al uso de paneles solares y tecnología LED (Ver Figura 6.6).

Es importante mencionar que actualmente Tiki Cars trabaja con SILSA que es una empresa que brinda servicios de limpieza y mantenimiento, así como servicios especializados. Esta empresa está autorizada por el Ministerio de Salud (MINSA) para reciclar residuos sólidos. SILSA recoge las baterías, filtros y aceites usados para reciclarlos. Además, se llevan los trapos sucios con aceites para desecharlos en lugares autorizados de depósito de residuos peligrosos.

Dada la importancia de la responsabilidad social Tiki Cars comunicará adecuadamente a sus clientes y público en general sobre sus prácticas socialmente responsables. Esto lo realizará a través del panel electrónico colocado en la Avenida Raúl Ferrero, página web y página de Facebook. 


\section{CAPÍTULO VII: PLAN ECONÓMICO - FINANCIERO}

\subsection{Supuestos.}

Tiki Cars inició sus operaciones a fines del mes de abril de 2016. La vida del proyecto será más de 20 años, sin embargo, el análisis financiero se ha realizado en 5 años.

Los datos de las ventas de abril a octubre son reales. Para completar el cálculo de las ventas del año 2016 se ha sacado el promedio de las ventas de los tres últimos meses para estimar las ventas de noviembre y diciembre (incluyendo el 14\% de crecimiento mensual) y se le ha sumado a las ventas de abril a octubre. Para las ventas del año 2017 se considera el supuesto de crecimiento anual de ventas del 6\% (Ver tabla 7.1).

\begin{tabular}{|c|c|c|c|c|c|c|c|c|}
\hline \multirow{2}{*}{ VENTAS REALES } & \multirow{2}{*}{ DIAS LABORADOS } & \multirow{2}{*}{ CANT. CLIENTES } & \multirow{2}{*}{$\%$ SERVICIOS \pm} & \multicolumn{2}{|c|}{ PROM DE CLIENTES DIARAS } & \multicolumn{3}{|c|}{ TOTAL DE VENTAS DEL MES } \\
\hline & & & & LUN - VIER & SABADO & & SOLES & $\%$ VENTAS \pm \\
\hline ABRIL & 6 & 7 & & 1 & 1 & $\mathrm{~S} /$. & $2,371.53$ & \\
\hline MAYO & 25 & 113 & & 5 & 6 & $\mathrm{~S} / \mathrm{.}$ & $50,128.70$ & \\
\hline JUNIO & 25 & 152 & $35 \%$ & 6 & 8 & $\mathrm{~S} / \mathrm{.}$ & $56,492.73$ & $13 \%$ \\
\hline JULIO & 24 & 161 & $6 \%$ & 7 & 8 & $\mathrm{~S} /$. & $64,684.76$ & $15 \%$ \\
\hline AGOSTO & 26 & 190 & $18 \%$ & 7 & 9 & $\mathrm{~S} /$. & $89,191.31$ & $38 \%$ \\
\hline SEPTIEMBRE & 26 & 173 & $-9 \%$ & 6 & 9 & $\mathrm{~S} / \mathrm{s}$ & $84,048.94$ & $-6 \%$ \\
\hline OCTUBRE & 25 & 199 & $15 \%$ & 8 & 8 & $\mathrm{~S} /$. & $93,462.09$ & $11 \%$ \\
\hline PROMEDIO VENTAS 3 MESES & & & & & & $\mathrm{S} / \mathrm{s}$ & $88,900.78$ & $14 \%$ \\
\hline PROYECCION VENTAS 2017 & & & & & & $\mathrm{~S} /$. & $1,130,817.88$ & \\
\hline PROYECCION VENTAS 2016 & & & & & & $\mathrm{~S} /$. & $643,073.82$ & \\
\hline
\end{tabular}

Para obtener el costo de ventas se ha calculado la estructura de costos y el margen de ganancia de los principales servicios que brinda el taller, que son: mecánica, planchado, pintura y lavado. El costo de venta del planchado, pintura y lavado es $35 \%$ (contratistas) y de la mecánica es en promedio 27\% (Ver Tablas 7.2, 7.3, 7.4, 7.5, 7.6, 7.7). 
Tabla 7.2

Estructura de costos y margen Mantenimiento Tiki Menor autos

\begin{tabular}{|c|c|c|c|c|c|c|c|c|c|c|}
\hline \multicolumn{2}{|l|}{ MANTENIMIENTO TIKI MENOR DOLARES AUTO } & \multicolumn{3}{|l|}{ TC } & \multirow[b]{2}{*}{ V.V.T } & \multirow{2}{*}{\multicolumn{2}{|c|}{ MARGEN IARGEN TO }} & \multirow[b]{2}{*}{$\%$} & \multirow[b]{2}{*}{ Descuento } & \multirow[b]{2}{*}{ P.V.P } \\
\hline Descripcion & Cantidad & Costo & COSTO TOT & V.V. & & & & & & \\
\hline EMPAQUE TAPON DE CARTER & 1 & 0.29 & 0.29 & 0.55 & 0.55 & 0.27 & 0.27 & $94 \%$ & $0 \%$ & 0.65 \\
\hline ACEITE 10W30 SINTETICO SHELL & 4 & 5.24 & 20.96 & 10.19 & 40.74 & 4.95 & 19.78 & $94 \%$ & $0 \%$ & 48.08 \\
\hline FILTRO DE ACEITE & 1 & 4.99 & 4.99 & 9.69 & 9.69 & 4.70 & 4.70 & $94 \%$ & $0 \%$ & 11.43 \\
\hline \multirow[t]{2}{*}{ LIMPIA PARABRISAS PRESTONE GL } & 1 & 1.07 & 1.07 & 2.09 & 2.09 & 1.01 & 1.01 & $94 \%$ & $0 \%$ & 2.46 \\
\hline & & 11.59 & 27.31 & 22.52 & 53.07 & 10.93 & 25.77 & $94 \%$ & & 62.63 \\
\hline MATERIALES (GRASA,WAYPE,DISOLVENTES & 1 & 1.99 & 1.99 & 3.86 & 3.86 & 1.88 & 1.88 & $94 \%$ & $0 \%$ & 4.56 \\
\hline MANTENIMIENTO PREVENTIVO TIKI & 1 & 11.04 & 11.04 & 21.46 & 21.46 & 10.42 & 10.42 & $94 \%$ & $0 \%$ & 25.33 \\
\hline LIMPIEZA, CHEQUEO Y REGULACION DE FF & 1 & 7.36 & 7.36 & 14.31 & 14.31 & 6.95 & 6.95 & $94 \%$ & $0 \%$ & 16.88 \\
\hline \multirow[t]{5}{*}{ LAVADO SIMPLE (CORTESIA) } & 1 & 4.42 & 4.42 & 8.59 & 8.59 & 4.17 & 4.17 & $94 \%$ & $0 \%$ & 10.13 \\
\hline & & 24.81 & 24.81 & 48.22 & 48.22 & 23.41 & 23.41 & $94 \%$ & & 56.90 \\
\hline & & 36.40 & 52.12 & 70.74 & 101.30 & 34.34 & 49.18 & $94 \%$ & & 119.53 \\
\hline & & & 52.12 & & 93.14 & & 41.02 & $79 \%$ & & 109.90 \\
\hline & & & 53.86 & & 89.75 & & 35.89 & $67 \%$ & & 105.90 \\
\hline
\end{tabular}

Tabla 7.3

Margen Mantenimiento Tiki Menor Camionetas

\begin{tabular}{|c|c|c|c|c|c|c|c|c|c|c|}
\hline \multicolumn{11}{|c|}{ MANTENIMIENTO TIKI MENOR DOLARES CAMIONETA } \\
\hline Descripcion & Cantidad & Costo & COSTO TOT & V.V. & V.V.T & MARGEN & IARGEN TO & $\%$ & Descuento & P.V.P \\
\hline EMPAQUE TAPON DE CARTER & 1 & 0.29 & 0.29 & 0.55 & 0.55 & 0.27 & 0.27 & $94 \%$ & $0 \%$ & 0.65 \\
\hline ACEITE 10 W30 SINTETICO SHELL & 6 & 5.24 & 31.45 & 10.19 & 61.12 & 4.95 & 29.67 & $94 \%$ & $0 \%$ & 72.12 \\
\hline FILTRO DE ACEITE & 1 & 9.97 & 9.97 & 19.38 & 19.38 & 9.41 & 9.41 & $94 \%$ & $0 \%$ & 22.87 \\
\hline \multirow{2}{*}{ LIMPIA PARABRISAS PRESTONE GL } & 1 & 1.07 & 1.07 & 2.09 & 2.09 & 1.01 & 1.01 & $94 \%$ & $0 \%$ & 2.46 \\
\hline & & 16.57 & 42.78 & 32.20 & 83.14 & 15.63 & 40.36 & $94 \%$ & & 98.10 \\
\hline MATERIALES (GRASA,WAYPE,DISOLVENTES & 1 & 1.99 & 1.99 & 3.86 & 3.86 & 1.88 & 1.88 & $94 \%$ & $0 \%$ & 4.56 \\
\hline MANTENIMIENTO PREVENTIVO TIKI & 1 & 14.36 & 14.36 & 27.90 & 27.90 & 13.54 & 13.54 & $94 \%$ & $0 \%$ & 32.92 \\
\hline LIMPIEZA, CHEQUEO Y REGULACION DE FF & 1 & 9.57 & 9.57 & 18.60 & 18.60 & 9.03 & 9.03 & $94 \%$ & $0 \%$ & 21.95 \\
\hline \multirow[t]{5}{*}{ LAVADO SIMPLE (CORTESIA) } & 1 & 5.74 & 5.74 & 11.16 & 11.16 & 5.42 & 5.42 & $94 \%$ & $0 \%$ & 13.17 \\
\hline & & 31.66 & 31.66 & 61.52 & 61.52 & 29.87 & 29.87 & $94 \%$ & & 72.60 \\
\hline & & 48.23 & 74.43 & 93.73 & 144.66 & 45.50 & 70.23 & $94 \%$ & & 170.70 \\
\hline & & & 74.43 & & 139.75 & & 65.31 & $88 \%$ & & 164.90 \\
\hline & & & 74.43 & & 131.36 & & 56.92 & $76 \%$ & & $\mathbf{1 5 5 . 0 0}$ \\
\hline
\end{tabular}

Tabla 7.4

Mantenimiento Tiki Mayor autos

\begin{tabular}{|c|c|c|c|c|c|c|c|c|c|c|}
\hline \multicolumn{2}{|l|}{ MANTENIMIENTO TIKI MAYOR DOLARES AUTO } & \multicolumn{3}{|c|}{3.4} & \multirow[b]{2}{*}{ V.V.T } & \multirow{2}{*}{ MARGEN } & \multirow[b]{2}{*}{ LARGEN TO } & \multirow[b]{2}{*}{$\%$} & \multirow[b]{2}{*}{ Descuento } & \multirow[b]{2}{*}{ P.V.P } \\
\hline Descripcion & Cantidad & Costo & COSTO TOT & V.V. & & & & & & \\
\hline EMPAQUE TAPON DE CARTER & 1 & 0.29 & 0.29 & 0.55 & 0.55 & 0.27 & 0.27 & $94 \%$ & $0 \%$ & 0.65 \\
\hline ACEITE 10W30 SINTETICO SHELL & 4 & 5.24 & 20.96 & 10.19 & 40.74 & 4.95 & 19.78 & $94 \%$ & $0 \%$ & 48.08 \\
\hline FILTRO DE ACEITE & 1 & 4.99 & 4.99 & 9.69 & 9.69 & 4.70 & 4.70 & $94 \%$ & $0 \%$ & 11.43 \\
\hline BUJIAS & 4 & 1.84 & 7.35 & 3.57 & 14.29 & 1.73 & 6.94 & $94 \%$ & $0 \%$ & 16.86 \\
\hline FILTRO DE AIRE & 1 & 7.47 & 7.47 & 14.52 & 14.52 & 7.05 & 7.05 & $94 \%$ & $0 \%$ & 17.13 \\
\hline \multirow[t]{2}{*}{ LIMPIA PARABRISAS PRESTONE GL } & 1 & 1.07 & 1.07 & 2.09 & 2.09 & 1.01 & 1.01 & $94 \%$ & $0 \%$ & 2.46 \\
\hline & & 20.89 & 42.13 & 40.61 & 81.88 & 19.71 & 39.75 & $94 \%$ & & 96.62 \\
\hline MATERIALES (GRASA,WAYPE,DISOLVENTES & 1 & 1.99 & 1.99 & 3.86 & 3.86 & 1.88 & 1.88 & $94 \%$ & $0 \%$ & 4.56 \\
\hline MANTENIMIENTO PREVENTIVO TIKI & 1 & 11.04 & 11.04 & 21.46 & 21.46 & 10.42 & 10.42 & $94 \%$ & $0 \%$ & 25.33 \\
\hline BALANCEO Y ROTACION DE RUEDAS & 4 & 3.52 & 14.08 & 5.86 & 23.44 & 2.34 & 9.36 & $66 \%$ & $0 \%$ & 27.66 \\
\hline LIMPIEZA, CHEQUEO Y REGULACION DE FF & 1 & 7.36 & 7.36 & 14.31 & 14.31 & 6.95 & 6.95 & $94 \%$ & $0 \%$ & 16.88 \\
\hline \multirow[t]{4}{*}{ LAVADO SIMPLE (CORTESIA) } & 1 & 4.42 & 4.42 & 8.59 & 8.59 & 4.17 & 4.17 & $94 \%$ & $0 \%$ & 10.13 \\
\hline & & 28.33 & 38.89 & 54.08 & 71.66 & 25.75 & 32.77 & $84 \%$ & & 84.56 \\
\hline & & 49.23 & 81.02 & 94.69 & 153.54 & 45.46 & 72.52 & $90 \%$ & & 181.18 \\
\hline & & S/. 49.23 & 81.02 & & 146.61 & & 65.59 & $81 \%$ & & 173.00 \\
\hline
\end{tabular}




\section{Tabla 7.5}

Mantenimiento Tiki Mayor camionetas

\begin{tabular}{|c|c|c|c|c|c|c|c|c|c|c|}
\hline \multicolumn{11}{|c|}{ MANTENIMIENTO TIKI MAYOR DOLARES CAMIONETA } \\
\hline Descripcion & Cantidad & Costo & COSTO TOT & V.V. & V.V.T & MARGEN & RGEN TO & $\%$ & Descuento & P.V.P \\
\hline EMPAQUE TAPON DE CARTER & 1 & 0.29 & 0.29 & 0.55 & 0.55 & 0.27 & 0.27 & $94 \%$ & $0 \%$ & 0.65 \\
\hline ACEITE 10 W30 SINTETICO SHELL & 6 & 5.24 & 31.45 & 10.19 & 61.12 & 4.95 & 29.67 & $94 \%$ & $0 \%$ & 72.12 \\
\hline FILTRO DE ACEITE & 1 & 9.97 & 9.97 & 19.38 & 19.38 & 9.41 & 9.41 & $94 \%$ & $0 \%$ & 22.87 \\
\hline BUJIAS & 6 & 1.84 & 11.03 & 3.57 & 21.43 & 1.73 & 10.40 & $94 \%$ & $0 \%$ & 25.29 \\
\hline FILTRO DE AIRE & 1 & 7.47 & 7.47 & 14.52 & 14.52 & 7.05 & 7.05 & $94 \%$ & $0 \%$ & 17.13 \\
\hline \multirow[t]{2}{*}{ LIMPIA PARABRISAS PRESTONE GL } & 1 & 1.07 & 1.07 & 2.09 & 2.09 & 1.01 & 1.01 & $94 \%$ & $0 \%$ & 2.46 \\
\hline & & 25.88 & 61.27 & 50.30 & 119.09 & 24.42 & 57.81 & $94 \%$ & & 140.52 \\
\hline MATERIALES (GRASA,WAYPE,DISOLVENTES & 1 & 1.99 & 1.99 & 3.86 & 3.86 & 1.88 & 1.88 & $94 \%$ & $0 \%$ & 4.56 \\
\hline MANTENIMIENTO PREVENTIVO TIKI & 1 & 14.36 & 14.36 & 27.90 & 27.90 & 13.54 & 13.54 & $94 \%$ & $0 \%$ & 32.92 \\
\hline BALANCEO Y ROTACION DE RUEDAS & 4 & 4.39 & 17.56 & 7.33 & 29.32 & 2.94 & 11.76 & $67 \%$ & $0 \%$ & 34.60 \\
\hline LIMPIEZA, CHEQUEO Y REGULACION DE FF & 1 & 9.57 & 9.57 & 18.60 & 18.60 & 9.03 & 9.03 & $94 \%$ & $0 \%$ & 21.95 \\
\hline \multirow[t]{4}{*}{ LAVADO SIMPLE (CORTESIA) } & 1 & 5.74 & 5.74 & 11.16 & 11.16 & 5.42 & 5.42 & $94 \%$ & $0 \%$ & 13.17 \\
\hline & & 36.05 & 49.22 & 68.85 & 90.84 & 32.81 & 41.63 & $85 \%$ & & 107.19 \\
\hline & & 61.92 & 110.49 & 119.15 & 209.93 & 57.22 & 99.44 & $90 \%$ & & 247.72 \\
\hline & & S/. 61.92 & 110.49 & & 184.75 & & 74.26 & $67 \%$ & & 218.00 \\
\hline
\end{tabular}

Tabla 7.6

Margen contratistas Lavado

\begin{tabular}{|c|c|c|c|c|c|c|c|c|c|c|c|c|}
\hline \multirow{3}{*}{$\begin{array}{l}\text { MARGEN CONTRATISTAS (LAVADO) } \\
\text { LAVADOR (01) JORGE CONDORI } \\
\text { AYUDANTE LAVADO (02) }\end{array}$} & \multicolumn{12}{|c|}{$31 \%$} \\
\hline & \multicolumn{6}{|c|}{ COSTO AUTO } & \multicolumn{6}{|c|}{ COSTO CAMIONETA } \\
\hline & AUTO & INSUMOS & SUB TOT & V.V & MARGEN & $\%$ & 'AMIONET & TINSUMC & SSSUB TOT & V.V & MARGEN & $\%$ \\
\hline LAVADO,ASPIRADO Y PULVERIZADO DE MOTOR. & 6.52 & 4.28 & 10.80 & 25.44 & 14.63 & $58 \%$ & 6.52 & 5.42 & 11.94 & 33.07 & 21.12 & $64 \%$ \\
\hline LAVADO,ASPIRADO,PULVERIZADO DE MOTOR Y E & 16.43 & 4.81 & 21.24 & 52.99 & 31.75 & $60 \%$ & 21.36 & 5.70 & 27.06 & 68.89 & 41.83 & $61 \%$ \\
\hline LAVADO SALON & 65.71 & 14.48 & 80.18 & 211.96 & 131.78 & $62 \%$ & 85.42 & 20.89 & 106.31 & 275.55 & 169.24 & $61 \%$ \\
\hline TRATAMIENTO DE PINTURA & 65.71 & 8.11 & 73.82 & 211.96 & 138.14 & $65 \%$ & 85.42 & 10.50 & 95.92 & 275.55 & 179.63 & $65 \%$ \\
\hline LAVADO PREMIUN & 98.56 & 22.59 & 121.15 & 317.95 & 196.80 & $62 \%$ & 128.13 & 31.39 & 159.52 & 413.33 & 253.80 & $61 \%$ \\
\hline UNDERCOATING & 131.42 & 15.78 & 147.20 & 423.93 & 276.73 & $65 \%$ & 170.84 & 25.98 & 196.83 & 551.11 & 354.28 & $64 \%$ \\
\hline PRECIOS NO INCLUYEN IGV & & & & & & & & & & & & \\
\hline
\end{tabular}

Tabla 7.7

Margen servicio planchado y pintura

\begin{tabular}{|c|c|c|c|c|c|c|c|c|c|c|c|c|}
\hline \multicolumn{13}{|l|}{ MARGEN CONTRATISTAS (PLANCHADO) } \\
\hline PLANCHADOR (01) ABRAHAM & & & COSTO AU' & & & & & & OSTO CAMI & ONETA & & \\
\hline AYUDANTE PLANCHADO (01) & AUTO & INSUMO & OSSUB TOT & V.v & MARGEN & $\%$ & 'AMIONE & TINSUMO & SSUB TOT & V.V & MARGEN & $\%$ \\
\hline PLANCHADO H/H PARTICULAR SOLES & 12.69 & 0.75 & 13.44 & 42.29 & 28.85 & $68 \%$ & 12.69 & 0.75 & 13.44 & 42.29 & 28.85 & $68 \%$ \\
\hline PLANCHADO H/H MAPFRE DOLARES & 3.60 & 1.75 & 5.35 & 12.00 & 6.65 & $55 \%$ & 3.60 & 1.75 & 5.35 & 12.00 & 6.65 & $55 \%$ \\
\hline $\begin{array}{l}\text { PLANCHADO H/H POSITIVA DOLARES } \\
\text { PRECIOS NO INCLUYEN IGV }\end{array}$ & 4.17 & 2.75 & 6.92 & 13.90 & 6.98 & $50 \%$ & 4.17 & 2.75 & 6.92 & 13.90 & 6.98 & $50 \%$ \\
\hline
\end{tabular}

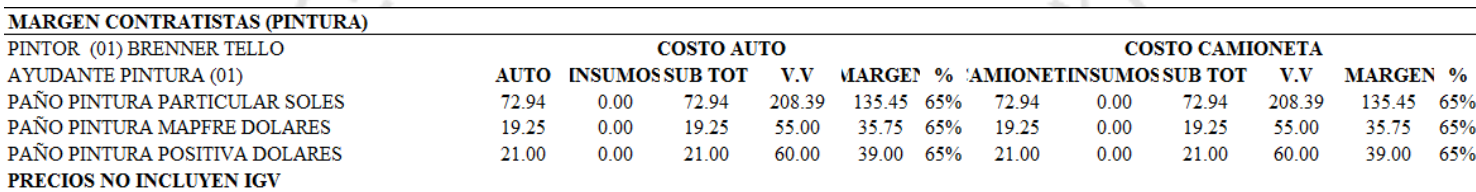


Se está suponiendo conservadoramente una tasa de crecimiento anual de ventas de $6 \%$ anual y un incremento de costos indirectos de $3 \%$ (de acuerdo a la inflación). Los gastos de ventas y administrativos no crecerán más del $2 \%$ pues se buscará reducirlos (Ver tabla 7.8).

Según las normas peruanas, se está considerando una tasa de impuesto a la renta del $28 \%$. Se está considerando un tipo de cambio de 3.4 y todos los valores se están presentando sin IGV.

\subsection{Plan de inversiones.}

El $100 \%$ del proyecto está financiado con recursos propios porque el accionista tiene excedente de capital y por política personal prefiere no endeudarse con el sistema financiero.

\subsection{Activos y depreciación.}

El principal activo es el local y este es alquilado. Se considera un periodo de vida útil de los activos de 10 años, con excepción de los equipos de cómputo que se consideran 5 años. El periodo considerado para las amortizaciones es de 5 años. En ambos casos el método de cálculo es lineal (Ver Tablas 7.9, 7.10).

\subsection{Capital de trabajo.}

\subsubsection{Cuentas por cobrar}

El principal cliente al crédito del taller serán las compañías de seguros. A la fecha de entrega de este proyecto Tiki Cars trabaja con las compañías de seguros Mapfre y La Positiva que tienen poca participación en el mercado asegurador (Ver figura 4.2). Se va a suponer que las compañías de seguro representan el $5 \%$ de las ventas el primer año, $15 \%$ el segundo año, $20 \%$ a partir del tercer año y $30 \%$ a partir del cuarto año. Se les da 30 días de crédito.

\subsubsection{Cuentas por pagar}

Suponemos que el $50 \%$ de las compras de material directo, costos indirectos y gastos de venta son al crédito de 15 días. 


\subsubsection{Días de inventario de materia prima}

Tiki Cars produce bajo el método "Just in Time", es decir, no almacena inventarios. Debido, sobre todo, a que es un taller multimarca que atiende a cientos de marcas diversas y representaría un costo muy elevado en capital de trabajo. El único insumo que guarda en sus almacenes es el aceite sintético que lo compra una vez al año por el diferencial de costos respecto a los aceites sintéticos que venden en el Perú (Anexo 8). Por este motivo, en días de inventario de materia prima se está considerando el costo de un pallet de aceites sintéticos puestos en Lima. Se considera un incremento de costo anual del 5\% debido a la devaluación del tipo de cambio (Ver Tabla 7.11).

Tabla 7.8

Crecimiento porcentual de márgenes, costos y porcentaje de costos sobre ventas

Crecimiento porcentual ventas y costos y porcentaje de costos

Tasa de crecimiento anual ventas

Costo directo

$35 \%$ ventas Planchado, pintura lavado

$30 \%$ de las ventas

Costo directo $27 \%$ Mecánica $70 \%$ de las ventas

Tasa de crecimiento costos indirectos $3 \%$

Tasa de crecimiento de mano de obra dirt $\quad 3 \%$

Tasa de crecimiento anual gastos de vente $2 \%$

Tasa de crecimiento anual gastos administ

$2 \%$

\subsection{Balances previsionales (Balance general).}

Se ha construido un balance con los datos del taller al 30 de setiembre de 2016 (Ver Tabla 7.12). Se observa que el inmueble, maquinaria y equipo representa el $35 \%$ de los activos y las existencias el 13\% de los activos que están conformadas básicamente por aceites sintéticos. Respecto a los pasivos, se debe considerar que se presentan pérdidas acumuladas porque durante todo el año 2015 se realizaron gastos e implementación para la puesta en marcha del taller que recién abrió sus puertas a fines de abril del 2016. La mayor deuda de la empresa la compone los aportes del accionista. 


\subsection{Cuentas de Explotación previsionales (GGPP).}

Respecto al Estado de resultados (Ver Tabla 7.13), se observa que los costos representan aproximadamente en promedio el 52\% de las ventas, los gastos de ventas y administrativos representan en promedio también el $23 \%$ de las ventas y la utilidad de operación en promedio el 25\% de las ventas. Después de la utilidad operativa, se descuenta la depreciación y amortización. No se registran ingresos ni gastos financieros.

Tabla 7.13

Estados de Resultados

\begin{tabular}{|c|c|c|c|c|c|c|c|c|c|c|c|c|}
\hline \multicolumn{13}{|l|}{ ESTADO DE RESULTADOS } \\
\hline Año & & 2016 & & 117 & & 2018 & 2019 & & 2020 & & 2021 & \\
\hline Ventas netas & $\mathrm{S} /$. & $643,073.82$ & $\mathrm{~S} /$. & $1,130,817.88$ & $\mathrm{~S} /$. & $1,198,666.95$ & S/ $1,270,586.97$ & $\mathrm{~S} /$. & $1,346,822.19$ & $\mathrm{~S} /$. & $1,427,631.52$ & \\
\hline Costo material directo & S/. & $189,063.70$ & S/. & $332,460.46$ & $\mathrm{~S} /$. & $352,408.08$ & S/. $\quad 373,552.57$ & $\mathrm{~S} /$. & $395,965.72$ & $\mathrm{~S} /$. & $419,723.67$ & \\
\hline Costo de mano de obra directa & S/. & $55,706.35$ & $\mathrm{~S} /$. & $83,559.52$ & $\mathrm{~S} /$. & $86,066.30$ & S/. $\quad 88,648.29$ & $\mathrm{~S} /$. & $91,307.74$ & $\mathrm{~S} /$. & $94,046.97$ & \\
\hline Costo indirecto & S/. & $116,767.33$ & S/. & $175,151.00$ & $\mathrm{~S} /$. & $180,405.53$ & S/. $\quad 185,817.70$ & $\mathrm{~S} /$. & $191,392.23$ & $\mathrm{~S} /$. & $197,133.99$ & \\
\hline Costo total & $\mathrm{S} /$. & $361,537.38$ & S/. & $591,170.97$ & $\mathrm{~S} /$. & $618,879.92$ & S/. $\quad 648,018.56$ & $\mathrm{~S} /$. & $678,665.69$ & $\mathrm{~S} /$. & $710,904.63$ & \\
\hline Costo total (\% de las ventas) & & $56 \%$ & & $52 \%$ & & $52 \%$ & $51 \%$ & & $50 \%$ & & $50 \%$ & $51 \%$ \\
\hline Utilidad Bruta & $\mathrm{S} /$. & $281,536.44$ & $\mathrm{~S} /$. & $539,646.91$ & $\mathrm{~S} /$. & $579,787.04$ & S/. $622,568.41$ & $\mathrm{~S} /$ & $668,156.50$ & $\mathrm{~S} /$. & $716,726.89$ & \\
\hline Utilidad bruta (\% de las ventas) & & $44 \%$ & & $48 \%$ & & $48 \%$ & $49 \%$ & & $50 \%$ & & $50 \%$ & $49 \%$ \\
\hline Gastos administrativos & & $161,426.08$ & $\mathrm{~S} /$. & $242,139.12$ & $\mathrm{~S} /$. & $246,981.90$ & S/. $251,921.54$ & S/ & $256,959.97$ & $\mathrm{~S} /$. & $262,099.17$ & \\
\hline Gastos de venta & & $18,385.36$ & $\mathrm{~S} /$. & $27,578.04$ & $\mathrm{~S} /$. & $28,129.60$ & S/. $\quad 28,692.19$ & $\mathrm{~S} /$. & $29,266.04$ & $\mathrm{~S} /$. & $29,851.36$ & \\
\hline Total gastos de venta y & & $179,811.44$ & & $269,717.16$ & & $275,111.50$ & $280,613.73$ & & $286,226.01$ & & $291,950.53$ & \\
\hline Gasto total (\% de las ventas) & & $28 \%$ & & $24 \%$ & & $23 \%$ & $22 \%$ & & $21 \%$ & & $20 \%$ & $22 \%$ \\
\hline Utilidad de Operación & & $101,725.00$ & & $269,929.75$ & & $304,675.53$ & $341,954.68$ & & $381,930.49$ & & $424,776.36$ & \\
\hline Utilidad operación (\% de las ventas) & & $15.82 \%$ & & $23.87 \%$ & & $25.42 \%$ & $26.91 \%$ & & $28.36 \%$ & & $29.75 \%$ & $27 \%$ \\
\hline Depreciación & & $5,501.10$ & & $5,501.10$ & & $5,501.10$ & $5,501.10$ & & $5,501.10$ & & $4,741.10$ & \\
\hline Amortización & & $49,063.41$ & & $49,063.41$ & & $49,063.41$ & $49,063.41$ & & $49,063.41$ & & & \\
\hline Utilidad antes de interés e impuesto & & $47,160.49$ & & $215,365.24$ & & $250,111.03$ & $287,390.17$ & & $327,365.98$ & & $680,235.82$ & \\
\hline
\end{tabular}

\subsection{Proyección de ventas y Flujo de Tesorería (Cash Flow).}

Se ha proyectado un crecimiento de ventas muy conservador de $6 \%$ anual. En el flujo de efectivo se considera la inversión inicial de 297,121.90 soles y un impuesto a la renta de $28 \%$. A la utilidad de operación después de impuestos se le suma la depreciación, la amortización y se le resta el capital de trabajo incremental (Ver Tabla 7.14). 
Tabla 7.14

Flujo de efectivo

\begin{tabular}{|c|c|c|c|c|c|c|c|c|c|c|c|c|c|c|}
\hline \multicolumn{15}{|l|}{ Flujo de efectivo } \\
\hline Año & & 2015 & & 2016 & & 2017 & & 2018 & & 2019 & & 2020 & & 2021 \\
\hline Año & & $\mathbf{0}$ & & 1 & & 2 & & 3 & & 4 & & 5 & & 6 \\
\hline Inversiones & & $(297,121.90)$ & & & & & & & & & & & & \\
\hline Ganancias & & & S/. & $47,160.49$ & S/. & $215,365.24$ & S/. & $250,111.03$ & S/. & $287,390.17$ & S/. & $327,365.98$ & $\mathrm{~S} /$. & $680,235.82$ \\
\hline $\begin{array}{l}\text { Utilidad de operación antes de } \\
\text { impuestos (EBITDA) }\end{array}$ & S/. & $-297,121.90$ & S/. & $47,160.49$ & S/. & $215,365.24$ & S/. & $250,111.03$ & S/. & $287,390.17$ & S/. & $327,365.98$ & S/. & $680,235.82$ \\
\hline Impuesto a la renta $28 \%$ & S/. & - & S/. & $1,295.20$ & S/. & $60,302.27$ & S/. & $70,031.09$ & S/. & $80,469.25$ & S/. & $91,662.47$ & S/. & $190,466.03$ \\
\hline $\begin{array}{l}\text { Utilidad de operación después de } \\
\text { impuestos }\end{array}$ & S/. & $-297,121.90$ & S/. & $45,865.29$ & S/. & $155,062.97$ & S/. & $180,079.94$ & S/. & $206,920.92$ & S/. & $235,703.51$ & S/. & $489,769.79$ \\
\hline Depreciación & & & S/. & $5,501.10$ & S/. & $5,501.10$ & $\mathrm{~S} /$. & $5,501.10$ & $\mathrm{~S} /$. & $5,501.10$ & S/. & $5,501.10$ & $\mathrm{~S} /$. & $4,741.10$ \\
\hline Amortización & & & S/. & $49,063.41$ & S/. & $49,063.41$ & $\mathrm{~S} /$. & $49,063.41$ & S/. & $49,063.41$ & S/. & $49,063.41$ & & \\
\hline Capital de trabajo incremental & & & S/. & $-35,064.70$ & S/. & $-12,788.35$ & $\mathrm{~S} /$. & $-10,117.30$ & $\mathrm{~S} /$. & $-19,099.85$ & S/. & $-4,347.51$ & $\mathrm{~S} /$. & $-4,591.49$ \\
\hline \multicolumn{15}{|l|}{ Valor de rescate del capital de trabajo } \\
\hline Flujo de efectivo & S/. & $-297,121.90$ & S/. & $65,365.10$ & S/. & $196,839.13$ & S/. & $224,527.14$ & S/. & $242,385.58$ & S/. & $285,920.50$ & & $490,253.13$ \\
\hline Flujo de efectivo acumulado & S/. & $-297,121.90$ & $\mathrm{~S} /$. & $-231,756.80$ & S/. & $-34,917.67$ & $\mathrm{~S} /$. & $189,609.47$ & S/. & $431,995.05$ & S/. & $717,915.55$ & $\mathrm{~S} /$. & $1,208,168.68$ \\
\hline Flujo de efectivo descontado & s/. & $-297,121.90$ & S/. & $57,604.61$ & S/. & $152,874.14$ & "S/. & $153,674.82$ & S/. & $146,201.54$ & "S/. & $151,985.36$ & S/. & $229,661.46$ \\
\hline $\begin{array}{l}\text { Flujo de efectivo descontado } \\
\text { acumulado }\end{array}$ & S/. & $-297,121.90$ & S/. & $-239,517.29$ & S/. & $-86,643.16$ & $\mathrm{~S} /$. & $67,031.67$ & S/. & $213,233.20$ & S/. & $365,218.56$ & S/. & $594,880.02$ \\
\hline
\end{tabular}

\subsection{Análisis de viabilidad y rentabilidad financiera.}

Se obtuvo un valor actual neto (VAN) de 594,880.02 soles sin considerar el valor de recate y empleando el costo ponderado de capital como tasa de descuento de $13.47 \%$.

La tasa interna de retorno que representa la rentabilidad del proyecto es de $54.43 \%$, que es superior al costo de financiamiento (WACC 13.47\%) lo que corrobora lo hallado por el VAN.

El índice de rentabilidad es 3.00.

El periodo de recuperación es de 2 años y 16 meses (Ver Tabla 7.15).

Tabla 7.15

Indicadores de viabilidad y rentabilidad financiera TIR y VAN

INDICADORES DE RENTABILIDAD

VAN sin valor de rescate

S/. $\quad 594,880.02$

VAN del valor de rescate

S/. $\quad 86,009.21$

VAN con valor de rescate

S/. $\quad 680,889.23$

TIR

$54.43 \%$

IR

Período de recupero Payback 


\subsection{Políticas de aplicación de resultados.}

Tiki Cars tiene una política de aplicación de entrega de utilidades del 75\% y de reinversión en activos en nuevas tecnologías del $15 \%$.

\subsection{Tasa de descuento del accionista.}

\begin{tabular}{lr}
\hline WACC & $13.47 \%$ \\
WACC & $\mathrm{Kd}(1-\mathrm{t}) * \mathrm{D} / \mathrm{V}+\mathrm{Kc}(\mathrm{P} / \mathrm{V})$ \\
\hline
\end{tabular}

\begin{tabular}{lr}
\hline Tasa de impuesto a la renta & $28.0 \%$ \\
WACC & $13.47 \%$ \\
Deuda: D/V & $20 \%$ \\
Capital: P/V & $80 \%$ \\
Impuesto: $\mathrm{t}$ & $28 \%$ \\
Kd: Costo de la deuda & $13 \%$ \\
kc: Costo del capital Propio: $\mathrm{Rf}+\mathrm{Rp}$ & $20 \%$ \\
Rf: Tasa libre de Riesgo & $4.50 \%$ \\
Rp: Prima por riesgo & $10 \%$ \\
\hline
\end{tabular}

Si bien el proyecto está siendo financiado al $100 \%$ con capital propio, se asume una estructura de capital de $20 \%$ financiado (D/V) y $80 \%$ de capital propio (P/V). El costo de la deuda $(\mathrm{Kd})$ en el sistema financiero peruano es de aproximadamente $13 \%$, el impuesto a la renta $28 \%$. Respecto al costo del capital propio $(\mathrm{Kc})$ la tasa libre de riesgo (Rf) se ha considerado la tasa interbancaria del sistema financiero peruano y la tasa de depósitos a plazo de bancos libres de riesgo que es $4.5 \%$. En relación a la prima por riesgo (Rp), se está considerando el rendimiento de la Bolsa de Valores de Lima de los últimos 5 años 2016 que es 10\% (Ver tabla 7.20), lo que da como costo ponderado de capital un $13.47 \%$ (Ver tabla 7.16).

\subsection{Indicadores de rentabilidad representativos}

Tabla 7.17

Indicadores de rentabilidad representativos

\begin{tabular}{|c|c|c|c|c|c|c|c|}
\hline \multicolumn{8}{|c|}{ INDICADORES DE RENTABILIDAD REPRESENTATIVOS } \\
\hline & Promedio & 2016 & 2017 & 2018 & 2019 & 2020 & 2021 \\
\hline ROE & & 1.384707097 & 4.169878821 & 4.756427165 & 5.134743771 & 6.056996128 & 10.38561868 \\
\hline ROS & 0.201581531 & 0.101644783 & 0.174067932 & 0.187314036 & 0.190766618 & 0.212292688 & 0.343403128 \\
\hline ROI & 0.757679077 & 0.1974068 & 0.5944668 & 0.6780864 & 0.7320201 & 0.8634983 & 1.4805960 \\
\hline
\end{tabular}


En Tiki Cars, cada sol de venta genera en promedio 0.20 centavos de utilidad. El proyecto tiene una rentabilidad sobre la inversión en promedio de $75 \%$ (Ver tabla 7.17).

\subsection{Análisis de riesgo y costo de oportunidad.}

Un riesgo importante para el taller sería que no se lograra ser taller afiliado de Rímac ni Pacífico Seguros, por lo cual las ventas mantendrían la tasa de crecimiento del $6 \%$ anual. Otro riesgo que se podría presentar es que el Banco Central de Reserva no controle la inflación en el rango meta de 3\% y la inflación supere el 5\% considerando un aumento anual de 5\% en los costos indirectos, gastos de venta, administrativos y costos de ventas. Se puede considerar que ante esta situación el accionista eleve su prima por riesgo a $15 \%$.

\subsection{Análisis por escenarios y gráficas.}

En un escenario optimista, se supondrá que Tiki Cars se logra convertir en taller afiliado de Rímac y Pacífico Seguros, lo que aumentaría las ventas del taller en no menos del 15\% anual. Se supone que los costos indirectos crecerían a un $6 \%$ anual, los gastos de venta y administrativos crecerían a una tasa de 3\% anual (Ver Tabla 7.18).

\section{Tabla 7.18}

Indicadores de rentabilidad escenario optimista

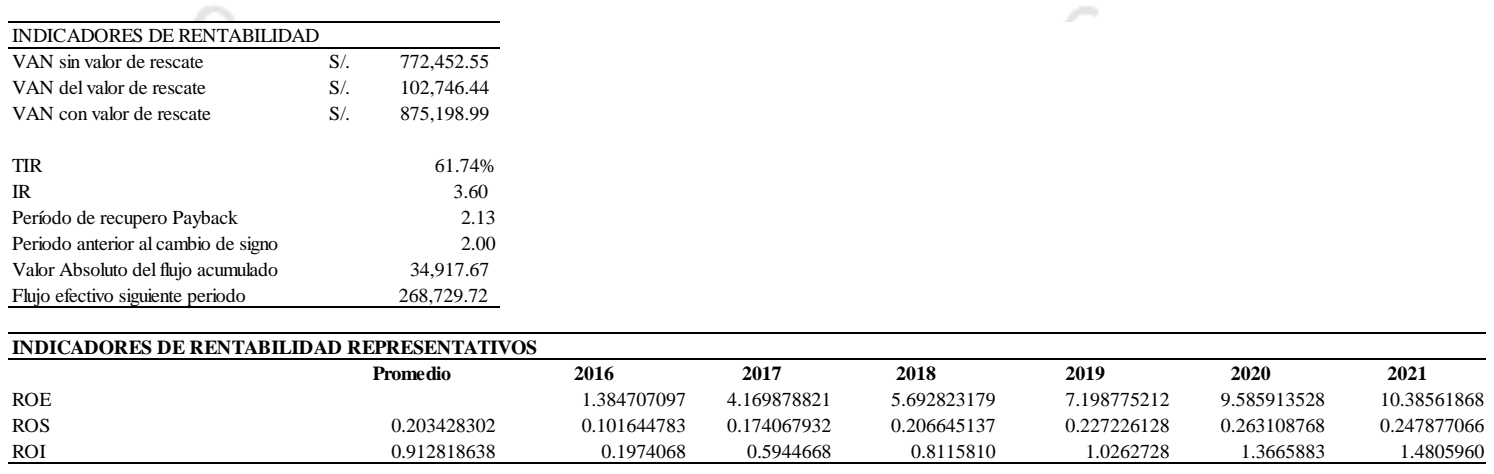

Bajo este escenario el VAN del proyecto aumenta a S/. 772,452.55, la tasa interna de retorno (TIR) aumenta a $61.74 \%$, el índice de rentabilidad aumenta a 3.60 y la rentabilidad sobre la inversión aumenta a $90 \%$ en promedio. 
Bajo el supuesto del escenario pesimista donde todos los costos aumentan a $5 \%$ debido a una inflación en la economía del Perú, el accionista exija una prima por riesgo de $15 \%$ más la tasa libre de riesgo (convirtiéndose el WACC en 17.47\%) y las ventas aumenten solamente $3 \%$, los resultados serían los siguientes:

Tabla 7.19

Indicadores de rentabilidad escenario pesimista

\begin{tabular}{lrr}
\hline INDICADORES DE RENTABILIDAD & \\
\hline VAN sin valor de rescate & S/. & $451,405.96$ \\
VAN del valor de rescate & S/. & $85,604.36$ \\
VAN con valor de rescate & S/. & $537,010.32$ \\
& & \\
TIR & & $52.84 \%$ \\
IR & 2.52 \\
Período de recupero Payback & 2.16 \\
Periodo anterior al cambio de signo & & 2.00 \\
Valor Absoluto del flujo acumulado & $34,917.67$ \\
Flujo efectivo siguiente periodo & $215,066.04$ \\
\hline
\end{tabular}

Valor Absoluto del flujo acumulad

Flujo efectivo siguiente periodo $\quad 215,066.04$

INDICADORES DE RENTABILIDAD REPRESENTATIVOS
Promedio

\begin{tabular}{lr} 
ROE & Promedio \\
ROS & 0.193880421 \\
ROI & 0.72753879 \\
\hline
\end{tabular}

El VAN del proyecto disminuiría a S/. 451,4051.96, la TIR disminuiría a $52.84 \%$, el índice de rentabilidad sería 2.52 el rendimiento sobre la inversión sería en promedio en los 5 años 72\% (Ver Tabla 7.19).

Se observa que aún en el escenario pesimista el proyecto continúa siendo rentable.

\subsection{Principales riesgos del proyecto (cualitativos) y Plan de Contingencia.}

El proyecto de Taller Automotriz Tiki Cars según la evaluación financiera es rentable, sin embargo, se debe tener en cuenta que el éxito dependerá en gran medida de una excelencia en la calidad del servicio, honradez en la detección de fallas, escucha permanente de la voz del cliente, innovación permanente en base a tecnología para que el cliente pueda ahorrar tiempo y tener servicios a precios competitivos. 
Un riesgo cualitativo importante es que se construirá un túnel en La Molina, de acuerdo a un artículo publicado en el diario El Comercio (2016), el túnel uniría La Molina (avenida Raúl Ferrero) con Miraflores (avenida Angamos) en 20 minutos. Esto ocasionaría tráfico, lo cual puede disminuir el flujo de entrada de carros al taller. Este riesgo se ha evaluado en el escenario pesimista y el proyecto sigue siendo rentable, sin embargo, una manera de atenuarlo es tratar de acostumbrar a los clientes a usar el servicio de delivery para que eviten la incomodidad del tráfico. Esto será realizado a través de comunicaciones con los asesores en cada servicio, las redes sociales, página web y publicidad a través de volantes a los vecinos de La Molina.

Otro riesgo que se debe considerar es que al aumentar las ventas producto de la afiliación de las compañías de seguro Rímac y Pacífico, aumento de las ventas, se deberá contratar más contratistas calificados en planchado y pintura y más mecánicos. Esto último, requiere contar con criterios de selección de personal exigentes para asegurar la calidad del servicio. 


\section{CONCLUSIONES}

Después de analizar los resultados de las encuestas, haber iniciado operaciones y considerando el análisis financiero se concluye que:

- Se valida la hipótesis principal de la investigación en la cual se afirma que los clientes están interesados en recibir una experiencia por servicios de mecánica, planchado y pintura que les permita ahorrar tiempo y obtener un servicio de calidad centrado en la persona, a través del resultado de la pregunta 10 en donde el $94.3 \%$ de los encuestados refiere que sí le gustaría que el taller de mecánica preste el servicio gratuito de recojo y entrega en el lugar que indique para los servicios de mantenimiento. Esto contribuye al ahorro de tiempo. Además, en la pregunta $\mathrm{N}^{\circ} 5$ los encuestados destacan que lo que esperan de un servicio de mantenimiento en un taller de mecánica es el buen trato al cliente antes, durante y después del servicio, garantía del servicio y precio justo.

- En la hipótesis secundaria 1 se defiende la importancia de la utilización de aceites sintéticos debido al tráfico de la ciudad, sin embargo los clientes desconocen la diferencia entre los aceites minerales y sintéticos y las ventajas de éstos últimas ya que en la pregunta $\mathrm{N}^{\circ} 10$, el $68.3 \%$ de los encuestados asegura no conocer la diferencia entre estos dos tipos de aceites. Esto lleva a la necesidad de Tiki Cars de capacitar a sus clientes informándoles de las bondades de los aceites sintéticos frente a los minerales a través de su página web y redes sociales.

- En la hipótesis secundaria 2 se defiende que la innovación, eficiencia y servicio de calidad de Tiki Cars se manifiestan en el recojo y entrega del vehículo a domicilio. Esta afirmación está relacionada directamente con la validación de la hipótesis principal ya que esta ventaja competitiva supone ahorro de tiempo. 
- En la hipótesis secundaria 3 se plantea que el trabajador se sentirá más gratificado con su trabajo gracias a las capacitaciones que lo harán crecer a nivel personal y profesional y esto se verá reflejado en el trato con el público. Esta hipótesis se valida con la respuesta a la pregunta 5 en donde los encuestados afirman que esperan que además del servicio de mantenimiento, el taller asegure el buen trato al cliente antes, durante y después del servicio.

- El análisis de costos y competencia realizado, ha permitido cobrar precios competitivos superando a la fecha el punto de equilibrio y logrando crecimientos de venta de $14 \%$ mensuales.

- Hacer publicidad en Facebook y repartir volantes en el distrito de La Molina ha permitido captar clientes nuevos y recomendaciones. 


\section{RECOMENDACIONES}

En base a todo el análisis realizado en la presente investigación y a los resultados obtenidos se presentan las siguientes recomendaciones:

- Tiki Cars debe continuar con su política de trabajo orientada a la satisfacción del cliente, realizando la detección correcta de fallas, control en sus procesos productivos y servicio post venta.

- Tiki Cars debe implementar de manera inmediata un sistema integrado que le permita ahorrar trabajo manual del personal administrativo para que se pueda orientar los esfuerzos hacia mejora de atención al cliente, captación de clientes nuevos y ahorro de costos.

- Se debe estar al día con las nuevas tendencias y tecnologías para aplicarlas al taller.

- Debe tratar de convertirse en Taller Afiliado de Rímac y Pacífico. 


\section{REFERENCIAS}

BCR deja estable tasa de referencia en 4.25\%. (10 de noviembre de 2016).Diario Gestión. Recuperado de http://gestion.pe/economia/bcr-mantiene-tasa-interes-referencia$\underline{\text { sin-variacion-2174420 }}$

Enst \& Young Global (2015). Megatendencias para 2015. Entender el mundo en constante movimiento. Recuperado del sitio de Internet de Ernst \& Young: http://www.ey.com/Publication/vwLUAssets/ey-megatendencias-para-2015entender-el-mundo-en-constante-movimiento/\%24FILE/ey-megatendenciaspara-2015-entender-el-mundo-en-constante-movimiento.pdf

Hernández, R., Fernández-Collado, C. \& Baptista, L. (2014). Metodología de la Investigación ( $6^{\mathrm{a}}$ ed.). México D.F.: McGraw-Hill.

Kasriel-Alexander, D. (2016). Top 10 Global consumer trends for 2016. Euromonitor international, pp.6-9, 14-17, 26-28.

Los baches y el despegue en la sinuosa ruta del mercado automotriz (21 de octubre de 2015). Diario Gestión. Recuperado de http://gestion.pe/mercados/baches-ydespegue-sinuosa-ruta-mercado-automotriz-2146102.

¿Por qué utilizar lubricantes sintéticos? (2016). Mobil. Recuperado de http://www.mobil.com.mx/mexico-spanish-lcw/heavydutyengineoils_whymobil-delvac_why-synthetics.aspx.

TWG: El 15\% de autos nuevos vendidos en 2015 contarían con garantías extendidas. (23 de enero de 2015). Diario Gestión. Recuperado de http://gestion.pe/mercados/15autos-nuevos-vendidos-2015-optarian-adquirir-garantias-extendidas-2121322. 
Túnel La Molina-Miraflores: construcción comenzaría el 2017 (30 de enero de 2016). Diario El Comercio. Recuperado de http://elcomercio.pe/sociedad/lima/tunelmolina-miraflores-construccion-comenzaria-2017-noticia-1874985.

Waze: Lima es la peor capital de Sudamérica para conducir (17 de setiembre de 2016). Diario El Comercio. Recuperado de http://elcomercio.pe/sociedad/lima/wazelima-peor-capital-sudamerica-conducir noticia1932287?ref=flujo_tags_92347\&ft=nota_2\&e=titulo 


\section{BIBLIOGRAFÍA}

Chase, R., \& Jacobs, R. (2014). Administración de operaciones y cadena de suministros (13 ed.). México D.F.: McGraw - Hill Education.

Kotler, P., \& Keller, K. (2009). Dirección de Marketing (14ª ed.). México D.F.: PearsonPrentice Hall.

Miller, O. and Wedell-Wedellsborg, T. (2013). Innovation as Usual: How to Help Your People Bring Great Ideas to Life. Harvard Business Review Press.

Pisano, G. (2015). You need an innovation strategy. Harvard Business Review. Recuperado de https://hbr.org/2015/06/you-need-an-innovation-strategy.

Porter, M., Heppelman, J. (2015). How smart, connected products are transforming companies. Harvard Business Review. Recuperado de https://hbr.org/2015/10/how-smart-connected-products-are-transformingcompanies.

Ross, S., \& Westerfield, J. (2010). Finanzas Corporativas (9ª ed.). México D.F.: McGraw - Hill. 
Schilling, M. A. (2009). Strategic Management of technological innovation (3rd ed.). New York: McGraw-Hill/Irwin.

W. Chan, K., \& Mauborgne, R. (2005). La estrategia del Océano Azul (1a ed.). Bogotá: Editorial Norma.

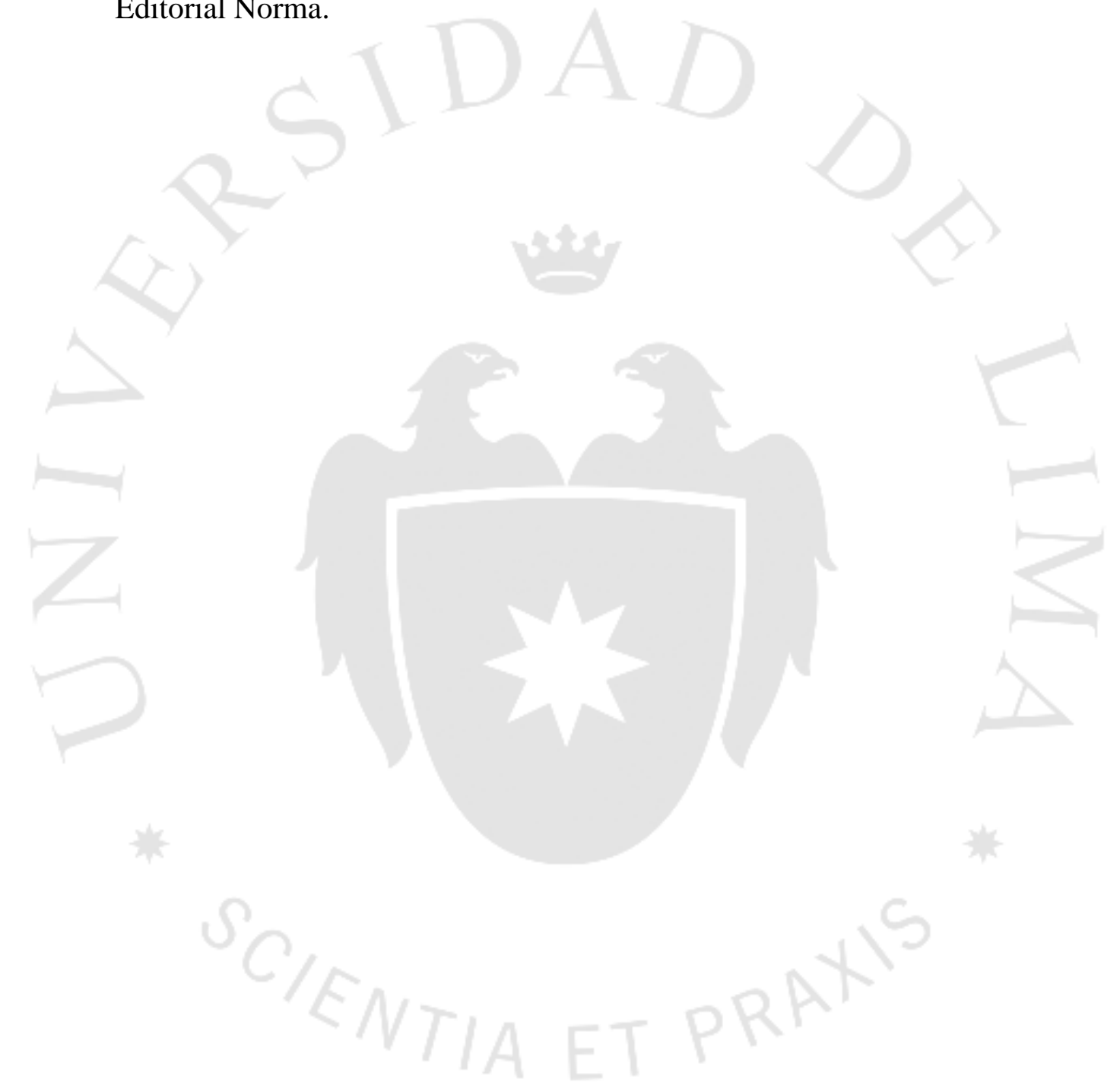




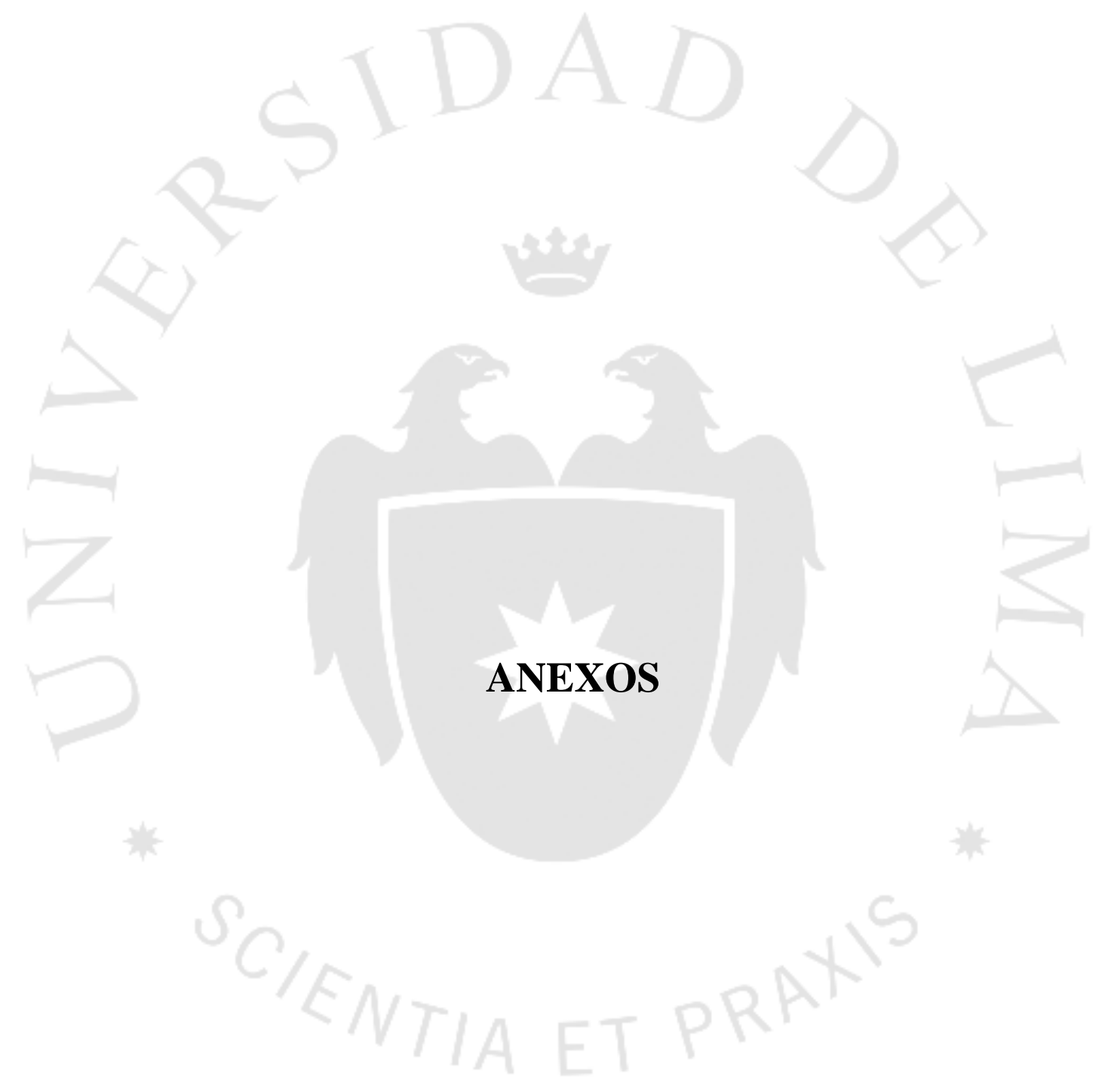




\section{ANEXO 1: ESTUDIO DE MERCADO PRECIOS SERVICIO MANTENIMIENTO}

\begin{tabular}{|c|c|c|c|c|c|c|c|c|c|c|c|c|}
\hline \multicolumn{13}{|c|}{ PRECIOS DE SERVICIOS DE MANTENIMIENTO MULTIMARCA (S/.) } \\
\hline & & & & NISSAN & & & & HONDA & & CHEVROLET & & \\
\hline Mano de Obra y & TOYOTA & TOYОТА & NISSAN AUTO & CAMIONETA & & KIA & HONDA & CAMIONET & CHEVROLET & CAMIONETA & SUZUKI & SUZUKI \\
\hline Repuestos (INC. & AUTO & CAMIONETA & (MAQUINARIA & (MAQUINARIA & KIA AUTO & CAMIONE & AUTO & A & AUTO & (AUTOFONF & AUTO & CAMIONET \\
\hline & (MITSUI) & (MITSUI) & S) & S) & (ALESE) & TA (ALESE) & (MASAKI) & (MASAKI) & (AUTOFONFO) & o) & (DERCO) & $\mathrm{A}(\mathrm{DERCO})$ \\
\hline $5,000 \mathrm{Km}$ & 577.00 & 650.00 & 433.00 & 650.00 & & & 545.00 & 930.00 & 555.00 & 750.00 & 480.00 & 870.00 \\
\hline $10,000 \mathrm{Km}$ & 700.00 & 800.00 & 670.00 & 850.00 & 1050.00 & 1350.00 & 1350.00 & 2280.00 & 920.00 & 2050.00 & 750.00 & 1496.00 \\
\hline \multicolumn{13}{|c|}{ OBSERVACIONES: } \\
\hline \multicolumn{13}{|c|}{ LOS PRECIOS SON APROXIMADOS. } \\
\hline \multicolumn{13}{|c|}{ LOS PRECIOS SON PARA VEHICULOS A GASOLINA } \\
\hline PFЕЕРГNT & EHICULOS & KIA SU SERVICI & IO LO REALIZAN & CADA $10,000 \mathrm{~K}$ & MS CON AC & ACEITE SIN & $\mathrm{CO}$ & & & & & \\
\hline
\end{tabular}

\section{ANEXO 2: ESTUDIO DE MERCADO PRECIOS SERVICIO PLANCHADO Y PINTURA}

\begin{tabular}{lcccc}
\hline \multicolumn{4}{l}{ ESTUDIO DE MERCADO-COMPARATIVO DE PRECIOS PLANCHADO Y PINTURA } \\
\hline & $\$$ & $\$$ & $\mathrm{~S} /$. & $\mathrm{S} /$. \\
& PAÑO & $\mathrm{H} / \mathrm{H}$ & $\mathrm{PAN \tilde {O }}$ & $\mathrm{H} / \mathrm{H}$ \\
GERMANIA DELUXE & & & 270.00 & 70.00 \\
GERMANIA MULTIMARCA & & & 220.00 & 45.00 \\
TALLERES PEQUEÑOS & & & 180.00 & 35.00 \\
TALLERES PEQUEÑOS & & & 200.00 & 40.00 \\
DIVEMOTOR & 84.75 & 45.00 & 288.15 & 153.00 \\
TOYOTA & 84.75 & 25.00 & 288.15 & 85.00 \\
GALLO AUTOS & & & 220.00 & 40.00 \\
TG AUTOS & & & 210.00 & 45.00 \\
TIKI CARS & 67.71 & 15.00 & 230.21 & 51.00
\end{tabular}

TC. S/. 3.4 


\section{ANEXO 3: ORDEN DE TRABAJO}

Av. Raúl Ferrero Rebagliati 1115

Urb. El Remanso

La Molina

ORDEN DE

Teléfono: 3697069

TRABAJO

$\frac{\text { CARS }}{\text { CARL }}$

Teléfono: 3697069

$\mathrm{N}^{\circ}$

Fecha:

\section{Cliente:}

DNI/RUC

Dirección:

Distrito:

Contacto:

Celular:

Teléfono Oficina:
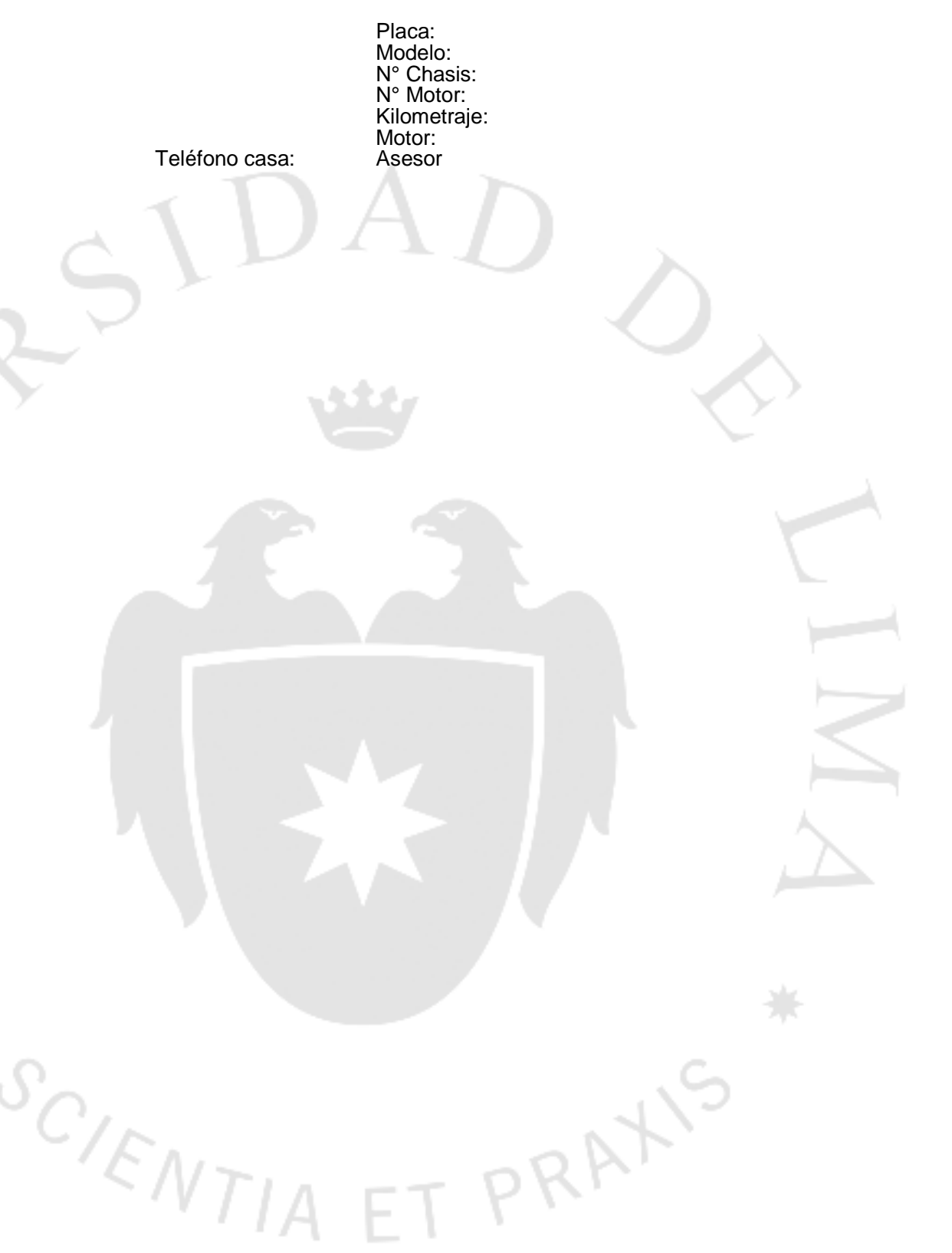


\section{ANEXO 4: INVENTARIO DEL VEHÍCULO}

Av. Raúl Ferrero Rebagliati 1115

Urb. El Remanso

No

La Molina

Fecha:

Teléfono: 3697069

\section{HOJA DE INVERTARIO DEL VEHÍCULO}

Nombre:

\begin{tabular}{l}
\hline \\
\hline Accesorios/ Objetos de \\
DOCUMENTACION \\
Tarjeta de \\
Propiedad \\
SOAT \\
Libro de servicio \\
Manual de \\
propietario \\
Revisión técnica \\
Permiso de lunas \\
polarizadas \\
$\quad$ INTERIOR \\
Llavero ( ) \\
Llaves ( ) \\
Alarma ( ) \\
Radio ( ) CD ( \\
) Máscara de radio \\
Control de puerta \\
de garaje \\
Alf del ( ) post ( \\
Piso del ( ) post \\
( ) \\
Encendedor del ( \\
) post ( ) \\
Cenicero \\
Tapasol \\
Claxon \\
\hline
\end{tabular}

OK, en buen estado

GPS
Placa:

stible:

$\begin{array}{ll}\begin{array}{l}\text { Brazos y plumillas } \\ \text { post }\end{array} & \begin{array}{l}\text { Amortiguador de } \\ \text { capó delantero }\end{array}\end{array}$

Faros delanteros

Faros posteriores

Aros

Espejos Lat

Emblemas

Delantero

Emblemas

Posterior

Tapa tanq

combustible

Tapiz maletera/

Tapa cartón

Tapa válvula llanta

Antena

Cobertor maletera

Micas laterales

Cromo timón

\section{EXTERIOR}

Vasos ( )

Parabrisas del ( ) post ( )

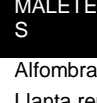

Llanta repuesto

Gata

Llave de ruedas

Dado de seguridad

Kit herramientas

Cable de baterias

Triángulo segurida

Gancho de
remolque

Botiquín

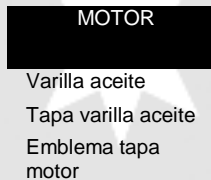

\section{INGRESO}

\section{FECHA}

$\mathrm{KM}$.

HORA
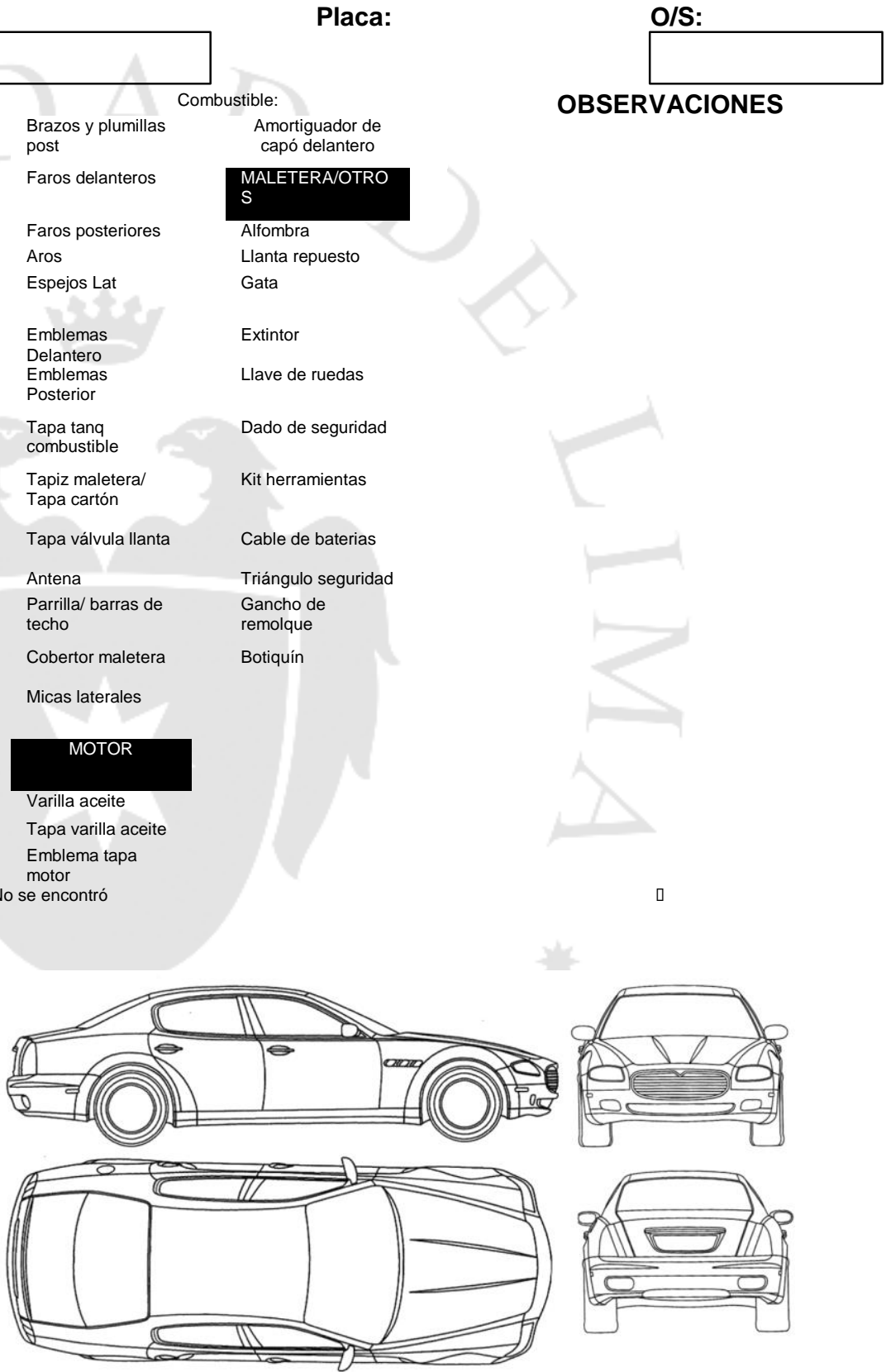

OBSERVACIONES

motor

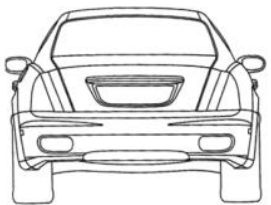

SALIDA

FECHA

$\mathrm{KM}$.

HORA

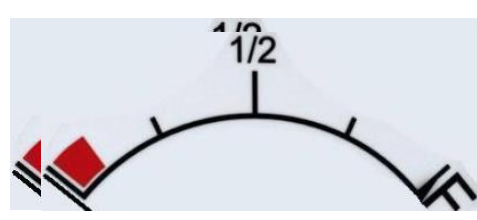

El cliente suscribe la presente en señal de conformidad con todo su contenido, incluyendo las condiciones generales del reverso que forman parte de la Orden de Servicio

Firma

Nombre:

$\mathrm{DNI}$ 


\section{ANEXO 5: ENCUESTA DE SATISFACCION POST SERVICIO}

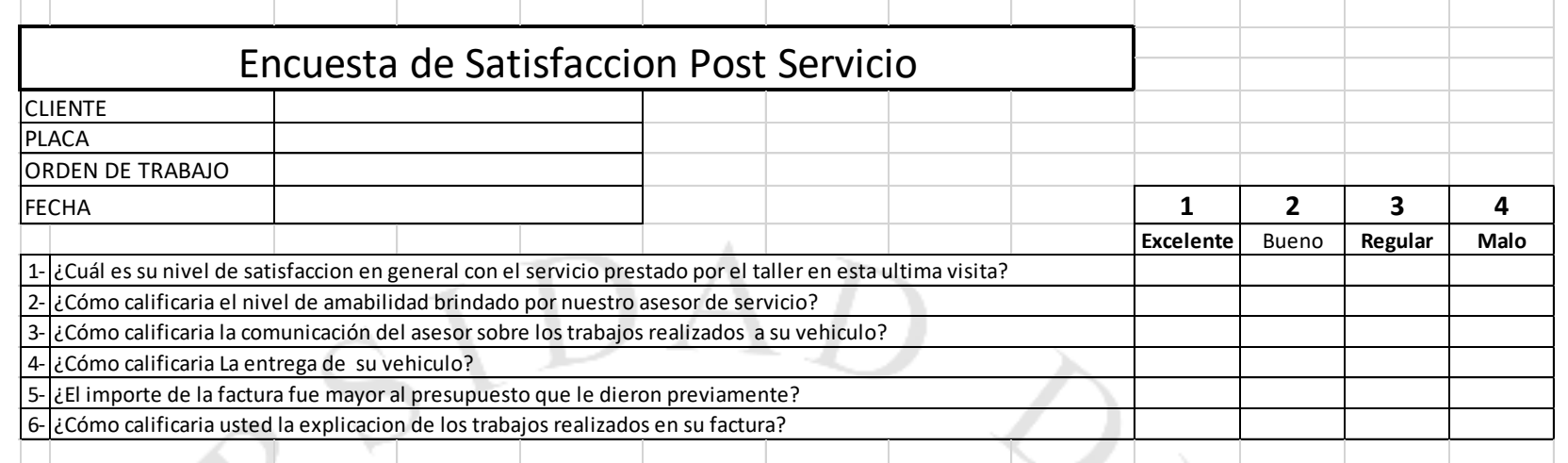




\section{ANEXO 6: CHECKLIST MECANICA Y LAVADO}

\begin{tabular}{|c|c|c|c|c|c|c|c|}
\hline \multirow[b]{2}{*}{$\mathbf{N}^{\circ}$ de orden } & \multicolumn{4}{|c|}{ Servicio de inspeccíon } & & & \\
\hline & $\mathbf{N}^{\circ}$ placa & $\mathbf{N}^{\circ}$ VIN del vehículo & Km & Letra distintiva de motor & & & \\
\hline & & & & & & $\begin{array}{l}\text { ○े } \\
\text { ż }\end{array}$ & 잏 \\
\hline \multicolumn{5}{|c|}{ Faros, intermitentes (delanteros, traseros), luces de emergencia, retroceso, luces de freno, luz de maletera: verificar funcionamiento. } & & & \\
\hline \multicolumn{5}{|c|}{ Iluminación del habitáculo y guantera, bocina, encendedor y testigos de control: verificar funcionamiento } & & & \\
\hline \multicolumn{5}{|c|}{ Airbags: verificación visual debido a daños exteriores } & & & \\
\hline \multicolumn{5}{|c|}{ Climatización y circulación de aire: comprobar funcionamiento } & & & \\
\hline \multicolumn{5}{|c|}{ Alarmas, seguros y elevalunas eléctricos: comprobar funcionami } & & & \\
\hline \multicolumn{5}{|c|}{ Limplailavaparabrisas y lavafaros: verificar funcionamiento, en caso necesario ajustar los eyectores } & & & \\
\hline \multirow{2}{*}{\multicolumn{5}{|c|}{ Plumillas de limpiaparabrisas: verificar la posición de reposo y angulo de ajuste, verificar barrido, si fuera necesario ajustar o cambiar }} & & & \\
\hline & & & & & & & \\
\hline \multicolumn{2}{|c|}{$\begin{array}{l}\text { Autodiagnóstico: consultar memoria de averías con scanner } \\
\text { Reloj: poner en hora }\end{array}$} & & & 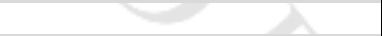 & & & \\
\hline \multicolumn{5}{|c|}{ Indicador de intervalos de servicio: poner en cero y/o programar } & & & \\
\hline \multicolumn{5}{|c|}{ Bisagras, retentores de puertas y pernos de fijación: lubricar } & & & \\
\hline \multicolumn{5}{|c|}{ Carriles o gufas de techo corredizo o replegable (sunroof): Lubricar } & & & \\
\hline \multicolumn{5}{|c|}{ Batería: verificar el nivel del etectrolito, si fuera necesario reponer agua destilada } & & & \\
\hline \multicolumn{5}{|c|}{ Motor y compartimiento de motor (por arriba): verificación visual con respecto a fugas y daños } & & & \\
\hline Sistema de Refrigera & : verificar nive & entración de anticongetant & 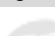 & & & & \\
\hline Depósito limpiaparak & s, anadir líquic & & & & & & \\
\hline Filtro de aire: limpiar & Fasa y sustitu & tucho del filtro & & & & & \\
\hline Filtro de combustible & & & & & & & \\
\hline Servodirección: com & ar el nivel de I & rellenar si requerido & & & & & \\
\hline Filtro de polvo y pole & visar $\mathrm{y} / 0 \mathrm{cam}$ & & & & & & \\
\hline Correas Poly - V y/o & Dezoidal verific & do y tensión, si es necesar & biar & & & & \\
\hline Faja de distribución: & icar a partir $\mathrm{d}$ & $000 \mathrm{~km}$. Cambiar como m & a los & & & & \\
\hline Faja de bombas de $\mathrm{i}$ & ción en V6: & a partir de los $60,000 \mathrm{~km}$, & I máx & $90,000 \mathrm{~km}$. & & & \\
\hline Nivel de líquido de fre & (según desga & pastillas): verificar, cambiar & 2 años & & & & \\
\hline Aceite de motor y filt & & & & & & & \\
\hline Motor y compartimie & de motor (por & verificación visual con resp & fugas & & & & \\
\hline Caja de cambios, m & de semiejes & os de palier: verificación vis & n resp & gas y daños & & & \\
\hline Caja automáticas: ve & ar nivel de ATt & dir si es necesario & & & & & \\
\hline Caja de cambios ma & : comprobar $n$ & aceite y añadir si fuera nec & & & & & \\
\hline Sistema de frenos: $\mathrm{V}$ & ación visual c & ecto a fugas y daños & & & & & \\
\hline Pastillas de freno de & ras y traseras & ar el espesor, cambiar de & esaric & & & & \\
\hline Amortiguadores dela & os y posterior & car daños, fuga, inspeccio & ichos & & & & \\
\hline Sistema de gases $d$ & cape: verificac & al con respecto a fugas, da & a sufi & & & & \\
\hline Protección de parte & del vehiculo: & Jación visual & & & & & \\
\hline Articulaciones y mur & $s$ de ejes: ver & ualmente & 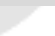 & 3 & & & \\
\hline Rótulas: verificar el j & , fijación y los & polvos & & & & & \\
\hline Terminates de direcc & comprobar ju & años & & & & & \\
\hline Neumáticos, incluye & el de repuestc & ar el estado y emblema & & & & & \\
\hline Verificar cocada de $r$ & láticos (incluy & de repuesto): anotar si un & oes $r$ & specificando neumático & & & \\
\hline Presión de inflado de & neumáticos ( & do el de repuesto): verifica & egir s & sario & & & \\
\hline Faros: verificar el aju & regular de $\mathrm{s}$ & sario & & $=10 \times$ & & & \\
\hline Pegar adhesivo próx & mantenimient & & & & & & \\
\hline Solo jefe de taller: re & a un recorrido & ba y llenar hoja de prueba & & 10 & & & \\
\hline Torque neurnaticos & & & & & & & \\
\hline Posición original de & oria asientos & & & & & & \\
\hline Programar emisoras & & & & & & & \\
\hline Colocar tapas, pitón & da y tapa de $\mathrm{F}$ & & & & & & \\
\hline Todos los puntos deb & ser realizados & mulario original deberá arch & unto a & e trabajo. & & & \\
\hline & & & & & & & \\
\hline & & & & & & & \\
\hline & & Nombre / Firma del $n$ & & Firma (Jefe de taller) & & & \\
\hline & & & & & & & \\
\hline
\end{tabular}




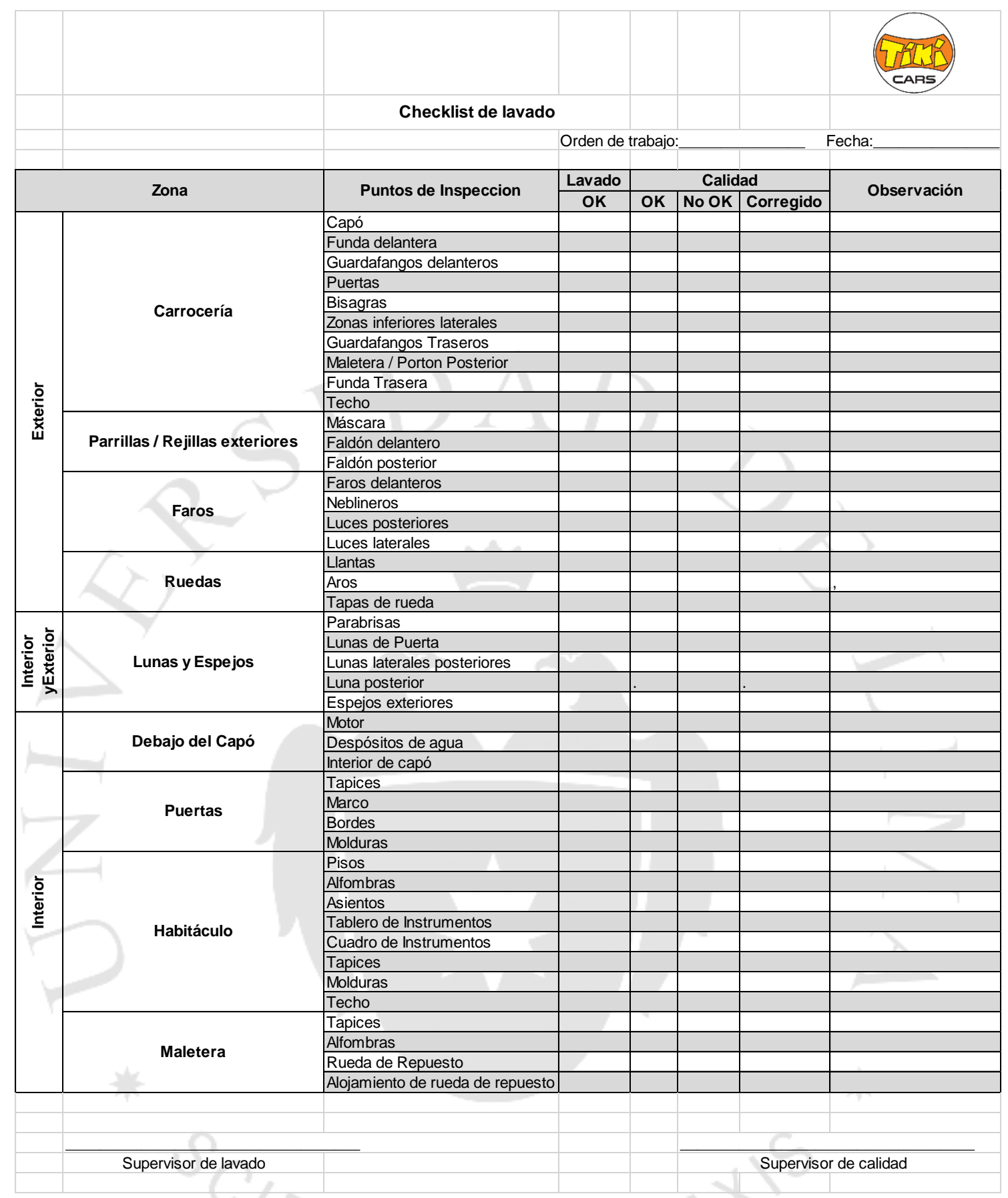


Prueba de manejo (realizada exclusivamente por Jefe de taller)

\begin{tabular}{|l|c|c|c|c|}
$\mathbf{N}^{\circ}$ de orden & $\mathbf{N}^{\circ}$ placa & $\mathbf{N}^{\circ}$ VIN del vehículo & $\mathbf{K m}$ & Letra distintiva de motor \\
\hline
\end{tabular}

Las siguientes indicaciones dependen del equipamiento del vehículo y de las posibilidades existentes (país/estado) para juzgar la prueba

Este formulario es para uso interno únicamente, no debe entregarse al cliente

Motor

Potencia

Fallos de encendido

Comportamiento del ralenti (rpm, estabilidad-considerar tipo de motorización y características

Aceleración

Arranque en caliente

Funcionamiento de Cruise Control

Embrague

Comportamiento del arranque

Juego del pedal

Fuerza del pedal

Olor

Cambio manual

Funcionamiento

Engrane en marchas (sincronismo)

Suavidad de los cambios

Posición de la palanca de cambios

Cambio automático

Posición de la palanca selectora

Shift-lock / bloqueo con la llave de contacto

Funcionamiento (secuencia de cambios)

Indicador en el panel de instrumentos (si equipa)

Funcionamiento de mandos de multitrónic en el volante

Frenos de rueda

Funcionamiento

Recorrido en vacío

Eficacia de frenado

Desviación al frenar

Chirrido

Vibración

Frenos ABS

Funcionamiento. Debe percibirse una vibración en el pedal al momento de aplicar el freno

Dirección y suspensión

Funcionamiento

Regulación de la altura allroad

Juego de la dirección y el timón

Timón alineado estando las ruedas en posición recta

Desviación de la dirección (jata a la izquierda o derecha), considerar nivelación de pista

Desequilibrio - vibración

Ruido o zumbido de rodamientos de ruedas

Ruido de terminales y brazos de suspensión

Palieres

Balanceo de ruedas

Techo corredizo / Sunroof

Verificar funcionamiento

Cinturones de seguridad

Verificar funcionamiento, trabamiento y retractibilidad (regreso sin interferencia)

Velocímetro y cuentakilometros

Funcionamiento del velocímetro principal y parcial

Indicador multifunción

Probar todas las funciones

Aire acondicionado

Funcionamiento (enfriamiento, accionamiento de compuertas)

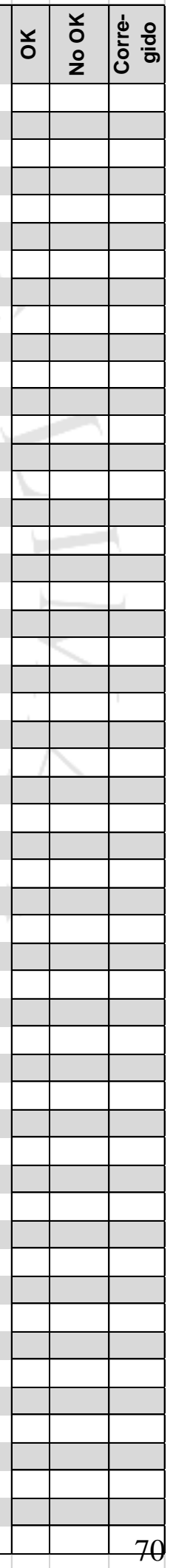




\section{ANEXO 7: RESULTADO ENCUESTAS}

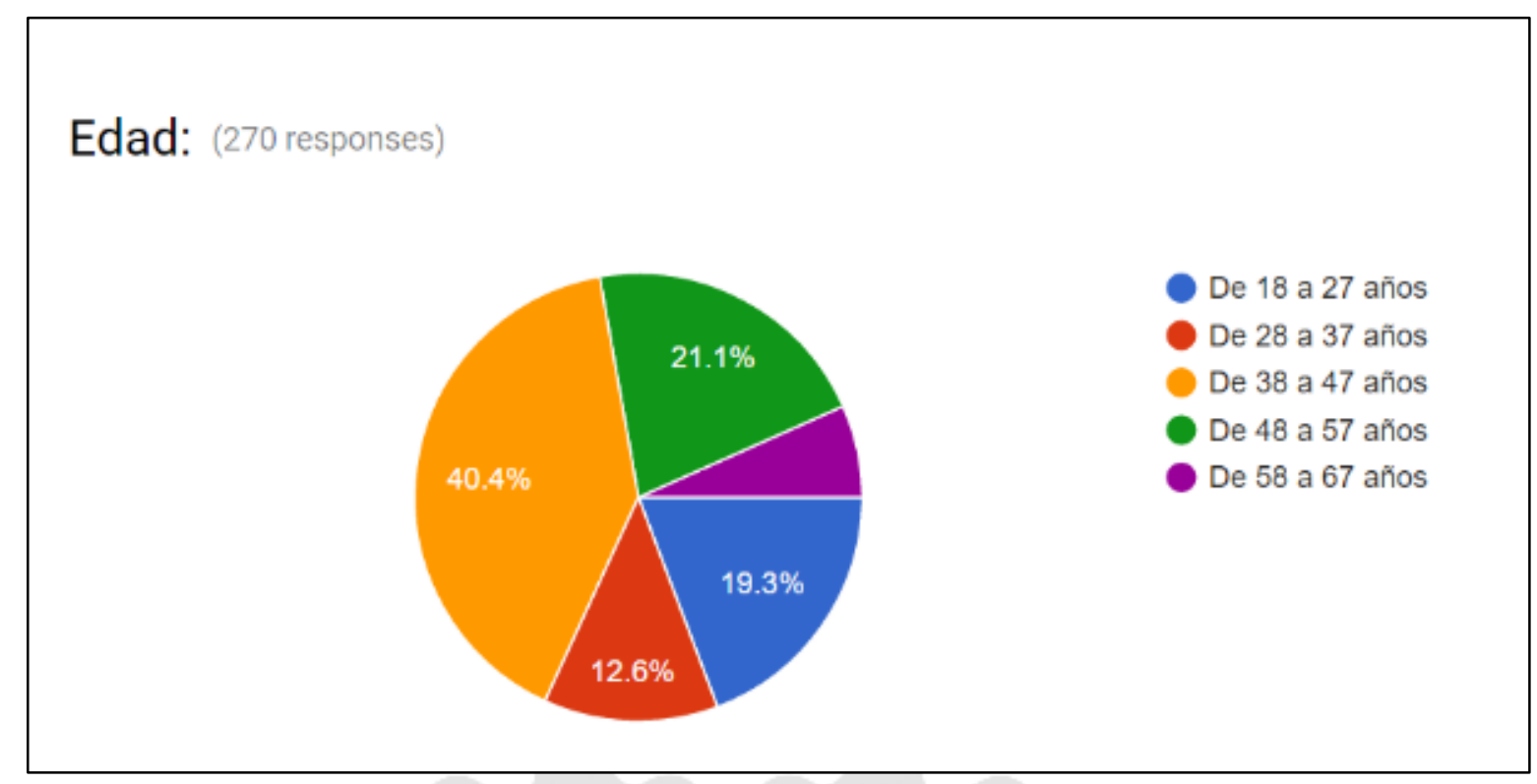

De acuerdo al gráfico se puede observar que el $40.4 \%$ de las personas encuestadas tienen entre 38 y 47 años de edad.

Sexo: (269 responses)

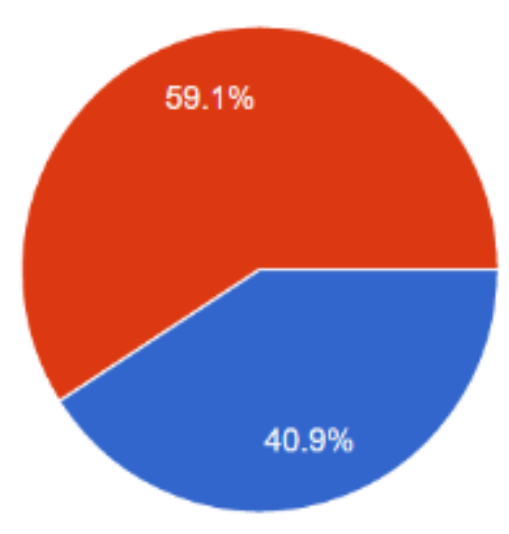

El $59.1 \%$ de la muestra encuestada son mujeres y el $40.9 \%$ varones. 
Zona distrital donde vive, de acuerdo a tabla en la que se ubica el distrito (zonas de 1 a 10):

(268 responses)

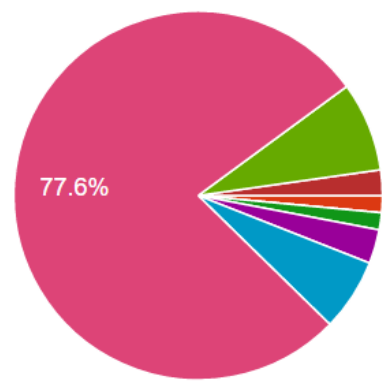

Zona 1 (Puente Piedra, Comas Carabayllo)

Zona 2 (Independencia, Los Olivos,...

Zona 3 (San Juan de Lurigancho)

Zona 4 (Cercado, Rímac, Breña, La..

Zona 5 (Ate, Chaclacayo, Luriganch.

Zona 6 (Jesús María, Lince, Pueblo..

Zona 7 (Miraflores, San Isidro, San..

Zona 8 (Surquillo, Barranco, Chorrill.

Otro

Se observa que el 77.6\% de la muestra encuestada pertenece a la Zona 7, que la conforman los distritos de Miraflores, San Isidro, San Borja, Surco y La Molina. Cabe destacar que el mercado objetivo de Tiki Cars se encuentra en esta zona.

¿Qué aspectos considera que debe de tener un taller mecánico de calidad? Elegir TRES ALTERNATIVAS

(268 responses)

Buena recep.

Facilidades.

Tecnologia y.

Servicio de.

Garantia por

Que los mec.

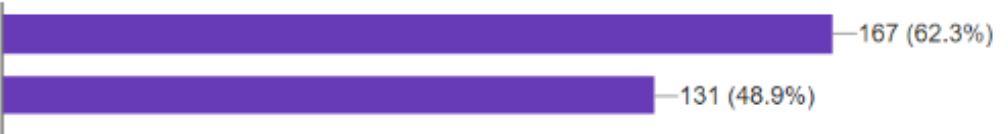

$(62.3 \%)$
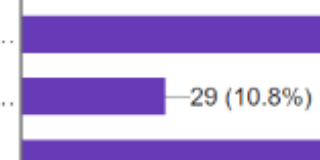

$218(81.3 \%)$

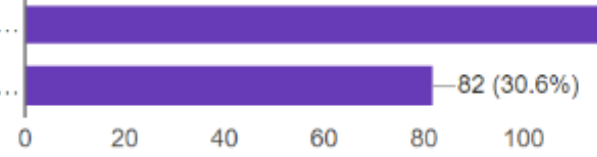

$-173(64.6 \%)$

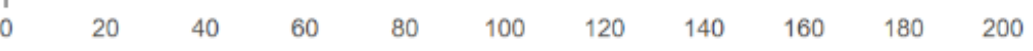

Entre los aspecto que los encuestados consideran que debe tener un taller mecánico de calidad, un $81.3 \%$ destaca la "Tecnología y calidad a precio justo" y $64.6 \%$ espera “Garantía por las reparaciones”. 
¿Qué otra cosa esperaría de un servicio de mantenimiento preventivo en un taller mecánico? A parte de honestidad en la identificación de las fallas, calidad y garantía del trabajo, rápida entrega del vehículo y presentes de cortesía.

(202 responses)

\section{Precio justo}

Precio justo

Precio justo

Precio justo

Precio justo

En relación a qué otra cosa esperarían los encuestados de un servicio de mantenimiento preventivo, destacan tres aspectos, en primer lugar el trato al cliente antes, durante, y después del servicio; en segundo lugar, la garantía del servicio, que no se presenten fallas antes del próximo servicio.; y en tercer lugar, el precio justo.

¿Qué servicio adicional le gustaría recibir del servicio mecánico? (171 responses)
Asesoria tecnica
Asesoria tecnica
Asesoria tecnica
Asesoria tecnica
Puntualidad

Respecto al servicio adicional, los encuestados en su mayoría refieren que les gustaría, en primer lugar, limpieza de cortesía; en segundo lugar, movilidad de cortesía; en tercer lugar, servicio de Wifi mientras esperan la entrega de su vehículo; y en cuarto lugar, asesorías técnicas que les permita conocer más sobre el servicio impartido, así como los detalles técnicos. 


\section{¿Qué tiempo estaría dispuesto a esperar para el servicio de planchado y}

pintura de su vehículo?

(267 responses)

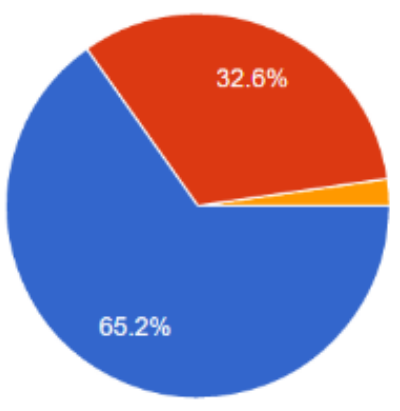

- Estaria dispuesto a esperar más de 20 dias.

Se puede observar que el $65.2 \%$ de los encuestados está dispuesto a esperar entre 3 y 5 días por el servicio de planchado y pintura de su vehículo.

Le gustaría que el taller de mecánica cuente con... (Puede elegir más de una alternativa).

(268 responses)

Sistema de pr.

Café y bocadi.

Ambien

Música de fo.

Servicio de re...

Lavados de c...

Venta de gra.

Tienda surtid.

Televisión por

Todos los ser..
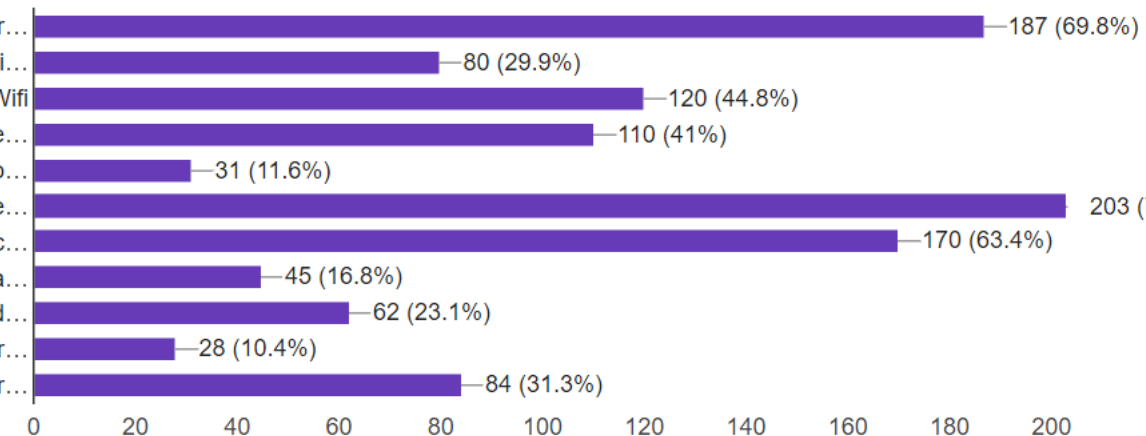

$40-60-80$

El $75.7 \%$ de los encuestados considera que el taller de mecánica debe de contar con "Servicio de recojo del vehículo a domicilio y luego dejarlo donde el cliente disponga", el 69.8\% con un "Sistema de programación de citas en línea" y un 63.4\% con "Lavados de cortesía para clientes frecuentes". 


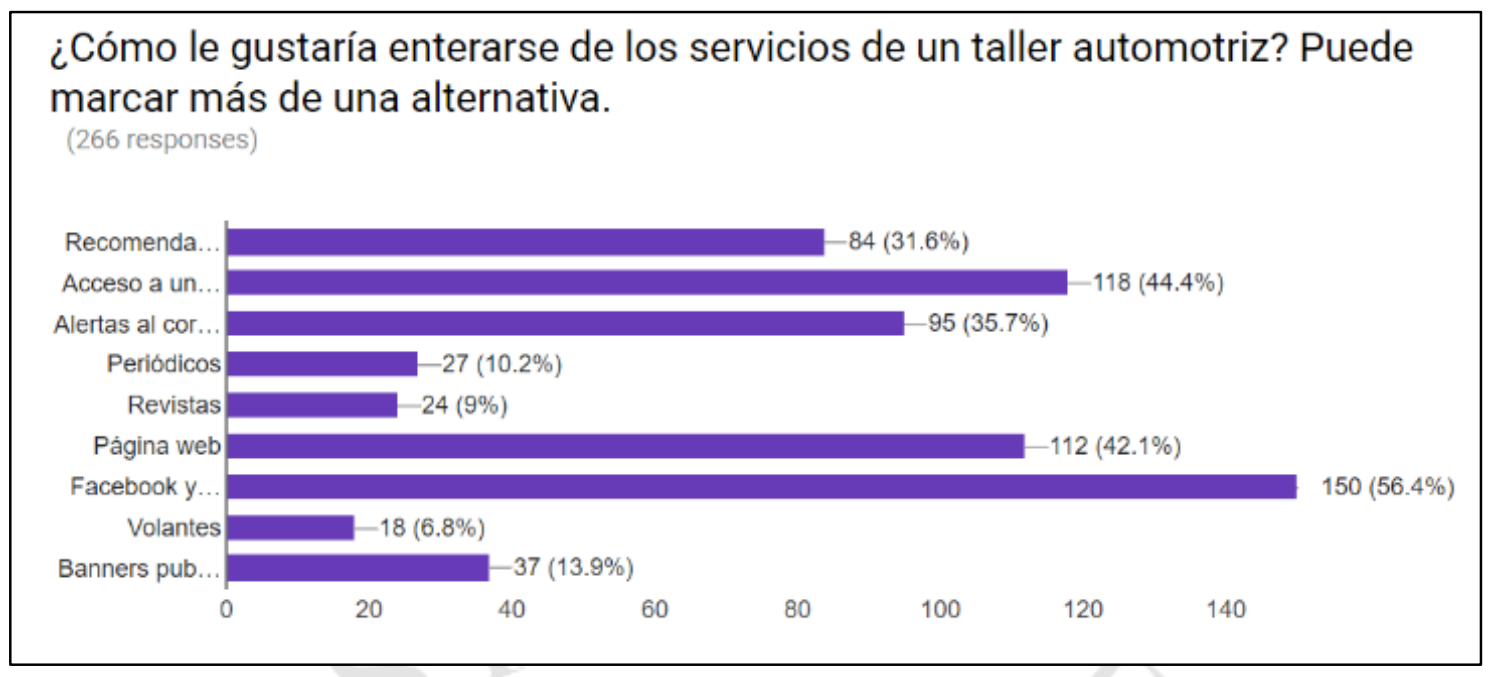

Al 56.4\% de la muestra encuestada, le gustaría enterarse de los servicios de un taller automotriz a través de "Facebook y otras redes sociales", un 44.4\% prefiere enterarse por “Acceso a un app" y a un $42.1 \%$ por "Página web”.

¿Conoce la diferencia entre el aceite sintético y el mineral para el cuidado de su automóvil?

(161 responses)

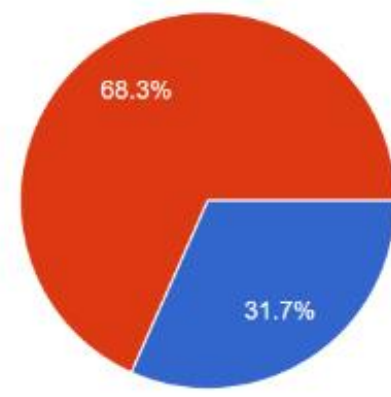

Se puede observar que el $68.3 \%$ de la muestra encuestada no conoce la diferencia entre el aceite sintético y el mineral. 


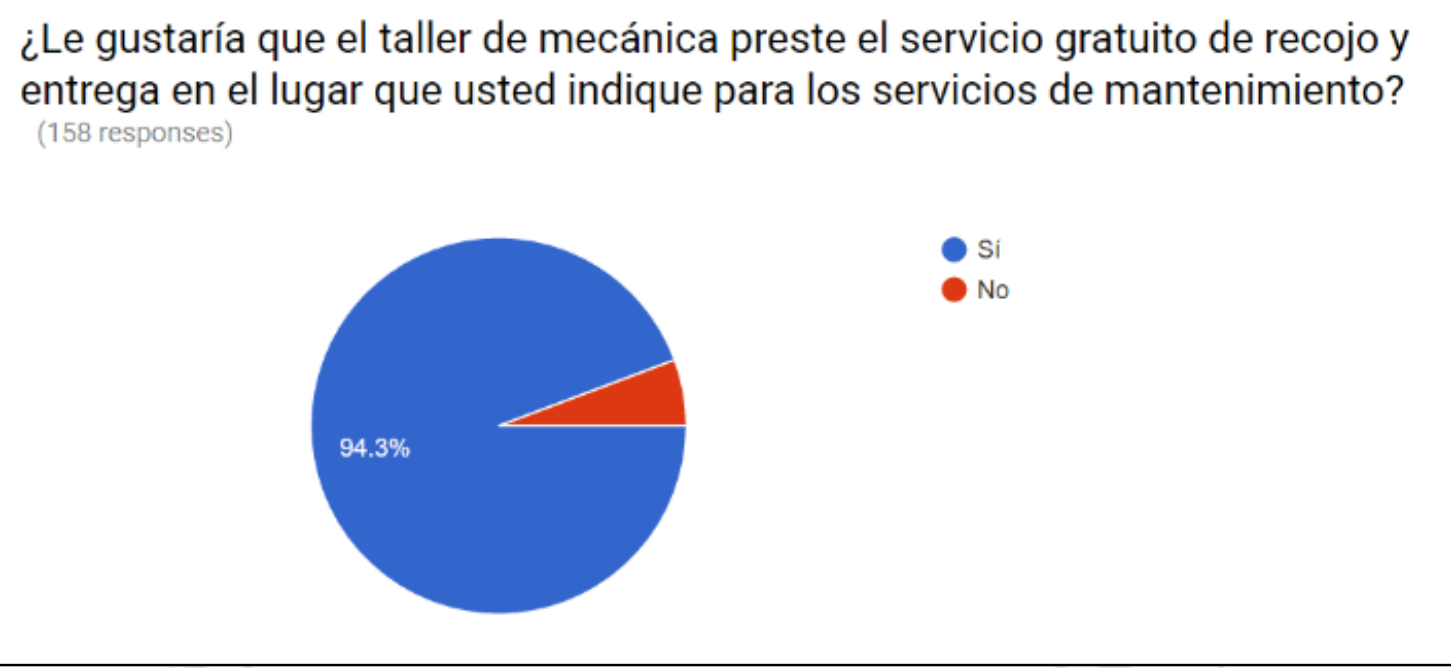

El $94.3 \%$ de la muestra encuestada refiere que sí le gustaría que el taller de mecánica tenga el servicio gratuito de recojo y entrega del vehículo en el lugar que el cliente indique para los servicios de mantenimiento.

¿Qué precio está dispuesto a pagar por un servicio de mantenimiento completo para su vehículo? El mantenimiento completo es cambio de aceite, cambio de filtro de aceite, aire y gasolina, revisión de 50 puntos, enllante y balanceo, limpieza y regulación de frenos y lavado completo.

(158 responses)

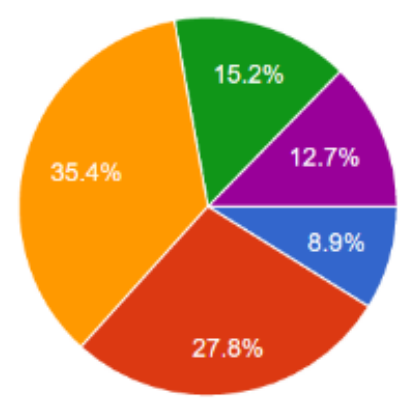

S/. $100-S / .200$

S/. $200-S / .300$

S/. $300-S / .400$

S/. $400-S / .500$

S/. $500-S / .600$

Se puede observar que por el servicio de mantenimiento completo, el $35.4 \%$ de los encuestados está dispuesto a pagar entre 300 y 400 soles y el $27.8 \%$ entre 200 y 300 soles. 
¿Qué obsequios le gustaría que le den por sus servicios de mantenimiento en el taller automotriz?

(209 responses)

Lavado gratis
Aromatizantes
Aromatizantes
Chocolates
Chocolates
Ambientadores
Ambientadores
Ambientador
Ambientador
Accesorios para el auto
Accesorios para el auto
Acumulacion de puntos para descuentos

La mayoría de encuestados refiere que les gustaría recibir como obsequios por los servicios de mantenimiento: accesorios para el auto y lavado de cortesía.

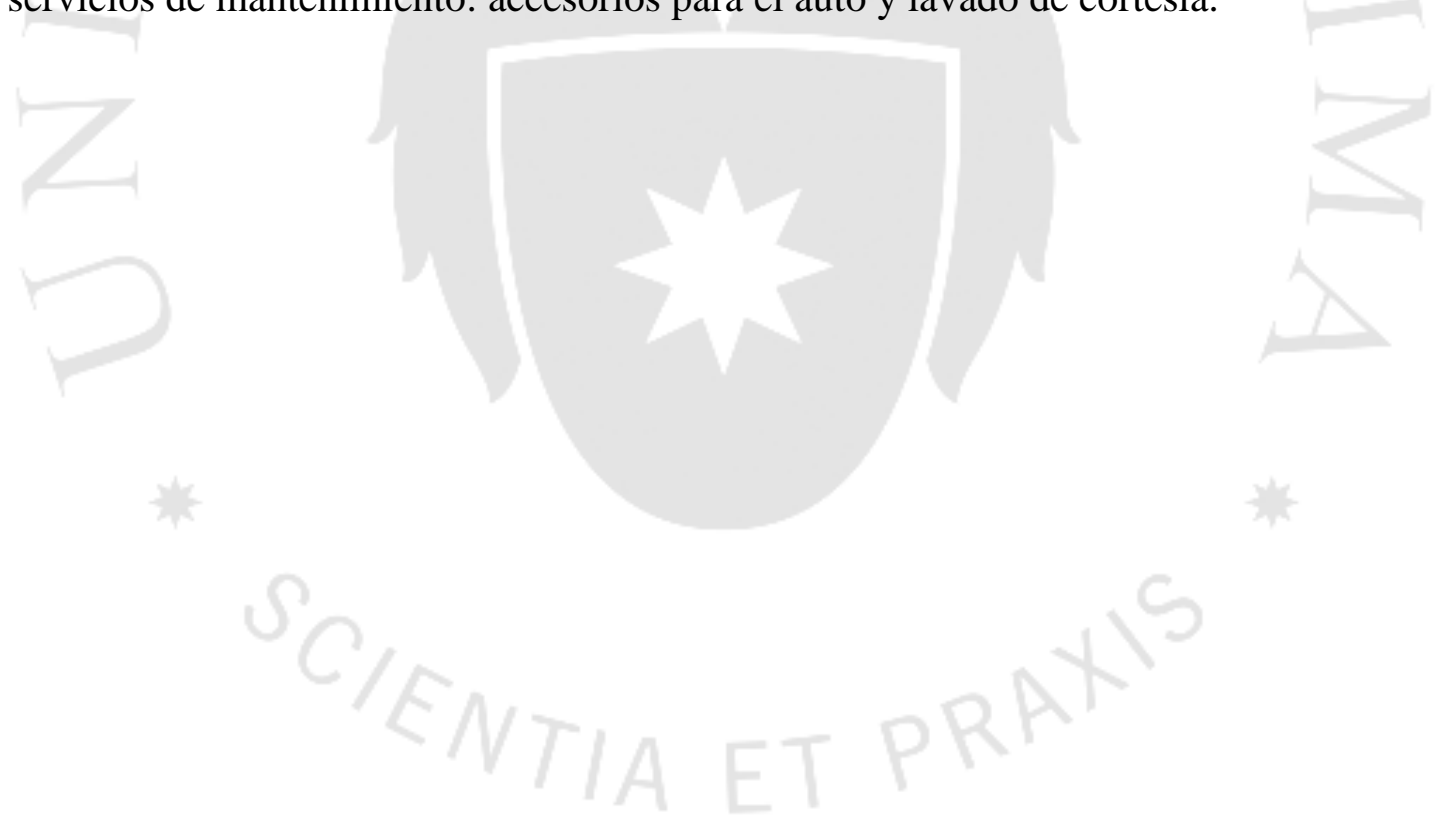


ANEXO 8: ESTUDIO COMPARATIVO COSTOS MINERALES VERSUS ACEITES SINTETICOS

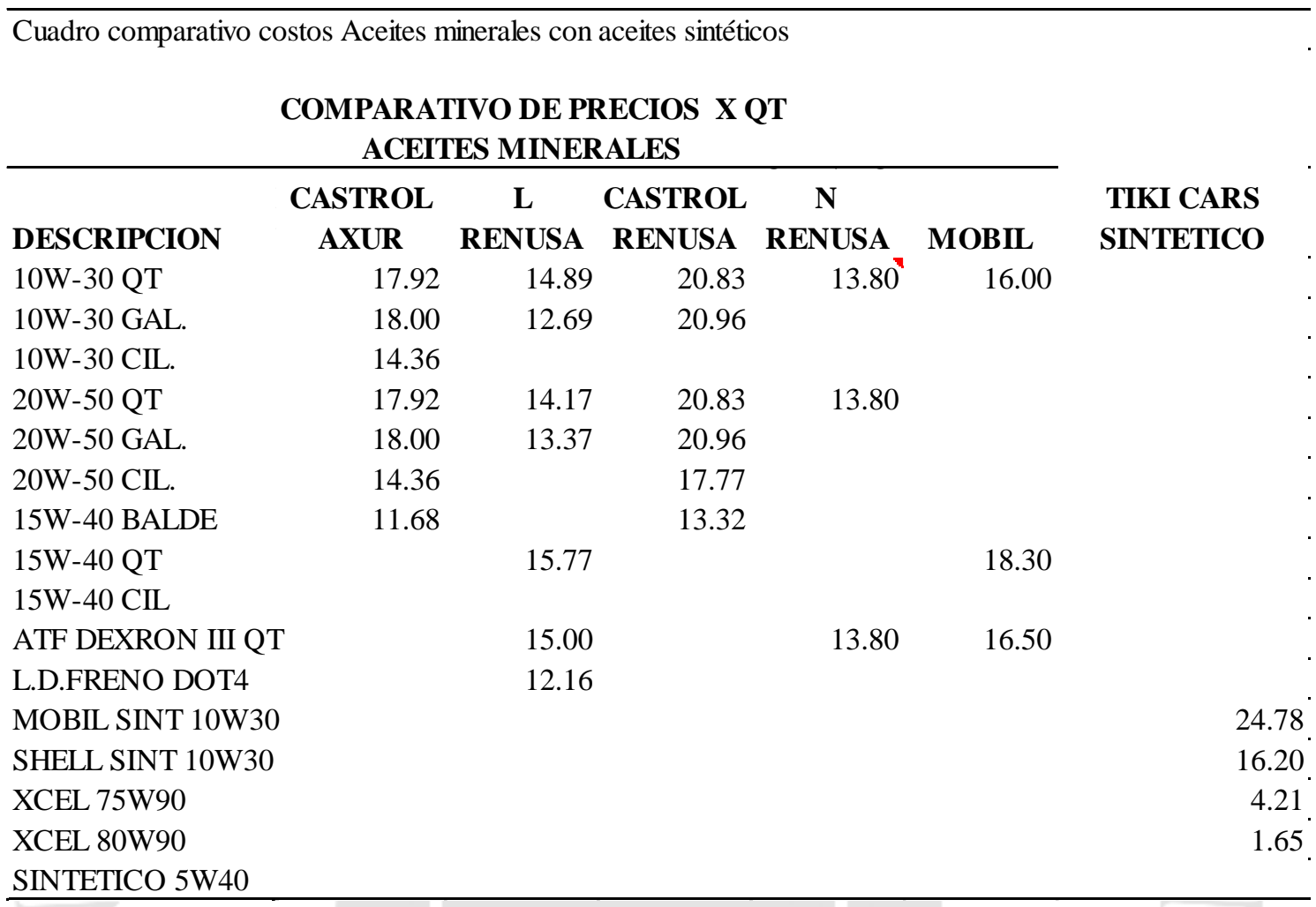




\section{ANEXO 9: MODELO DE ENCUESTA}

Encuesta Taller Automotriz

Esta encuesta es administrada con el fin de recolectar información para contribuir a analizar la viabilidad comercial de un taller automotriz.

1. Edad:

De 18 a 27 años

De 28 a 37 años

De 38 a 47 años

De 48 a 57 años

De 58 a 67 años

Sexo:

Masculino

Femenino

2. Zona distrital donde vive, de acuerdo a tabla en la que se ubica el distrito (zonas de 1

a 10):

Zona 1 (Puente Piedra, Comas, Carabayllo)

Zona 2 (Independencia, Los Olivos, San Martín de Porras)

Zona 3 (San Juan de Lurigancho)

Zona 4 (Cercado, Rímac, Breña, La Victoria)

Zona 5 (Ate, Chaclacayo, Lurigancho, Santa Anita, San Luis, El Agustino)

Zona 6 (Jesús María, Lince, Pueblo Libre, Magdalena, San Miguel)

Zona 7 (Miraflores, San Isidro, San Borja, Surco, La Molina)

Zona 8 (Surquillo, Barranco, Chorrillos, San Juan de Miraflores)

Otro

3. ¿Qué aspectos considera que debe de tener un taller mecánico de calidad? Elegir

TRES ALTERNATIVAS

Buena recepción de clientes, desde la programación de la cita.

Facilidades de transporte cuando se deja el vehículo en mantenimiento

Tecnología y calidad a precio justo

Servicio de mantenimiento preventivo en dos horas

Garantía por las reparaciones

Que los mecánicos sean certificados

4 ¿Qué otra cosa esperaría de un servicio de mantenimiento preventivo en un taller

mecánico? A parte de honestidad en la identificación de las fallas, calidad y garantía del trabajo, rápida entrega del vehículo y presentes de cortesía.

Your answer

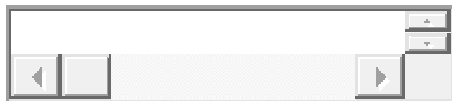

5 ¿Qué servicio adicional le gustaría recibir del servicio mecánico?

Your answer 
6. ¿Qué tiempo estaría dispuesto a esperar para el servicio de planchado y pintura de su vehículo?

De 3 a 5 días

De 7 a 10 días

De 15 a 20 días

Estaría dispuesto a esperar más de 20 días.

7. Le gustaría que el taller de mecánica cuente con... (Puede elegir más de una alternativa).

Sistema de programación de citas en línea

Café y bocaditos

Wifi

Ambiente de espera

Música de fondo

Servicio de recojo del vehículo a domicilio y luego dejarlo donde el cliente disponga Lavados de cortesía para clientes frecuentes

Venta de gran variedad de artículos (multimarca) para el vehículo

Tienda surtida de accesorios para el automóvil.

Televisión por cable.

Todos los servicios en un mismo lugar

8 ¿Cómo le gustaría enterarse de los servicios de un taller automotriz? Puede marcar más de una alternativa.

Recomendaciones

Acceso a un App

Alertas al correo, red social o celular

Periódicos

Revistas

Página web

Facebook y otras redes sociales

Volantes

Banners publicitarios en las calles

9 ¿Conoce la diferencia entre el aceite sintético y el mineral para el cuidado de su automóvil?

Sí

No

10 ¿Le gustaría que el taller de mecánica preste el servicio gratuito de recojo y entrega en el lugar que usted indique para los servicios de mantenimiento?

Sí

No

¿Qué precio está dispuesto a pagar por un servicio de mantenimiento completo para su vehículo? El mantenimiento completo es cambio de aceite, cambio de filtro de aceite, aire y gasolina, revisión de 50 puntos, enllante y balanceo, limpieza y regulación de frenos y lavado completo.

S/. $100-$ S/. 200

S/. $200-S / .300$ 
S/. $300-$ S/. 400

S/. $400-$ S/. 500

S/. $500-S / .600$

¿Qué obsequios le gustaría que le den por sus servicios de mantenimiento en el taller automotriz? 
ANEXO 10: PAGINA WEB, FACEBOOK, Y PUBLICACIÓN EN REVISTAS ESPECIALIZADAS

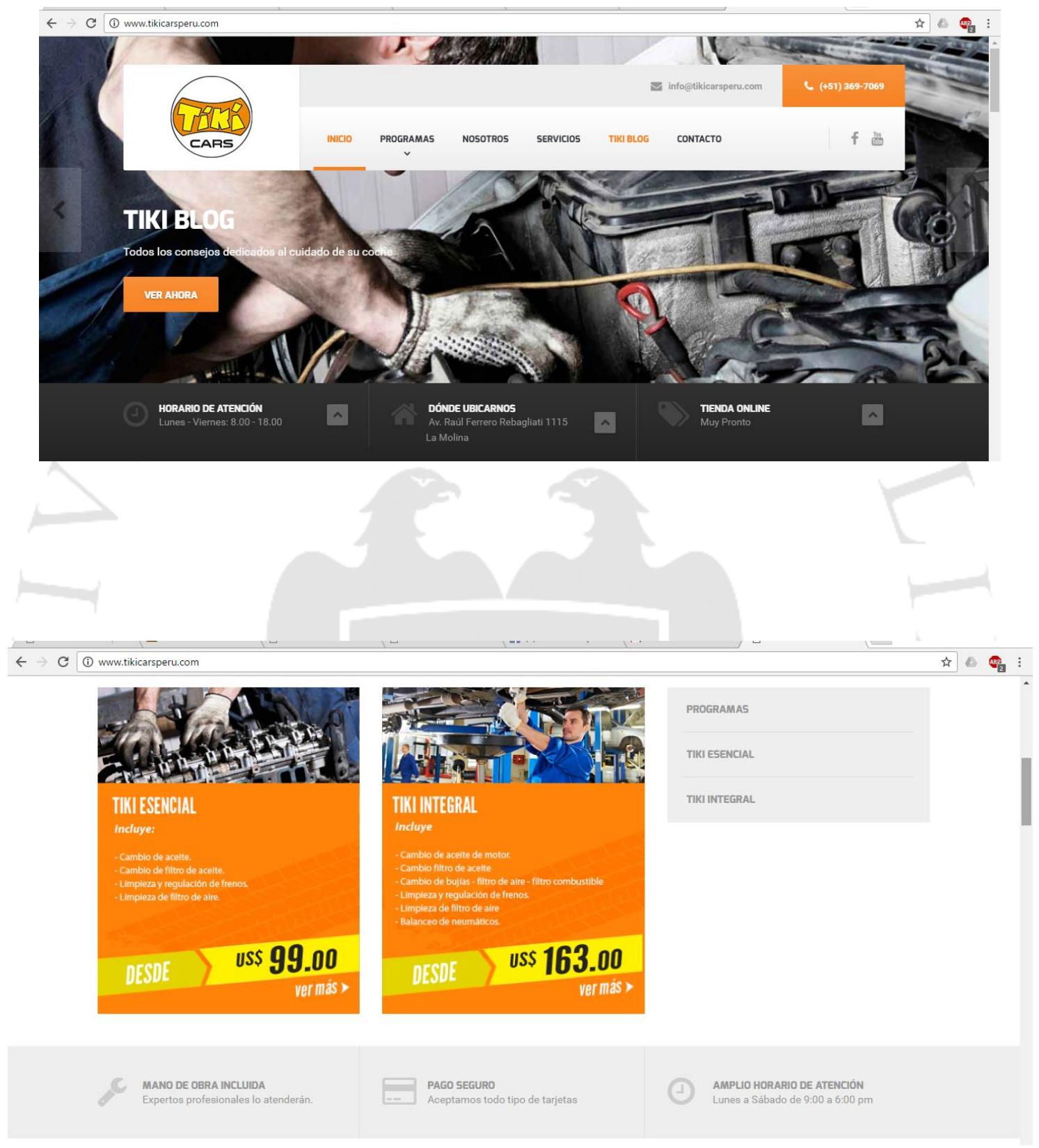




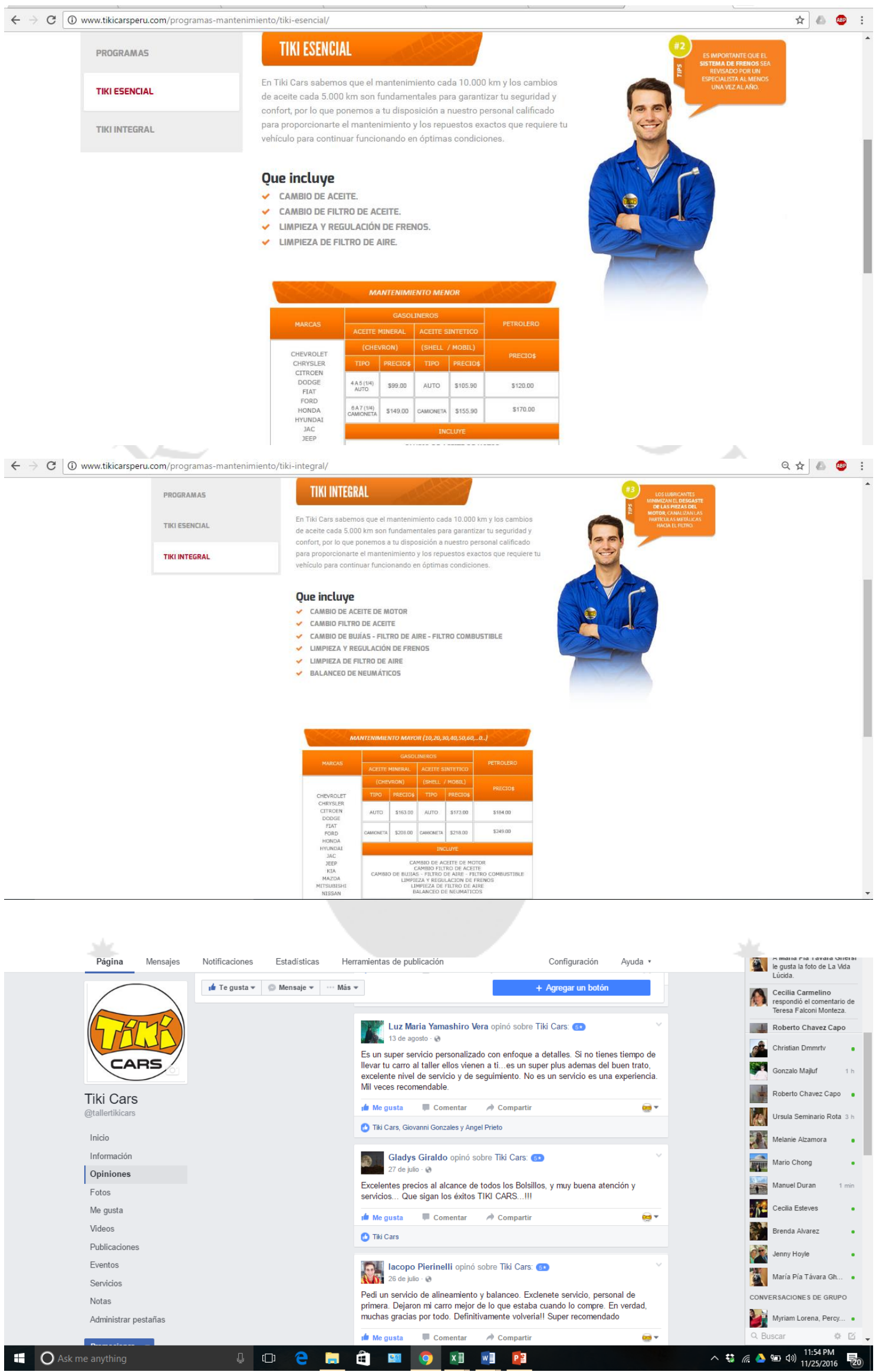



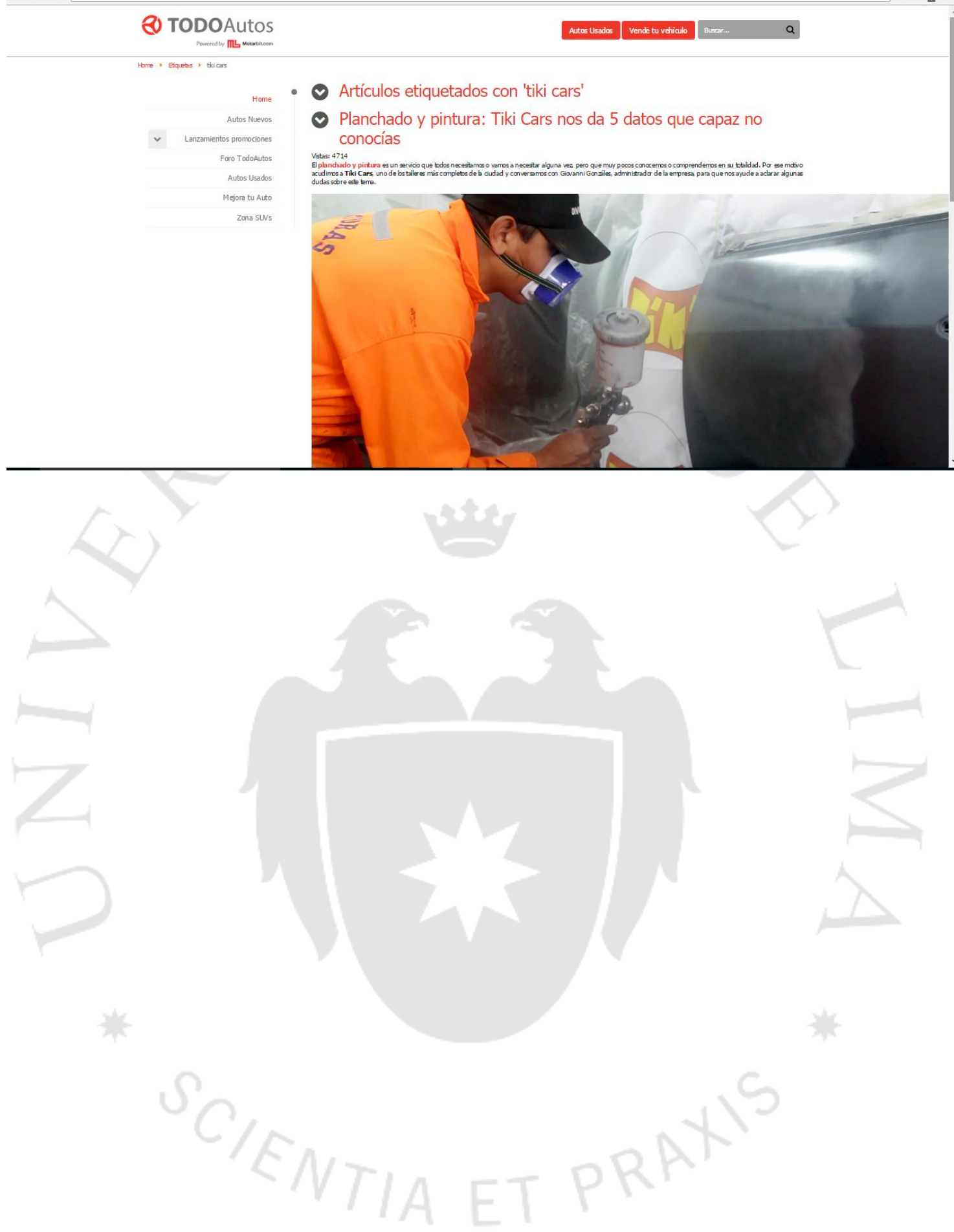
Tabla 5.1

Métricas de Servicio

METRICAS SERVICIOS TALLER TIKI CARS

JULIO AGOSTO SETIEMBRE OCTUBRE NOVIEMBRE

LAVADO

LAVADO SALON

$29 \quad 31$

34

UNDERCOATING

$\begin{array}{ll}7 & 6\end{array}$

10

29

PLANCHADO Y PINTURA

$12-14$

MANTENIMIENTO TIKI MENOR

$12-14$

$37 \quad 21$

MANTENIMIENTO TIKI MAYOR

$30 \quad 30$

MECANICA

BATERIAS

$39 \quad 45$

$15 \quad 11$

LLANTAS

4

4

3

3
23

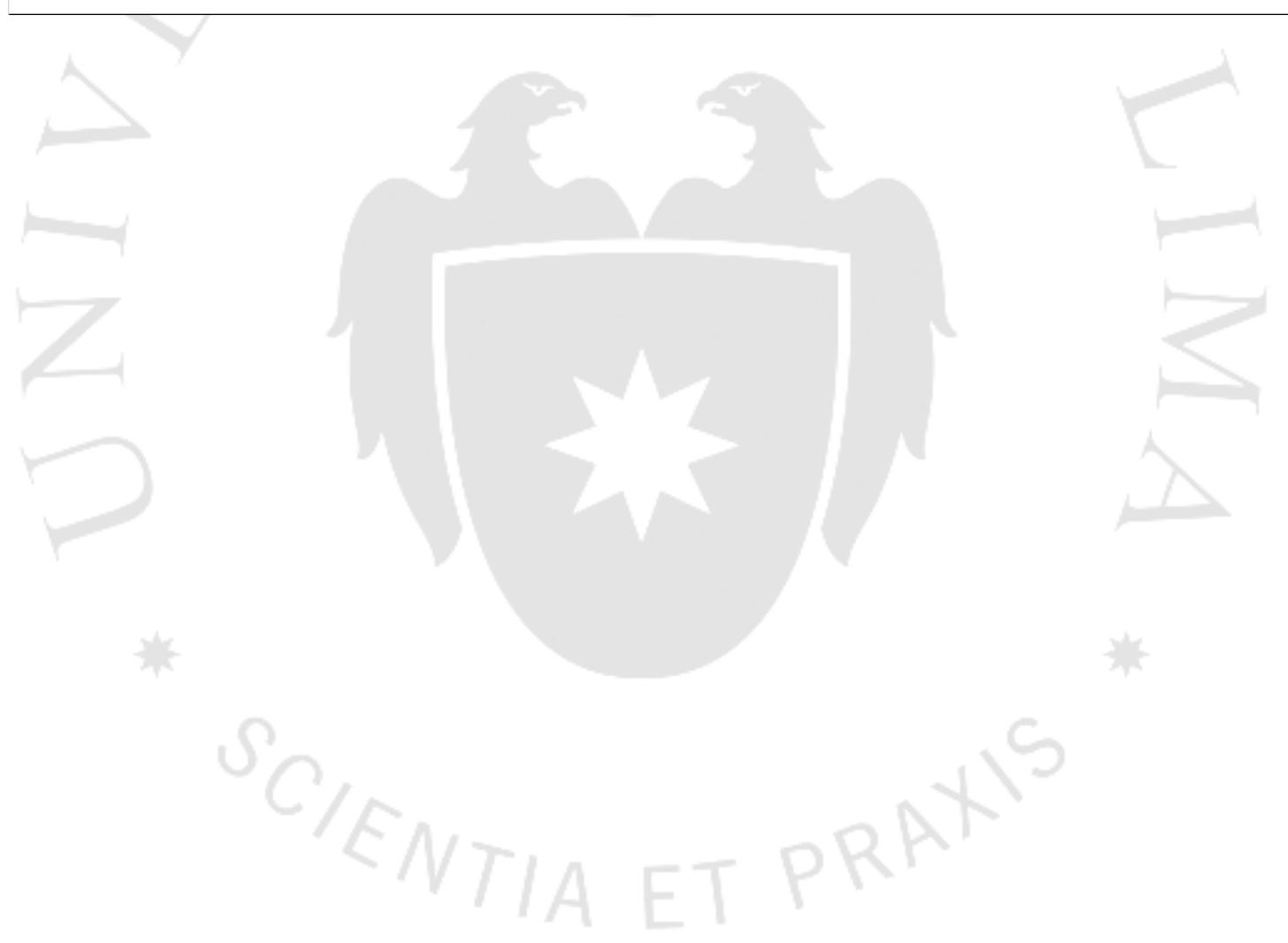


Tabla 6.1

Gastos Personal administrativo

\begin{tabular}{|c|c|c|c|}
\hline $\begin{array}{l}\text { GASTOS PERSONAL ADMINISTRATIVOS } \\
\end{array}$ & CANT & MONTO & ANUAL + FACTOR 36.89\% \\
\hline GERENTE GENERAL & & $3,520.00$ & \\
\hline ADMINISTRADOR & & $3,500.00$ & \\
\hline ASESOR DE SERVICIO & & $1,458.32$ & \\
\hline ASESOR DE SERVICIO & & $1,458.32$ & \\
\hline ASISTENTE ADMINISTRATIVO & & $1,600.00$ & \\
\hline ASISTENTE ADMINISTRATIVO & & $1,800.00$ & \\
\hline TOTAL MENSUAL & & $13,336.64$ & $219,078.32$ \\
\hline
\end{tabular}

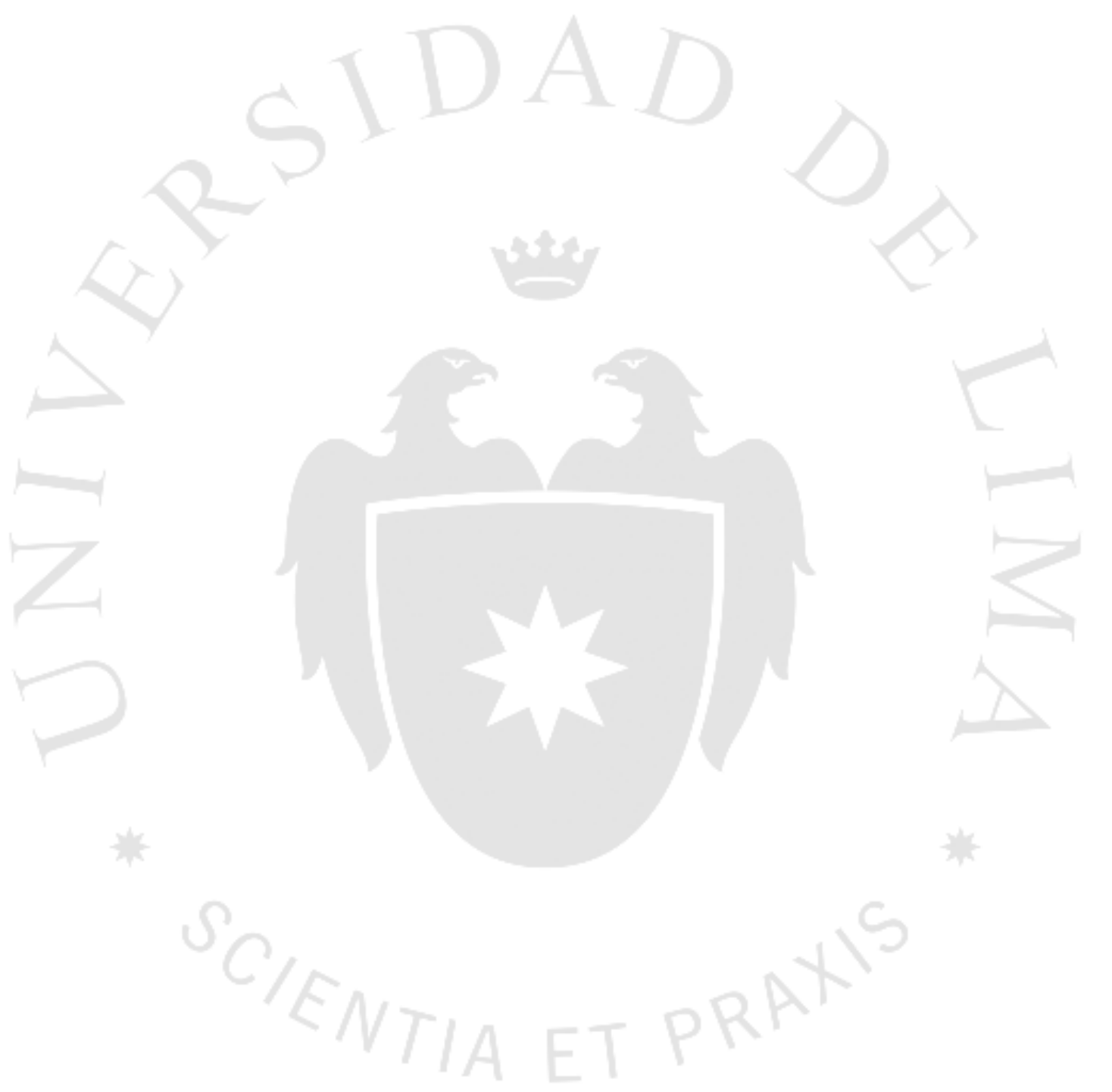


Tabla 6.2

Gastos mano de obra directa

MANO DE OBRA DIRECTA

Personal Mano de obra directa Función

IMPORTE S/. factor 36.89\%\% Annual

BUSTILLOS BALDEON, V. Almacén transt

$1,312.20$

$1,796.27$

$21,555.25$

MUÑOZ SULCA, AGUSTII Mecánico

$1,308.01$

$1,790.53$

$21,486.42$

CERNA MENESES, JOSE F Mecánico

$1,214.16$

$1,662.06$

$19,944.76$

PUSMA NEYRA, EDWIN Mecánico

$1,252.41$

$1,714.42$

20,573.09

Total mano de obra directa

$\mathbf{5 , 0 8 6 . 7 8}$

6,963.29

$\mathbf{8 3 , 5 5 9 . 5 2}$

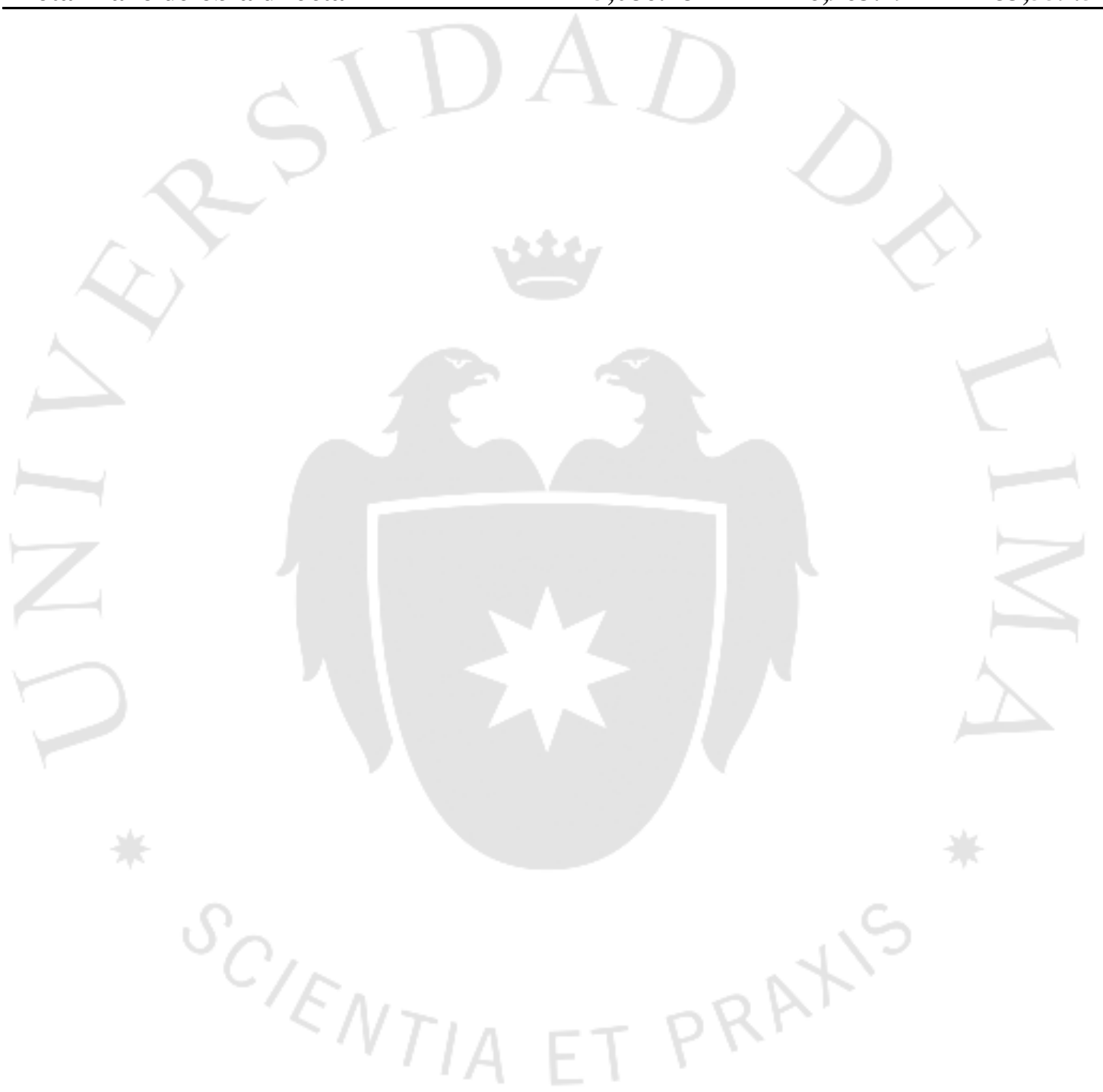


Tabla 7.1

Ventas y proyección de ventas

Datos y Proyecciones de ventas

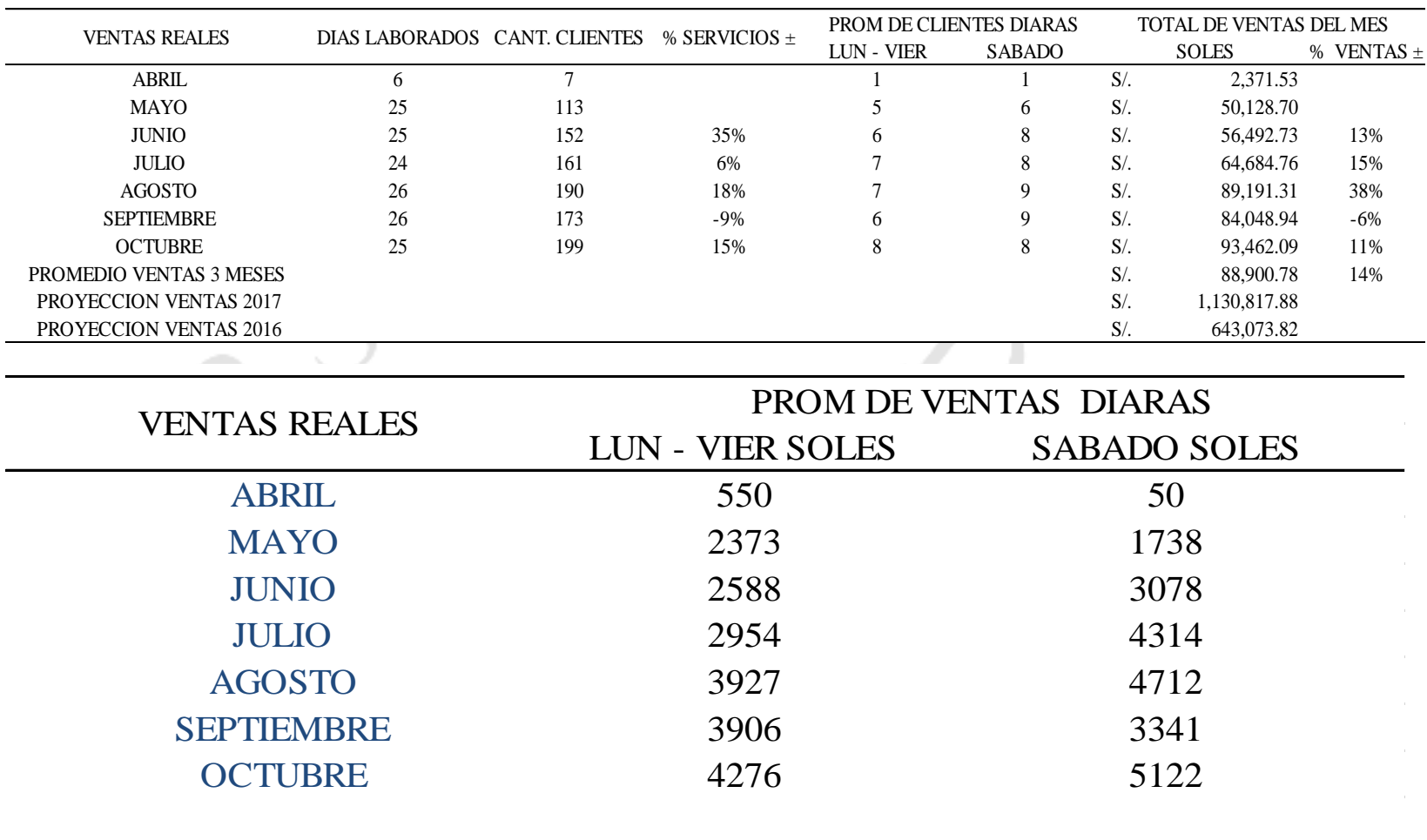


Tabla 7.2

Estructura de costos y margen Mantenimiento Tiki Menor autos

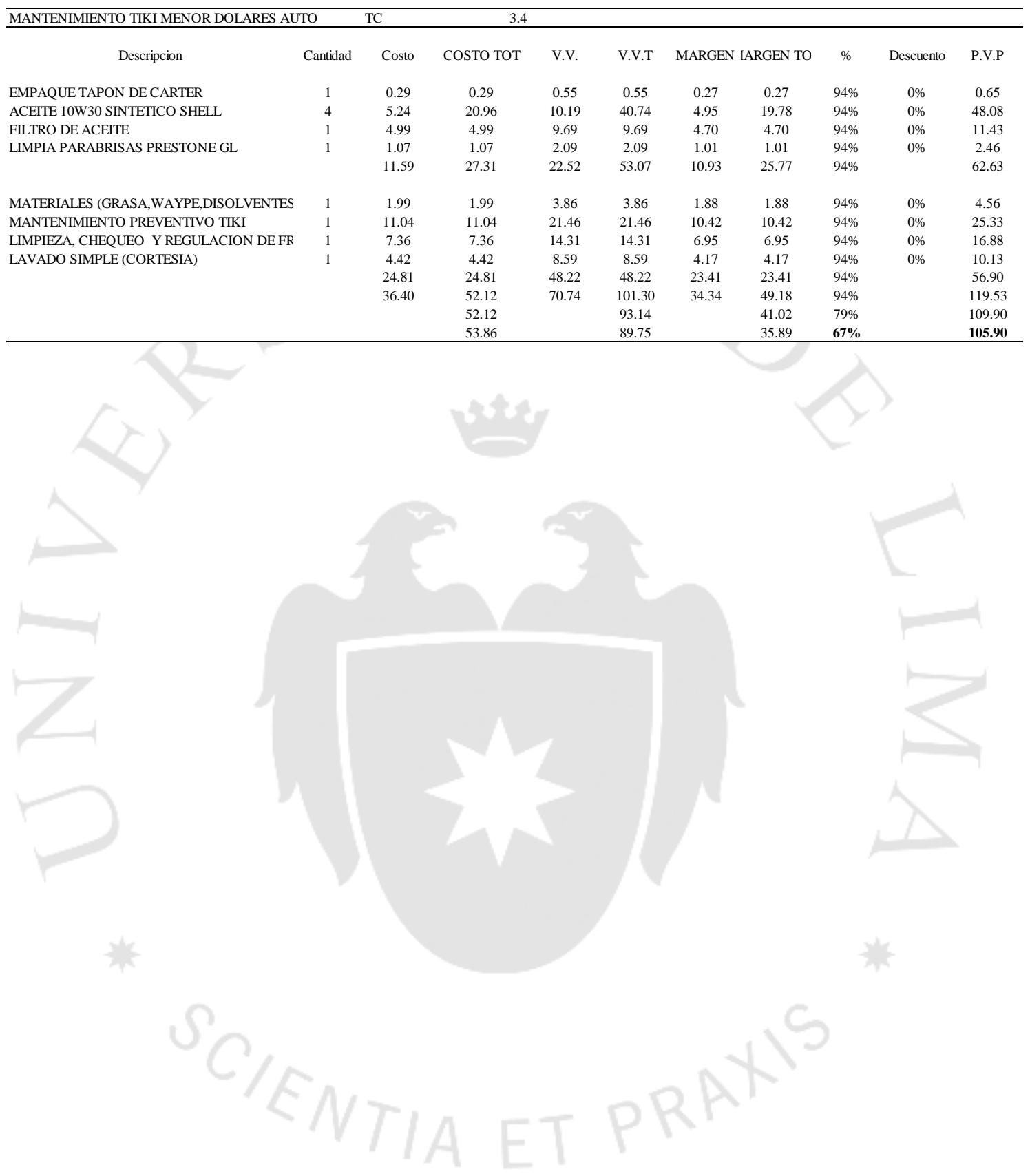




\section{Tabla 7.3}

\section{Margen Mantenimiento Tiki Menor Camionetas}

MANTENIMIENTO TIKI MENOR DOLARES CAMIONETA

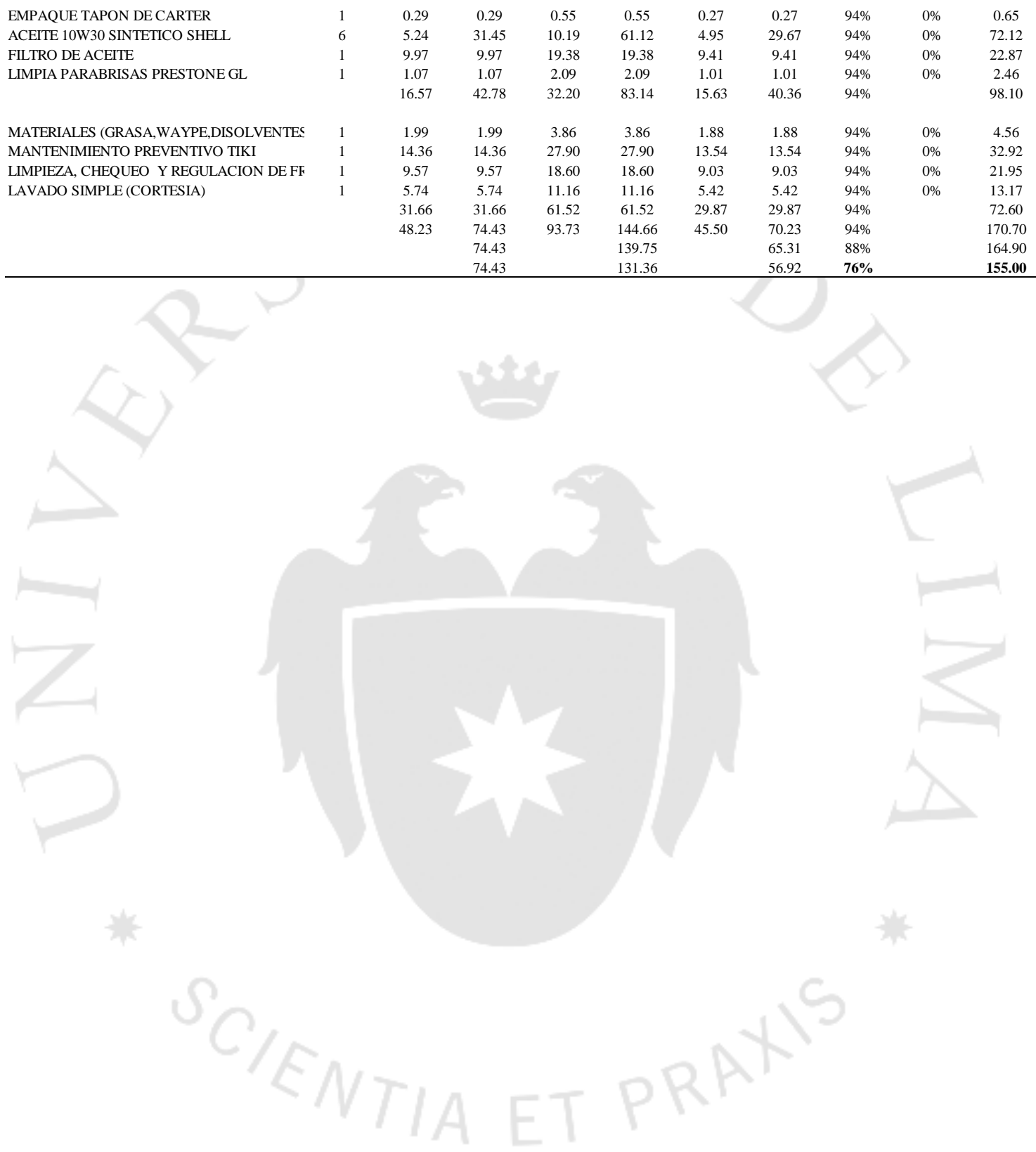


Tabla 7.4

Mantenimiento Tiki Mayor autos

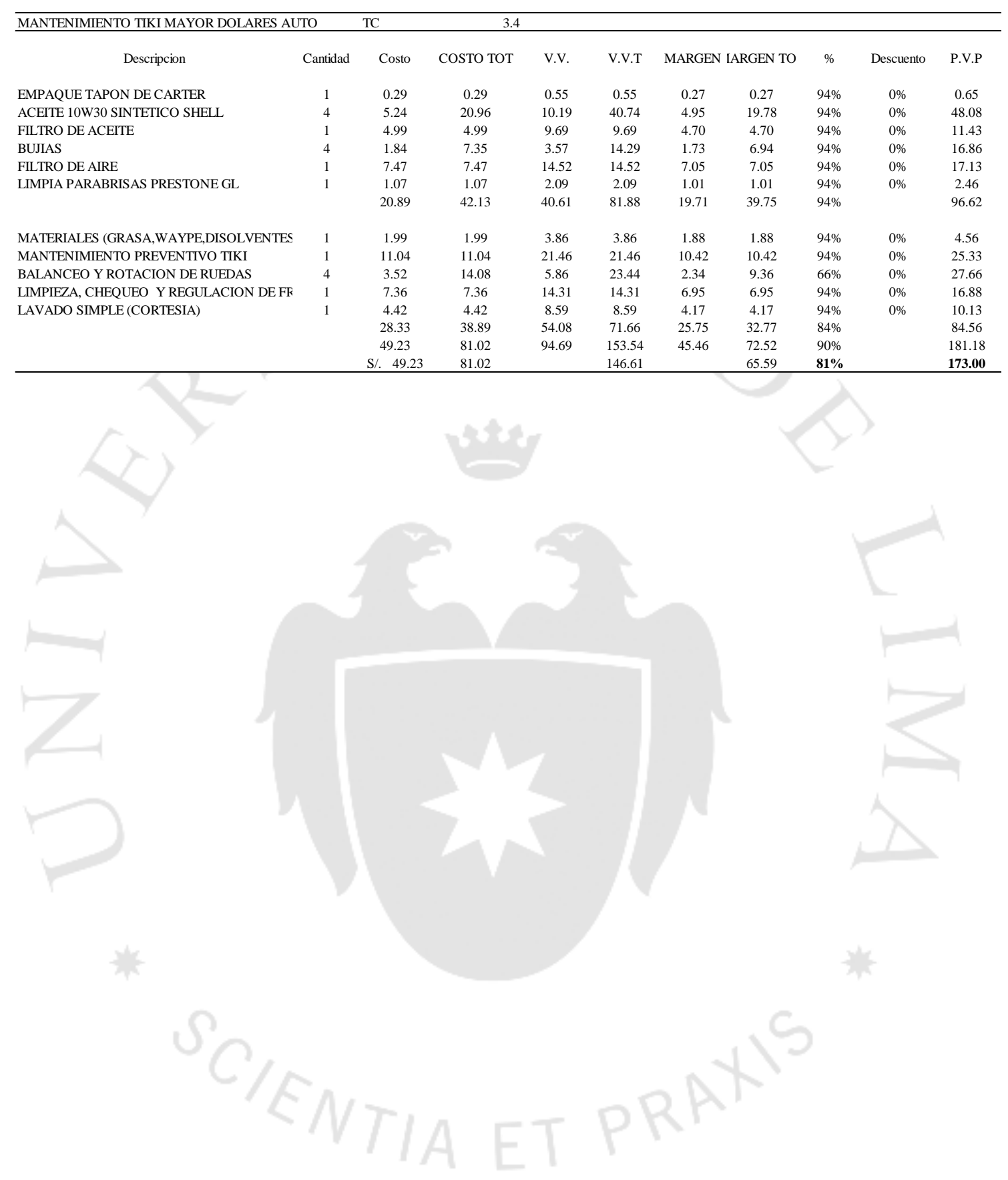




\section{Tabla 7.5}

\section{Mantenimiento Tiki Mayor camionetas}

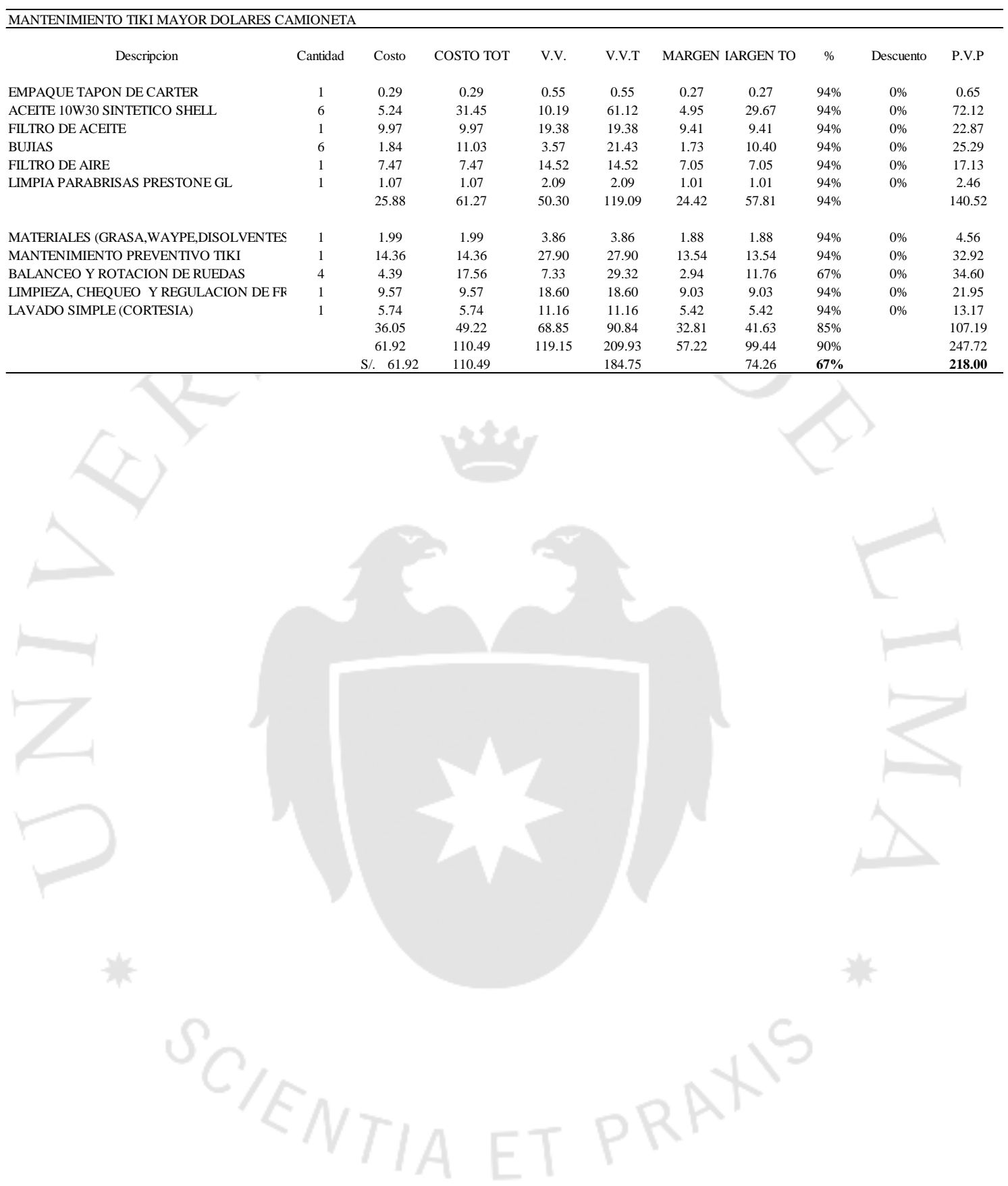


Tabla 7.6

\section{Margen contratistas Lavado}

\begin{tabular}{|c|c|c|c|c|c|c|c|c|c|c|c|c|}
\hline \multirow{3}{*}{$\begin{array}{l}\text { MARGEN CONTRATISTAS (LAVADO) } \\
\text { LAVADOR (01) JORGE CONDORI } \\
\text { AYUDANTE LAVADO (02) }\end{array}$} & \multicolumn{12}{|c|}{$\mathbf{3 1 \%}$} \\
\hline & \multicolumn{6}{|c|}{ COSTO AUTO } & \multicolumn{6}{|c|}{ COSTO CAMIONETA } \\
\hline & AUTO & INSUMOS & SSUB TOT & V.V & MARGEN & $\%$ & 'AMIONE & ETINSUMC & OSSUB TOT & V.V & MARGEN & $\%$ \\
\hline LAVADO,ASPIRADO Y PULVERIZADO DE MOTOR. & 6.52 & 4.28 & 10.80 & 25.44 & 14.63 & $58 \%$ & 6.52 & 5.42 & 11.94 & 33.07 & 21.12 & $64 \%$ \\
\hline LAVADO,ASPIRADO,PULVERIZADO DE MOTOR Y E & 16.43 & 4.81 & 21.24 & 52.99 & 31.75 & $60 \%$ & 21.36 & 5.70 & 27.06 & 68.89 & 41.83 & $61 \%$ \\
\hline LAVADO SALON & 65.71 & 14.48 & 80.18 & 211.96 & 131.78 & $62 \%$ & 85.42 & 20.89 & 106.31 & 275.55 & 169.24 & $61 \%$ \\
\hline TRATAMIENTO DE PINTURA & 65.71 & 8.11 & 73.82 & 211.96 & 138.14 & $65 \%$ & 85.42 & 10.50 & 95.92 & 275.55 & 179.63 & $65 \%$ \\
\hline LAVADO PREMIUN & 98.56 & 22.59 & 121.15 & 317.95 & 196.80 & $62 \%$ & 128.13 & 31.39 & 159.52 & 413.33 & 253.80 & $61 \%$ \\
\hline UNDERCOATING & 131.42 & 15.78 & 147.20 & 423.93 & 276.73 & $65 \%$ & 170.84 & 25.98 & 196.83 & 551.11 & 354.28 & $64 \%$ \\
\hline PRECIOS NO INCLUYEN IGV & & & & & & & & & & & & \\
\hline
\end{tabular}

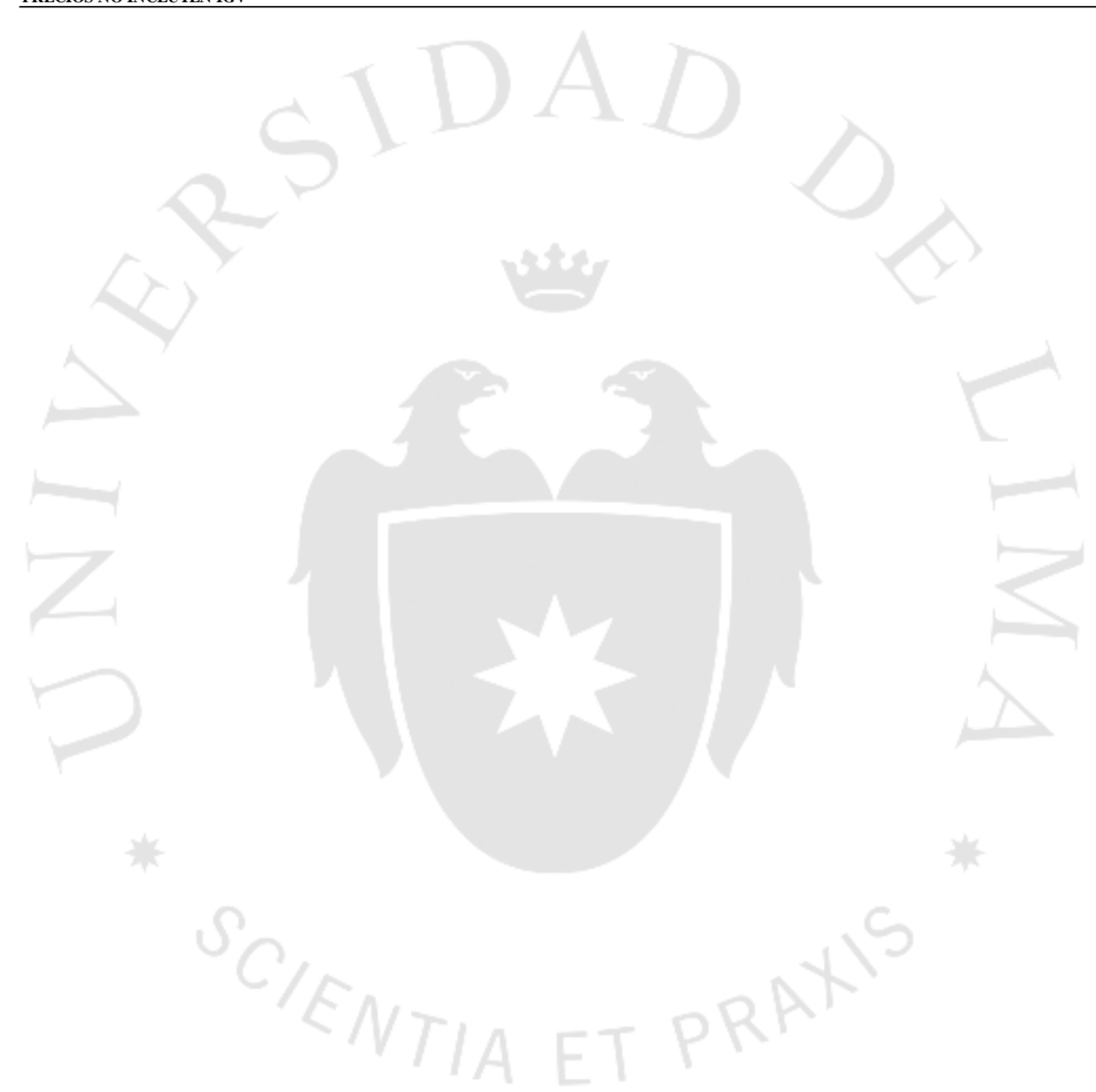




\section{Tabla 7.7}

\section{Margen servicio planchado y pintura}

\begin{tabular}{|c|c|c|c|c|c|c|c|c|c|c|c|c|c|}
\hline \multicolumn{14}{|l|}{ MARGEN CONTRATISTAS (PLANCHADO) } \\
\hline PLANCHADOR (01) ABRAHAM & \multicolumn{7}{|c|}{ COSTO AUTO } & \multicolumn{6}{|c|}{ COSTO CAMIONETA } \\
\hline AYUDANTE PLANCHADO (01) & & AUTO & INSUMOSSU & JB TOT & V.V & MARGEN & $\%$ & 'AMIONE & ETINSUMC & OSSUB T & ГOT & V.V & MARGEN \% \\
\hline PLANCHADO H/H PARTICULAR SOLES & & 12.69 & 0.75 & 13.44 & 42.29 & 28.85 & $68 \%$ & 12.69 & 0.75 & 13.44 & & 42.29 & $28.8568 \%$ \\
\hline PLANCHADO H/H MAPFRE DOLARES & & 3.60 & 1.75 & 5.35 & 12.00 & 6.65 & $55 \%$ & 3.60 & 1.75 & 5.35 & & 12.00 & 6.65 \\
\hline PLANCHADO H/H POSITIVA DOLARES & & 4.17 & 2.75 & 6.92 & 13.90 & 6.98 & $50 \%$ & 4.17 & 2.75 & 6.92 & & 13.90 & 6.98 \\
\hline \multicolumn{14}{|l|}{ PRECIOS NO INCLUYEN IGV } \\
\hline \multicolumn{14}{|l|}{ MARGEN CONTRATISTAS (PINTURA) } \\
\hline PINTOR (01) BRENNER TELLO & \multicolumn{5}{|c|}{ COSTO AUTO } & \multicolumn{7}{|c|}{ COSTO CAMIONETA } & \\
\hline AYUDANTE PINTURA (01) & AUTO & INSUN & MOSSUB TOT & V.V & MARGE : & $\%$ :AMI & ONET & TINSUMOS & SSUB TOT & v.v & MAR & RGEN \% & \\
\hline PAÑO PINTURA PARTICULAR SOLES & 72.94 & 0.00 & 72.94 & 208.39 & 135.45 & $65 \%$ & 2.94 & 0.00 & 72.94 & 208.39 & 135 & $4565 \%$ & \\
\hline PAÑO PINTURA MAPFRE DOLARES & 19.25 & 0.00 & 19.25 & 55.00 & 35.75 & $65 \%$ & 9.25 & 0.00 & 19.25 & 55.00 & 35 & $75 \quad 65 \%$ & \\
\hline PAÑO PINTURA POSITIVA DOLARES & 21.00 & 0.00 & 21.00 & 60.00 & 39.00 & $65 \%$ & 1.00 & 0.00 & 21.00 & 60.00 & 39 & $00 \quad 65 \%$ & \\
\hline
\end{tabular}

PRECIOS NO INCLUYEN IGV 


\section{Tabla 7.8}

Crecimiento porcentual de márgenes, costos y porcentaje de costos sobre ventas

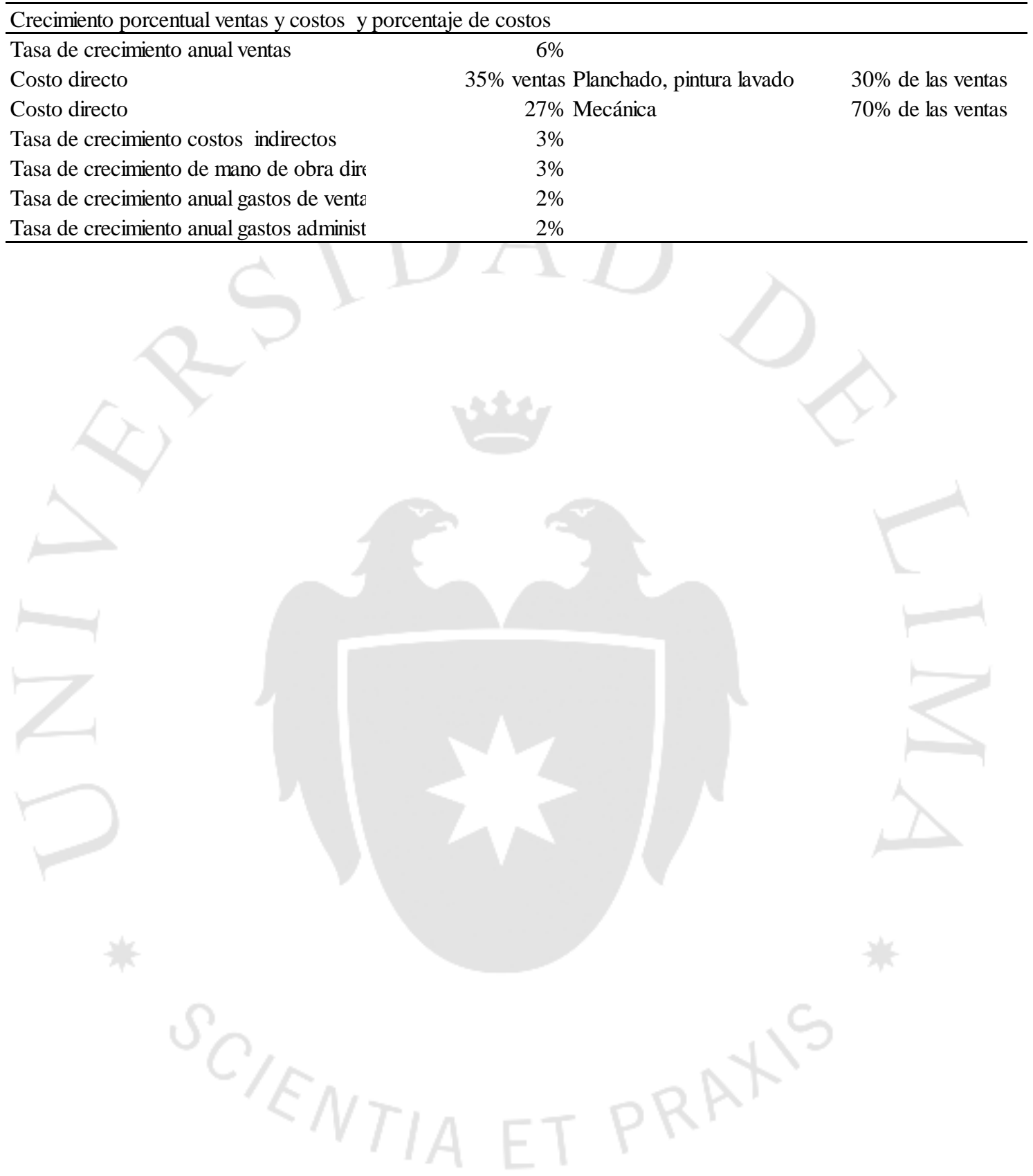


Tabla 7.9

Depreciación Activos Fijos

\begin{tabular}{|c|c|c|c|c|c|c|c|c|c|c|c|c|c|c|c|c|}
\hline DEPRECIACION ACTIVOS FIJOS & & & & & $\begin{array}{c}\text { Vida útil } \\
\text { (período de } \\
\text { depreciación } \\
\text { según } \\
\text { SUNAT) }\end{array}$ & $\begin{array}{l}\text { Depreciación } \\
\text { anual (lineal) }\end{array}$ & & 2017 & & 2018 & & 2019 & & 2020 & 2021 & $\begin{array}{l}\text { Valor contable } \\
\text { residual }\end{array}$ \\
\hline MAQUINARIAS Y EQUIPOS & & & $13,497.47$ & $13,497.47$ & 10 & S/. $1,349.75$ & $\mathrm{~S} /$. & $1,349.75$ & $\mathrm{~S} /$. & $1,349.75$ & $\mathrm{~S} /$. & $1,349.75$ & $\mathrm{~S} /$. & $1,349.75$ & S/. $1,349.75$ & S/. $\quad 6,748.74$ \\
\hline MUEBLES & & 115.00 & $3,872.96$ & $3,987.96$ & 10 & S/. $\quad 398.80$ & $\mathrm{~S} /$. & 398.80 & $\mathrm{~S} /$. & 398.80 & $\mathrm{~S} /$. & 398.80 & $\mathrm{~S} /$. & 398.80 & S/. $\quad 398.80$ & S/. $1,993.98$ \\
\hline EQUIPOS DE CÓMPUTO & & 753.30 & $5,489.08$ & $6,242.38$ & 5 & S/. $1,248.48$ & $\mathrm{~S} /$. & $1,248.48$ & $\mathrm{~S} /$. & $1,248.48$ & $\mathrm{~S} /$. & $1,248.48$ & $\mathrm{~S} /$. & $1,248.48$ & S/. $1,248.48$ & $\mathrm{~S} /$. \\
\hline OTROS EQUIPOS DIVERSOS & & $10,593.88$ & $2,686.37$ & $13,280.25$ & 10 & S/. $1,328.03$ & $\mathrm{~S} /$. & $1,328.03$ & $\mathrm{~S} /$. & $1,328.03$ & $\mathrm{~S} /$. & $1,328.03$ & $\mathrm{~S} /$. & $1,328.03$ & S/. $1,328.03$ & S/. $\quad 6,640.13$ \\
\hline \multirow[t]{2}{*}{ HERRAMIENTAS } & & & $4,160.57$ & $4,160.57$ & 10 & S/. $\quad 416.06$ & $\mathrm{~S} /$. & 416.06 & $\mathrm{~S} /$. & 416.06 & $\mathrm{~S} /$. & 416.06 & $\mathrm{~S} /$. & 416.06 & S/. $\quad 416.06$ & S/. $\quad 2,080.29$ \\
\hline & TOTAL ACTIVOS FIJI & $11,462.18$ & $29,706.45$ & $41,168.63$ & & & $\mathrm{~S} /$. & $4,741.10$ & $\mathrm{~S} /$. & $4,741.10$ & $\mathrm{~S} /$. & $4,741.10$ & $\mathrm{~S} /$. & $4,741.10$ & S/. $4,741.10$ & S/. 20,584.32 \\
\hline
\end{tabular}


Tabla 7.10

\section{Amortización intangibles}

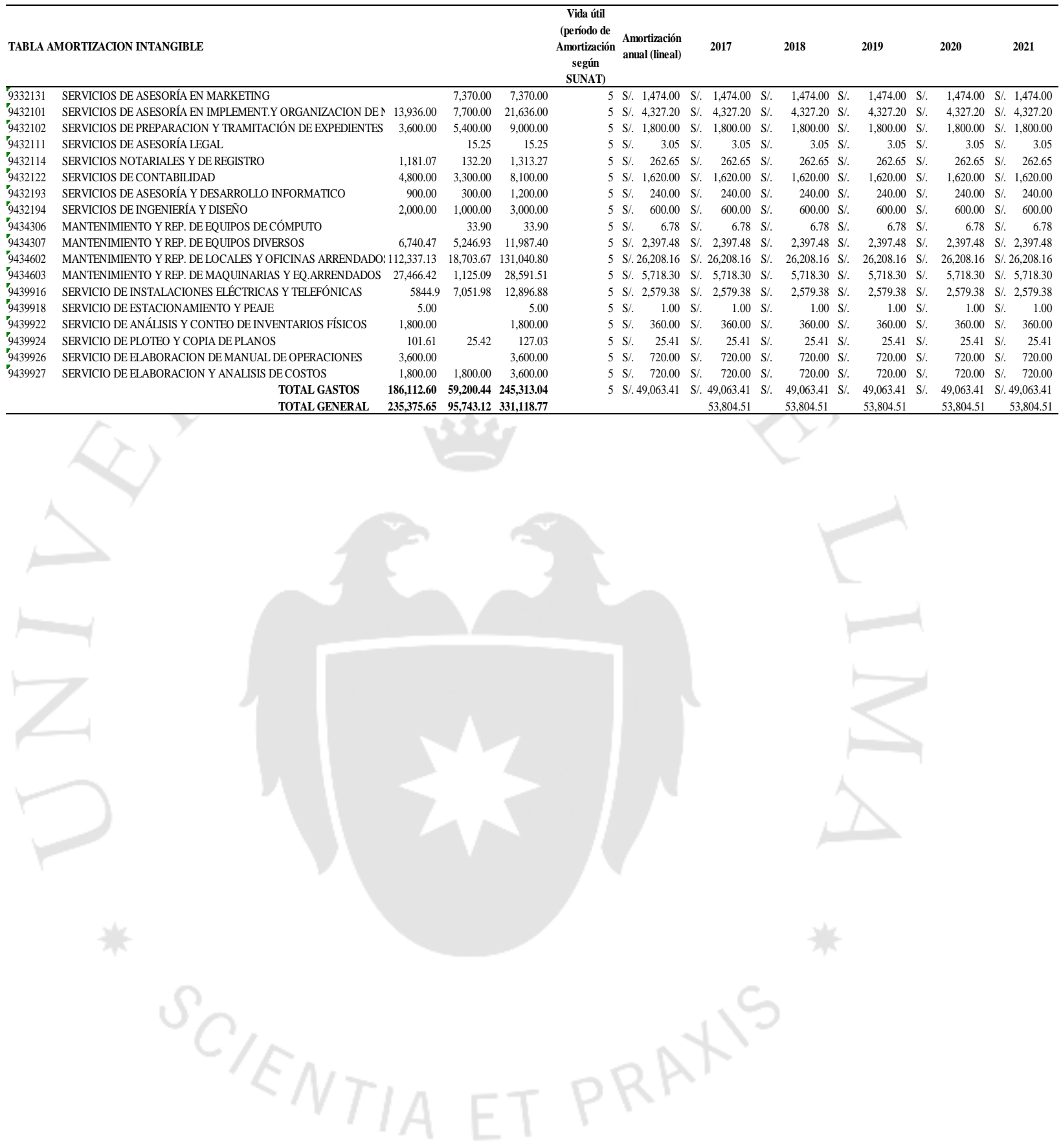


Tabla 7.11

Capital de Trabajo

\begin{tabular}{|c|c|c|c|c|c|c|c|c|c|c|c|c|}
\hline \multirow{2}{*}{$\begin{array}{l}\text { Capital de trabajo } \\
\text { Cuenta por cobrar a } 30 \text { días útiles* }\end{array}$} & \multicolumn{2}{|c|}{ Año 2016} & \multicolumn{2}{|c|}{ Año 2017} & \multicolumn{2}{|c|}{ Año 2018} & \multicolumn{2}{|c|}{ Año 2019} & \multicolumn{2}{|c|}{ Año 2020} & \multicolumn{2}{|c|}{ Año 2021} \\
\hline & S/. & $4,019.21$ & $\mathrm{~S} /$. & $21,202.84$ & $\mathrm{~S} /$. & $29,966.67$ & $\mathrm{~S} /$. & $47,647.01$ & S/. & $50,505.83$ & S/. & $53,536.18$ \\
\hline Cuentas por pagar a 15 días $* *$ & S/. & $6,754.51$ & $\mathrm{~S} /$. & $11,149.78$ & S/. & $11,686.32$ & S/. & $12,251.30$ & $\mathrm{~S} /$. & $12,846.33$ & S/. & $13,473.10$ \\
\hline Inventario de aceites & $\mathrm{S} /$. & $37,800.00$ & $\mathrm{~S} /$. & $37,800.00$ & $\mathrm{~S} /$. & $39,690.00$ & $\mathrm{~S} /$. & $41,674.50$ & $\mathrm{~S} /$. & $43,758.23$ & S/. & $45,946.14$ \\
\hline \multicolumn{13}{|l|}{ Días de inventario de producto } \\
\hline Capital de trabajo & S/. & $35,064.70$ & $\mathrm{~S} /$. & 47,853.05 & S/. & $57,970.36$ & $\mathrm{~S} /$. & $77,070.21$ & S/. & $81,417.72$ & S/. & $86,009.21$ \\
\hline Capital de trabajo (\% de las ventas) & & $5.5 \%$ & & $4.2 \%$ & & $4.8 \%$ & & $6.1 \%$ & & $6.0 \%$ & & $6.0 \%$ \\
\hline Capital de trabajo incremental & S/. & $35,064.70$ & S/. & $12,788.35$ & S/. & $10,117.30$ & S/. & $19,099.85$ & S/. & $4,347.51$ & S/. & $4,591.49$ \\
\hline
\end{tabular}

$\begin{array}{llll}\text { Capital de trabajo incremental } & \text { S/ } & 35,064.70 & \text { S/ }\end{array}$

$\begin{array}{llllllll}2,788.35 & \text { S/. } & 10,117.30 & \text { S/. } & 19,099.85 & \text { S/. } & 4,347.51 & \text { S/ }\end{array}$

$4,591.49$

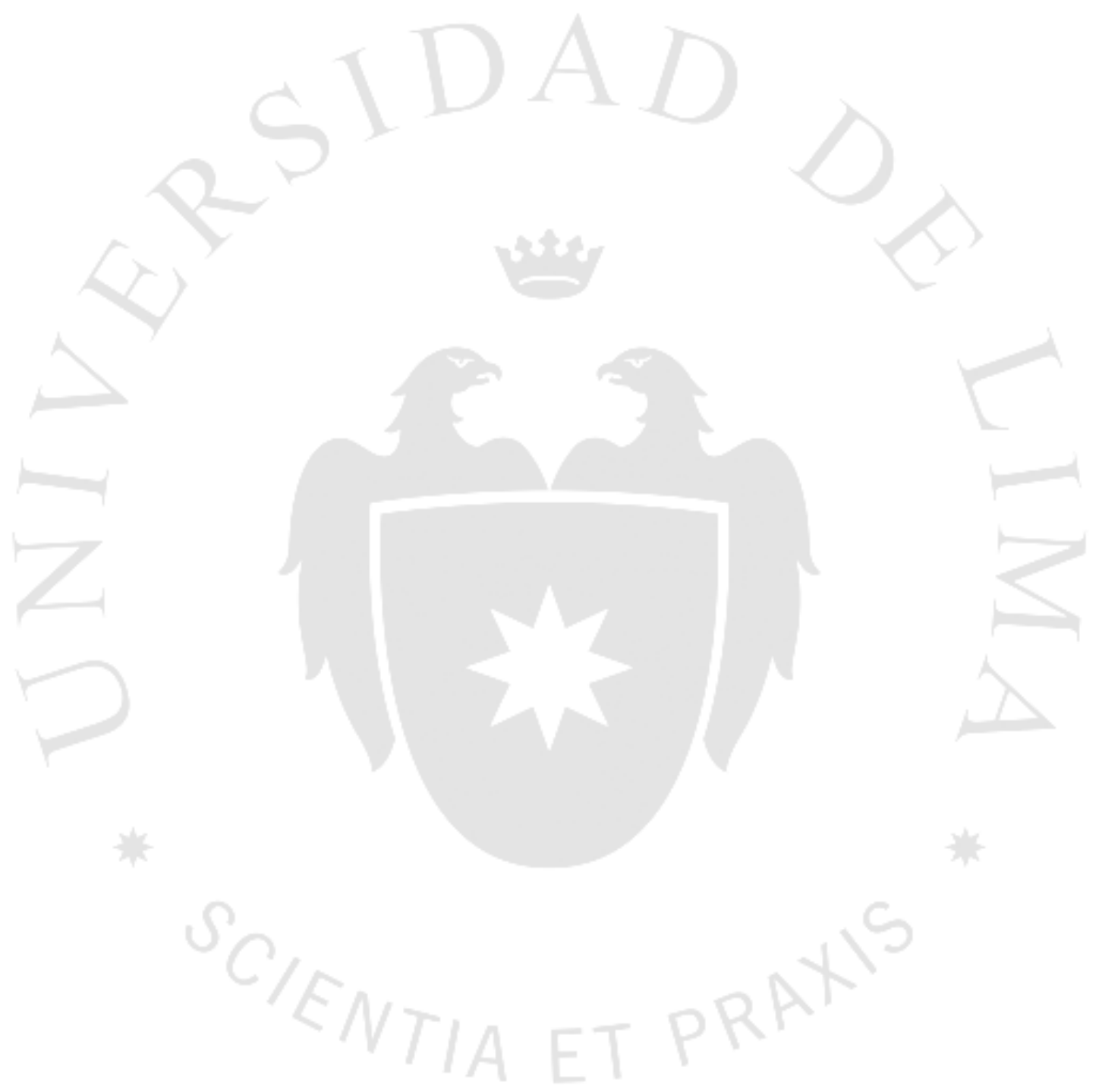


Tabla 7.12

Balance General al 30 de setiembre 2016

\section{BALANCE GENERAL CROWN INVESTMENTS}

BALANCE GENERAL AL 30 DE SETIEMBRE DE 2016

(EXPRESADO EN NUEVOS SOLES)

\section{ACTIVO}

\section{ACTIVO CORRIENTE}

EFECTIVO Y EQUIVALENTES DE EFECTIVO CUENTAS POR COBRAR COMERCIALES CUENTAS POR COBRAR DIVERSAS MATERIAS AUXILIARES, SUMINISTROS Y REPUES SERVICIOS Y OTROS CONTRATADOS POR ADELA CREDITO FISCAL IGV

CREDITO IMPUESTO A LA RENTA

TOTAL ACTIVO CORRIENTE

ACTIVO NO CORRIENTE

INTANGIBLES

INVERSIONES MOBILIARIAS

INMUEBLES, MAQUINARIA Y EQUIPO

(-) DEPRECIACIÓN ACUMULADA

TOTAL ACTIVO NO CORRIENTE ACTIVO TOTAL
PASIVO

\section{PASIVO CORRIENTE}

$41,458.31$ $10,221.20$

$2,745.76$

$28,086.45$

$10,689.24$

$8,009.74$

$3,900.00$

$\mathbf{1 0 5 , 1 1 0 . 7 0}$

$30,551.78$

$30,551.78$
$3,403.56$

$72,606.72$

$(3,101.73)$

$103,460.33$ 208,571.03
$19.88 \%$ TRIBUTOS POR PAGAR

4.90\% CUENTAS POR PAGAR COMERCIALES

$1.32 \%$ CUENTAS POR PAGAR DIVERSAS

13.47\% TOTAL PASIVO CORRIENTE

5.12\% TOTAL PASIVO NO CORRIENTE

3.84\% CUENTAS POR PAGAR A LOS ACCIONISTAS

$1.87 \%$ TOTAL PASIVO

\section{PATRIMONIO}

$14.65 \%$

$1.63 \%$ CAPITAL SOCIAL

$34.81 \%$ PERDIDAS ACUMULADAS

-1.49\% RESULTADO DEL PERIODO TOTAL PATRIMONIO TOTAL PASIVO Y PATRIMONIO
$3,997.90$

$13,800.36$

$35,412.00$

$53,210.26$

$268,168.23$

$268,168.23$

321,378.49
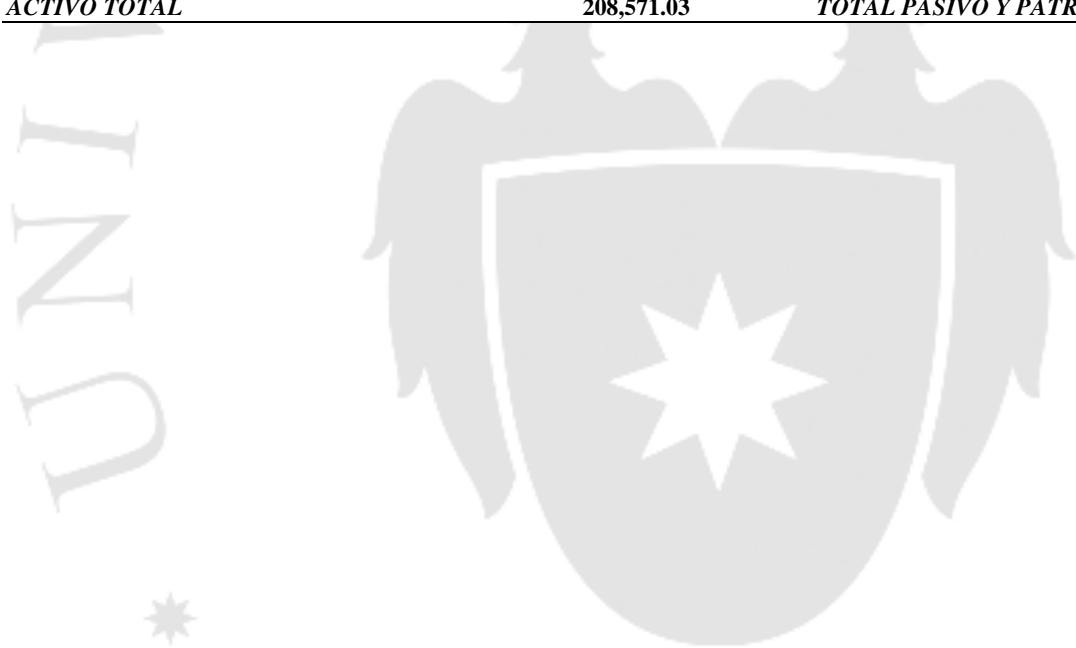

$47,205.00 \quad 22.63 \%$ $-188,959.10 \quad-90.60 \%$

$28,946.64 \quad 13.88 \%$
$1.92 \%$

$6.62 \%$ $16.98 \%$ $25.51 \%$ $128.57 \%$ $128.57 \%$ 


\section{Tabla 7.13}

\section{Estados de Resultados}

\begin{tabular}{|c|c|c|c|c|c|c|c|c|c|c|c|c|}
\hline \multicolumn{13}{|l|}{ ESTADO DE RESULTADOS } \\
\hline Año & & 2016 & & 017 & & 2018 & 2019 & & 2020 & & 2021 & \\
\hline Ventas netas & S/. & $643,073.82$ & $\mathrm{~S} /$. & $1,130,817.88$ & $\mathrm{~S} /$. & $1,198,666.95$ & S/. $1,270,586.97$ & $\mathrm{~S} /$. & $1,346,822.19$ & $\mathrm{~S} /$. & $1,427,631.52$ & \\
\hline Costo material directo & S/. & $189,063.70$ & $\mathrm{~S} /$ & $332,460.46$ & $\mathrm{~S} /$ & $352,408.08$ & S/. $\quad 373,552.57$ & $\mathrm{~S} /$ & $395,965.72$ & $\mathrm{~S} /$ & $419,723.67$ & \\
\hline Costo de mano de obra directa & S/. & $55,706.35$ & $\mathrm{~S} /$. & $83,559.52$ & S/. & $86,066.30$ & S/. $\quad 88,648.29$ & $\mathrm{~S} /$. & $91,307.74$ & $\mathrm{~S} /$. & $94,046.97$ & \\
\hline Costo indirecto & S/. & $116,767.33$ & $\mathrm{~S} /$. & $175,151.00$ & S/. & $180,405.53$ & S/. $\quad 185,817.70$ & $\mathrm{~S} /$ & $191,392.23$ & $\mathrm{~S} /$ & $197,133.99$ & \\
\hline Costo total & S/. & $361,537.38$ & $\mathrm{~S} /$. & $591,170.97$ & $\mathrm{~S} /$ & $618,879.92$ & S/. $\quad 648,018.56$ & $\mathrm{~S} /$ & $678,665.69$ & $\mathrm{~S} /$ & $710,904.63$ & \\
\hline Costo total (\% de las ventas) & & $56 \%$ & & $52 \%$ & & $52 \%$ & $51 \%$ & & $50 \%$ & & $50 \%$ & $51 \%$ \\
\hline Utilidad Bruta & S/. & $281,536.44$ & $\mathrm{~S} /$. & $539,646.91$ & S/. & $579,787.04$ & S/. $\quad 622,568.41$ & $\mathrm{~S} /$. & $668,156.50$ & $\mathrm{~S} /$. & $716,726.89$ & \\
\hline Utilidad bruta (\% de las ventas) & & $44 \%$ & & $48 \%$ & & $48 \%$ & $49 \%$ & & $50 \%$ & & $50 \%$ & $49 \%$ \\
\hline Gastos administrativos & & $161,426.08$ & $\mathrm{~S} /$. & $242,139.12$ & $\mathrm{~S} /$. & $246,981.90$ & S/. $\quad 251,921.54$ & $\mathrm{~S} /$. & $256,959.97$ & $\mathrm{~S} /$. & $262,099.17$ & \\
\hline Gastos de venta & & $18,385.36$ & $\mathrm{~S} /$. & $27,578.04$ & $\mathrm{~S} /$ & $28,129.60$ & S/ $\quad 28,692.19$ & $\mathrm{~S} /$ & $29,266.04$ & $\mathrm{~S} /$ & $29,851.36$ & \\
\hline Total gastos de venta y & & $179,811.44$ & & $269,717.16$ & & $275,111.50$ & $280,613.73$ & & $286,226.01$ & & $291,950.53$ & \\
\hline Gasto total (\% de las ventas) & & $28 \%$ & & $24 \%$ & & $23 \%$ & $22 \%$ & & $21 \%$ & & $20 \%$ & $22 \%$ \\
\hline Utilidad de Operación & & $101,725.00$ & & $269,929.75$ & & $304,675.53$ & $341,954.68$ & & $381,930.49$ & & $424,776.36$ & \\
\hline Utilidad operación (\% de las ventas) & & $15.82 \%$ & & $23.87 \%$ & & $25.42 \%$ & $26.91 \%$ & & $28.36 \%$ & & $29.75 \%$ & $27 \%$ \\
\hline Depreciación & & $5,501.10$ & & $5,501.10$ & & $5,501.10$ & $5,501.10$ & & $5,501.10$ & & $4,741.10$ & \\
\hline Amortización & & $49,063.41$ & & $49,063.41$ & & $49,063.41$ & $49,063.41$ & & $49,063.41$ & & & \\
\hline Utilidad antes de interés e impuesto & & $47,160.49$ & & $215,365.24$ & & $250,111.03$ & $287,390.17$ & & $327,365.98$ & & $680,235.82$ & \\
\hline
\end{tabular}


Tabla 7.14

Flujo de efectivo

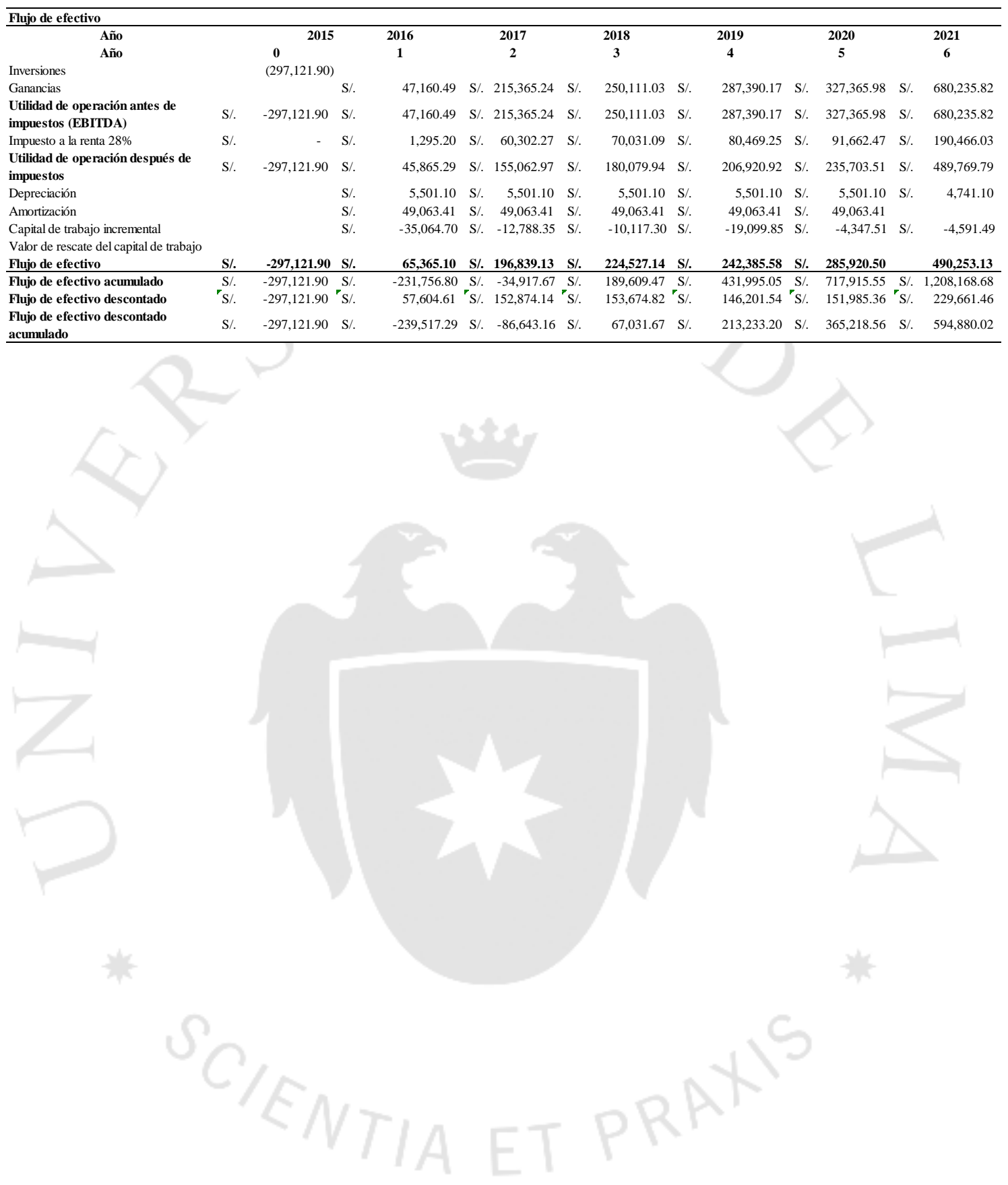


Tabla 7.15

Indicadores de viabilidad y rentabilidad financiera TIR y VAN

\begin{tabular}{lcr}
\hline INDICADORES DE RENTABILIDAD & \\
\hline VAN sin valor de rescate & $\mathrm{S} /$. & $594,880.02$ \\
VAN del valor de rescate & $\mathrm{S} /$. & $86,009.21$ \\
VAN con valor de rescate & $\mathrm{S} /$. & $680,889.23$ \\
& & \\
TIR & & $54.43 \%$ \\
IR & & 3.00 \\
Período de recupero Payback & & 2.16
\end{tabular}


Tabla 7.16

Tasa de descuento del accionista

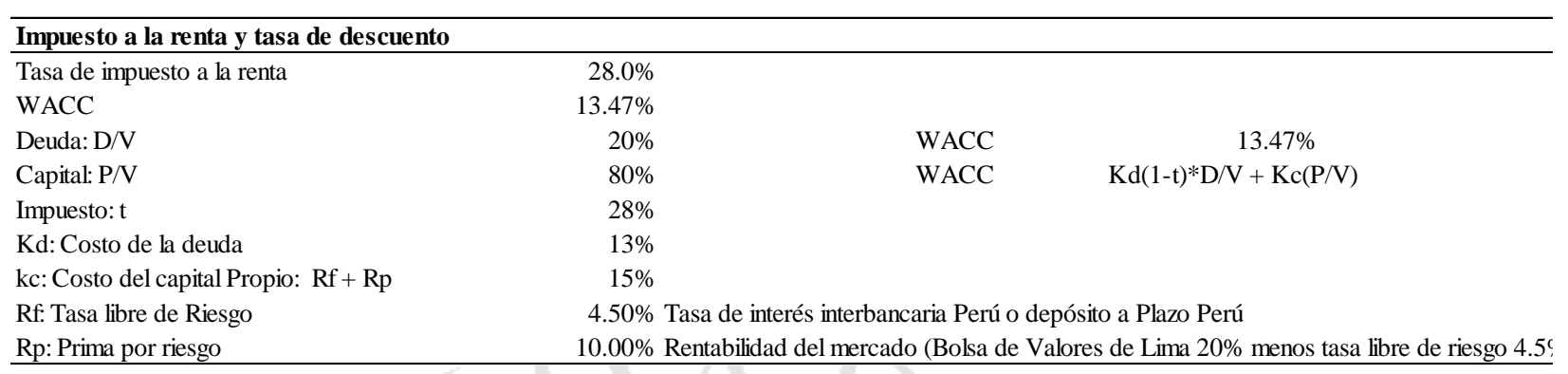

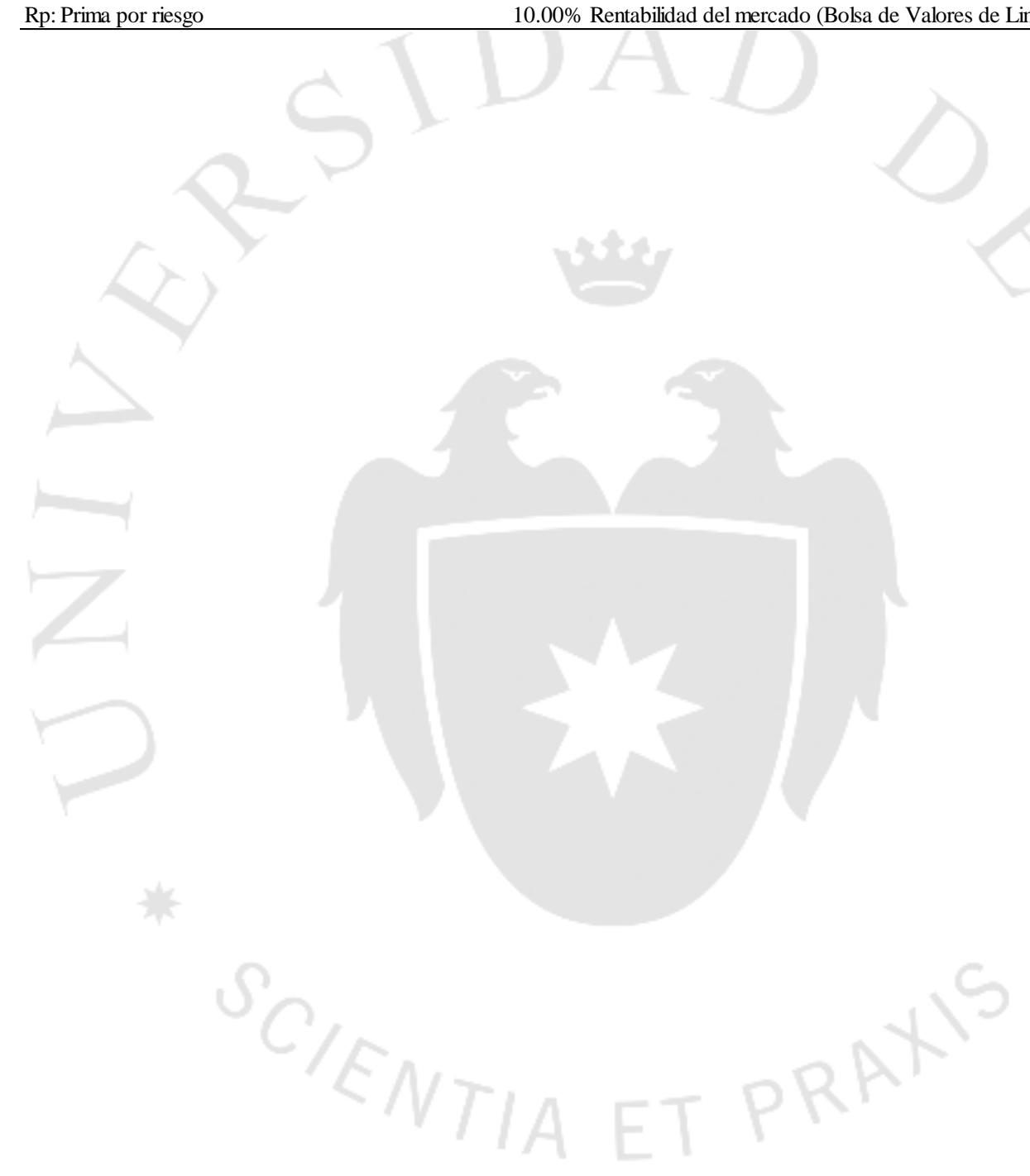


Tabla 7.17

Indicadores de rentabilidad representativos

\begin{tabular}{|c|c|c|c|c|c|c|c|}
\hline \multicolumn{8}{|c|}{ INDICADORES DE RENTABILIDAD REPRESENTATIVOS } \\
\hline & Promedio & 2016 & 2017 & 2018 & 2019 & 2020 & 2021 \\
\hline ROE & & 1.384707097 & 4.169878821 & 4.756427165 & 5.134743771 & 6.056996128 & 10.38561868 \\
\hline ROS & 0.201581531 & 0.101644783 & 0.174067932 & 0.187314036 & 0.190766618 & 0.212292688 & 0.343403128 \\
\hline ROI & 0.757679077 & 0.1974068 & 0.5944668 & 0.6780864 & 0.7320201 & 0.8634983 & 1.4805960 \\
\hline
\end{tabular}

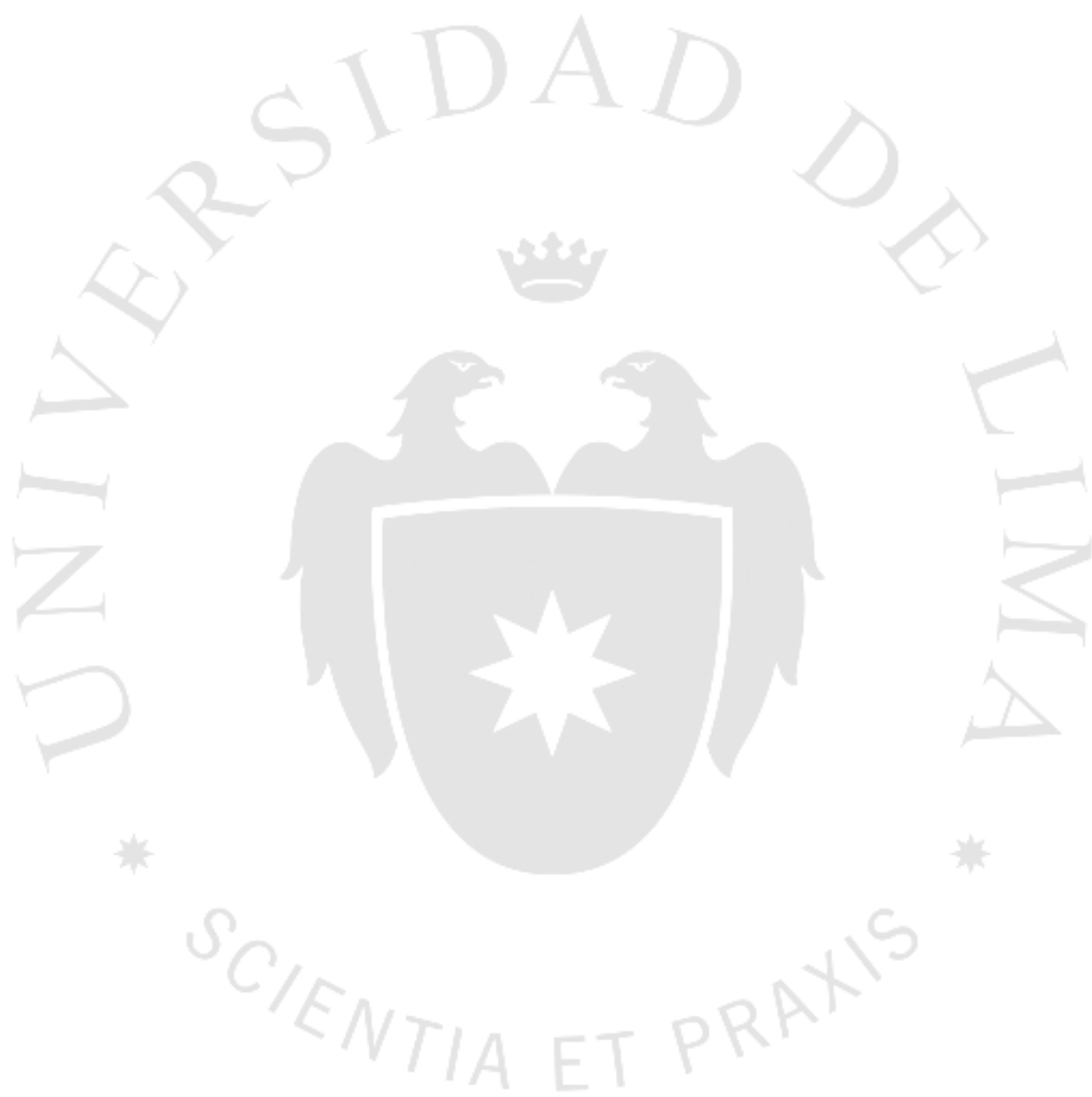


Tabla 7.18

Indicadores de rentabilidad escenario optimista

\begin{tabular}{lcc}
\hline INDICADORES DE RENTABILIDAD & \\
\hline VAN sin valor de rescate & S/. & $772,452.55$ \\
VAN del valor de rescate & S/. & $102,746.44$ \\
VAN con valor de rescate & S/. & $875,198.99$ \\
& & \\
TIR & & $61.74 \%$ \\
IR & 3.60 \\
Período de recupero Payback & 2.13 \\
Periodo anterior al cambio de signo & 2.00 \\
Valor Absoluto del flujo acumulado & $34,917.67$ \\
Flujo efectivo siguiente periodo & $268,729.72$ \\
\hline
\end{tabular}

\begin{tabular}{|c|c|c|c|c|c|c|c|}
\hline \multicolumn{8}{|c|}{ INDICADORES DE RENTABILIDAD REPRESENTATIVOS } \\
\hline & Promedio & 2016 & 2017 & 2018 & 2019 & 2020 & 2021 \\
\hline ROE & & 1.384707097 & 4.169878821 & 5.692823179 & 7.198775212 & 9.585913528 & 10.38561868 \\
\hline ROS & 0.203428302 & 0.101644783 & 0.174067932 & 0.206645137 & 0.227226128 & 0.263108768 & 0.247877066 \\
\hline ROI & 0.912818638 & 0.1974068 & 0.5944668 & 0.8115810 & 1.0262728 & 1.3665883 & 1.4805960 \\
\hline
\end{tabular}

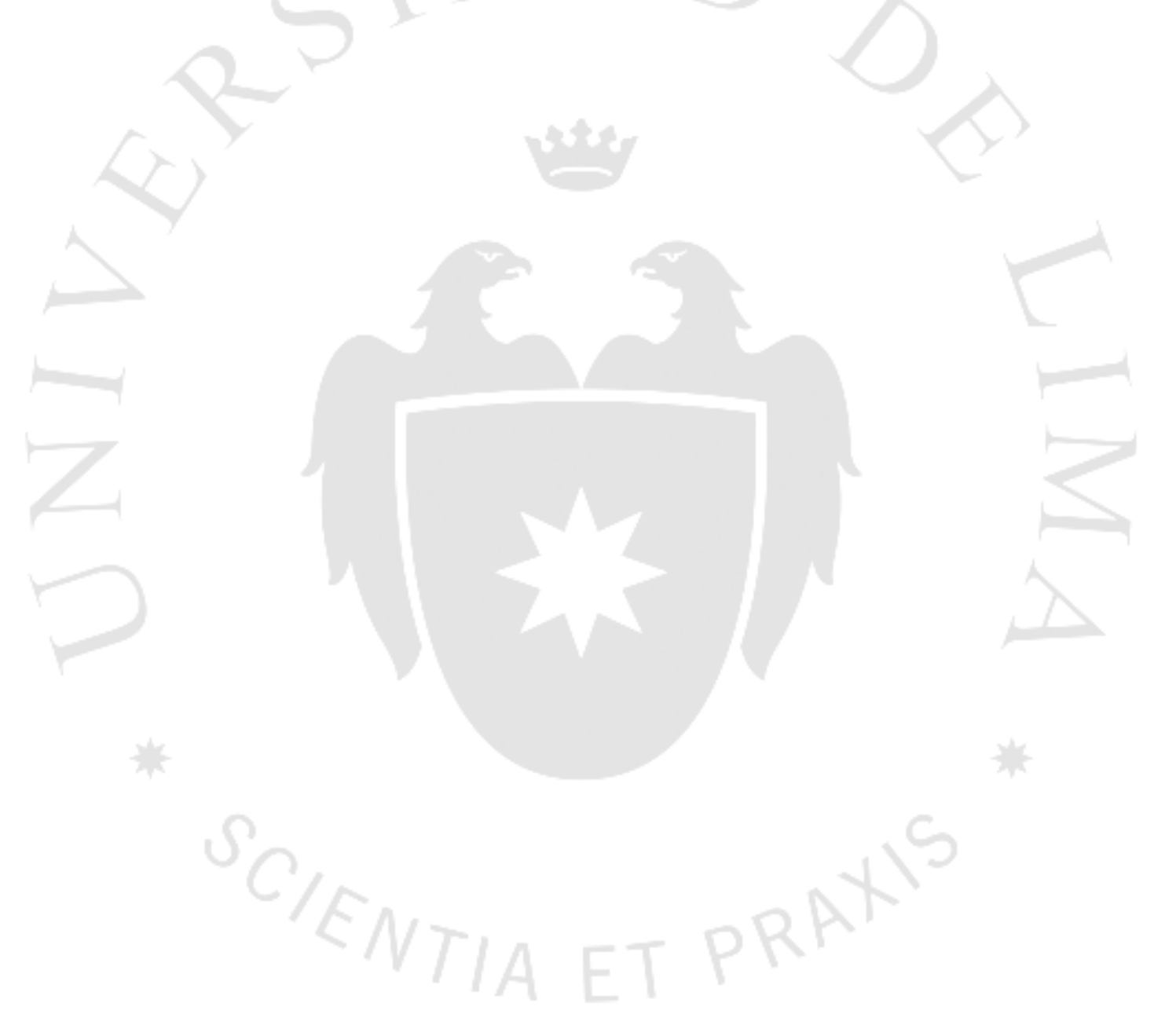


Tabla 7.19

Indicadores de rentabilidad escenario pesimista

\begin{tabular}{lcc}
\hline INDICADORES DE RENTABILIDAD & \\
\hline VAN sin valor de rescate & S/. & $451,405.96$ \\
VAN del valor de rescate & S/. & $85,604.36$ \\
VAN con valor de rescate & S/ & $537,010.32$ \\
& & \\
TIR & & $52.84 \%$ \\
IR & 2.52 \\
Período de recupero Payback & 2.16 \\
Periodo anterior al cambio de signo & 2.00 \\
Valor Absoluto del flujo acumulado & $34,917.67$ \\
Flujo efectivo siguiente periodo & $215,066.04$ \\
\hline
\end{tabular}

\begin{tabular}{|c|c|c|c|c|c|c|c|}
\hline \multicolumn{8}{|c|}{ INDICADORES DE RENTABILIDAD REPRESENTATIVOS } \\
\hline & Promedio & 2016 & 2017 & 2018 & 2019 & 2020 & 2021 \\
\hline ROE & & 1.384707097 & 4.169878821 & 4.556001232 & 4.717177195 & 5.406477076 & 10.38561868 \\
\hline ROS & 0.193880421 & 0.101644783 & 0.174067932 & 0.179421012 & 0.175253135 & 0.189492535 & 0.343403128 \\
\hline $\mathrm{ROI}$ & 0.72753879 & 0.1974068 & 0.5944668 & 0.6495133 & 0.6724909 & 0.7707589 & 1.4805960 \\
\hline
\end{tabular}

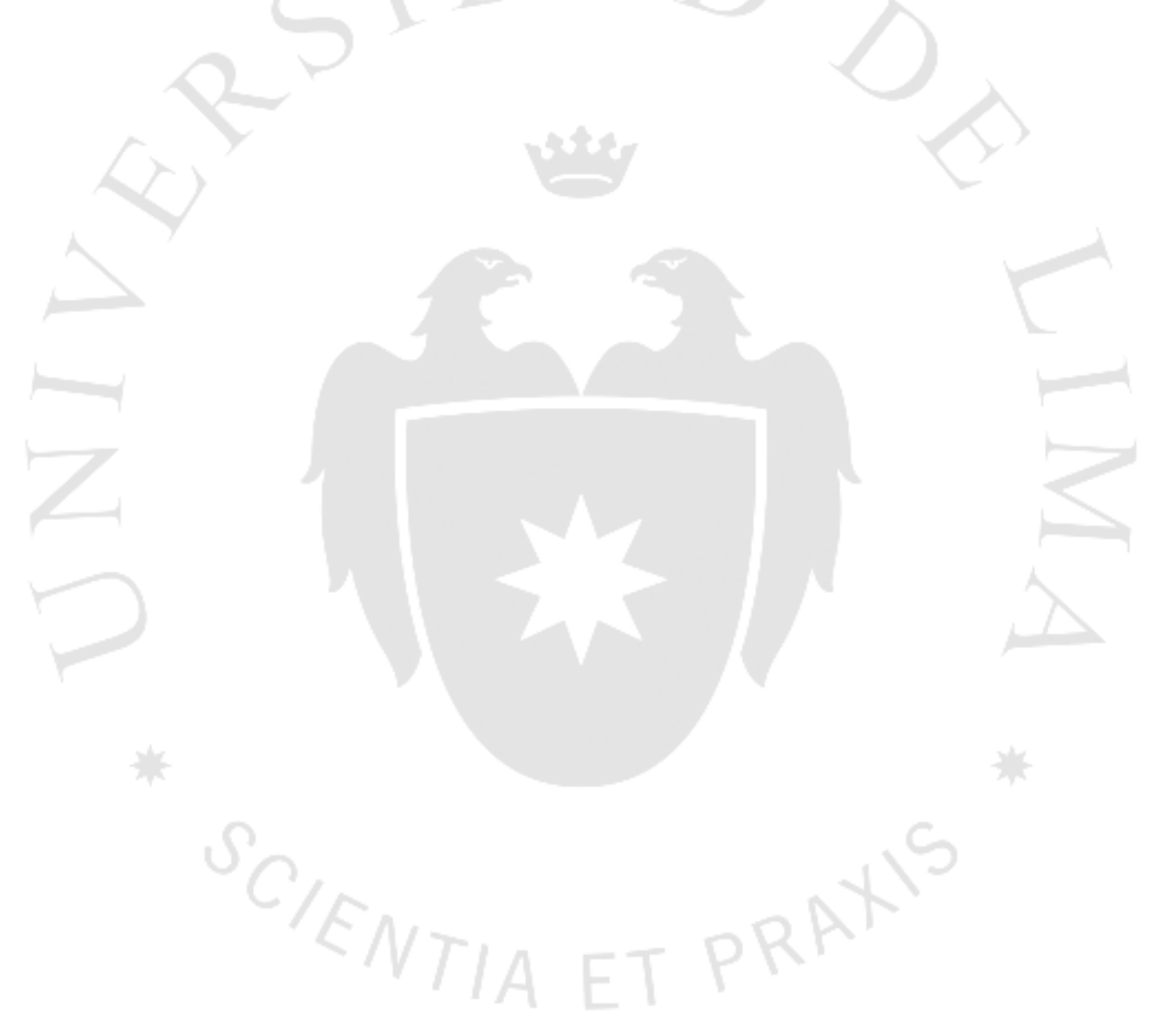


Tabla 7.20

Rendimiento bolsa de valores de Lima últimos 5 años

Rendimiento Bolsa de Valores de Lima últimos 5 años

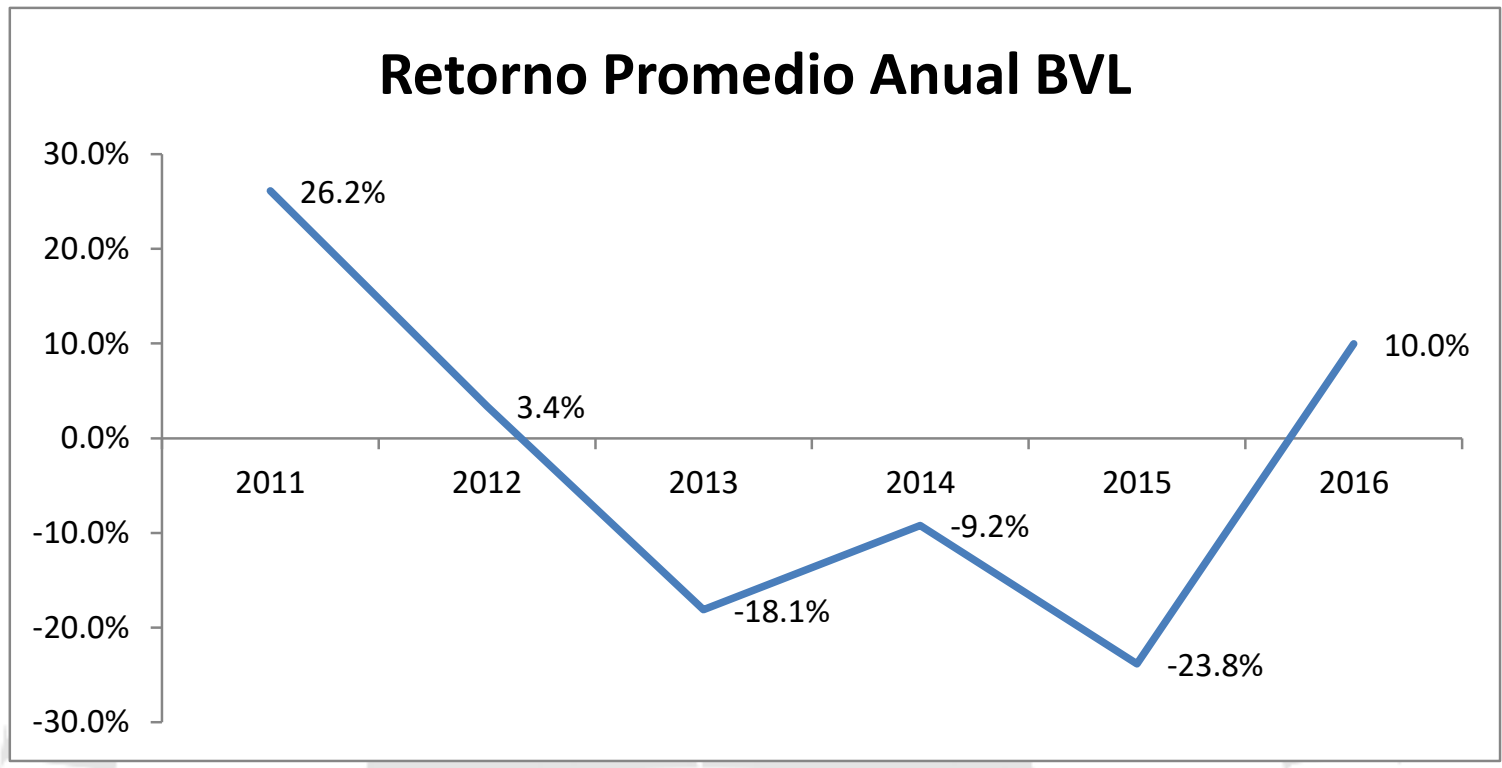

Fuente: Equity Research Scotia SAB 
Figura 1.1

Ventajas competitivas

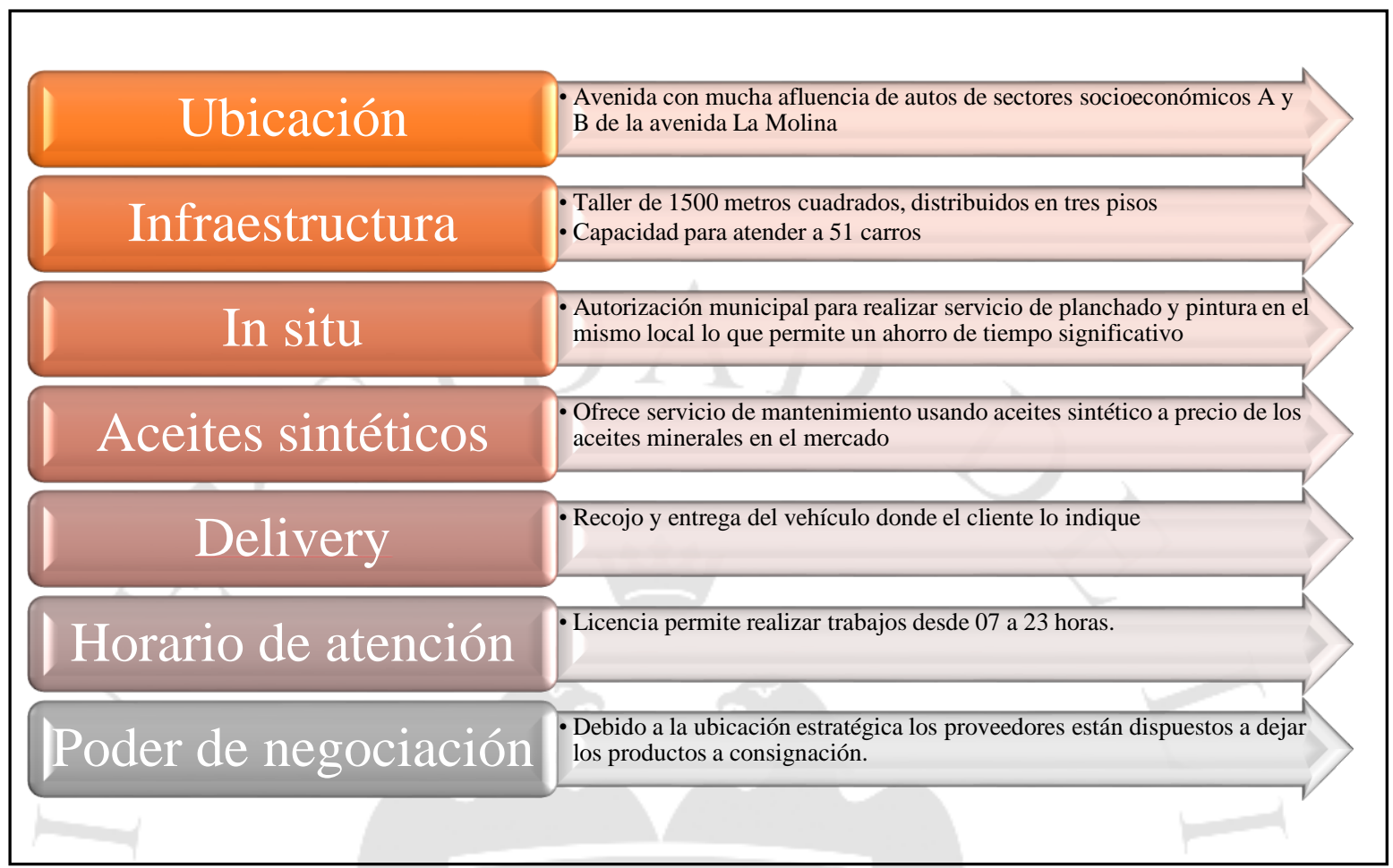

Figura 2.1

Distribución de zonas APEIM por niveles

\section{Apeim}

(\%) VERTICALES

\begin{tabular}{|c|c|c|c|c|c|c|c|}
\hline \multirow{2}{*}{ Zona } & \multicolumn{5}{|c|}{ Niveles Socioeconómicos } & \multirow{2}{*}{ Muestra } & \multirow{2}{*}{ Error (\%) } \\
\hline & NSE A & NSE B & NSE C & NSE D & NSE E & & \\
\hline Total & 100 & 100 & 100 & 100 & 100 & 4,964 & 1.6 \\
\hline Zona 1 (Puente Piedra, Comas, Carabayllo) & 2.1 & 5.1 & 11.7 & 13.8 & 17.3 & 289 & 5.5 \\
\hline Zona 2 (Independencia, Los Olivos, San Martin de Porras) & 5.0 & 14.6 & 17.9 & 12.1 & 4.5 & 324 & 5.3 \\
\hline Zona 3 (San Juan de Lurigancho) & 0.0 & 9.1 & 11.2 & 12.4 & 16.4 & 283 & 6.1 \\
\hline Zona 4 (Cercado, Rimac, Breña, La Victoria) & 6.9 & 11.3 & 10.5 & 7.7 & 5.7 & 498 & 4.4 \\
\hline $\begin{array}{l}\text { Zona } 5 \text { (Ate, Chaclacayo, Lurigancho, Santa Anita, San } \\
\text { Luis, El Agustino) }\end{array}$ & 4.2 & 5.9 & 10.9 & 16.2 & 12.6 & 347 & 5.2 \\
\hline $\begin{array}{l}\text { Zona } 6 \text { (Jesús Maria, Lince, Pueblo Libre, Magdalena, San } \\
\text { Miguel) }\end{array}$ & 15.8 & 15.6 & 3.3 & 1.3 & 0.5 & 286 & 5.7 \\
\hline $\begin{array}{l}\text { Zona } 7 \text { (Miraflores, San Isidro, San Borja, Surco, La } \\
\text { Molina) }\end{array}$ & 57.0 & 17.3 & 3.0 & 1.8 & 1.4 & 321 & 5.6 \\
\hline $\begin{array}{l}\text { Zona 8(Surquillo, Barranco, Chorrillos, San Juan de } \\
\text { Miraflores) }\end{array}$ & 6.2 & 9.5 & 8.1 & 6.3 & 4.5 & 284 & 5.9 \\
\hline $\begin{array}{l}\text { Zona 9(Villa El Salvador, Villa Maria del Triunfo, Lurin, } \\
\text { Pachacamác) }\end{array}$ & 0.0 & 3.1 & 11.8 & 17.9 & 18.3 & 279 & 5.6 \\
\hline $\begin{array}{l}\text { Zona 10 (Callao, Bellavista, La Perla, La Punta, Carmen } \\
\text { de la Legua, Ventanilla) }\end{array}$ & 2.7 & 8.4 & 11.0 & 9.9 & 16.6 & 1,004 & 3.1 \\
\hline Otros & 0.0 & 0.2 & 0.7 & 0.7 & 2.2 & 49 & 14.3 \\
\hline
\end{tabular}




\section{Figura 2.2}

Distribución de hogares según nivel socioeconómico, perfil de hogares y gastos por Nivel Socio Económico

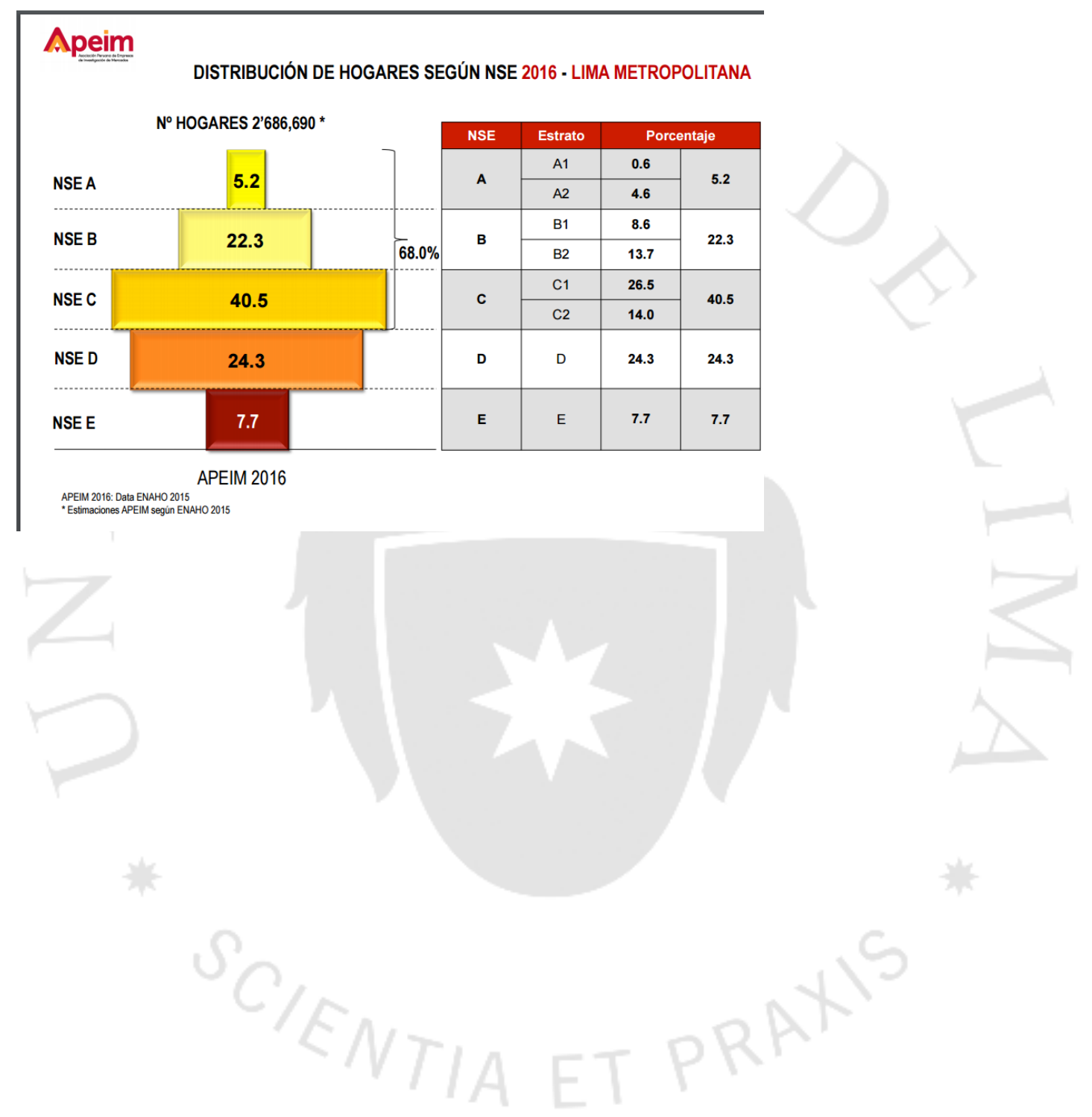




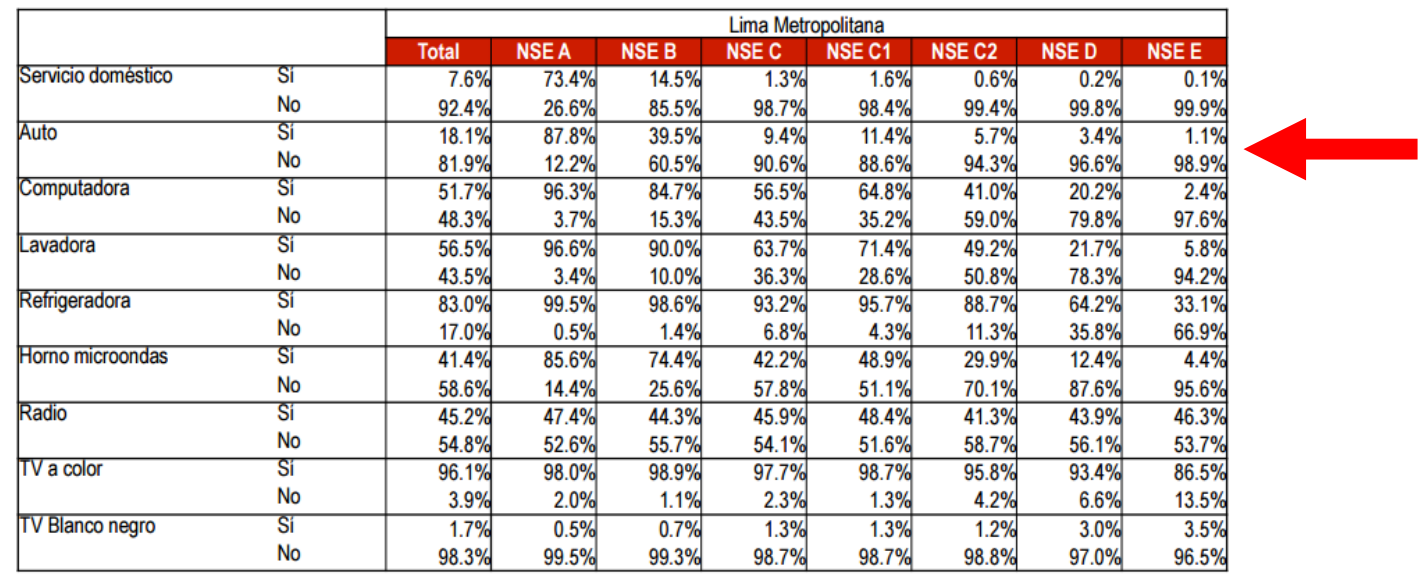

\section{Apeim}

INGRESOS Y GASTOS SEGÚN NSE 2016 - PERÚ URBANO

PROMEDIOS

\begin{tabular}{|c|c|c|c|c|c|c|c|}
\hline Grupo 1 : Alimentos - gasto promedio & S/. 598 & $\mathrm{~S} / .813$ & S/. 662 & SI. 687 & Sl. 625 & S/. 523 & S/. 399 \\
\hline Grupo 2: Vestido y Calzado - gasto promedio & S/. 95 & S/. 174 & S/. 101 & SI. 107 & S/. 91 & S/. 71 & S/. 49 \\
\hline $\begin{array}{l}\text { Grupo } 3 \text { : Alquiler de vivienda, Combustible, Electricidad y Conservación } \\
\text { de la Vivienda - gasto promedio }\end{array}$ & S/. 182 & S/. 360 & SI. 200 & SI. 223 & S/. 166 & S/. 123 & SI. 70 \\
\hline $\begin{array}{l}\text { Grupo } 4 \text { : Muebles, Enseres y Mantenimiento de la vivienda - gasto } \\
\text { promedio }\end{array}$ & S/. 95 & SI. 245 & S/. 79 & S/. 86 & $S / .69$ & SI. 56 & Sl. 42 \\
\hline $\begin{array}{l}\text { Grupo } 5 \text { : Cuidado, Conservación de la Salud y Servicios Médicos - } \\
\text { gasto promedio }\end{array}$ & S/. 109 & Sl. 208 & Sl. 119 & SI. 133 & S/. 99 & SI. 78 & $\mathrm{~S} / .46$ \\
\hline Grupo 6 : Transportes y Comunicaciones - gasto promedio & S/. 173 & S/. 447 & S/. 168 & SI. 188 & S/. 137 & S/. 89 & Sl. 50 \\
\hline $\begin{array}{l}\text { Grupo } 7 \text { : Esparcimiento, Diversión, Servicios Culturales y de } \\
\text { Enseñanza - gasto promedio }\end{array}$ & S/. 177 & $\mathrm{~S} / .450$ & S/. 180 & S/. 199 & SI. 150 & S/. 91 & S/. 48 \\
\hline Grupo 8 : Otros bienes y servicios - gasto promedio & Sl. 101 & S/. 189 & S/. 106 & S/. 115 & S/. 92 & SI. 75 & Sl. 52 \\
\hline PROMEDIO GENERAL DE GASTO FAMILIAR MENSUAL & SI. 2,553 & SI. 4,647 & SI. 2,746 & SI. 2,938 & SI. 2,451 & SI. 1,883 & SI. 1,275 \\
\hline PROMEDIO GENERAL DE INGRESO FAMILIAR MENSUAL* & Sl. 3,171 & Sl. 6,379 & $\mathrm{~S} / .3,363$ & Sl. 3,604 & Sl. 2,994 & Sl. 2,161 & Sl. 1,365 \\
\hline
\end{tabular}


Figura 2.3

Población para determinación de la muestra a encuestar

\begin{tabular}{|c|c|c|c|}
\hline \multicolumn{4}{|c|}{ Tamaño de la Población de la Muestra y demanda potencial } \\
\hline Hogares & $2,686,690.00$ & & \\
\hline & NSEA & NSEB & \\
\hline & $5.20 \%$ & $22.30 \%$ & \\
\hline Población & $139,707.88$ & $599,131.87$ & \\
\hline Zona 7 & $57 \%$ & $17.30 \%$ & \\
\hline Población & $79,633.49$ & $103,649.81$ & $183,283.31$ \\
\hline Población con auto & $87 \%$ & $39 \%$ & \\
\hline Demanda Potencial & $69,281.14$ & $40,423.43$ & $109,704.56$ \\
\hline
\end{tabular}

Figura 3.1

Valores y ética

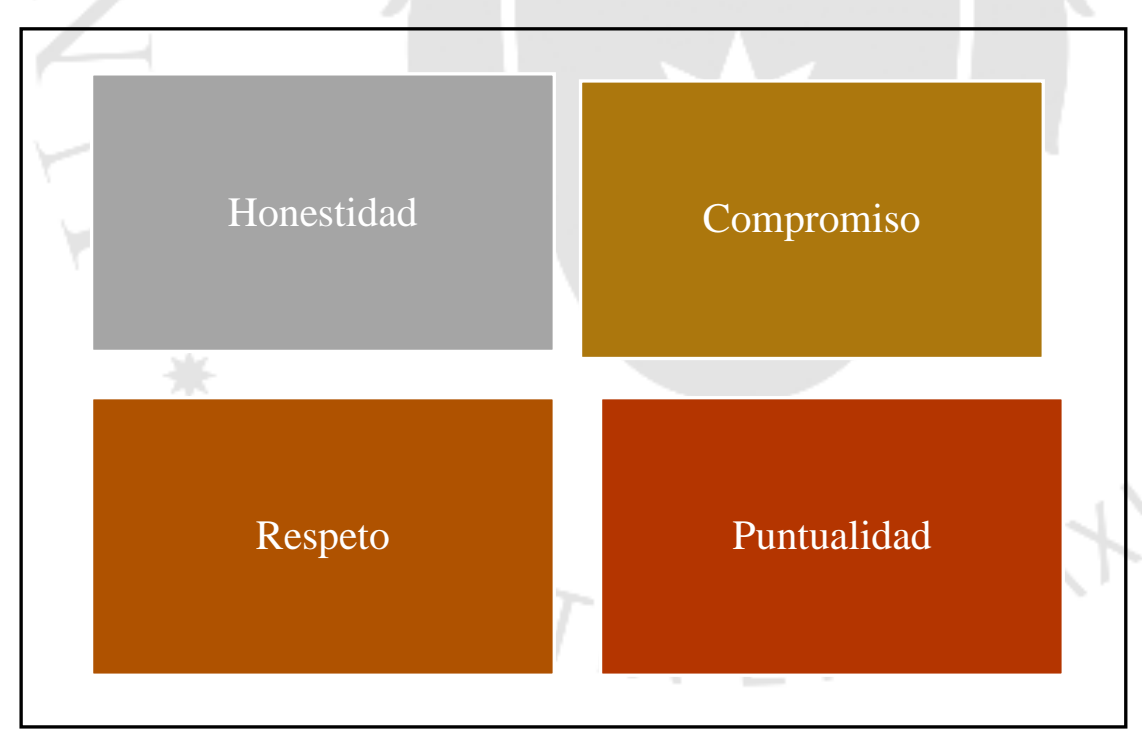


Figura 3.2

\section{Cultura organizacional}

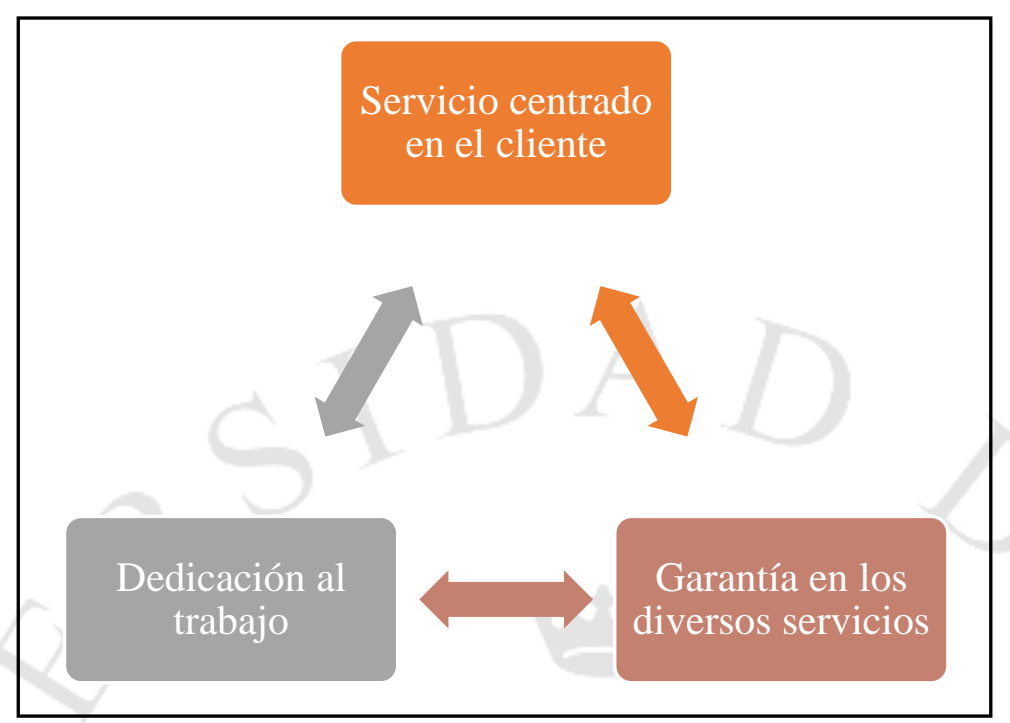

Figura 3.3

\section{Objetivos estratégicos}

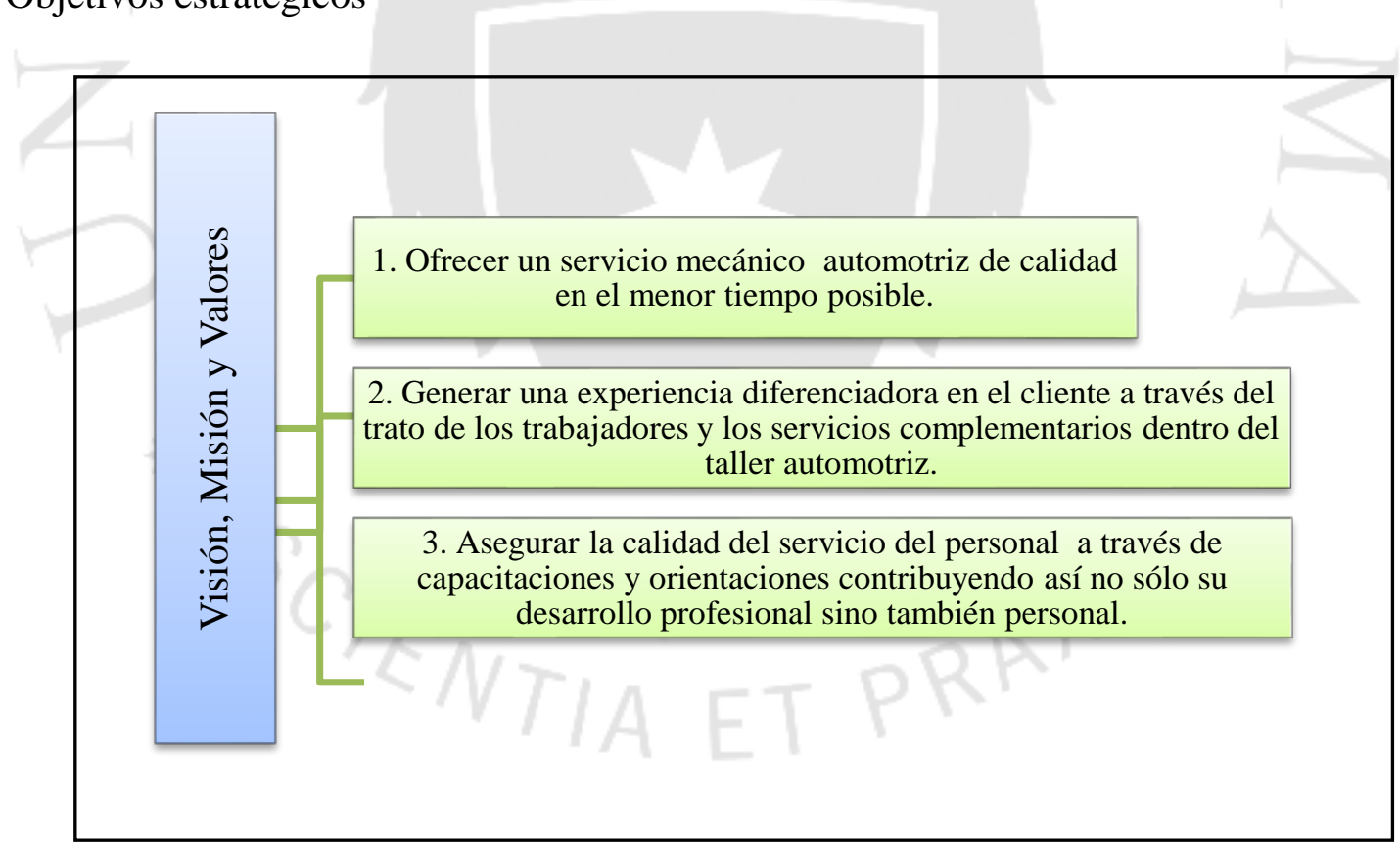


Figura 3.4

Problemática

\section{ESTRATEGIA}

PROBLEMÁTICA

¿Cuál es y deberia ser el

futuro modelo de negocio

del taller mecánico Tiki

Cars frente a los desafios

actuales y futuros?

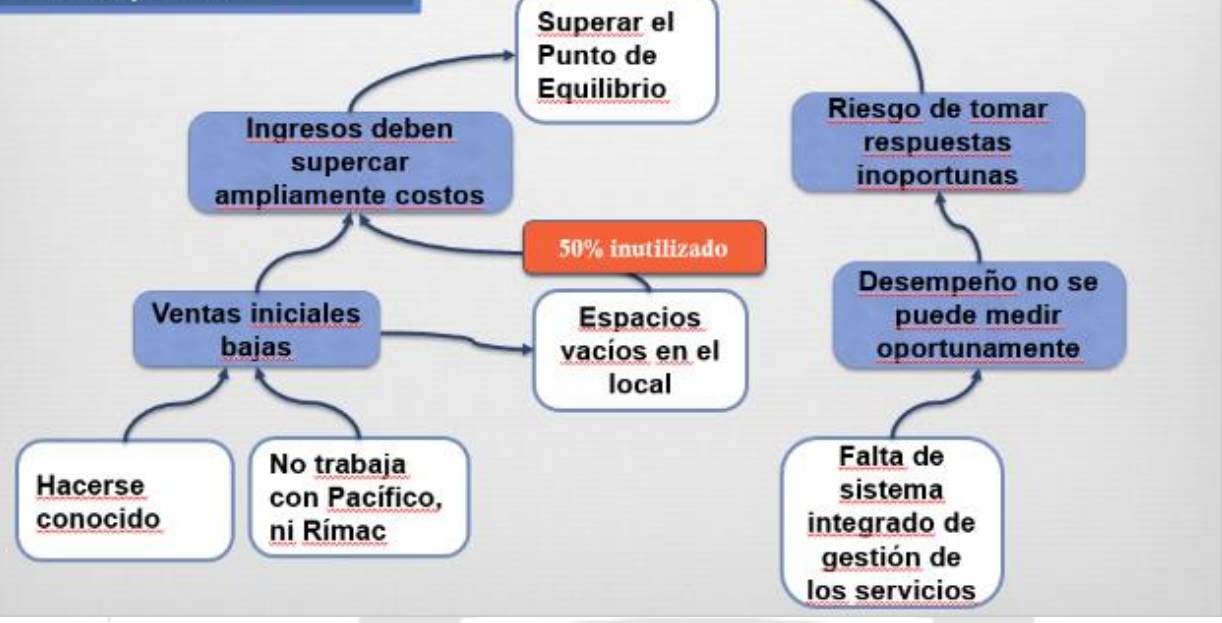

Figura 3.5

Estrategia frente a problemática

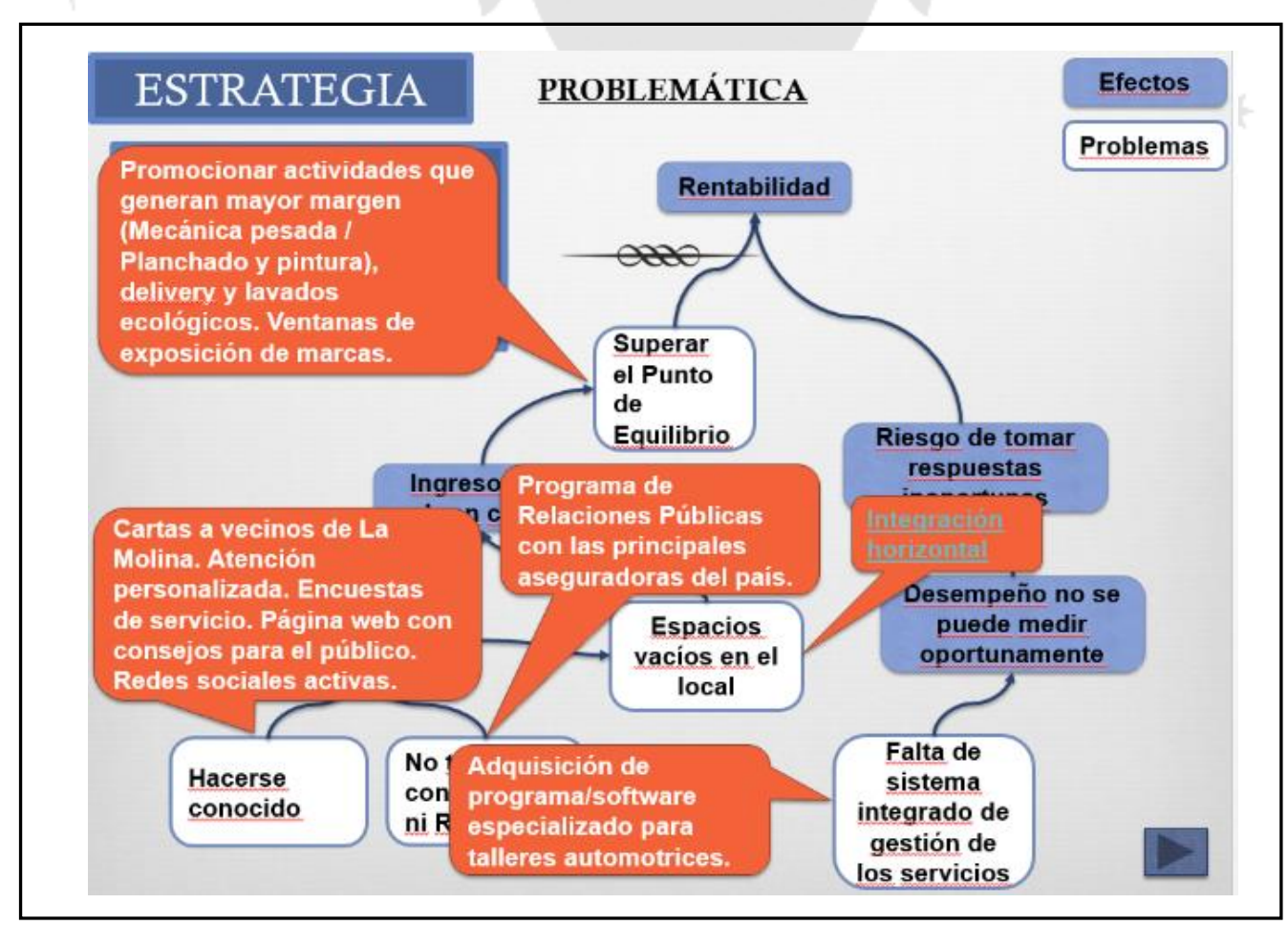


Figura 3.6

\section{Análisis externo PESTEL}

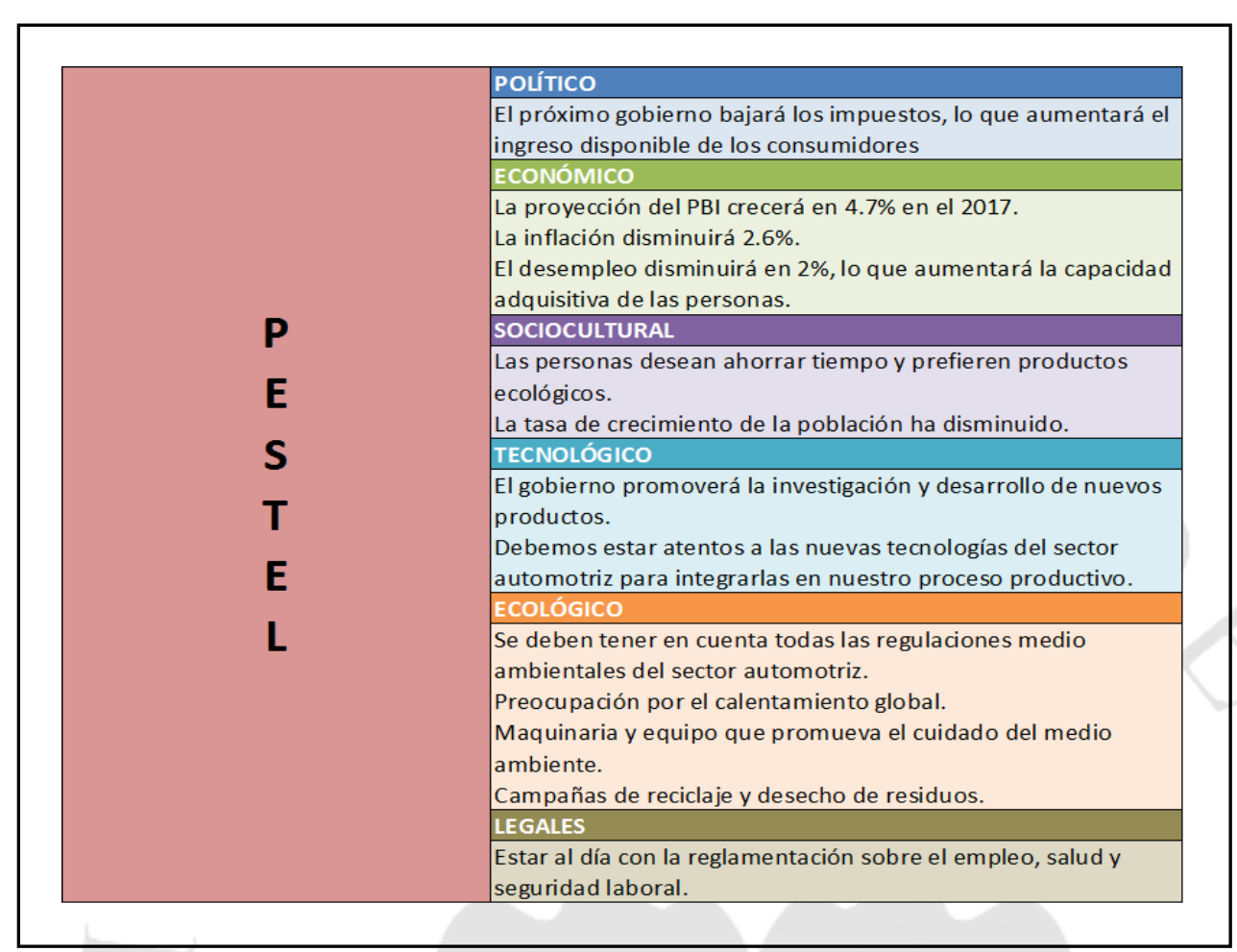


Figura 3.7

\section{Análisis interno PORTER}

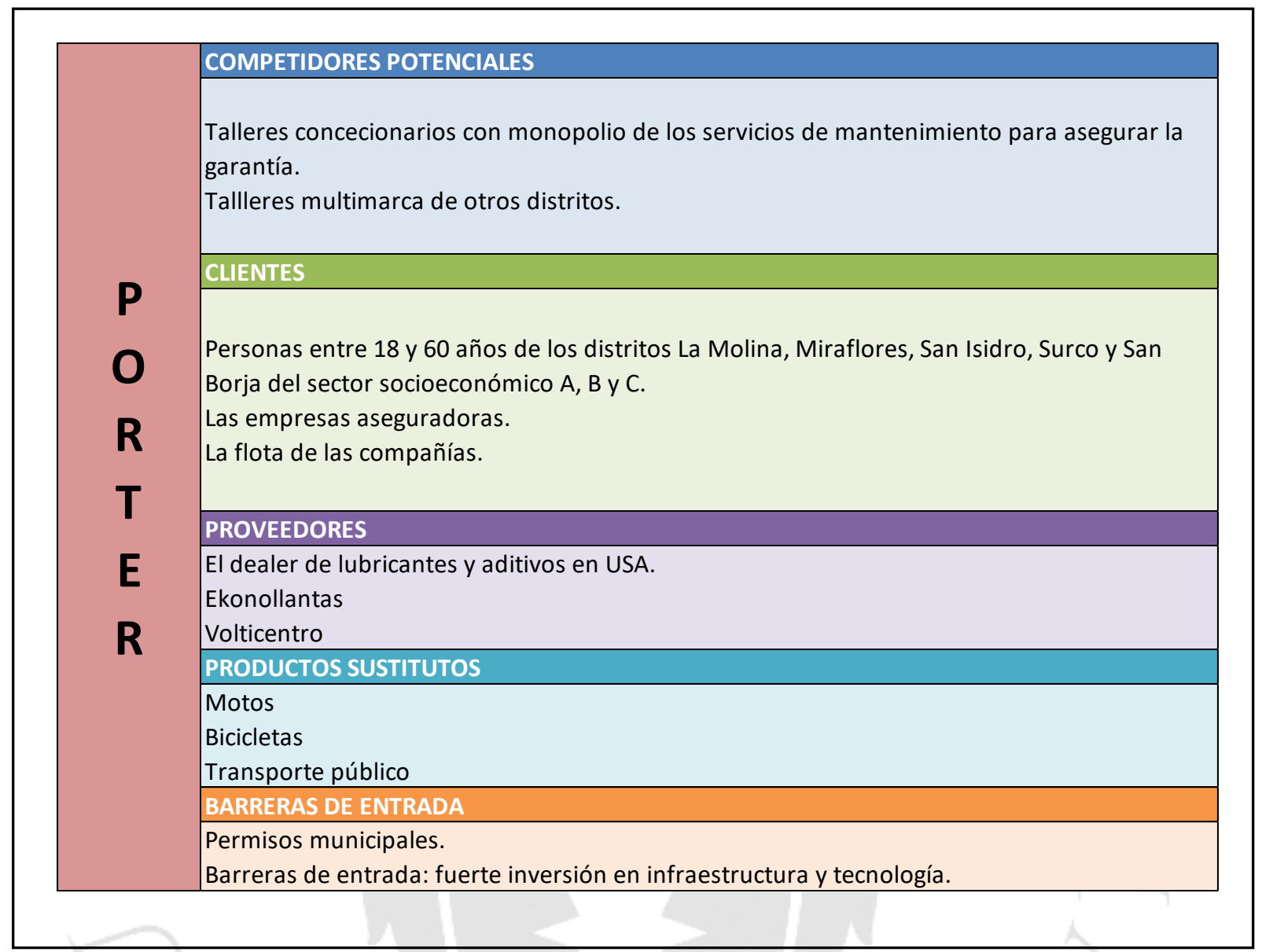

Figura 4.1

Objetivos generales de marketing

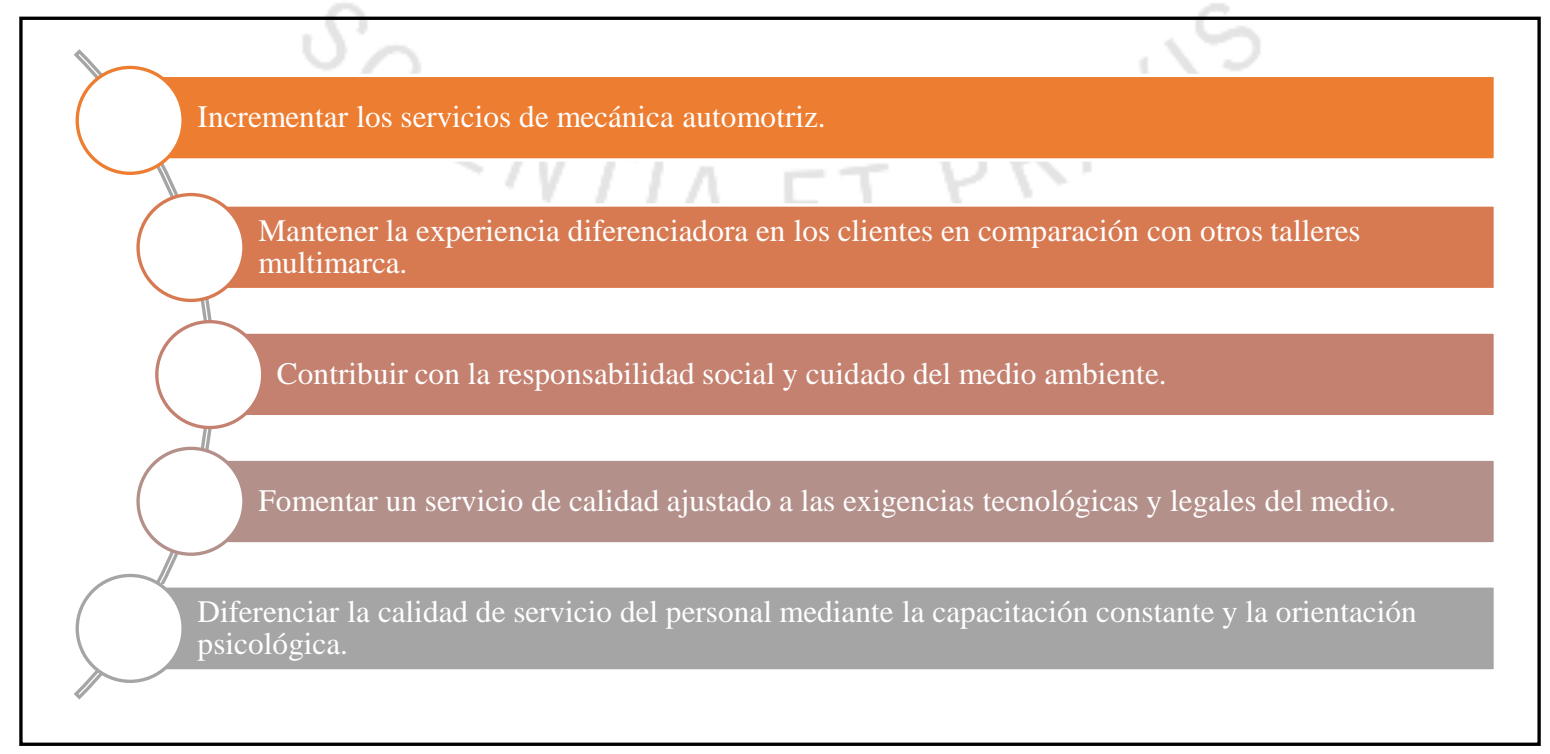


Figura 4.2

Participación porcentual de las empresas aseguradoras

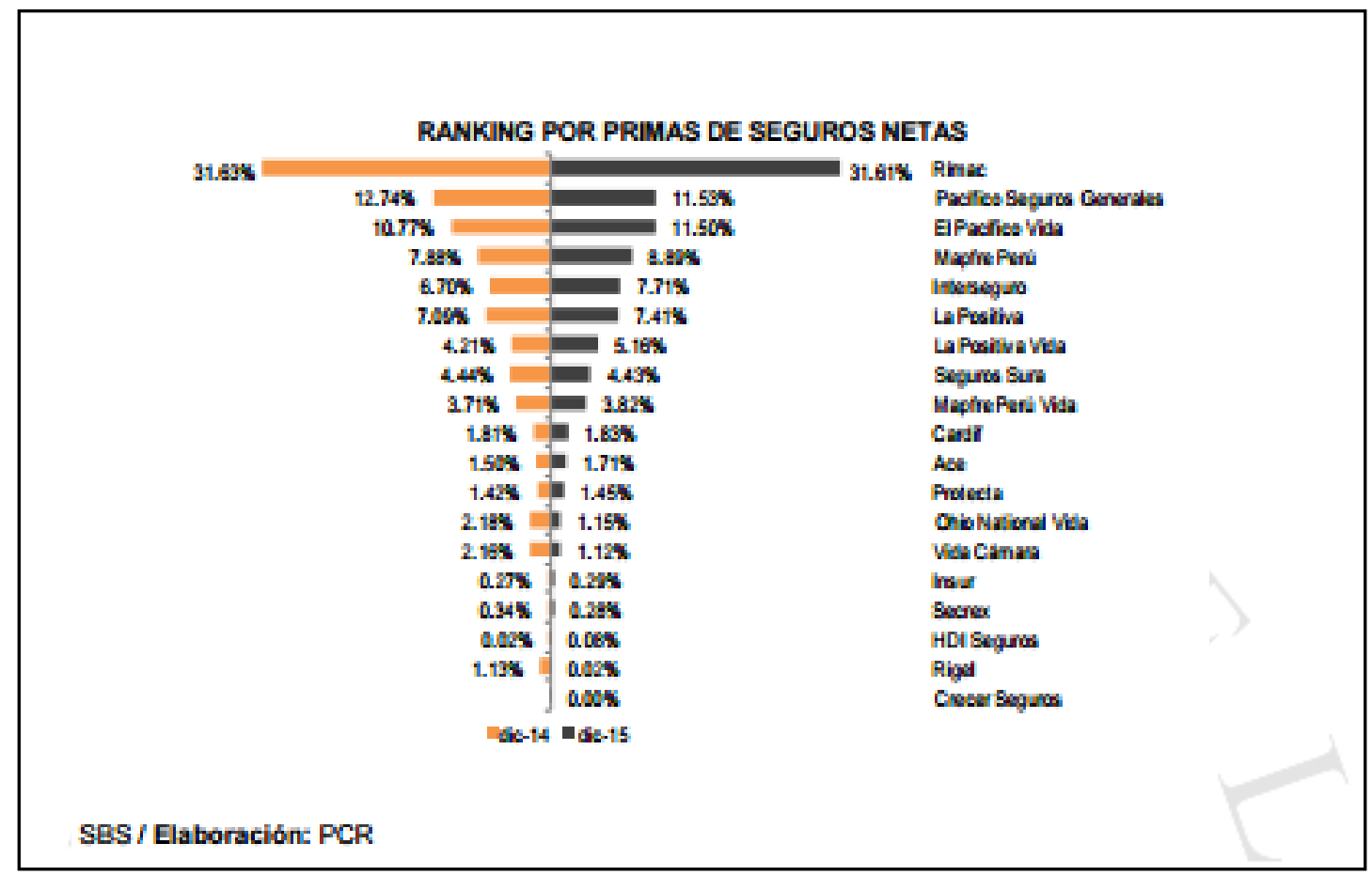

Figura 4.3

Venta anual de vehículos nuevos

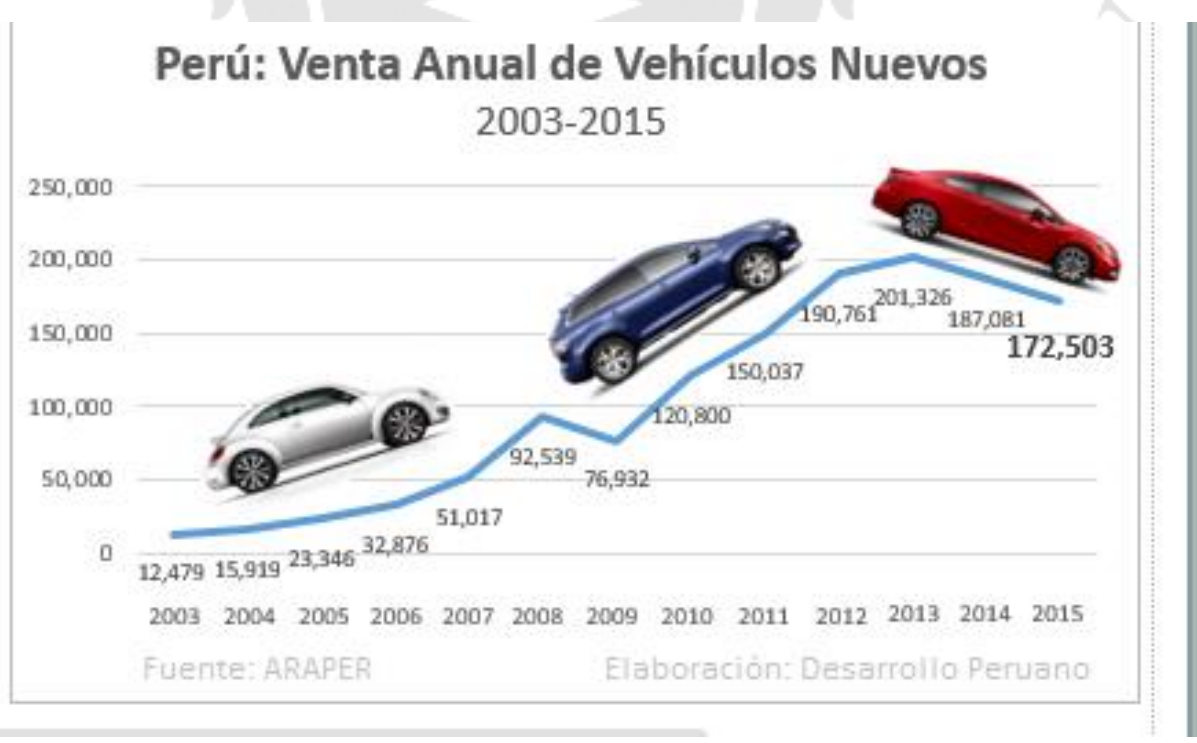


Figura 4.4

Evolución de ventas de autos nuevos 2015 - 2016

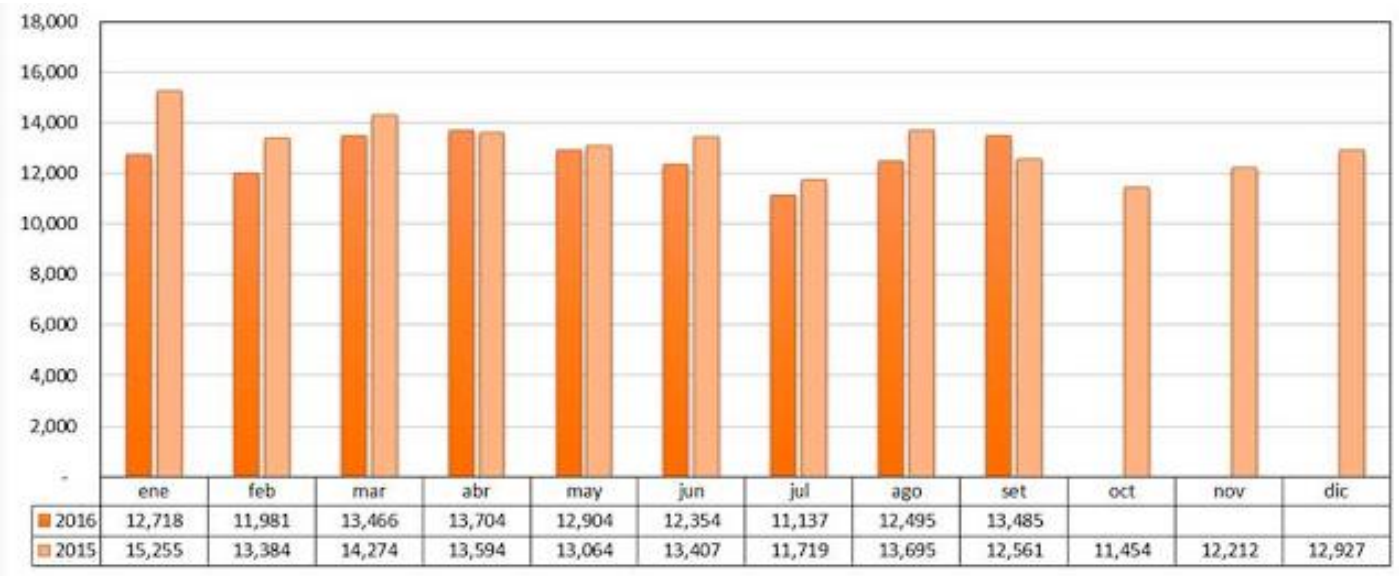

ESTADISTICA DE INMATRICULACIÓN DE VEHICULOS LIVIANOS. En el gráfico se muestra el comportamiento mensual de la inmatriculación de vehiculos livianos a setiembre 2016.

Fuente: SUNARP - AAP

V. Menores: motocicletas $y$ timotos.

olas pick un fumonetas station wagan, SUVS, foddertenos

V. Pesados: camiones tractocamiones minibás, ómnibus
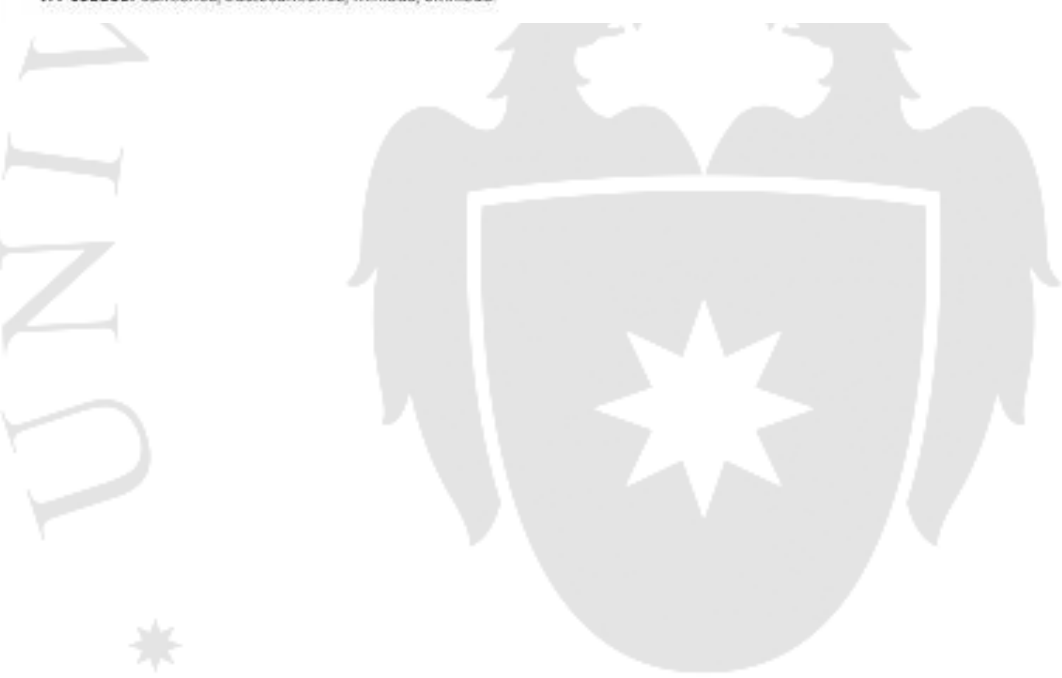
Figura 4.5

Marketing Mix

\section{PRODUCTO}

Tiki Cars ofrece un servicio de mantenimiento, reparación, servicios de lavado, planchado y pintura de calidad que permite ahorrar tiempo al cliente al ofrecer servicio de recojo y entrega a domicilio. Da la seguridad de la protección del vehículo ya que el cliente puede ver a través de una aplicación todo el proceso del servicio a través de las cámaras colocadas Nosotros resolvemos el problema de falta de tiempo al recoger y entregar el vehículo donde el cliente indique, y el problema de confianza con la garantía hasta el próximo servicio.

El cliente podrá ver el proceso del servicio de su carro desde su teléfono móvil.

PLAZA

La distribución de nuestro servicio es en el mismo local del taller. Sin embargo se ofrece la posibilidad de recojo a domicilio a los distritos del sector 7 de la clasificación de

$$
\text { APEIM. }
$$

Ofrecemos nuestros productos mediante la página web, redes sociales, volantes en el distrito, publicidad en revistas

especializadas y boca a boca

\section{PRECIO}

El precio de venta es al contado para el público en general. Las flotas de las empresas pagan a los 30 días y las compañías de seguros a los 60 días.

Los márgenes de precios varían de $50 \%$ a $70 \%$

\section{Las $4 \mathrm{P}$}

\section{PROMOCIÓN}

Todos los clientes que realizan servicios o compran productos en el taller se llevarán un obsequio para su carro o un dulce. También se realizarán promociones temporales de acuerdo a la festividad del año. 
Figura 5.1

Diseño y capacidad de Instalaciones

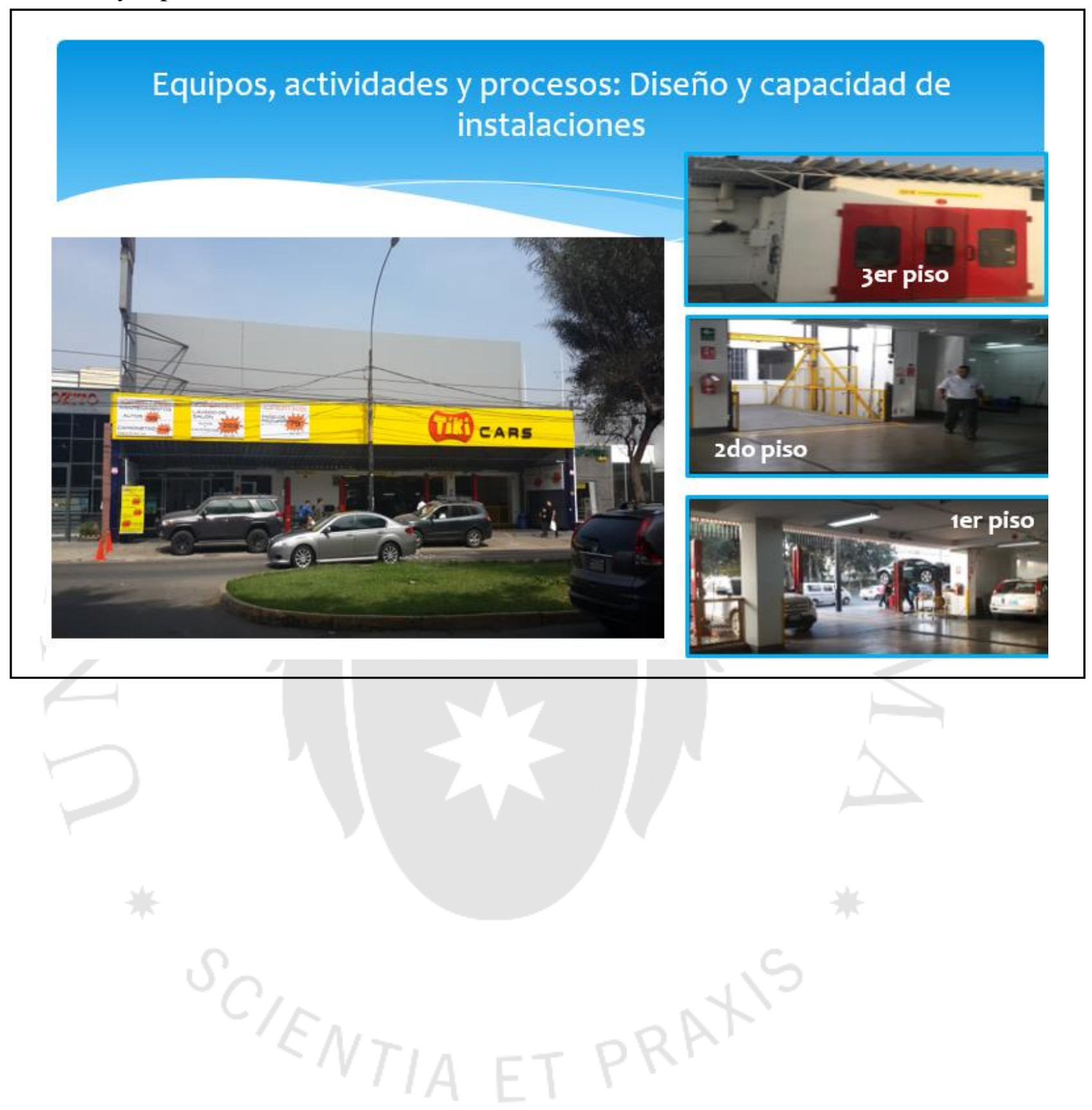


Figura 5.2

Equipos de trabajo y apoyos

Equipos, actividades y procesos: Equipos de trabajo y apoyo

Primer piso

Los elevadores sirven

para hacer el

diagnóstico, mecánica

ligera y frenos.
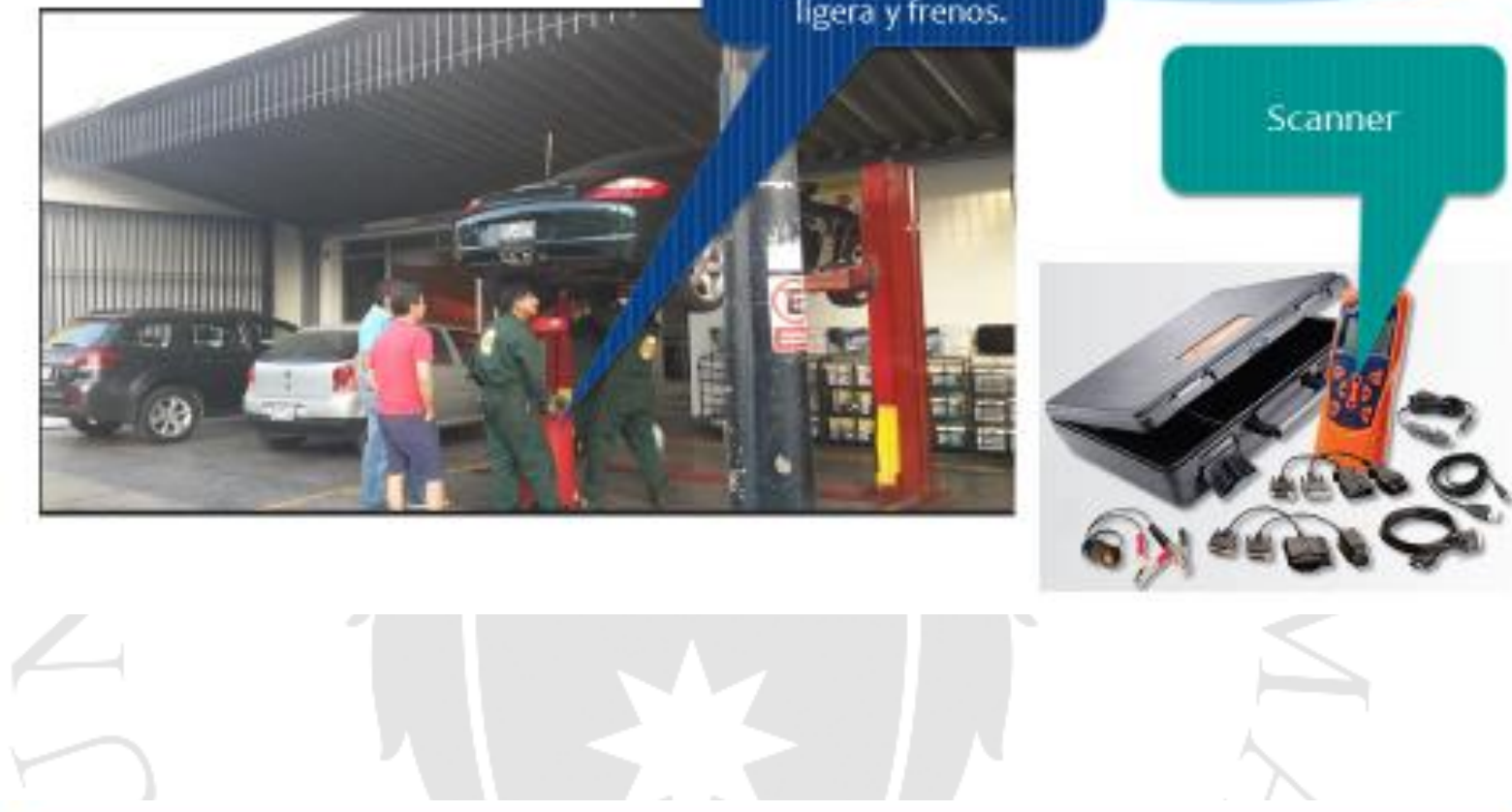

Equipos, actividades y procesos: Equipos de trabajo y apoyo

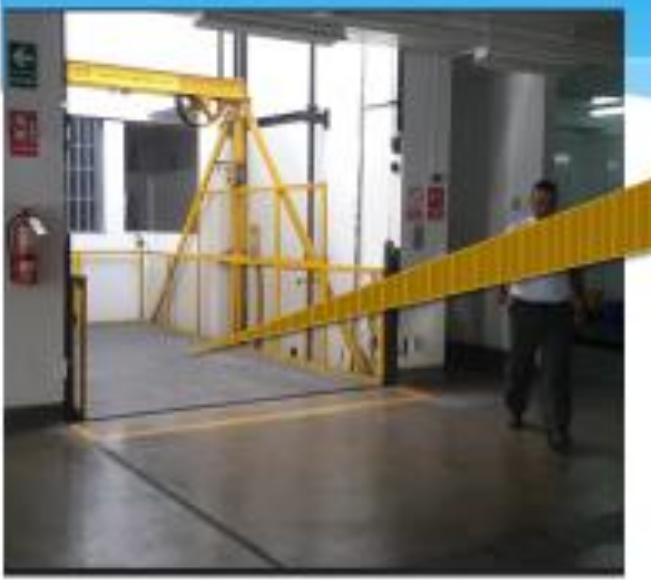

Segundoplso

A traves del

elevador, sesuben

los carros al segundo

piso para hacer

mecánica pesada

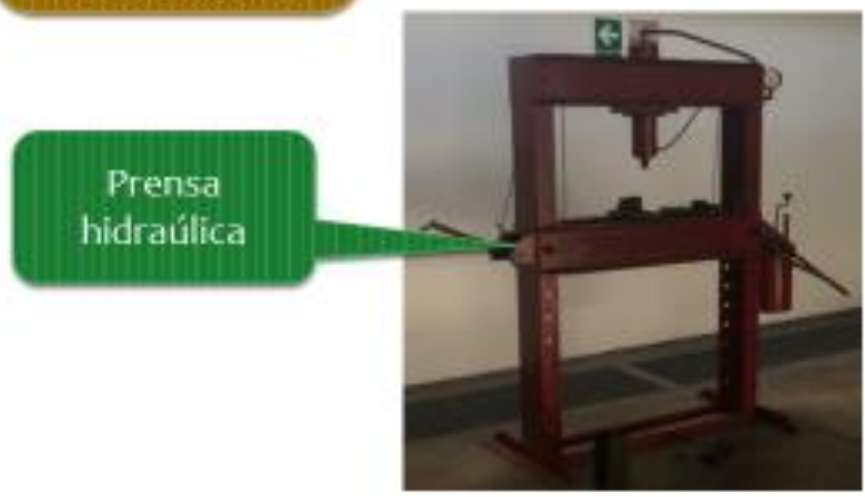


Figura 5.3

Equipos de trabajo y apoyos

Equipos, actividades y procesos: Equipos de trabajo y apoyo

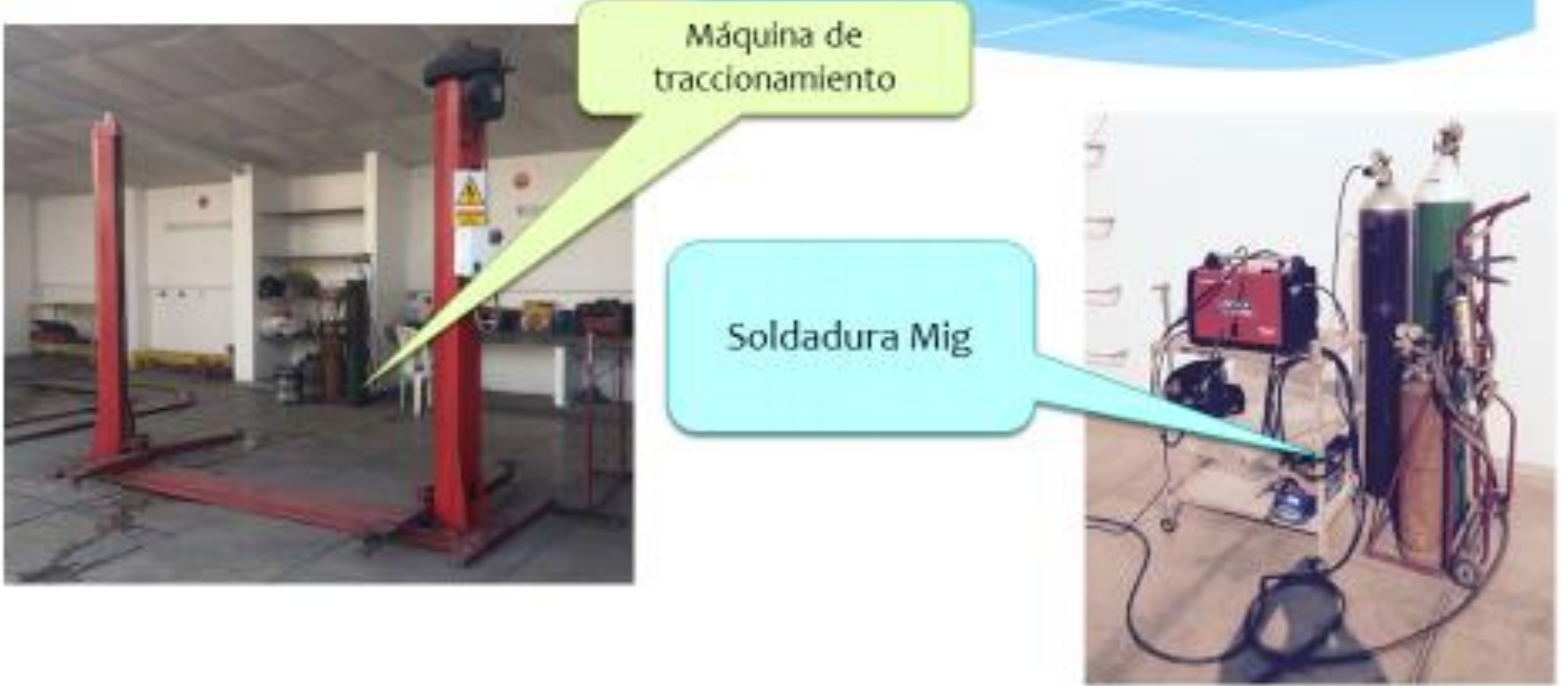

Figura 5.4

Just in time

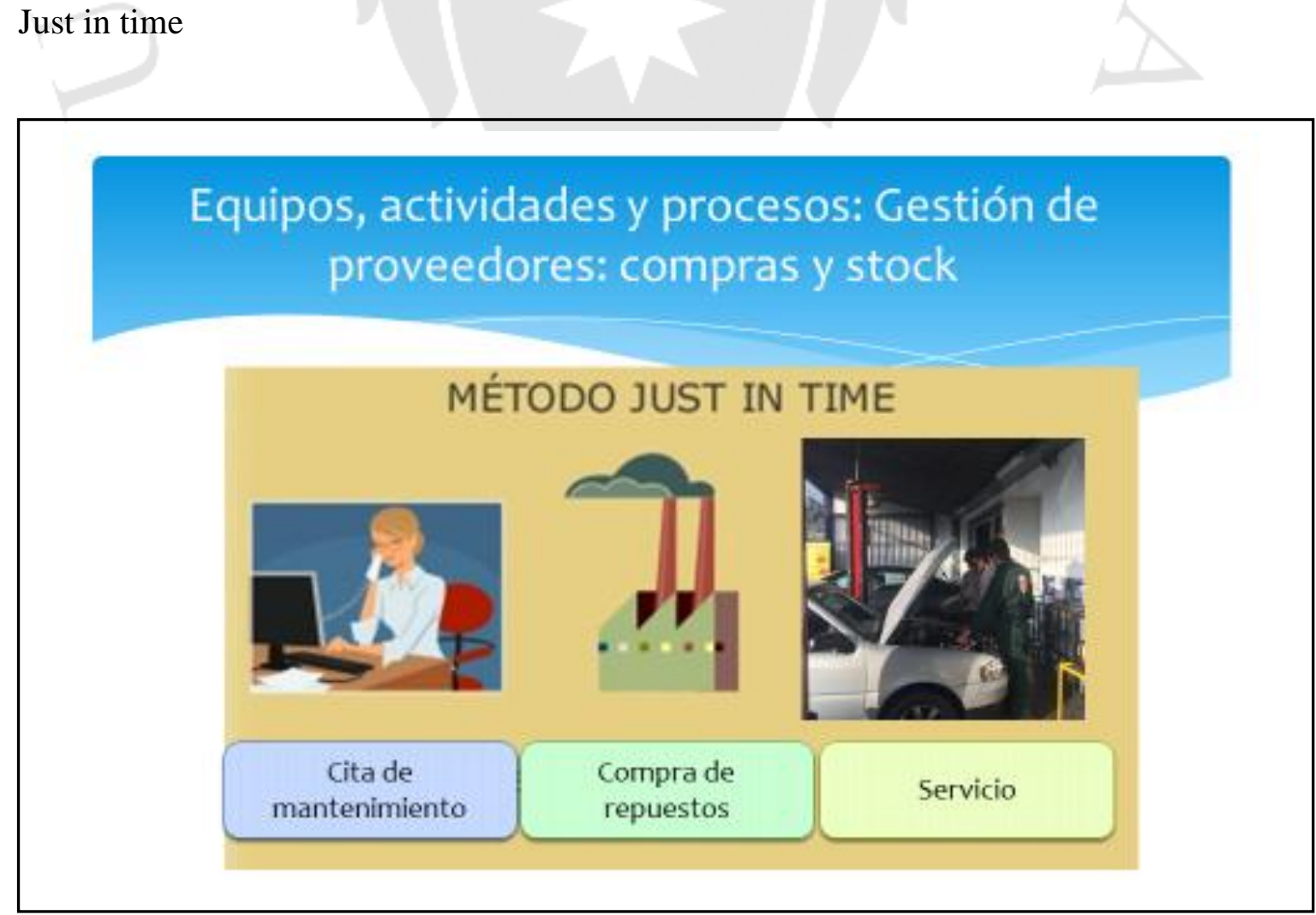


Figura 5.5

Cadena de valor

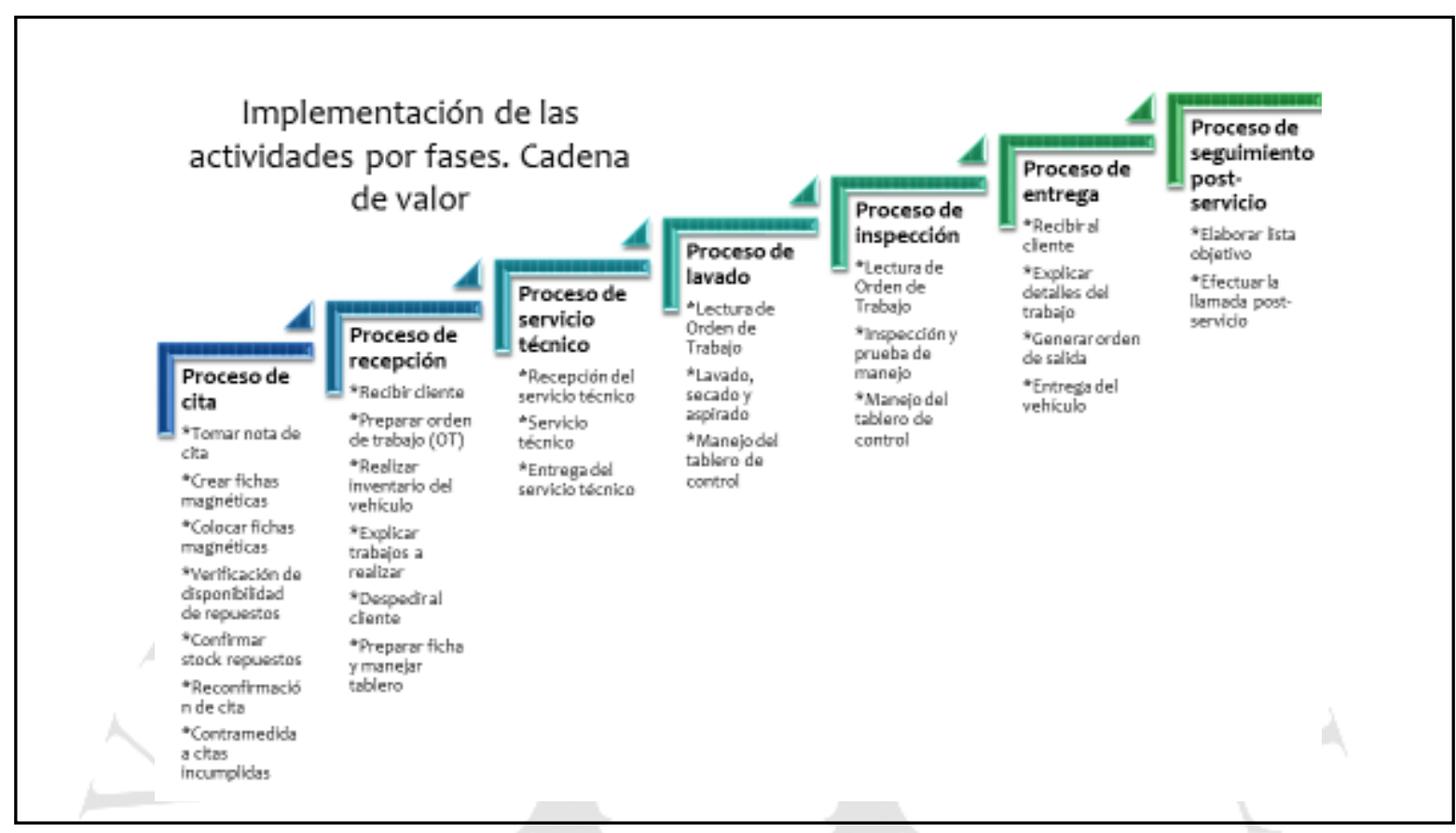


Figura 5.6

Actividades por fases: Citas

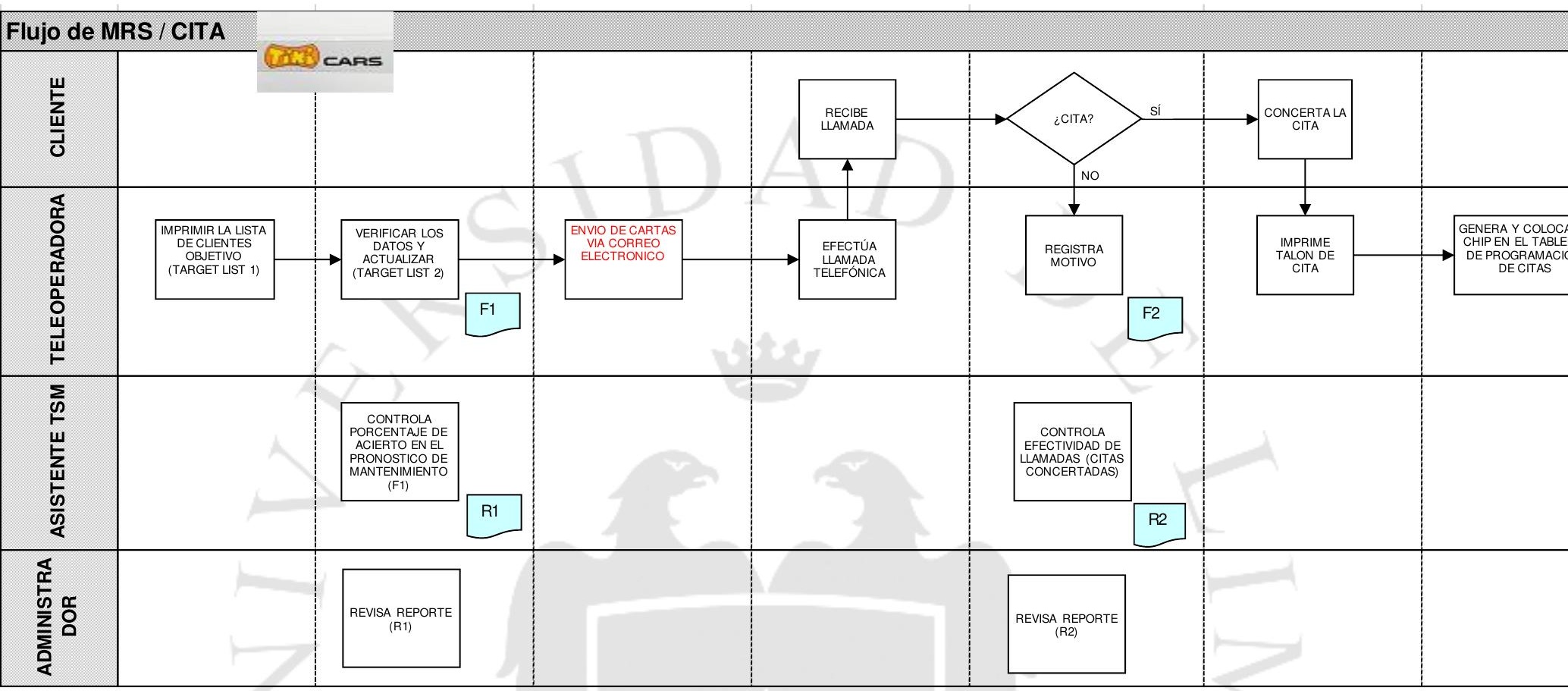


Figura 5.7

Actividades por fases: Recepción del vehículo

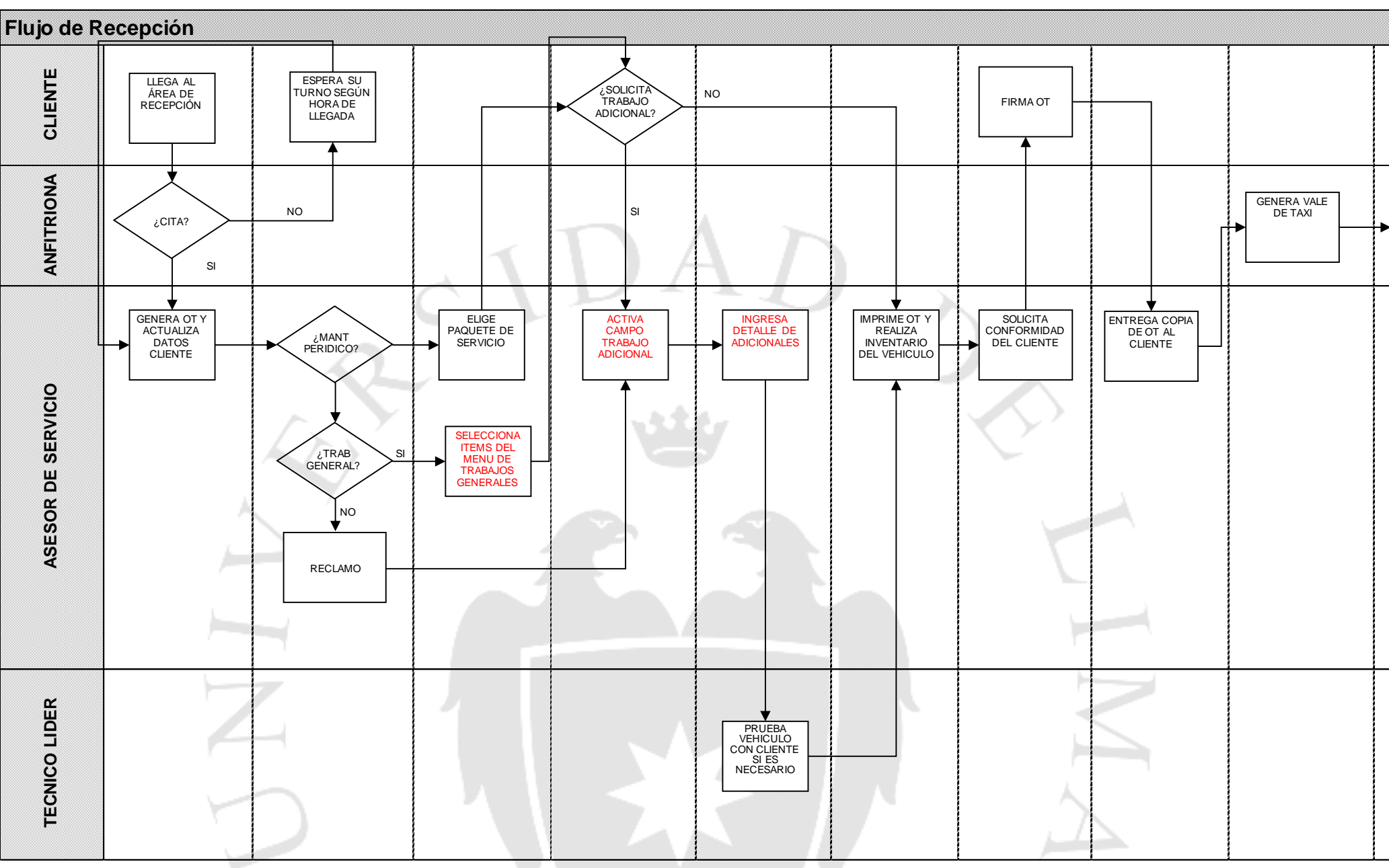


Figura 5.8

Actividades por fases: Servicios

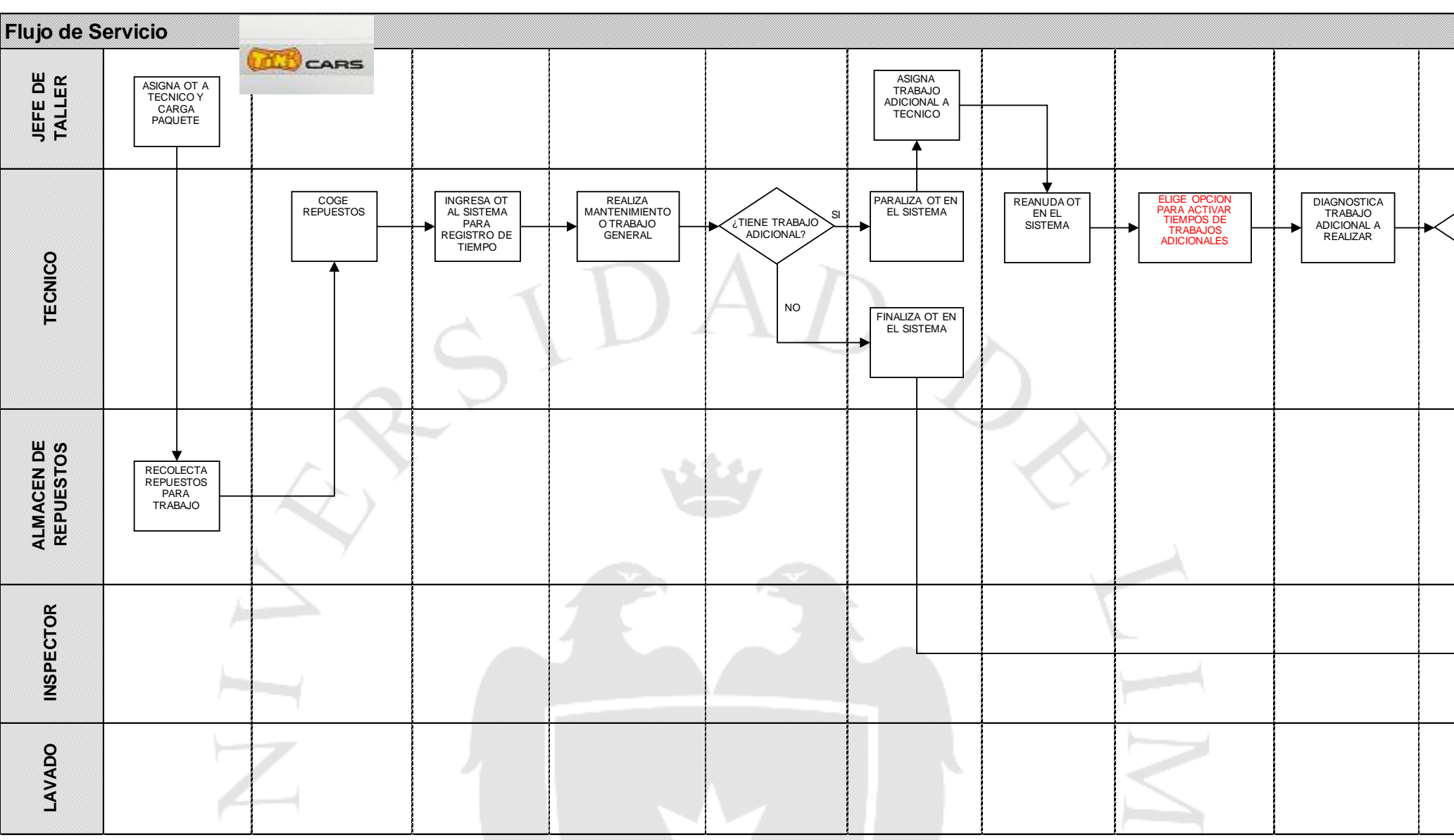


Figura 5.8

Actividades por fases: Proceso de entrega

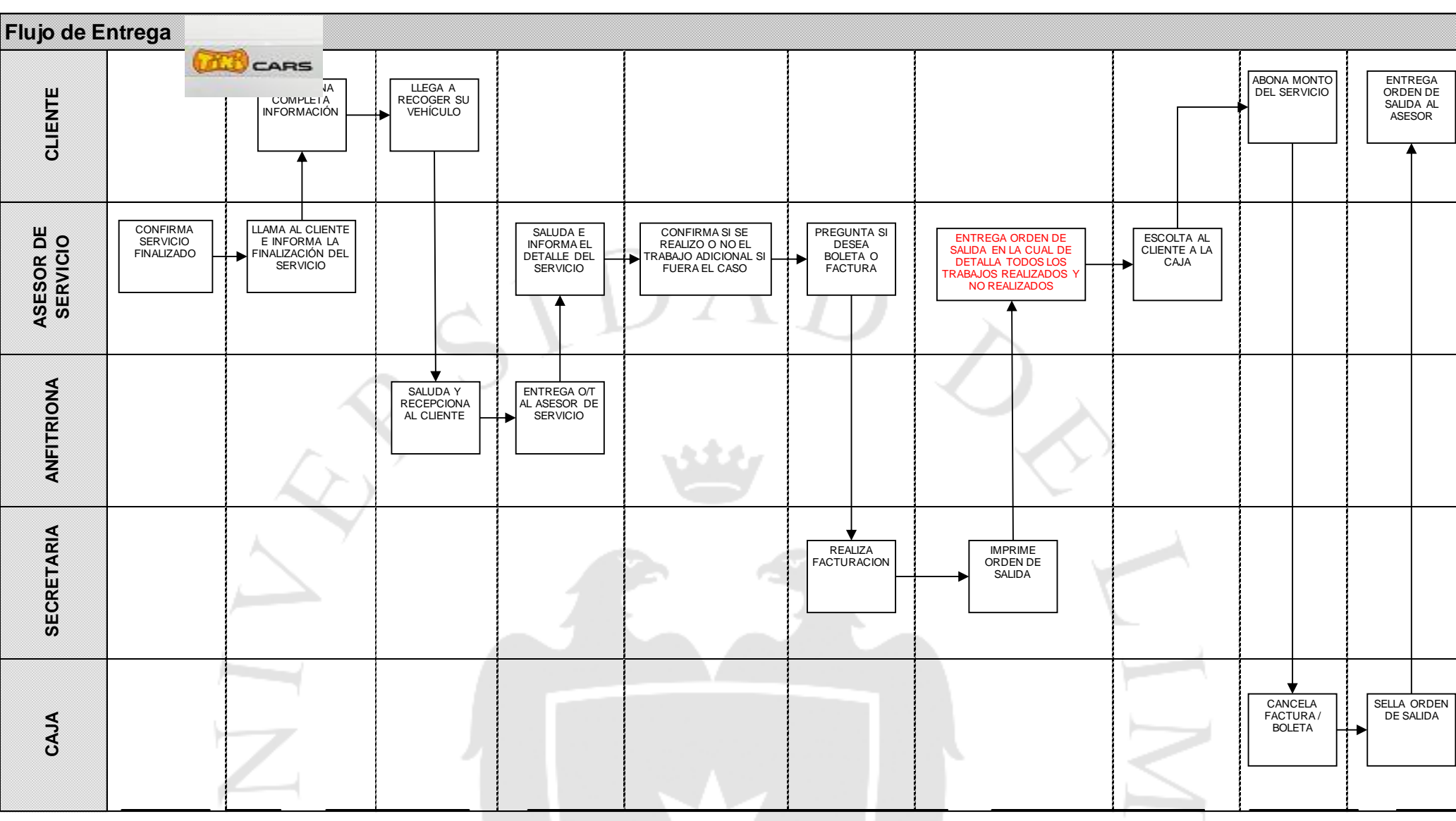


Figura 5.9

Actividades por fases: Proceso Post-Servicio

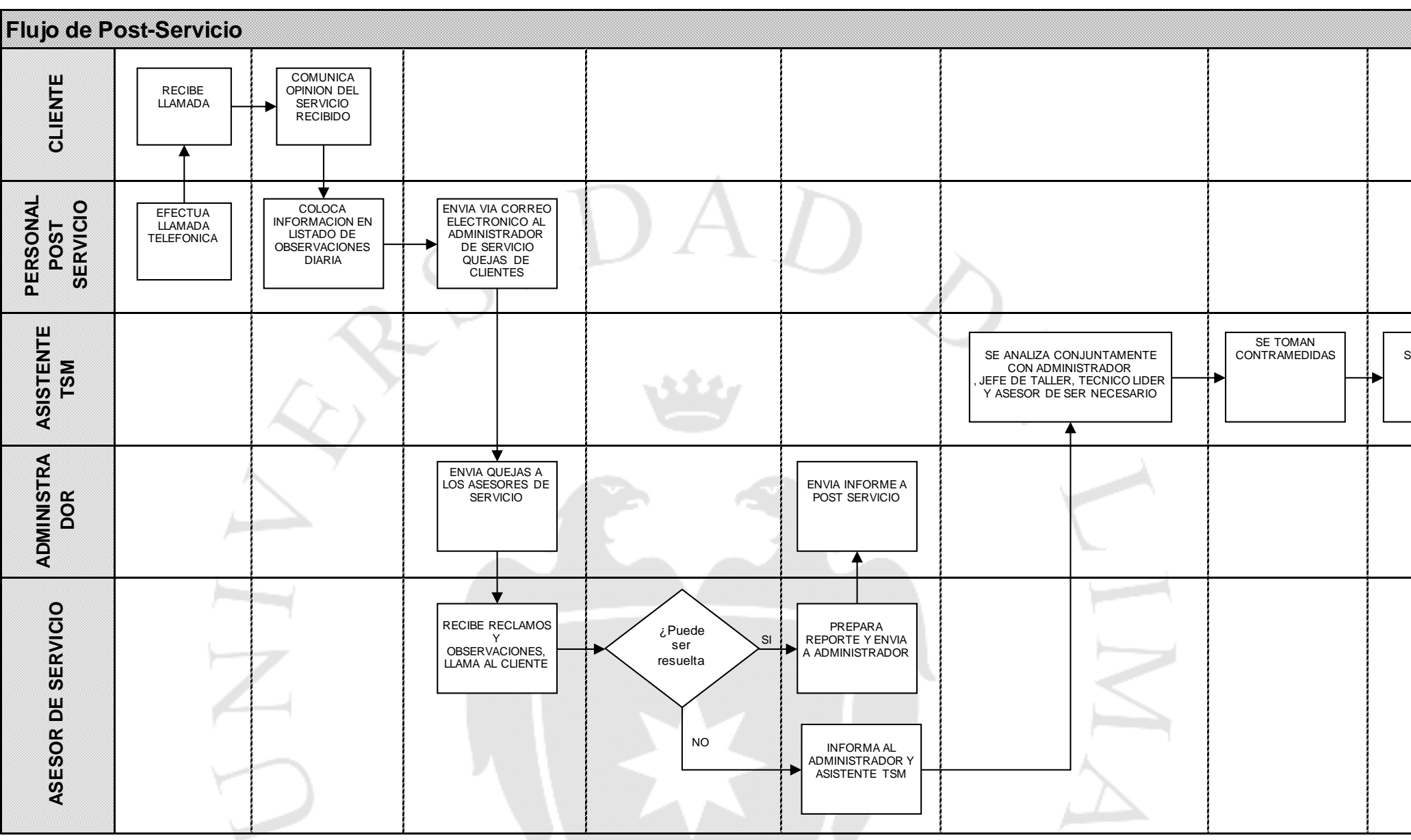


Figura 5.10

Actividades por fases: Recordatorio de llamadas

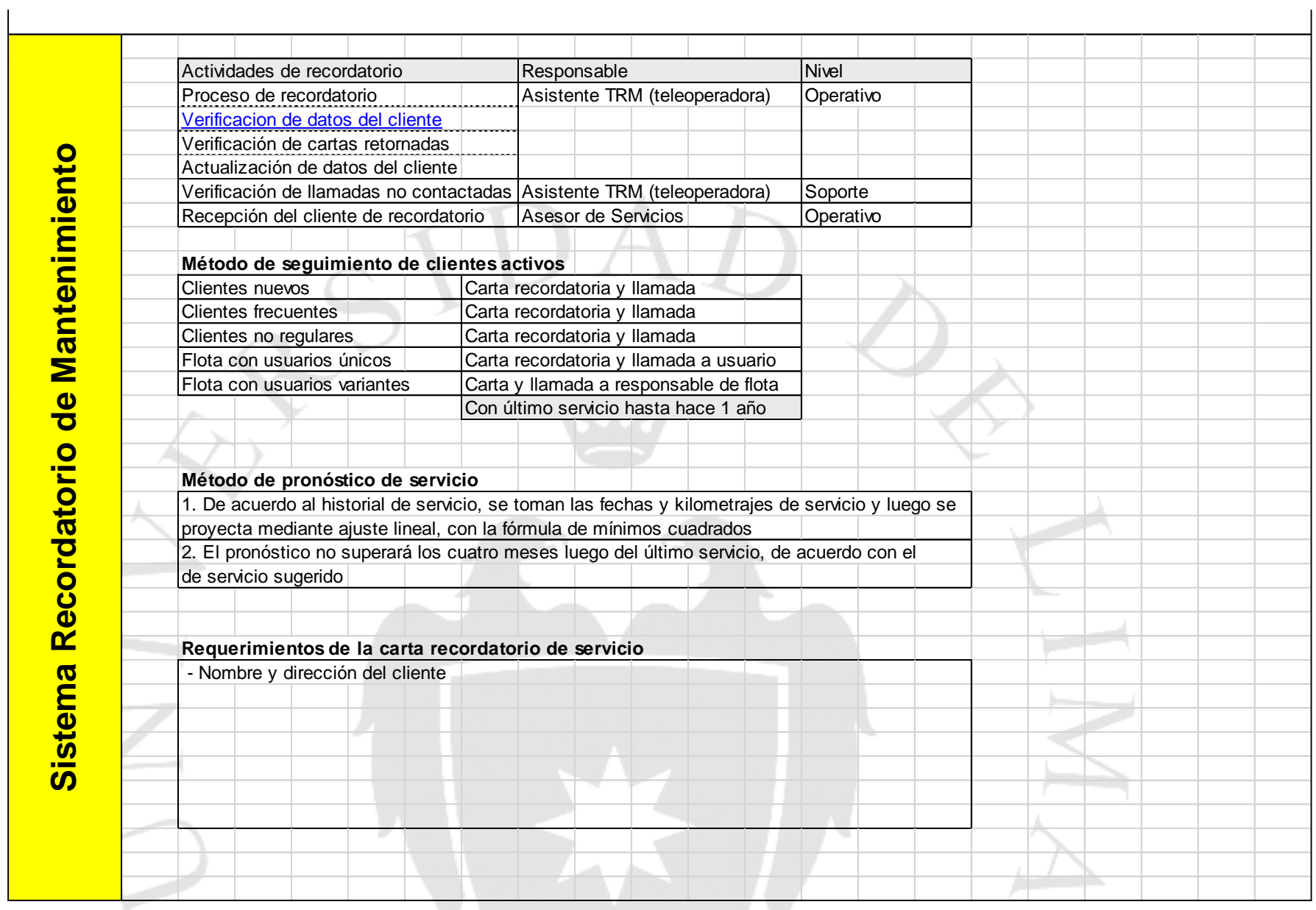


Figura 5.11

\section{Diagrama de Grantt}

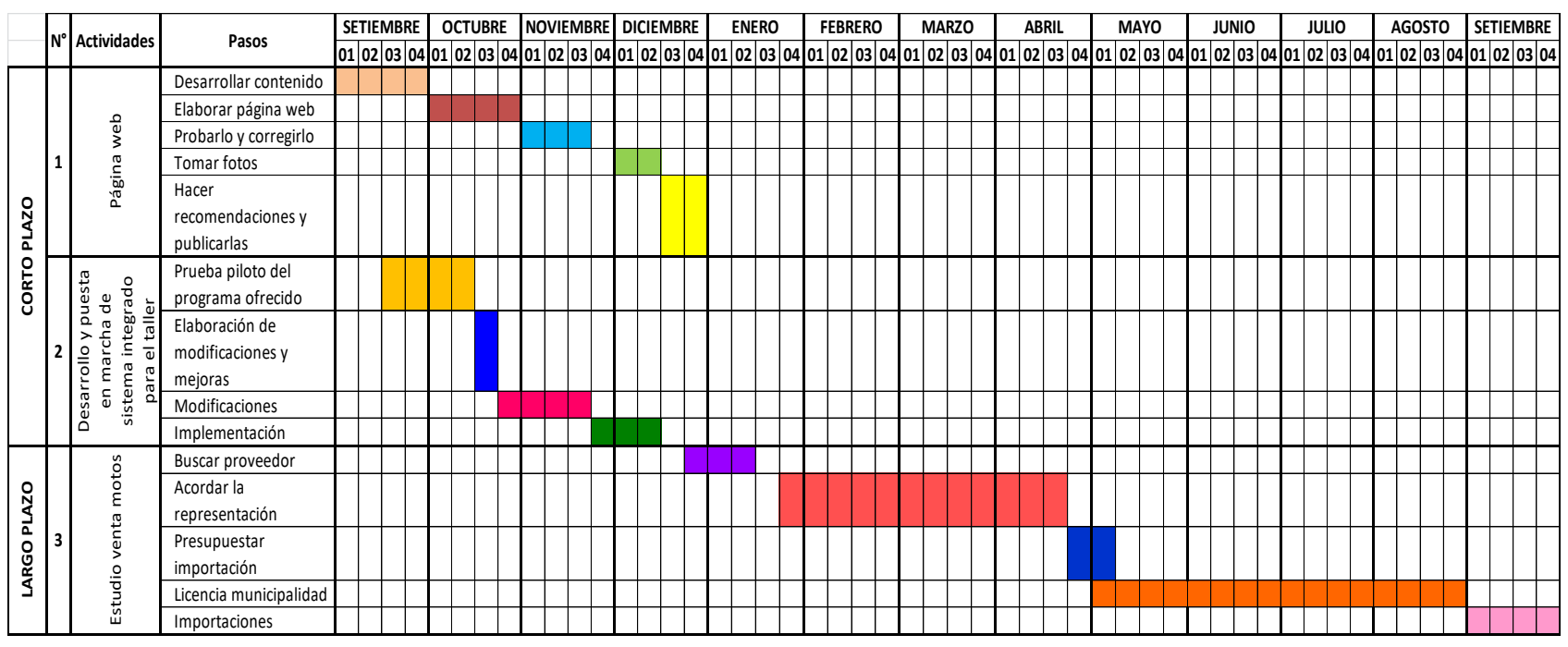


Figura 5.12

Balance Scorcard

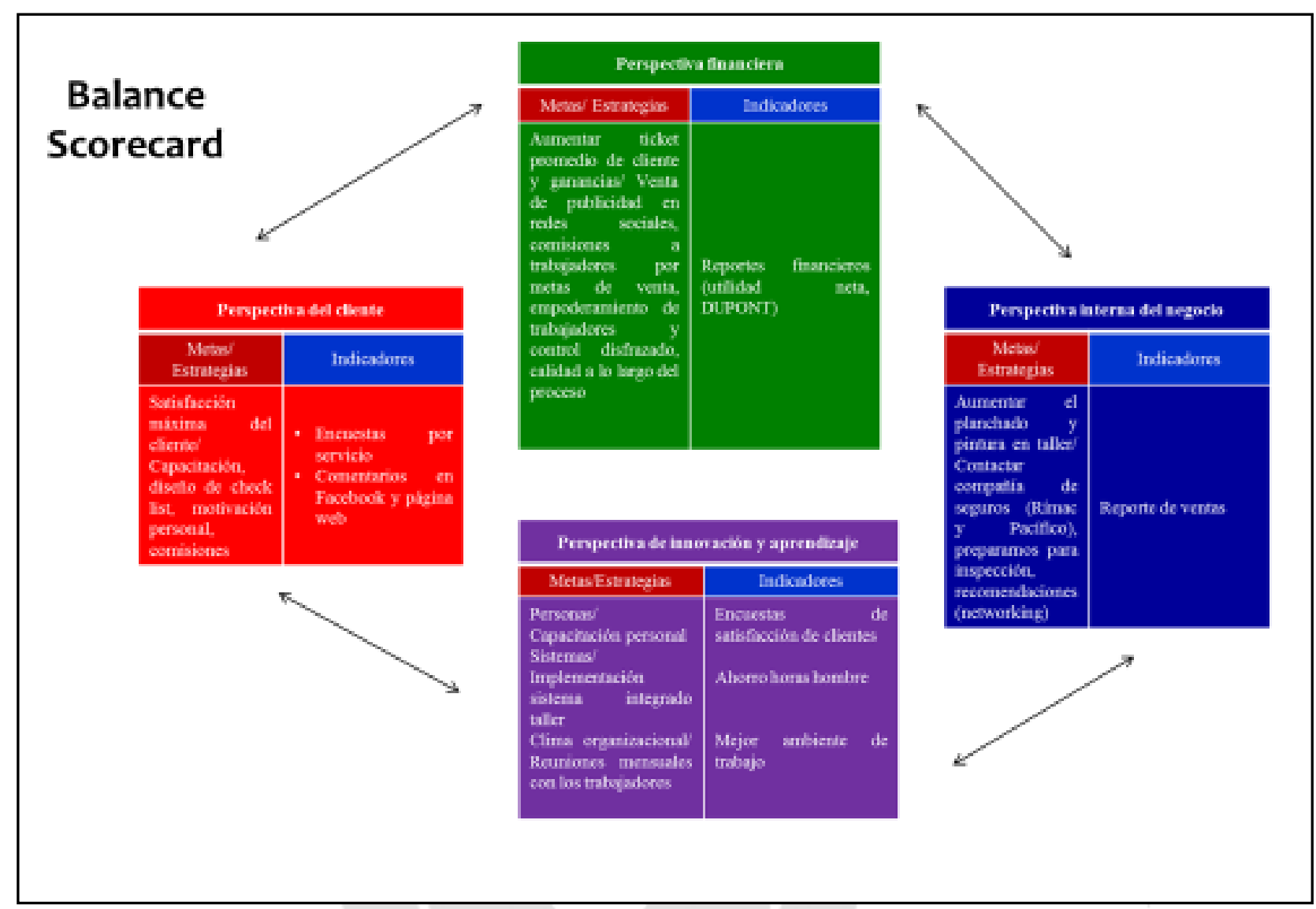




\section{Figura 6.1}

Manual de Funciones: Administrador

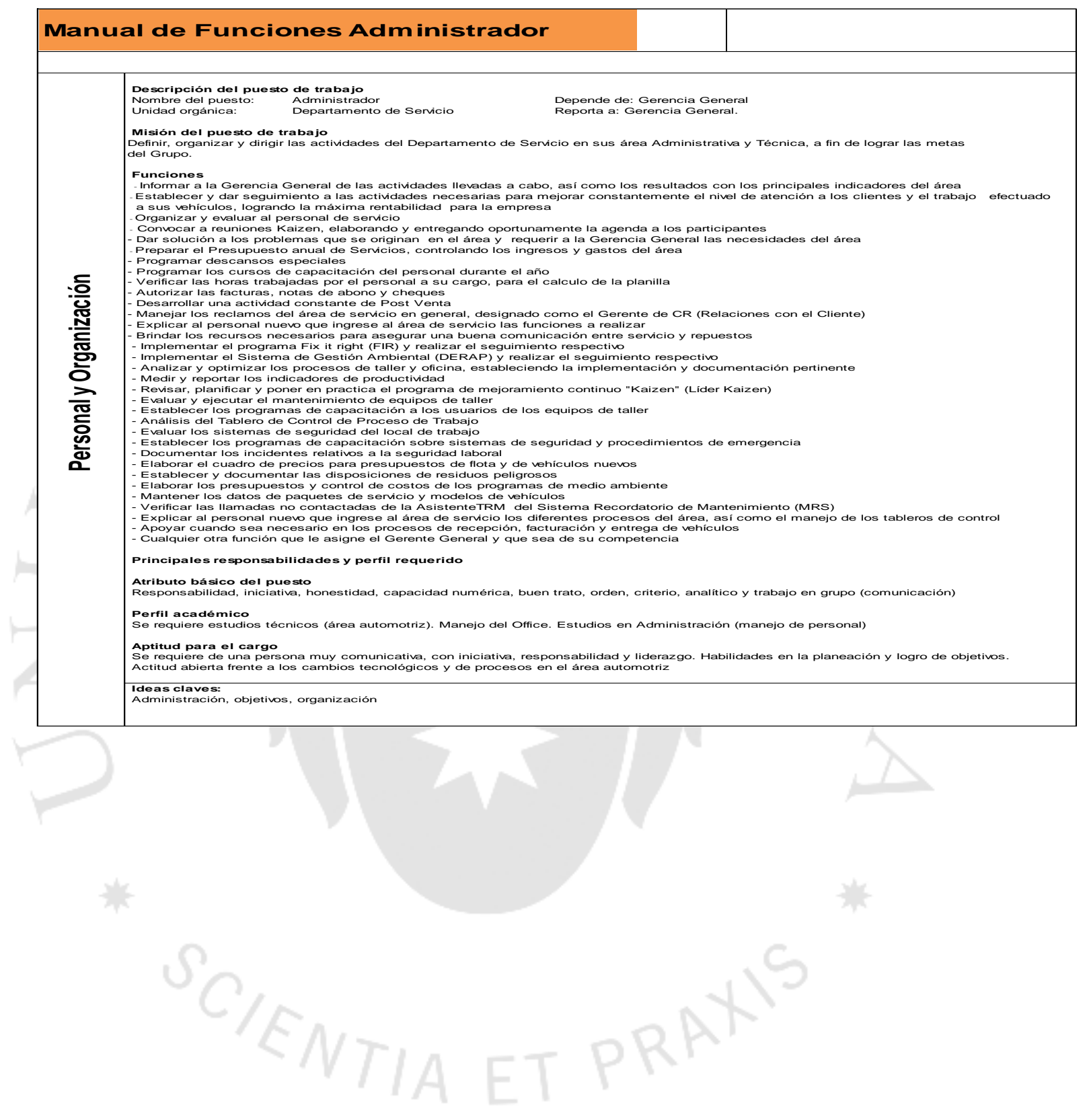


Figura 6.2

Manual de Funciones y servicios: Jefe de Taller

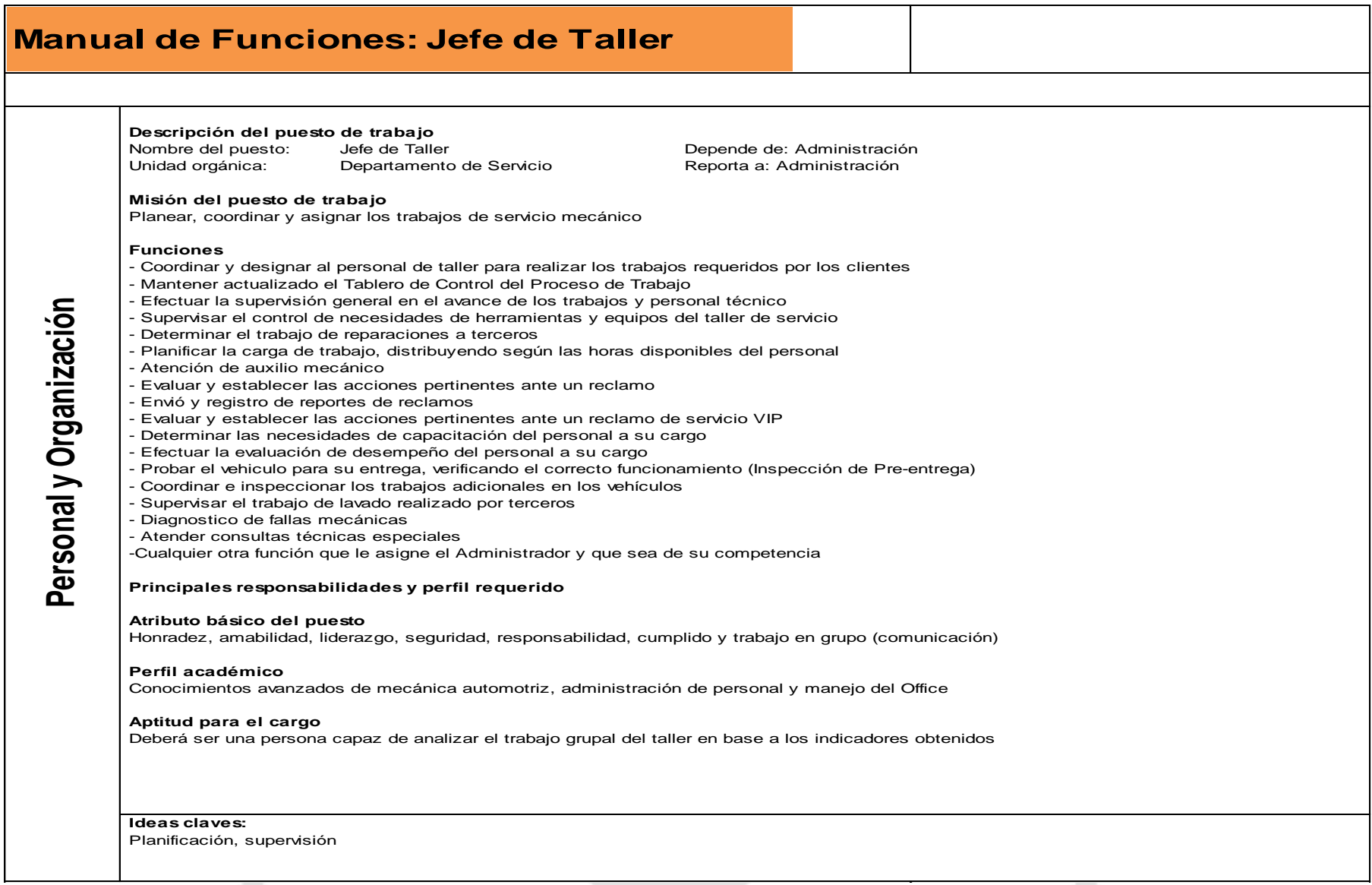




\section{Figura 6.3}

\section{Manual de Funciones y Servicios: Asesor de servicios}

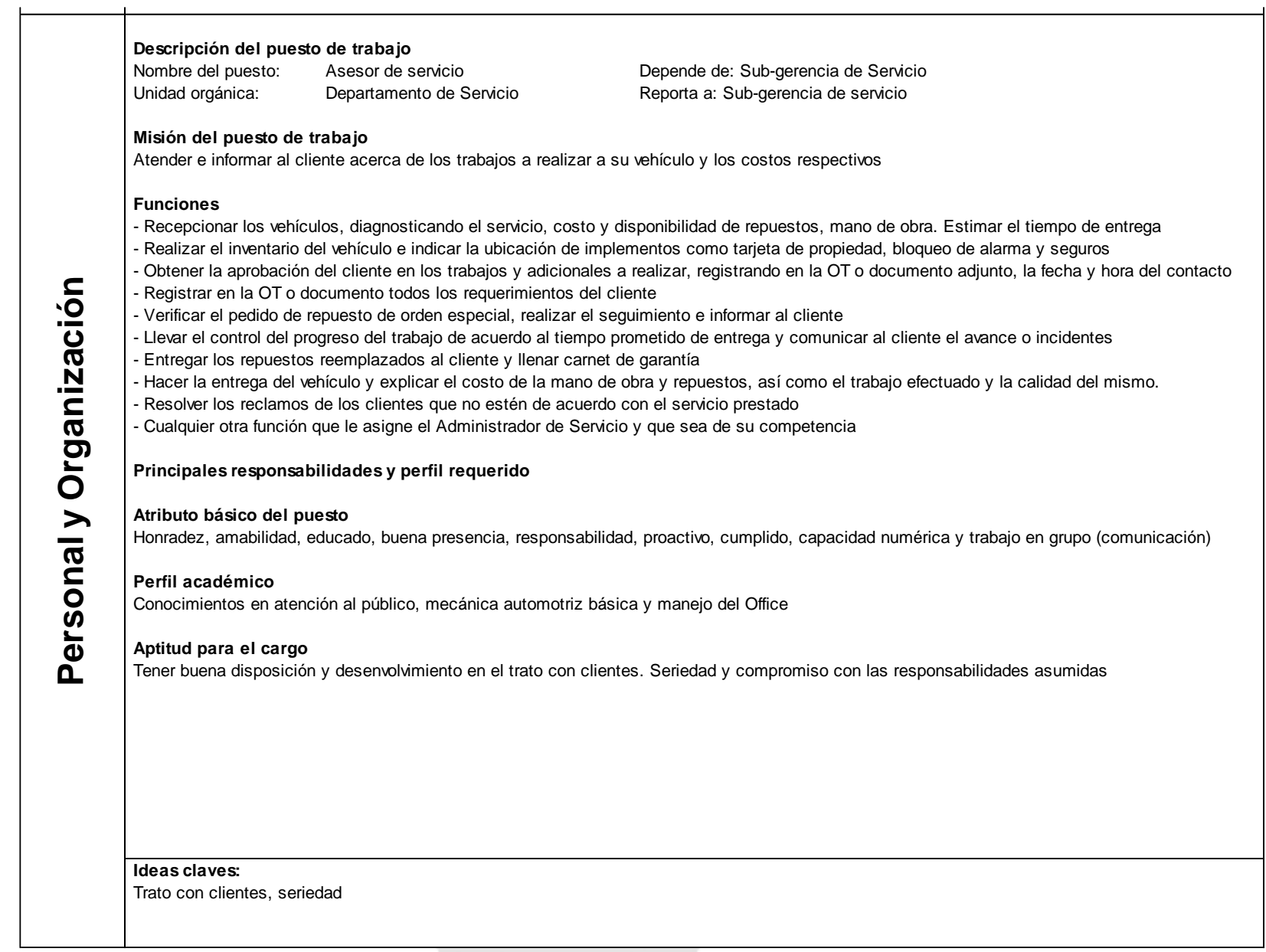


Figura 6.4

Capacitaciones

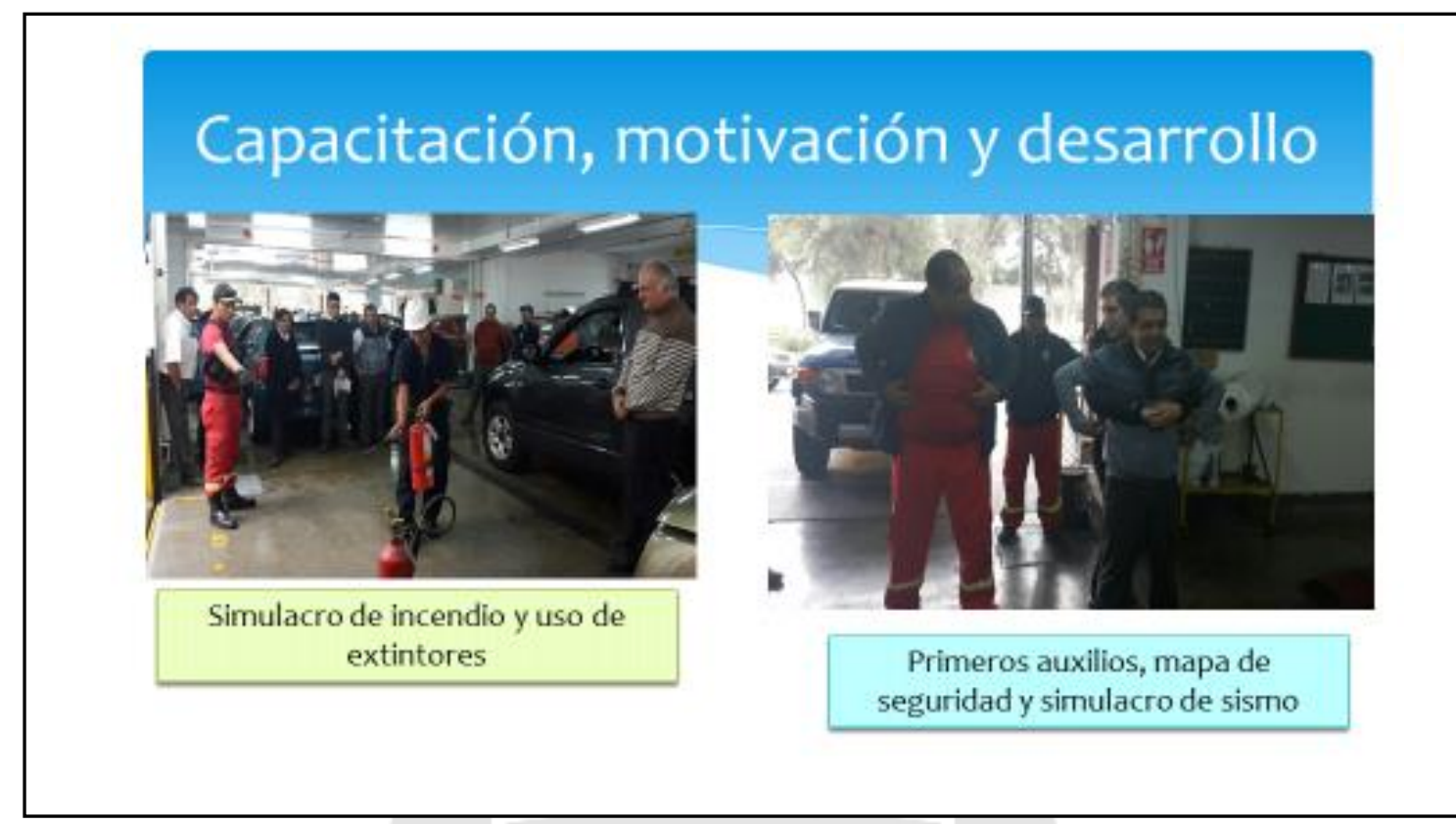

Figura 6.5

Responsabilidad Social

\section{Responsabilidad social}

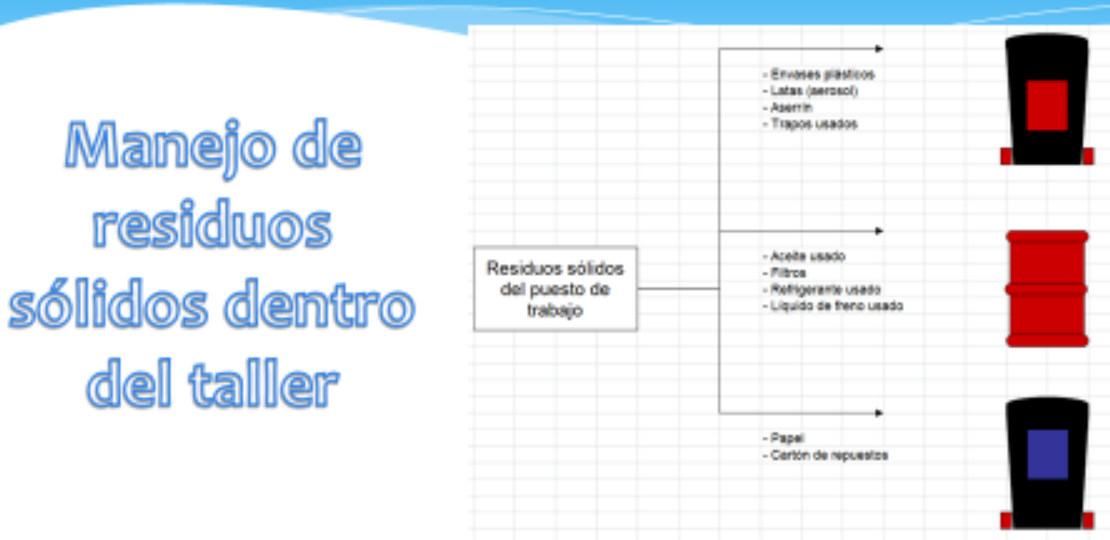


Figura 6.6

Implementación de uso de paneles solares y led

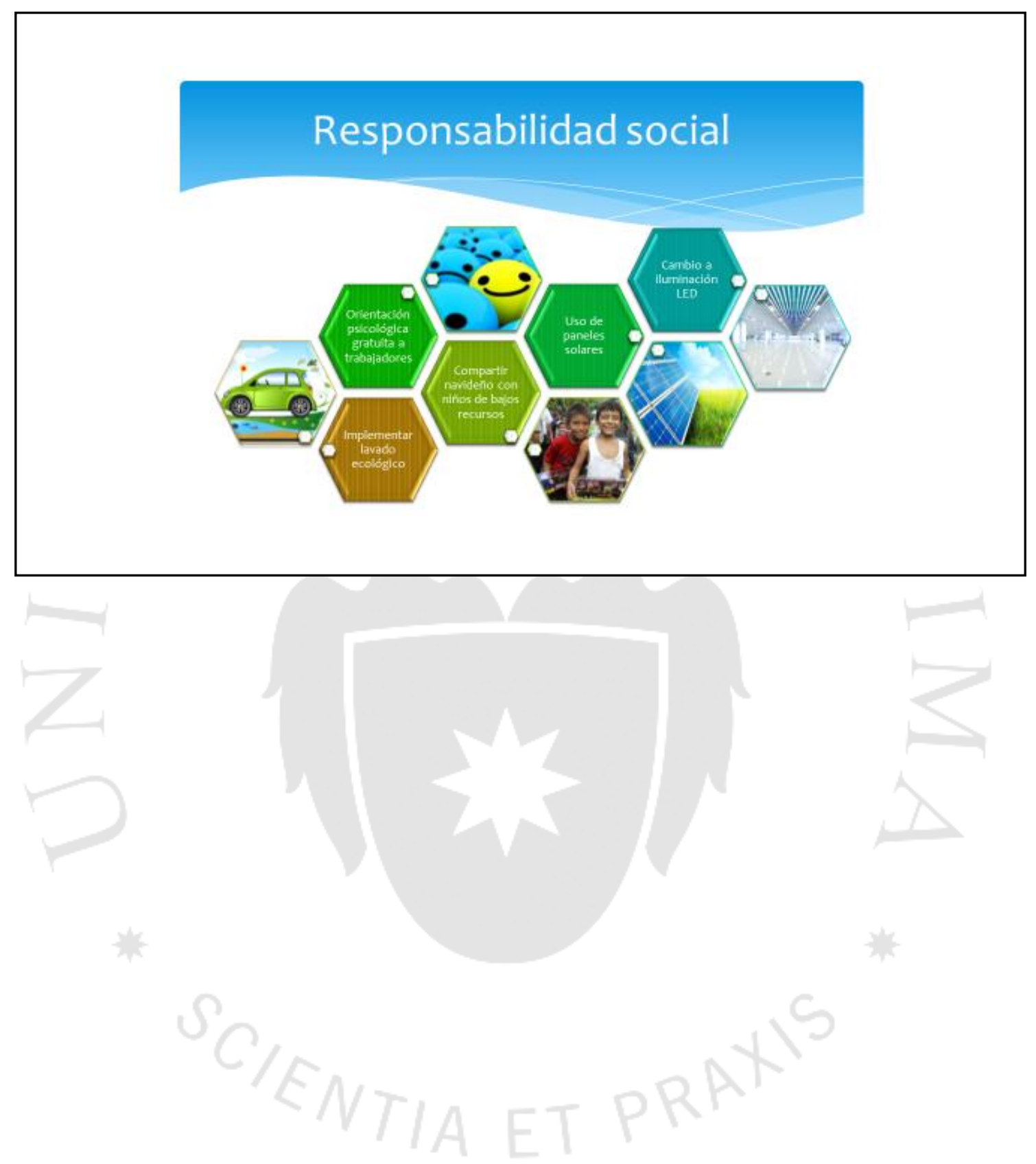

